$$
\text { Universidad Nacional de La Plata }
$$

Facultad de Ciencias Naturales y Museo

Inferencia filogeográfica aplicada a la conservación de hembras partenogenéticas del género Aylacostoma Spix, 1827 : especies amenazadas del río Paraná

Autor: Lic. Roberto Eugenio Vogler

\title{
TESIS DOCTORAI
}

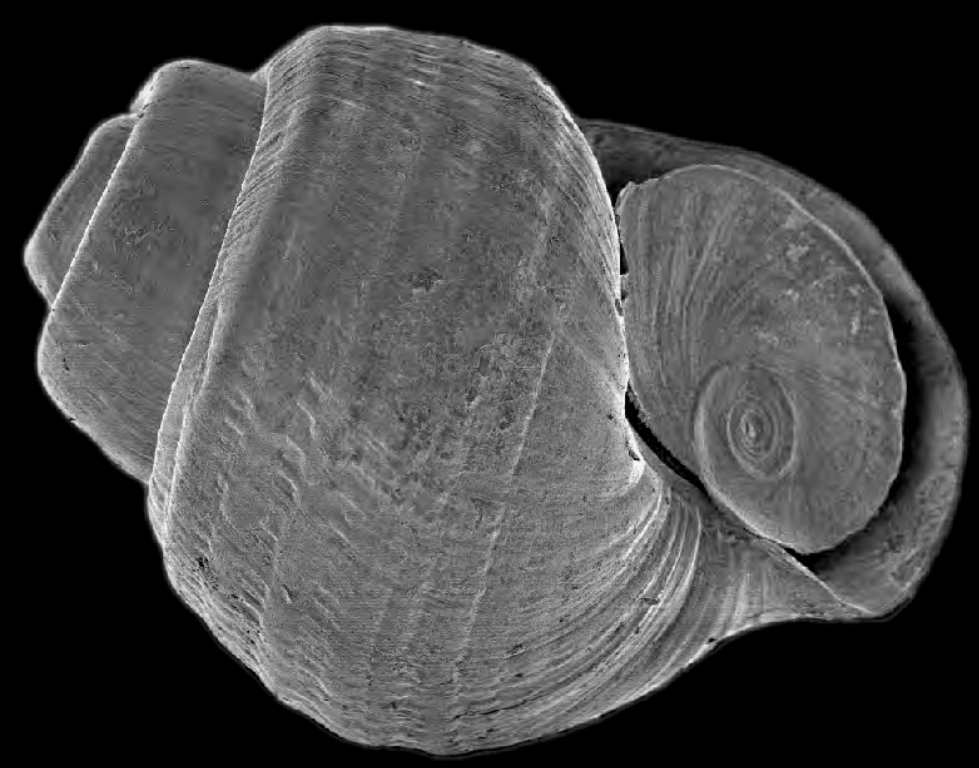

Directora: Dra. Alejandra Rumi Macchi Zubiaurre Codirectora: Dra. Carina Francisca Argüelles 


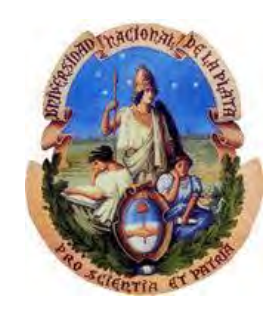

Universidad Nacional de La Plata

Facultad de Ciencias Naturales y Museo

\title{
Inferencia filogeográfica aplicada a la conservación de hembras partenogenéticas del género Aylacostoma Spix, 1827: especies amenazadas del río Paraná
}

\author{
Autor: Lic. Roberto Eugenio Vogler \\ Directora: Dra. Alejandra Rumi Macchi Zubiaurre \\ Codirectora: Dra. Carina Francisca Argüelles
}

Tesis presentada para optar al título de Doctor en Ciencias Naturales de la Universidad Nacional de La Plata

Lugar de Trabajo:

1-División Zoología Invertebrados, Museo de La Plata

Facultad de Ciencias Naturales y Museo

Universidad Nacional de La Plata

2-Laboratorio de Genética Molecular. Departamento de Genética.

Facultad de Ciencias Exactas, Químicas y Naturales

Universidad Nacional de Misiones

La Plata, 2013 
La presentación de esta tesis no constituye una publicación en el sentido del Artículo 8 del Código Internacional de Nomenclatura Zoológica (CINZ, 2000) y, por lo tanto, los actos nomenclaturales incluidos en ella carecen de disponibilidad hasta que sean publicados según los criterios del Capítulo 4 del Código. 
A mis papás, por brindarme siempre apoyo y comprensión, y demostrarme con su ejemplo que los logros se obtienen luchando día a día 


\section{Agradecimientos}

En muchos aspectos, el presente trabajo de tesis es la síntesis de un esfuerzo colectivo, que involucra a muchas personas, las cuales han contribuido en mayor o menor medida para su concreción aportando recursos, tiempo, conocimiento, consejos apoyo y contención. Deseo agradecer a quienes han colaborado en esta etapa:

A mi familia, por ser mi motor para seguir siempre para adelante.

A Alejandra, por darme la oportunidad de trabajar a su lado en la División Zoología de Invertebrados del Museo de La Plata. No sólo por inculcarme las diferentes ópticas del proceder científico, sino por su gran calidad humana y confianza, lo cual me ha ayudado a crecer como profesional y como persona.

A Carina, por orientarme con su extremadamente prolija manera de trabajar, su conocimiento, perspectiva y apoyo, y ser quien me permitió incursionar en los abordajes moleculares en caracoles, área que me ha dado muchísimas satisfacciones profesionales.

A todos los excelentes profesionales de la División Zoología de Invertebrados del Museo de La Plata, que me han hecho sentir como en casa, y particularmente a Cristina Damborenea, Gustavo Darrigran, Stella Martín, Inés César, Mónica Tassara, Analía Díaz, Estela Lopreto. Ni que hablar de mi querido grupo, Diego Gutiérrez Gregoric y Verónica Núñez que han formado parte de las distintas etapas de este trabajo, quienes me han permitido opinar siempre como su par, gracias chicos por sus consejos, conocimientos y ayuda.

A dos grandes colegas genetistas y amigos de la vida, Ariel Beltramino y Sandra Martens quienes me han padecido en mis peores humores durante esta etapa y a dos grandes paleontólogos amigos, Miguel Griffin y Santiago Genta Iturrería con quienes hemos compartidos largas y gratificantes horas de charlas.

A mi querida compañera de la cátedra de Genética Molecular, Cecilia Percuoco por tantas horas transitadas en el laboratorio.

Al grupo del Anexo de la Facultad de Ciencias Exactas, Químicas y Naturales de la Universidad Nacional de Misiones: Nelson Pividorí, Carlos Kusmeluk, Victor Llano, Cecilia Costigliolo, María José Molina y especialmente Juana Peso y Norma Meichtry de Zaburlín, dos excelentes profesionales y personas a las que admiro, quiero y respeto, 
que siempre me brindaron desinteresadamente un espacio para trabajar, me facilitaron material para mis análisis y que me han inculcado increíbles valores humanos.

A los chicos de la pensión en Berisso, mi hogar durante gran parte de este trabajo: Nacho, Mariano, Ale, Daro, Dani, Lucas, Lean, Iván, por su curiosidad, respeto y tantos buenos momentos.

A Diego Pérez de la Entidad Binacional Yacyretá y a Jean Pierre Pointier, por facilitarme información y material de análisis de difícil acceso, y a todos aquellos que por algún u otro motivo estoy olvidando en este momento.

A P. Daniel Ghiringhelli de la Universidad Nacional de Quilmes por permitirme utilizar rutinas computacionales de su autoría en mis análisis.

Finalmente deseo agradecer al Museo de La Plata de la Facultad de Ciencias Naturales y Museo (UNLP) y a la Facultad de Ciencias Exactas, Químicas y Naturales de la UNaM, por permitirme concretar esta investigación en sus laboratorios y a CONICET por su programa de becas de Áreas de Vacancia Geográfica, sin la cual este trabajo no hubiera podido ser realizado. 
Citas correspondientes a las publicaciones parciales y presentaciones a congresos del trabajo de tesis

\section{$\underline{\text { Publicaciones }}$}

Vogler RE, Beltramino AA, Gutiérrez Gregoric DE, Peso JG, Griffin M, Rumi A. 2012 Threatened Neotropical mollusks: analysis of shape differences in three endemic snails from High Paraná River by geometric morphometrics. Revista Mexicana de Biodiversidad 83(4): 1045-1052 (ISSN 1870-3453).

Vogler RE. 2012. Aylacostoma chloroticum Hylton Scott, 1954: antecedentes de la especie. Amici Molluscarum 20(1): 43-46 (ISSN 0718-9761).

\section{$\underline{\text { Presentaciones a congresos }}$}

25/09/12-29/09/12. XI International Congress on Medical and Applied Malacology. ICMAM. Rio de Janeiro. Brasil. Trabajo titulado: Concerning genetic lineages and conservation units in Aylacostoma snails from High Paraná River (ArgentinaParaguay). Vogler RE; Beltramino AA; Peso JG; Argüelles CF; Rumi, A.

04/09/11-08/09/11. XXII Encontro Brasileiro de Malacologia. EBRAM. Fortaleza. Brasil. Trabajo titulado: Descripción de rádulas de topotipos de la especie amenazada Aylacostoma chloroticum Hylton Scott, 1954 (Caenogastropoda: Thiaridae). Vogler RE, Beltramino AA, Núñez V, Gutiérrez Gregoric DE, Peso JG, Rumi A.

01/10/2010-05/10/2010. XIV Congreso Latinoamericano de Genética. VIII Congreso de la Asociación Latinoamericana de Mutagénesis, Carcinogénesis y Teratogénesis Ambiental. XLII Congreso de la Sociedad Genética de Chile. XXXIX Congreso de la Sociedad Argentina de Genética. Viña del Mar. Chile. Presentación del trabajo titulado: Códigos de barra genéticos en Aylacostoma chloroticum (Gastropoda: Thiaridae), especie amenazada de Argentina”. Vogler RE; Rumi A, Peso JG, Argüelles CF.

27/10/09-30/10/09. VII Jornadas Científicas Tecnológicas de la Facultad de Ciencias Exactas, Químicas y Naturales. CIDeT. UNaM. Posadas. Misiones.Trabajo titulado: Análisis de morfometría geométrica en tres especies de gasterópodos del Alto Paraná. Vogler RE, Gutiérrez Gregoric DE, Beltramino AA, Peso JG, Rumi A.

19/07/09-24/07/09. XXI Encontro Brasileiro de Malacologia. EBRAM. Rio de Janeiro. Brasil. Trabajo titulado: Descripción cualitativa de conchillas del género Aylacostoma 
(Caenogastropoda) del Alto Paraná (Argentina-Paraguay).Vogler RE, Gutiérrez Gregoric DE, Peso JG, Argüelles CF, Rumi A. 


\section{ÍNDICE GENERAL}

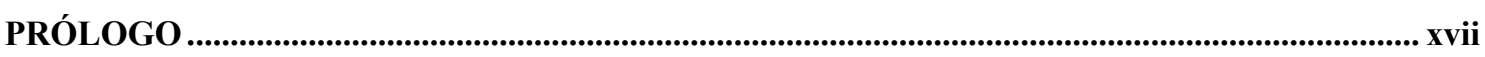

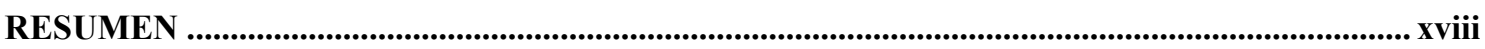

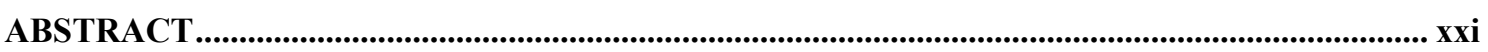

ORGANIZACIÓN GENERAL DE LA TESIS.............................................................................. xxiv

INTRODUCCIÓN GENERAL A LA TESIS........................................................................... 1

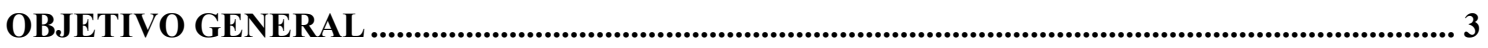

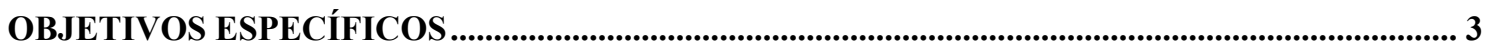

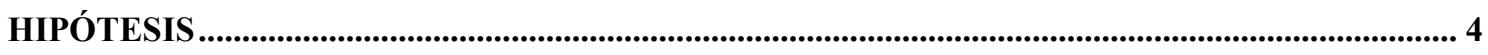

CAPÍTULO I: ANÁLISIS DE LA FORMA DE LAS Aylacostoma DESCRIPTAS PARA EL ALTO PARANÁ A TRAVÉS DE MORFOMETRÍA GEOMÉTRICA ........................................................... 5

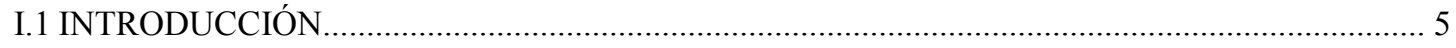

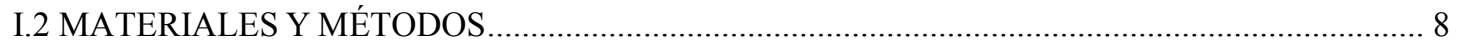

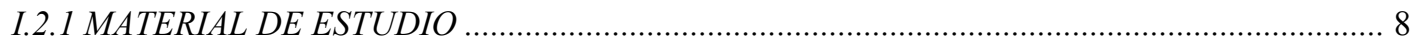

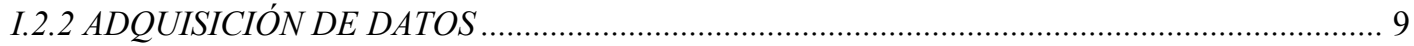

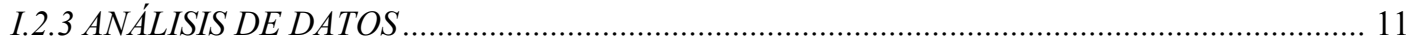

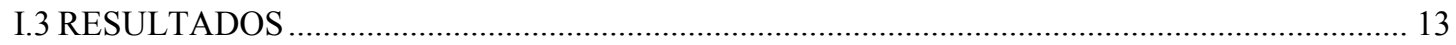

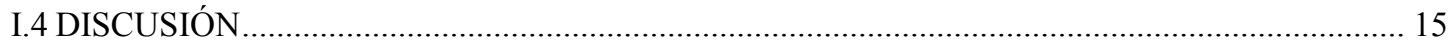

CAPÍTULO II: CARACTERIZACIÓN MORFOLÓGICA DE Aylacostoma chloroticum Y DE UN NUEVO MORFOTIPO DEL ALTO PARANÁ ........................................................................... 17

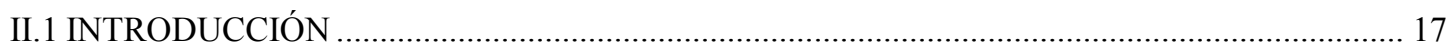

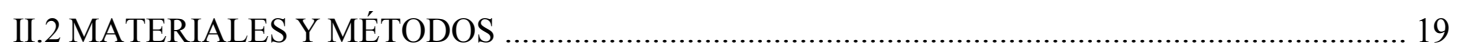

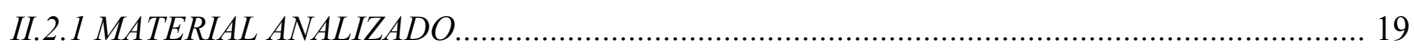

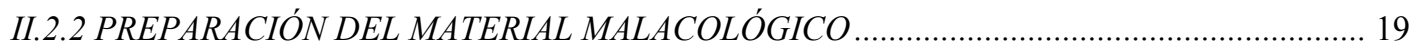

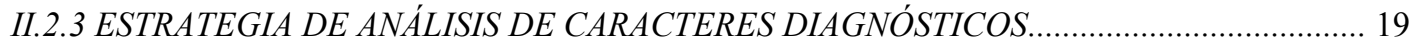

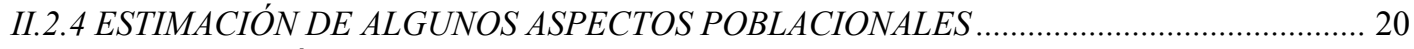

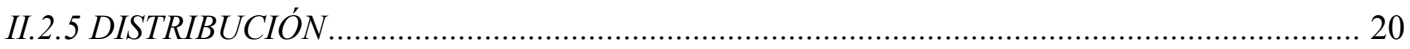

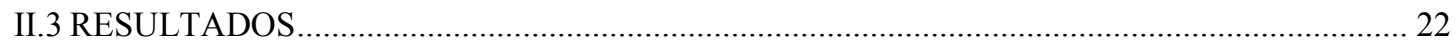

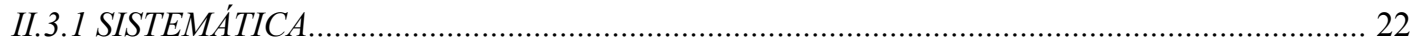

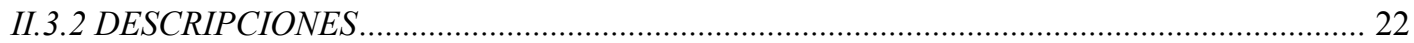

II.3.2.1 Aylacostoma chloroticum Hylton Scott, 1954 …………………………………………. 22

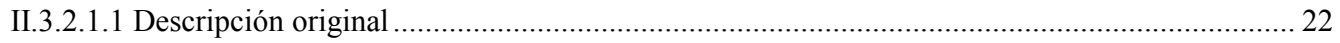

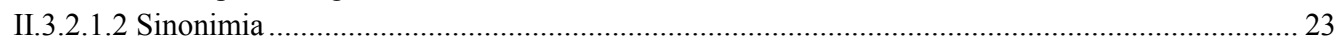

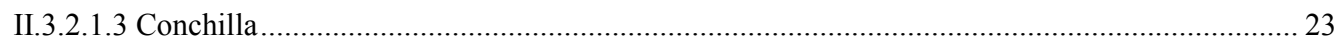

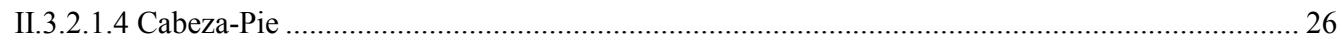

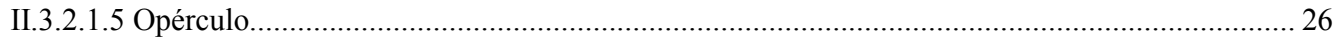

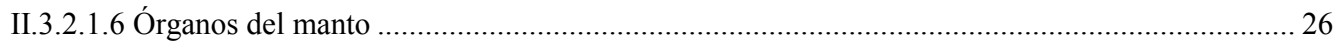

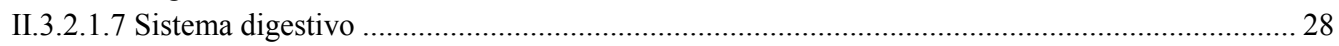

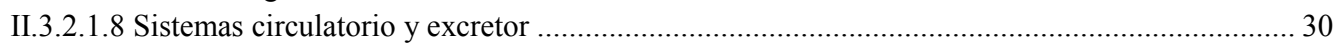

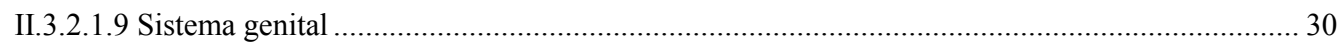

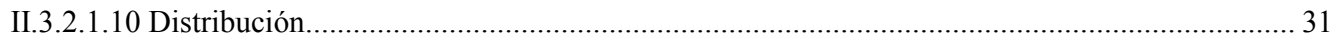

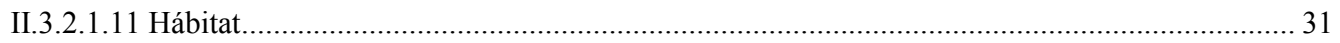

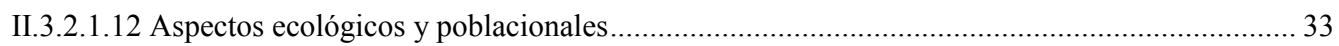

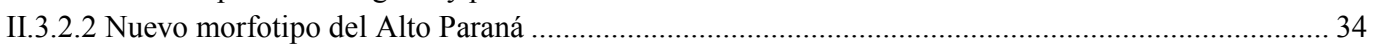

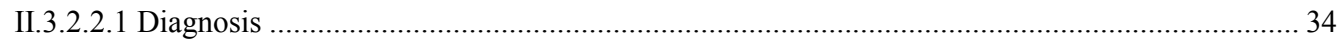

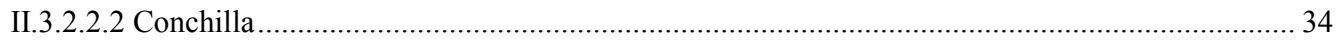

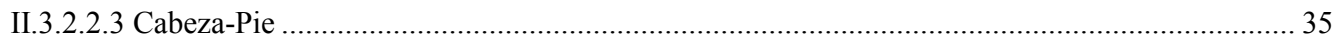




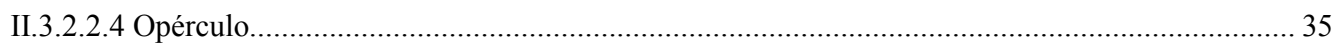

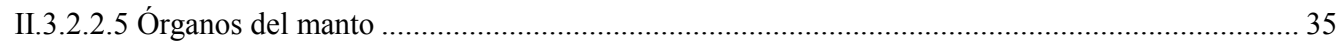

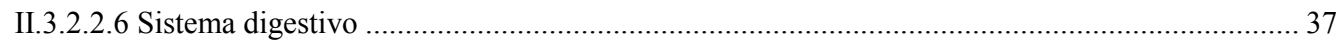

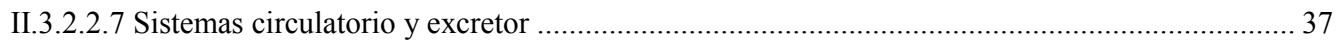

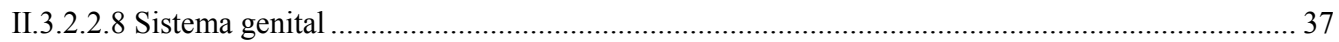

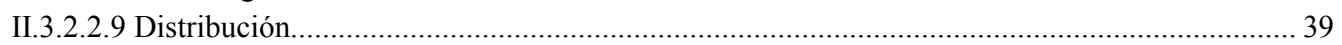

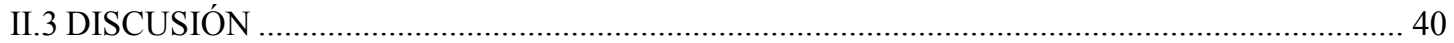

CAPÍTULO III: FILOGEOGRAFÍA DE POBLACIONES DE Aylacostoma sp. DEL ALTO PARANÁ Y SU APLICACIÓN EN CONSERVACIÓN ......................................................................... 42

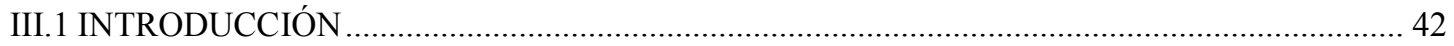

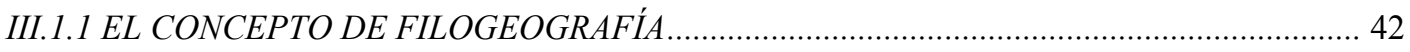

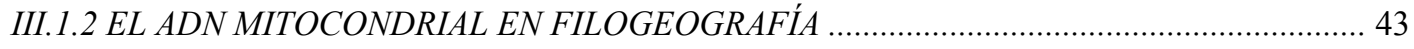

III.1.2.1 Genes frecuentemente utilizados en filogeografía de gasterópodos ............................................. 44

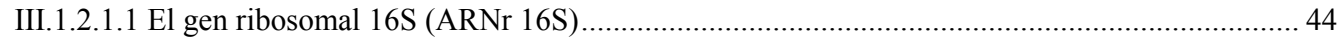

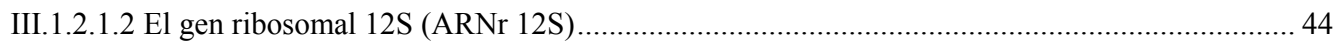

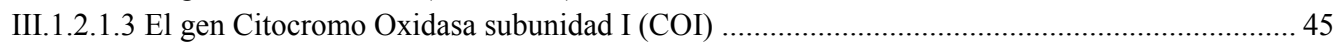

III.1.3 EL RELOJ MOLECULAR COMO ESTIMADOR DE DIVERGENCIA …............................ 45

III.1.4 LA INFERENCIA FILOGEOGRÁFICA APLICADA A CONSERVACIÓN ......................... 47

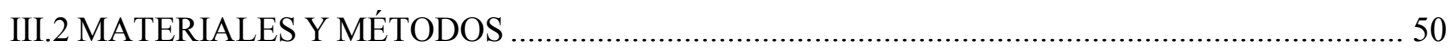

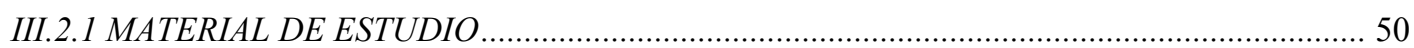

III.2.2 PREPARACIÓN DEL MATERIAL MALACOLÓGICO..................................................... 51

III.2.3 EXTRACCIÓN DE ADN GENÓMICO TOTAL ….............................................................. 52

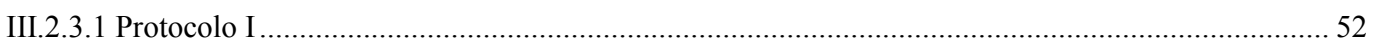

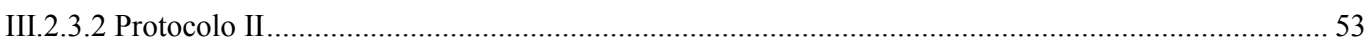

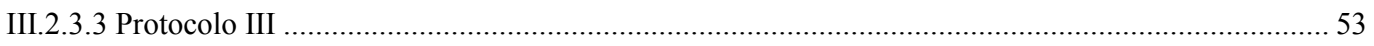

III.2.4 AMPLIFICACIÓN DE GENES MITOCONDRIALES ............................................... 54

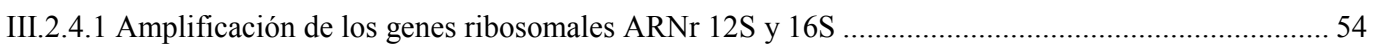

III.2.4.2 Amplificación del gen Citocromo Oxidasa subunidad I (COI) ..................................................... 55

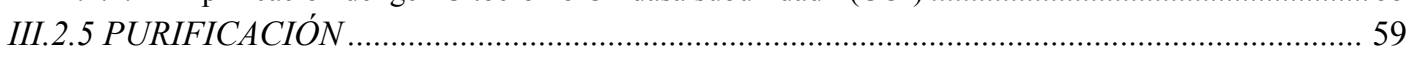

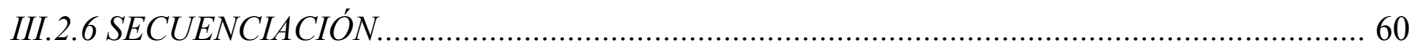

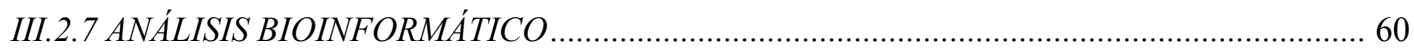

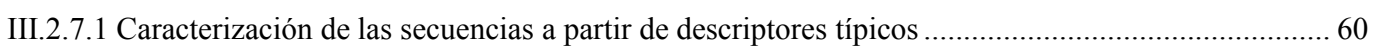

III.2.7.2 Caracterización de las secuencias a partir de descriptores adicionales ........................................... 61

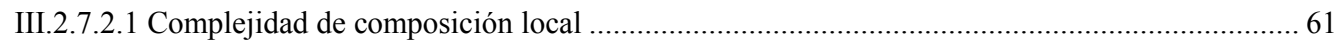

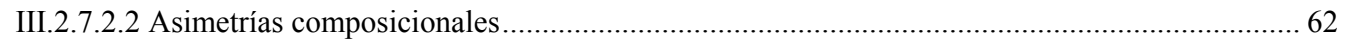

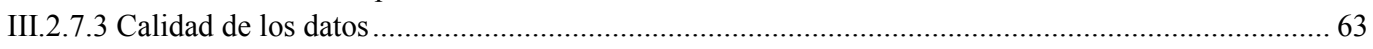

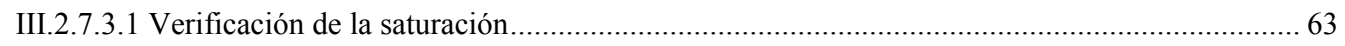

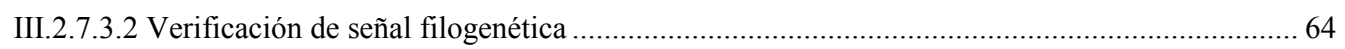

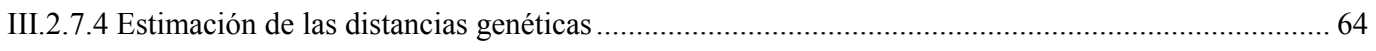

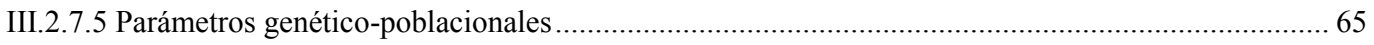

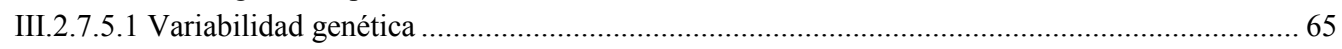

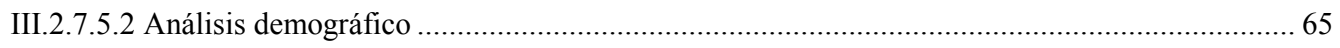

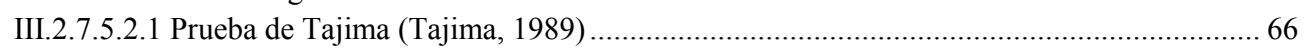

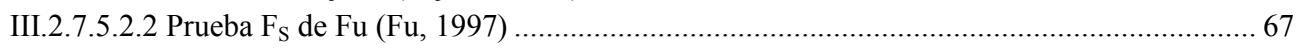

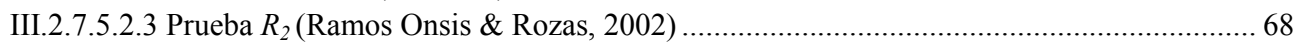

III.2.7.5.2.4 Distribución de discrepancias pareadas o pairwise mismatch distribution (Rogers \&

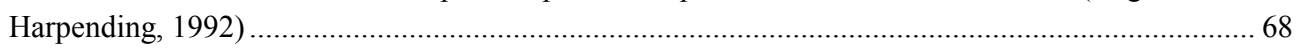

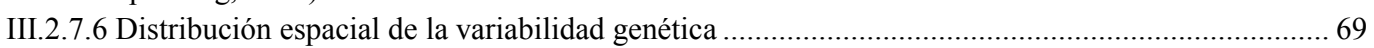

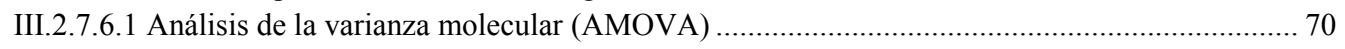

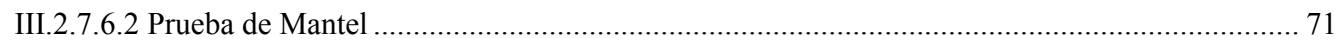

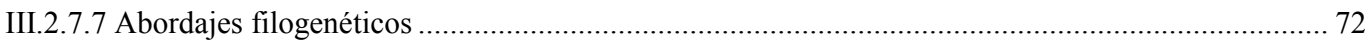

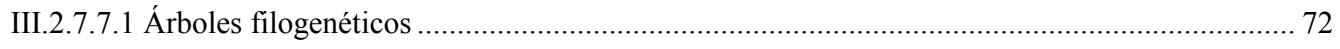

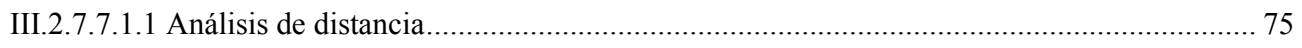

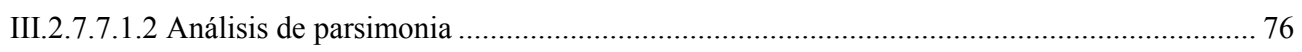

III.2.7.7.1.3 Análisis de Máxima Verosimilitud o Maximum Likelihood............................................... 76 


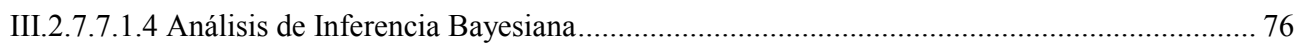

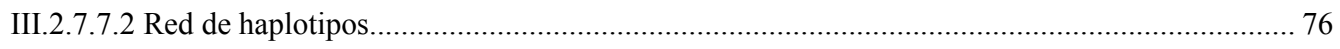

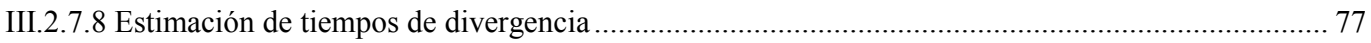

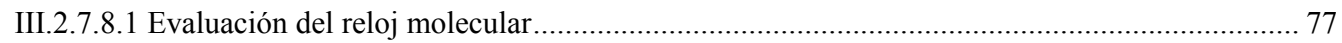

III.2.7.8.1.1 Prueba de razón de verosimilitud global (Global likelihood ratio test) ............................ 77

III.2.7.8.1.2 Prueba de tasas relativas de Tajima (Tajima's relative rate test)..................................... 78

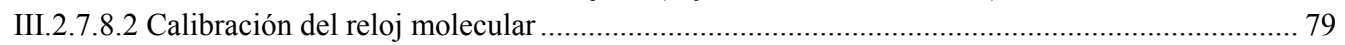

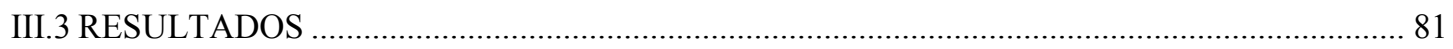

III.3.1 CAMPAÑAS EXPLORATORIAS Y RECOLECCIÓN DE EJEMPLARES ............................. 81

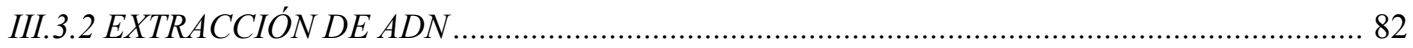

III.3.3 AMPLIFICACIÓN DE LOS MARCADORES MITOCONDRIALES ................................... 84

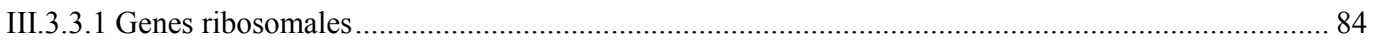

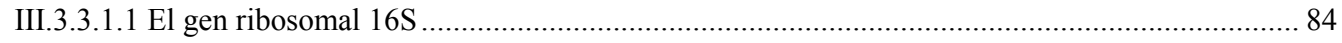

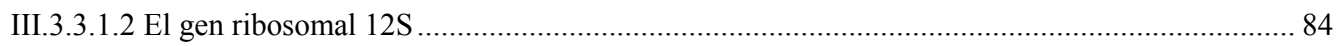

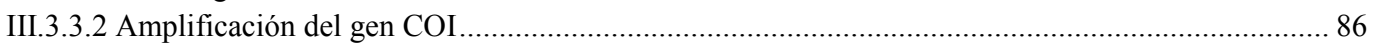

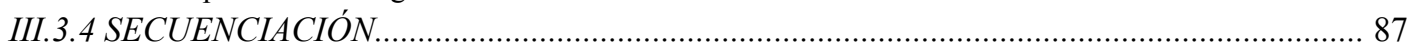

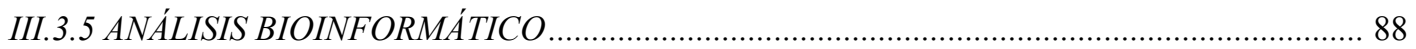

III.3.5.1 Caracterización de las secuencias a partir de descriptores típicos .................................................. 88

III.3.5.2 Caracterización de las secuencias a partir de descriptores adicionales ........................................ 91

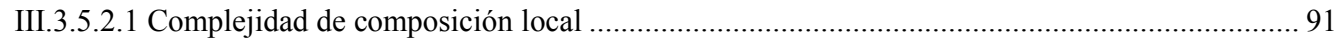

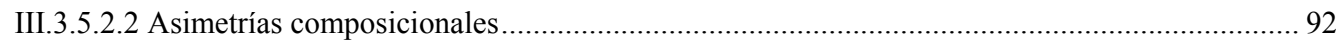

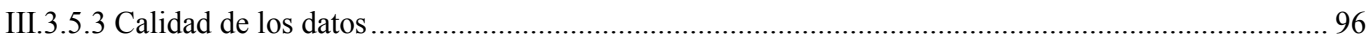

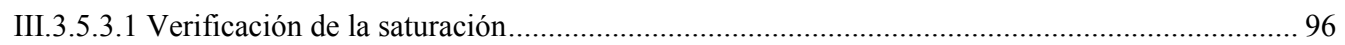

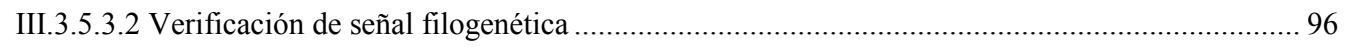

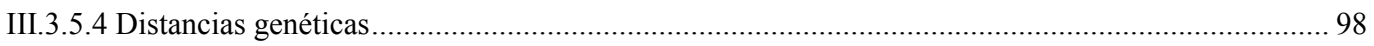

III.3.5.5 Estimación de los parámetros genético-poblacionales ......................................................... 100

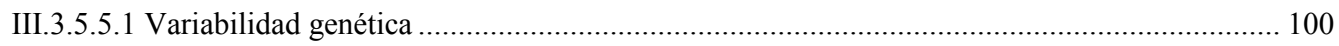

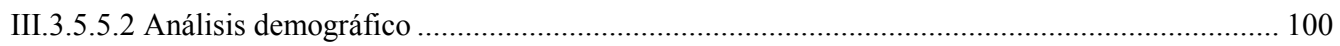

III.3.5.6 Distribución espacial de la variabilidad genética en el Alto Paraná ............................................ 100

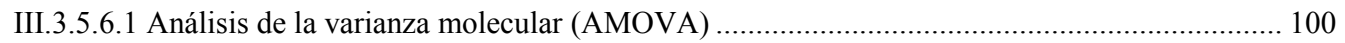

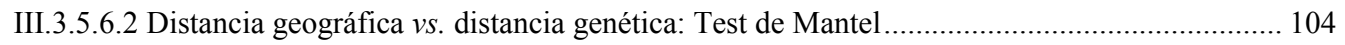

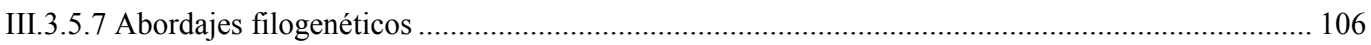

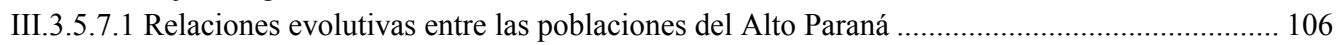

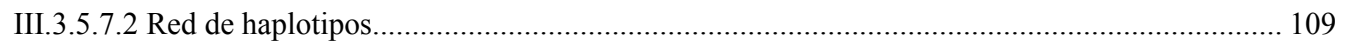

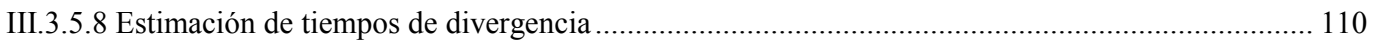

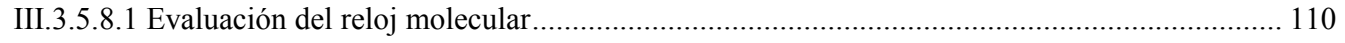

III.3.5.8.1.1 Prueba de razón de verosimilitud global (Global likelihood ratio test) ........................ 110

III.3.5.8.1.2 Comparación de linajes en Aylacostoma: prueba de tasas relativas de Tajima (Tajima's

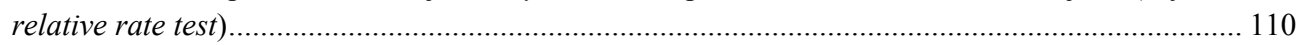

III.3.5.8.2 Estimación de los tiempos de divergencia: calibración del reloj ......................................... 111

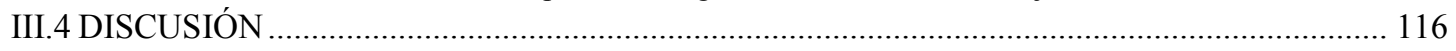

III.4.1 DIFICULTADES AL UTILIZAR GENES RIBOSOMALES MITOCONDRIALES EN

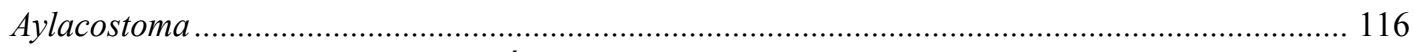

III.4.2 VARIABILIDAD NUCLEOTÍDICA DEL GEN COI EN Aylacostoma ............................... 118

III.4.3 DIVERSIDAD, HISTORIA DEMOGRÁFICA Y ESTRUCTURA GENÉTICA: ¿REFLEJOS DE

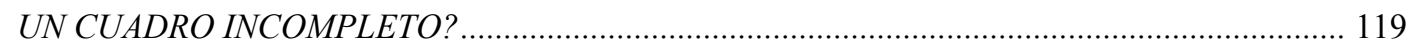

III.4.4 PATRONES FILOGEOGRÁFICOS Y LA HISTORIA DEL ALTO PARANÁ ..................... 123

III.4.5 DELIMITACIÓN DE ESUS: UNA CONTRIBUCIÓN PARA LA CONSERVACIÓN DE LAS

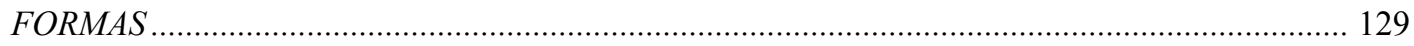

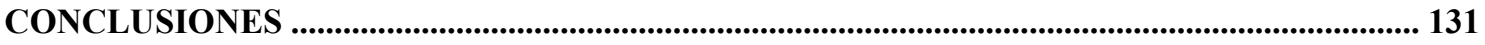

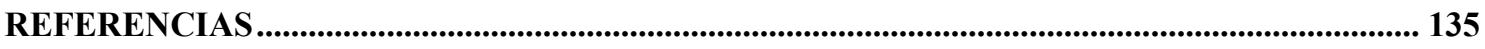

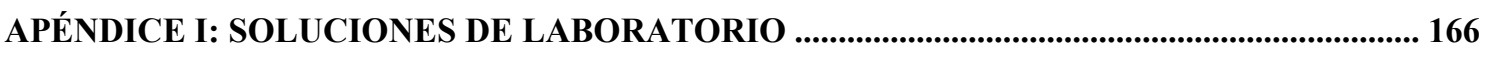

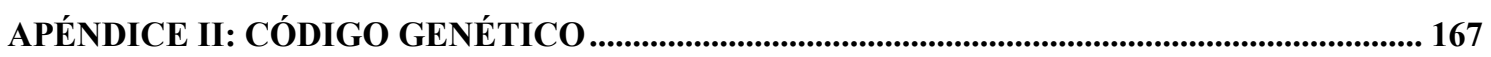

\begin{tabular}{lc}
\hline Tesis Doctoral - Roberto Eugenio Vogler & $\mathrm{x}$
\end{tabular} 


\section{ÍNDICE DE FIGURAS}

Figura 1. Especies de Aylacostoma Spix, 1827 descriptas por Hylton Scott para el Alto Paraná............... 2

Figura 2. Ejemplares analizados de las tres especies endémicas de Aylacostoma del Alto Paraná.............. 8

Figura 3. Posición de los landmarks seleccionados en las conchillas. ................................................. 9

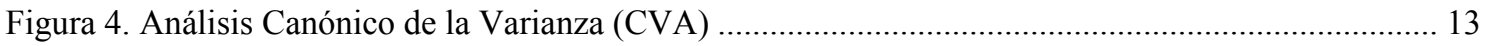

Figura 5. Retículas de deformación a lo largo de los dos ejes canónicos ............................................. 14

Figura 6. Etiquetas que acompañan a los paratipos de A. chloroticum depositados en el Museo Argentino

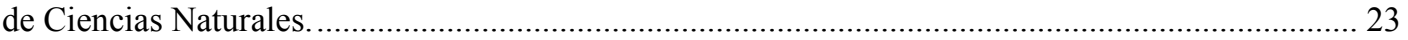

Figura 7. Detalle de la protoconcha de tres juveniles de $A$. chloroticum al MEB ................................ 25

Figura 8. Diseño de la conchilla de un juvenil de $A$. chloroticum ....................................................... 26

Figura 9. Anatomía externa de A chloroticum .............................................................................. 27

Figura 10. Detalle del opérculo y del área entre la braquia y el seno ad-rectal de $A$. chloroticum ........... 28

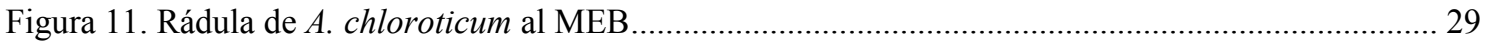

Figura 12. Ejemplares de menos de dos vueltas y abertura de la bolsa incubadora ................................ 31

Figura 13. Distribución de $A$. chloroticum en el Alto Paraná ............................................................... 32

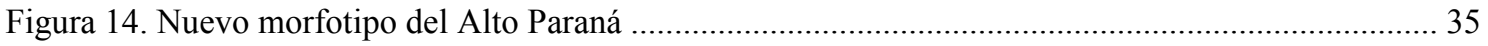

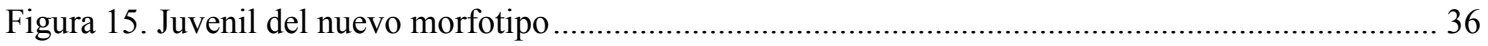

Figura 16. Detalle de la branquia y de los vasos transversales entre la branquia y el seno ad-rectal en el

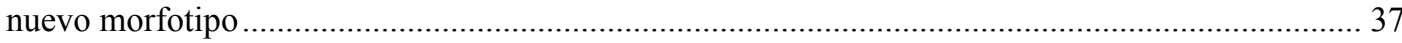

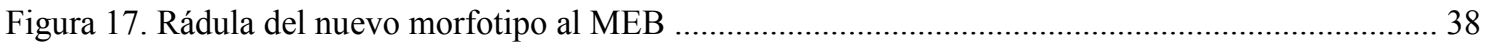

Figura 18. Distribución conocida del nuevo morfotipo en el Alto Paraná ............................................. 39

Figura 19. Vista frontal y dorsal de un ejemplar de Aylacostoma chloroticum ...................................... 52

Figura 20. Modificación del río Paraná entre Posadas (Argentina) y Encarnación (Paraguay) antes del

llenado del embalse Yacyretá a su cota definitiva en 2011 ......................................................... 81

Figura 21. Antiguo puerto de la localidad de Candelaria ...................................................................... 82

Figura 22. Ejemplares de Aylacostoma chloroticum colectados en la zona del antiguo puerto de la localidad argentina de Candelaria, Misiones.

Figura 23. Obtención de ADN genómico total en ejemplares de A. chloroticum de diferentes localidades mediante el Protocolo III.

Figura 24. Amplificación del gen ribosomal mitocondrial $16 \mathrm{~S}$ a partir de diferentes pares de cebadores 86 Figura 25. Amplificación del gen ribosomal mitocondrial 12S a partir de diferentes pares de cebadores 86

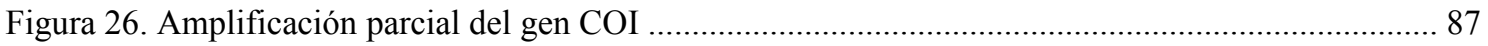

Figura 27. Comparación de la calidad de los electroferogramas obtenidos a partir de los cebadores sentido para los tres genes analizados en un individuo de $A$. chloroticum .................................................. 88

Figura 28. Sequence logos del alineamiento múltiple de las 43 secuencias obtenidas para ejemplares de Aylacostoma .....

Figura 29. Composición nucleotídica porcentual por base y para cada uno de los tres haplotipos analizados

Figura 30. Conservación de la secuencia aminoacídica de los tres haplotipos.

Figura 31. Gráficos comparativos de la complejidad del contenido informativo de la región parcial del gen COI en Aylacostoma...

Figura 32. Análisis de asimetría composicional A vs. T de la región parcial del gen COI. ......................94

Figura 33. Análisis de asimetría composicional C vs. G de la región parcial del gen COI ...................... 95

Figura 34. Comparación de las transiciones (Ts) y transversiones (Tv) respecto de la distancia genética sin incluir los taxa del grupo externo.

Figura 35. Comparación de las transiciones (Ts) y transversiones (Tv) respecto de la distancia genética al incluir los taxa del grupo externo...

Figura 36. Distribución de puntajes de la prueba PTP en las secuencia COI.......................................97

Figura 37. Distribución de discrepancias pareadas ........................................................................... 102

Figura 38. Correlogramas de Mantel a partir de 1000 permutaciones al azar entre las matrices de distancias genéticas y geográficas. 
Figura 39. Reconstrucción filogenética de Aylacostoma spp. del Alto Paraná basada en 658 nucleótidos

de la región parcial del gen COI

Figura 40. Reconstrucción filogenética basada en la región parcial del gen COI ................................ 108

Figura 41. Red de haplotipos obtenida mediante el algoritmo "median joining network" ...................... 109

Figura 42. Tiempos de divergencia estimados para Aylacostoma procedente del Alto Paraná................ 115 


\section{ÍNDICE DE TABLAS}

Tabla I. Descripción de la posición de los landmarks en la conchillas ................................................... 10

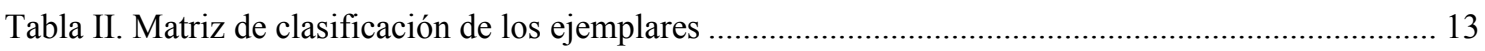

Tabla III. Medidas relevadas a partir de 15 conchillas de $A$. chloroticum................................................ 24

Tabla IV. Registros de A. chloroticum en el Alto Paraná (Argentina-Paraguay). .................................. 32

Tabla V. Medidas de los reclutamientos a partir de una hembra de A. chloroticum ................................ 33

Tabla VI. Medidas relevadas a partir de 6 conchillas del nuevo morfotipo (MLP 13613) ...................... 35

Tabla VII. Procedencia del material de estudio ........................................................................... 51

Tabla VIII. Detalle de los cebadores utilizados para la amplificación de los genes ribosomales .............. 55

Tabla IX. Detalle de la composición de las diferentes mezclas de reacción ensayadas en la amplificación

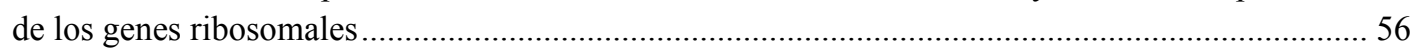

Tabla X. Detalle de los perfiles térmicos (PT) ensayados en la amplificación de los genes ribosomales . 57

Tabla XI. Resumen de las combinaciones de mezclas de reacción y perfiles térmicos ensayados en la optimización de las reacciones de amplificación de los genes ribosomales .................................... 58

Tabla XII. Composición de la mezcla de reacción utilizada en la amplificación del gen COI .................. 59

Tabla XIII. Productos de amplificación obtenidos de los genes ribosomales mitocondriales a partir de diferentes cebadores, mezclas de reacción y perfiles térmicos ........................................................ 85

Tabla XIV. Datos de los ejemplares analizados y número de accesos a la región parcial del gen COI..... 89

Tabla XV. Composición de secuencia de los tres haplotipos identificados en Aylacostoma .................... 91

Tabla XVI. Valores de asimetrías composicionales calculados para los tres haplotipos del gen COI procedentes del Alto Paraná....................................................................................................... 96

Tabla XVII. Niveles de saturación de acuerdo a la prueba de Xia et al. (2003) .................................... 96

Tabla XVIII. Resultados de la prueba PTP ........................................................................................ 98

Tabla XIX. Distancia nucleotídica entre pares de haplotipos mitocondriales del gen COI según diferentes modelos de sustitución nucleotídica

Tabla XX. Distancias genéticas entre A. chloroticum y el nuevo morfotipo según diferentes modelos de sustitución nucleotídica......

Tabla XXI. Principales estadísticos obtenidos de las secuencias COI analizadas ................................ 101

Tabla XXII. Significación estadística de las distribuciones pareadas bajo los modelos de expansión súbita

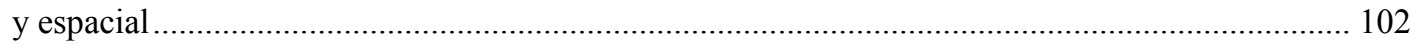

Tabla XXIII. Valores de $\Phi_{\mathrm{ST}}$ de la comparación pareada de las seis poblaciones de A. chloroticum...... 103

Tabla XXIV. Análisis jerárquico por regiones de la variación genética en $A$. chloroticum ..................... 103

Tabla XXV. Valores de $\Phi_{\mathrm{ST}}$ de la comparación pareada de las poblaciones del Alto Paraná incluyendo el nuevo morfotipo como parte de $A$. chloroticum ........................................................................... 104

Tabla XXVI. Distribución de los haplotipos por población ............................................................. 104

Tabla XXVII. Análisis jerárquico por regiones de la variación genética .............................................. 104

Tabla XXVIII. Resultados de la prueba de tasas relativas de Tajima ..................................................... 111

Tabla XXIX. Estimación Bayesiana de los tiempos de divergencia entre A. chloroticum y el nuevo morfotipo, y entre linajes de $A$. chloroticum .......................................................................... 112

Tabla XXX. Estimación de los tiempos de divergencia entre A. chloroticum y el nuevo morfotipo....... 113

Tabla XXXI. Estimación de los tiempos de divergencia entre los linajes de A. chloroticum .................. 114

Tabla XXXII. Código genético mitocondrial de invertebrados........................................................ 167 


\section{ABREVIATURAS MÁS FRECUENTES}

- $\boldsymbol{\theta}$ : Diversidad genética.

- $\pi$ : Diversidad nucleotídica.

- $\mathbf{\Phi : ~ P h i - e s t a d i ́ s t i c o s . ~}$

- A: Adenina.

- $\mathbf{A}^{\circ}$ : Arroyo.

- AA: Ancho de la abertura.

- ADNmt: ADN mitocondrial.

- AE: Ancho de la espira.

- AICc: Criterio de Información de Akaike corregido.

- AMOVA: Análisis de la varianza molecular (Analysis of Molecular Variance).

- AR: Argentina.

- ARNr12 S: Gen ribosomal 12S.

- ARNr16 S: Gen ribosomal 16S.

- AT: Ancho total.

- AYC: Aylacostoma chloroticum.

- C: Citosina.

- COI: Gen Citocromo Oxidasa subunidad I.

- Corr.: Provincia de Corrientes, Argentina.

- CR: Colección de referencia.

- CS: Centroid size.

- CV: Eje canónico derivado del CVA.

- CVA: Análisis canónico de la varianza (Canonical Variates Analysis).

- DS: Desvío estándar.

- DZI: División Zoología Invertebrados, FCNyM, UNLP.

- EBY: Entidad Binacional Yacyretá.

- EGSC: Concepto de especie Genético Evolutivo (Evolutionary Genetic Species Concept).

- ES: Error estándar.

- ESU: Unidad evolutiva significativa (Evolutionary Significant Unit).

- F84: Modelo de evolución nucleotídica Felsenstein 84.
- FCEQyN: Facultad de Ciencias Exactas, Químicas y Naturales, UNaM.

- FCNyM: Facultad de Ciencias Naturales y Museo, UNLP.

- FNV: Variación de nicho congelado (Frozen Niche Variation).

- G: Guanina.

- GPA: Análisis generalizado de Procrustes (Generalized Procrustes Analysis).

- GPG: Genotipo de propósito generalista (General Purpose Genotype).

- H: Haplotipo.

- Hd: Diversidad haplotípica.

- IB: Inferencia Bayesiana.

- Ita.: Departamento Itapúa, Paraguay.

- Iss: Índice de saturación de secuencia.

- I Iss.C: Índice de saturación de secuencia, valor crítico.

- JC: Modelo de evolución nucleotídica JukesCantor.

- K2P: Modelo de evolución nucleotídica Kimura dos Parámetros.

- LA: Largo de la abertura.

- LCC: Complejidad de composición local (Local Compositional Complexity).

- LE: Longitud de la espira.

- Lg.: Laguna.

- LM: Landmark.

- LPA: Longitud del penúltimo anfracto.

- LSU: Subunidad ribosomal grande (Large subunit).

- LR: Likelihood Ratio.

- LRT: Likelihood Ratio Test.

- LT: Longitud total.

- LUA: Longitud del último anfracto.

- Ma: Millones de años. 
- MACN: Museo Argentino de Ciencias Naturales "Bernardino Rivadavia".

- MANOVA: Análisis multivariado de la varianza (Multivariate Analysis of Variance).

- MEB: Microscopio electrónico de barrido

- Mis.: Provincia de Misiones, Argentina.

- ML: Máxima verosimilitud (Maximum Likelihood).

- MLP: Museo de La Plata.

- MO: Microscopio óptico.

- MP: Máxima parsimonia.

- NG: Nanogramo.

- NJ: Neighbour Joining.

- NM: Nuevo morfotipo.

- NP-MANOVA: MANOVA no paramétrico.

- NUMTS: Nuclear Mitochondrial DNA Sequences.

- ON: Overnight.

- ORF: Marco de lectura abierto (Open Reading Frame).
- PB: Pares de bases.

- PCR: Reacción en Cadena de la Polimerasa.

- PT: Perfil térmico.

- Pto.: Puerto.

- PTP: Permutation Tail Probability Test.

- PY: Paraguay.

- RW: Relative warp.

- RWA: Relative Warp Analysis.

- S: Número de sitios segregantes.

- T: Timina.

- TN84: Modelo de evolución nucleotídica Tajima \& Nei 84.

- TN93: Modelo de evolución nucleotídica Tamura \& Nei 93

- TPS: Thin-Plate Splines.

- TS: Transiciones.

- TV: Transversiones.

- UNaM: Universidad Nacional de Misiones.

- UNLP: Universidad Nacional de La Plata. 


\section{PRÓLOGO}

La presente Tesis de Doctorado forma parte de los requerimientos académicos para la obtención del Título de Posgrado de "Doctor en Ciencias Naturales" que otorga la Facultad de Ciencias Naturales y Museo (FCNyM) de la Universidad Nacional de La Plata (UNLP).

Como directora de esta tesis fue elegida la docente investigadora Dra. Alejandra Rumi (FCNyM, UNLP) y como codirectora la docente investigadora Dra. Carina F. Argüelles (FCEQyN, UNaM) quienes aceptaron la propuesta del postulante respecto del tema de tesis, el cual fue remitido a la Comisión de Grado Académico (CGA) de la FCNyM-UNLP, donde fue evaluado y aprobado según consta en la Resolución $\mathrm{N}^{\circ}$ 268/2008 con fecha del 29 de agosto de 2008.

Este trabajo se ha realizado en las instalaciones de la División Zoología Invertebrados (DZI) del Museo de La Plata (MLP) dependiente de la FCNyM-UNLP, y se ha desarrollado en colaboración con el Laboratorio de Genética Molecular de la Facultad de Ciencias Exactas, Químicas y Naturales (FCEQyN) de la Universidad Nacional de Misiones (UNaM).

Las actividades desarrolladas fueron financiadas mediante fondos provenientes de los siguientes proyectos dirigidos por la Dra. Alejandra Rumi: i- Biodiversidad y patrones demográficos de Mollusca y Ostracoda (Crustacea) continentales de la Argentina, en especial de Misiones e Isla Martín García (Programa Nacional de Incentivos, FCNyMUNLP N636); ii- Riqueza, diversidad y vulnerabilidad de Moluscos continentales de la Provincia de Misiones, Argentina (PICT-2008-2042); iii- Moluscos de agua dulce de la Argentina. Biodiversidad y patrones demográficos. (Programa Nacional de Incentivos, FCNyM-UNLP N470). Asimismo, parte de las actividades fueron financiadas por dos pequeños subsidios obtenidos por el tesista: iv- Filogeografía aplicada a conservación de caracoles de los rápidos, Aylacostoma Spix, 1827: especies amenazadas de Argentina y Paraguay (Oportunidades Internacionales para Conservación, Investigación y Educación, CREOI), y v- Subsidio a Tesistas de la Facultad de Ciencias Naturales y Museo 2010. (FCNyM, Universidad Nacional de La Plata). 


\section{RESUMEN}

En el presente trabajo de Tesis se realizó un estudio filogeográfico sobre las especies endémicas y amenazadas del género Aylacostoma Spix, 1827 de la región del Alto Paraná (Argentina-Paraguay) enfocado en comprender la estructura genética e historia de sus poblaciones, con el fin último de aportar información fundamental para el desarrollo de estrategias de conservación y manejo de las especies. En la década de 1950 fueron formalmente descriptas tres especies para esta región, las que habitaban ambientes altamente oxigenados del río Paraná como lo eran los rápidos del Apipé, sitio actual de emplazamiento de la Represa Binacional Yacyretá. La construcción y llenado de Yacyretá, provocó un cambio ambiental drástico y nocivo para la subsistencia de estas especies, y en la actualidad se encuentran catalogadas en la Lista Roja de las Especies Amenazadas como "extinguidas en la naturaleza". Al presente, dos de las formas pueden considerarse extintas: A. guaraniticum (Hylton Scott, 1953) y A. stigmaticum (Hylton Scott, 1954). Sin embargo, A. chloroticum Hylton Scott, 1954 aún persiste en la naturaleza aunque en situación crítica. De esta manera, y a los efectos de recabar la mayor información posible sobre las especies del Alto Paraná, en el presente trabajo se utilizaron básicamente tres ejes de análisis: conchillas, caracteres endosomáticos y secuencias de ADN mitocondrial.

La variación de forma entre las especies extintas y la única representante en la naturaleza, fue analizada mediante un abordaje de morfometría geométrica. Este análisis fue exitoso en la asignación de especímenes individuales a sus especies particulares y reveló la existencia de diferencias significativas de forma, las cuales podrían vincularse a un uso diferencial del hábitat y/o al grado de exposición a la corriente.

Por otra parte, se realizó el examen de las conchillas y partes blandas de $A$. chloroticum, hasta la fecha descriptos sólo sus aspectos conquiliológicos, así como de un nuevo morfotipo identificado para el Alto Paraná, caracterizándose por primera vez la organización anatómica de ambas entidades. Este abordaje incluyó el examen de caracteres de conchilla, rádula, cabeza-pie, opérculo, órganos del manto, sistemas digestivo, circulatorio, excretor y genital, así como la compilación de los principales aspectos conocidos para ambas entidades. Las conchillas presentaron patrones de coloración y ornamentación característicos para cada forma, y a nivel anatómico, el nuevo morfotipo pudo ser diferenciado de A. chloroticum por la presencia de vasos transversales conspicuos en el manto (entre la branquia y el seno ad-rectal), muy poco 
evidentes en la última especie. Asimismo y a partir de la caracterización de rádulas, $A$. chloroticum y el nuevo morfotipo fueron fácilmente discriminadas de las especies descriptas para Brasil por la presencia de dos dentículos basales en cada vértice exterior del raquídeo, estos últimos ausentes en las especies brasileñas.

Por último, a través de secuencias de ADN mitocondrial fue posible analizar la estructura y diversidad genética de ejemplares procedentes de poblaciones naturales y en cautiverio de $A$. chloroticum y del nuevo morfotipo, así como reconstruir su historia filogeográfica. Mediante secuencias del gen Citocromo Oxidasa subunidad I (COI) pertenecientes a 43 especímenes del Alto Paraná y tres de un grupo externo, se realizó la primera caracterización genética del género para Sudamérica. Los principales abordajes realizados consistieron en: i- caracterización de las secuencias basada en descriptores típicos y adicionales; ii- estimación de distancias genéticas; iii- estimación de los niveles de diversidad génica; iv- cómputo de pruebas de neutralidad; v- análisis de la distribución espacial de la variabilidad genética; y vi- abordajes filogenéticos. Como resultado, se identificaron tres haplotipos, dos dentro de A. chloroticum y uno en el nuevo morfotipo, para los cuales se verificó: un alto contenido de AT; un marco de lectura en +2 con secuencia aminoacídica conservada; altos valores de complejidad de composición local; asimetría composicional AT negativa; ausencia de saturación; fuerte señal filogenética; divergencia notable entre los haplotipos de A. chloroticum respecto del haplotipo del nuevo morfotipo; bajos niveles de diversidad genética con uniformidad en la constitución de la mayoría de las poblaciones de A. chloroticum; inexistencia de variación genética dentro del nuevo morfotipo; y ausencia de correlación entre la distancia genética y distancia geográfica en A. chloroticum. Asimismo, a partir de los abordajes filogenéticos se evidenció monofília recíproca entre A. chloroticum y el nuevo morfotipo, cuya divergencia habría ocurrido probablemente entre mediados del Plioceno e inicios del Pleistoceno. En este marco temporal, esta divergencia podría estar vinculada a la historia geomorfológica del río Paraná, donde el ancestro de las formas podría haber especiado a partir de una oportunidad de ambientes transicionales en la zona de convergencia entre el Alto Paraná Encajonado y el tramo inferior del Alto Paraná. Adicionalmente, en términos de conservación, se sugiere que los tres haplotipos identificados y caracterizados ameritan ser reconocidos como Unidades Evolutivas Significativas (ESUs). Esta sugerencia se basa en que cada linaje representa una historia evolutiva independiente condicionada a la partenogénesis apomíctica característica del 
grupo. Asimismo, se identificó que la región de mayor interés en términos de conservación en el Alto Paraná, está representada por la zona de entrada del embalse de Yacyretá, y particularmente en torno a la localidad paraguaya de Río Beach $\left(27^{\circ} 24^{\prime} 29,83^{\prime \prime} \mathrm{S} ; 5^{\circ} 49^{\prime} 32,94^{\prime \prime} \mathrm{W}\right)$, donde convergen las tres ESUs. Esta situación, no sólo confiere al área un estatus de relicto en términos de diversidad genética, sino que también resulta una fuente clave de diversidad genética y morfológica para alimentar la conservación ex situ de las formas argentino-paraguayas de Aylacostoma. Así, en función de la distribución espacial de la variabilidad genética obtenida, se sugiere que las futuras reintroducciones de ejemplares conservados ex situ deberían efectuarse siempre que fuera posible- en la zona de entrada del embalse, a los efectos de preservar los procesos evolutivos y comprometer en menor medida el futuro del potencial evolutivo de estos gasterópodos.

Finalmente, a partir de la caracterización anatómica y genética efectuada, se propone que el nuevo morfotipo del Alto Paraná representa una especie nueva para la ciencia la cual amerita, al igual que A. chloroticum, las máximas prioridades de conservación. 


\begin{abstract}
In the present Thesis, a phylogeographic study of the endemic and endangered species of the genus Aylacostoma Spix, 1827 from the Alto Parana region (ArgentinaParaguay) was conducted, with the main objective of providing key information for the generation and development of strategies for species conservation and management. In the 1950s, three species were formally described for this area, inhabiting highly oxygenated environments at the Paraná River such as the Apipé rapids, the place where Yacyretá Binational Dam is presently located. As a consequence of damming and the filling up of the reservoir these species were highly threatened, and they are now cataloged as "extinct in the wild" in the Red List of Threatened Species. Currently, two of the tree species could be considered as extinct: A. guaraniticum (Hylton Scott, 1953) and A. stigmaticum (Hylton Scott, 1954). However, the remaining species $A$. chloroticum Hylton Scott, 1954 still persist in nature but in critical conditions. Thus, with the intention of gathering as much information as possible about the Alto Paraná species, three different approaches were conducted. These were based on the analysis of shells, soft parts, as well as mitochondrial DNA sequences.
\end{abstract}

Variation in shape among the two extinct species and the living one was analyzed by using geometric morphometric methods. Analysis was successful in assigning individual specimens to particular species and revealed statistically significant differences in the last whorl, aperture, and spire. These differences could be related to a differential use of habitat and/or to the level of exposure to water current.

Morphological examination was conducted on specimens of A. chloroticum and a new morphotype recently identified from Alto Paraná. This is the first time that anatomical organization is characterized for both of them; since A. chloroticum was only described based on shells characters. This approach involved the examination of characters from shell, radula, head-foot, operculum, mantle organs, digestive, circulatory, excretory and genital systems, and the compilation of the all known aspects from literature. A. chloroticum and the new morphotype exhibit shells that differed in color and ornamentation, and at the anatomical level the new morphotype could be discriminated from A. chloroticum by the presence of conspicuous transverse vessels in the mantle (between the gill and the ad-rectal sinus), not so evident in the latter species. 
In the same way, both forms from Alto Paraná differed from those anatomically characterized for Brazil in the presence and the number of basal cusps of the central tooth.

Using mitochondrial DNA sequences, the genetic structure and diversity of individuals from natural and captive populations of $A$. chloroticum and the new morphotype was analyzed and the phylogeographic history was reconstructed. Using sequences from cytochrome oxidase subunit I (COI) gene of 43 specimens from Alto Paraná, and three from an outgroup, we were able to obtain the first genetic characterization for this genus and for South America. The main approaches consisted in: i- characterizing sequences by typical and additional descriptors; ii- estimating genetic distances; iii- estimating levels of genetic diversity, iv- computing neutrality test; v- analyzing spatial distribution of genetic variability, and vi- inferring intraspecific relationships. As a result, three haplotypes were identified, two in A. chloroticum and one in the new morphotype, being verified also: a high AT content; an open reading frame in +2 , with the conservation of amino acid sequence; high local compositional complexity values; negative AT skew; absence of saturation; strong phylogenetic signal; remarkable divergence between the haplotypes of $A$. chloroticum regarding the new morphotype haplotype; low levels of genetic diversity with uniformity in the constitution of most populations of $A$. chloroticum; lack of genetic variation within the new morphotype; and lack of correlation between genetic distance and geographic distance in $A$. chloroticum. In addition and by using phylogenetic approaches, reciprocal monophyly between $A$. chloroticum and new morphotype was detected. The divergence between both may take place probably by the mid-Pliocene and early Pleistocene. In this time frame, such differences could be linked to the geomorphological history of Paraná River, where the speciation of ancestor might be related to transitional environments opportunity in the convergence zone between Alto Paraná Encajonado and the lower stretch of Alto Paraná. In addition, and in terms of conservation, our results suggest the three identified and characterized haplotypes should be considered as Evolutionary Significant Units (ESUs). The latter is based on the fact that each lineage represents a separate evolutionary history conditioned on the apomictic parthenogenesis of the group. Furthermore, we identified that the region of interest in terms of conservation was the more lotic zone of Yacyretá Reservoir, and particularly around the

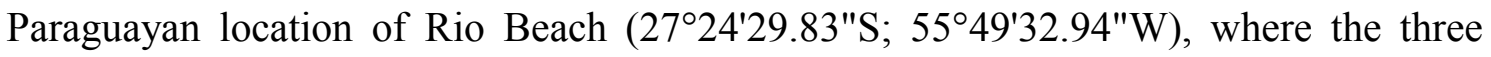


ESUs converge. This situation not only confers to this area the status of genetic relict, but also represents a key source of genetic diversity for ex situ conservation of Aylacostoma specimens. Thus, by considering the spatial distribution of genetic diversity obtained we suggest that whenever possible, future reintroductions should be done in this area, so the evolutionary processes and the evolutionary potential of these gastropods could be preserved.

Finally, based on the anatomical and genetic characterization conducted, we proposed that the new morphotype from Alto Paraná represents a new species which deserves together with $A$. chloroticum the highest conservation priorities. 


\section{ORGANIZACIÓN GENERAL DE LA TESIS}

El presente trabajo de tesis está organizado de la siguiente manera: una Introducción General elaborada con el objeto de presentar los principales antecedentes y conceptos teóricos que condujeron al planteo de los objetivos e hipótesis de trabajo. Asimismo, debido a los diversos abordajes metodológicos empleados, se decidió estructurar la información en tres capítulos, y así facilitar su lectura y comprensión.

En la Introducción General, se plantea el estado de situación y se describen los principales aspectos que habrían conducido a la extinción de dos especies de caracoles del género Aylacostoma, objeto de estudio en el presente trabajo, y se expone el caso crítico de una tercera especie, de la cual aún se conocen ejemplares en su ambiente natural. Con este apartado se pretende generar el contexto que permitirá comprender la aplicabilidad de los resultados obtenidos.

El primer capítulo representa el punto de partida al primer objetivo de esta Tesis referido al examen de los caracteres diagnósticos de las especies de Aylacostoma utilizando conchillas. Allí se analizan las formas de las especies conocidas por medio de la morfometría geométrica, no sólo con el objeto de complementar su diagnosis específica, sino también con el fin de intentar responder a la pregunta de ¿por qué sólo una de las especies persistió en la naturaleza?

En el segundo capítulo se aborda el estudio de los caracteres morfológicos en $A$. chloroticum, única representante de las especies descriptas del Alto Paraná de la cual se cuenta con partes blandas, que permiten la redescripción de la especie, información que a su vez es complementada con la compilación de los principales aspectos conocidos de la especie. Finalmente, en este mismo capítulo se describe por primera vez, una nueva entidad del género Aylacostoma proveniente de la región del Alto Paraná, de la cual se cuenta con escasos ejemplares, la que ameritaría el estatus de especie amenazada, de igual forma que su congénere.

En el tercer capítulo, se caracteriza la diversidad genética de las poblaciones naturales de los caracoles del género Aylacostoma a través de la información proporcionada por genes presentes en el ADN mitocondrial (ADNmt). Se analiza la distribución espacial y se interpretan los datos genéticos en el contexto de dos modelos 
ecológicos vigentes para organismos de reproducción partenogenética, como es el caso que nos ocupa. También en este capítulo, y a través de la reconstrucción de la historia filogeográfica de las especies y de la delimitación de unidades de conservación conocidas como ESUs, se intenta dar respuestas a preguntas tales como ¿cuántos linajes genéticos de estos caracoles están presentes en la naturaleza? y ¿sobre qué localidad es conveniente priorizar los recursos tendientes a optimizar la conservación ex situ de estos caracoles?

Finalmente, el lector se encontrará con una conclusión general en la que se sintetizan e integran los principales resultados obtenidos en este trabajo de Tesis. 


\section{INTRODUCCIÓN GENERAL A LA TESIS}

En términos del número de especies, los moluscos continentales pertenecen al segundo phylum animal más diverso. Se estima que existen aproximadamente 24.000 especies de moluscos terrestres y unas 4.000 de agua dulce con descripciones válidas y que probablemente existan 11.000 a 40.000 especies terrestres y 8.000 especies de agua dulce no descritas. Sin embargo, los moluscos continentales tienen el "dudoso record" de contar con el mayor número de extinciones documentadas que cualquier otro grupo taxonómico (Lydeard et al., 2004; Strong et al., 2008). Aproximadamente un 42\% de las extinciones de especies animales registradas desde el año 1500 son moluscos, lo que representa más que el total de todas las especies de tetrápodos que se han extinguido durante el mismo período (Lydeard et al., 2004). Particularmente, los gasterópodos dulceacuícolas (que representan aproximadamente el $5 \%$ de la fauna mundial de gasterópodos) enfrentan un grado desproporcionadamente alto de amenaza (Strong et al., 2008). De las 314 especies listadas en 2012 como extintas en la Lista Roja de las Especies Amenazadas de la IUCN ${ }^{1}, 73$ ( 20\%) son especies de gasterópodos de aguas continentales.

Los gasterópodos de agua dulce se encuentran en todos los continentes con excepción de la Antártida y en casi todos los ambientes acuáticos (Strong et al., 2008). Si bien para América del Sur no se cuenta con estimaciones globales de la riqueza de moluscos (Lévêque et al., 2005), las estimaciones de diversidad en grandes ríos sudamericanos (e.g. Uruguay, Paraná y Río de la Plata) y sus tributarios indican que la diversidad de gasterópodos de agua dulce en Sudamérica es alta, siendo sus cuencas, además ricas en poblaciones endémicas (Lévêque et al., 2005; Gutiérrez Gregoric et al., 2006; Rumi et al., 2006, 2008; Strong et al., 2008; Núñez et al., 2010).

En Argentina, Rumi et al. $(2006,2008)$ citan un total de 101 especies de gasterópodos dulceacuícolas distribuidos en 10 familias, de las cuales 40 son reconocidas como endémicas y 45 son consideradas vulnerables. La mayor diversidad de gasterópodos se concentra en la provincia malacológica Misionera. Seis especies son endémicas de esta provincia, las que a su vez son consideradas vulnerables y sólo se encuentran en torno a sus localidades tipo (Núñez et al., 2010). Entre estas especies se ubican las de la familia Thiaridae Gill, 1871, género Aylacostoma Spix, 1827, endémicas del Alto Paraná, entre Argentina y Paraguay.

\footnotetext{
${ }^{1}$ www.redlist.org
} 
La presencia de especies del género Aylacostoma en el Alto Paraná (ArgentinaParaguay) fue informada por primera vez por Hylton Scott a mediados de 1950 (Hylton Scott, 1953, 1954), quien describió tres especies: A. guaraniticum (Hylton Scott, 1953), A. chloroticum Hylton Scott, 1954 y A. stigmaticum Hylton Scott, 1954 (Figura 1). Estos gasterópodos habitaban ambientes altamente oxigenados en la zona de los rápidos de Yacyretá-Apipé en el río Paraná, sitio actual de emplazamiento de la Represa Binacional Yacyretá (Seddon, 2000; Ostrowski de Nuñez \& Quintana, 2008). Teniendo en cuenta que el área de Yacyretá era el único sitio donde fueron hallados, su extinción total era esperable con el llenado del embalse. Actualmente, las tres especies de Aylacostoma figuran como "extinguidas en estado silvestre" en la Lista Roja de las Especies Amenazadas de la UICN (Mansur 2000a, 2000b, 2000c), aunque A. chloroticum aún persiste en la naturaleza y está catalogada como una especie endémica y vulnerable para la Argentina (Núñez et al., 2010). Sin embargo, esta especie se encuentra en situación crítica, debido a la drástica modificación que sufrieron los ambientes que habitaba, tras el llenado de la represa. Así, al presente, es factible encontrar individuos en un único sitio que sufriera importantes cambios, entre ellos inundaciones y modificación de la línea de costa como consecuencia de alcanzarse la cota definitiva prevista para el embalse y por la construcción de la avenida costanera de la localidad de Candelaria (Misiones, Argentina). En este contexto, es importante destacar finalmente que se han encarado estrategias para la reproducción en cautiverio de la especie, a través de un programa de conservación ex situ del que participan la Entidad Binacional Yacyretá, el Museo Argentino de Ciencias Naturales "Bernardino Rivadavia" y la Universidad Nacional de Misiones, con el último propósito de reintroducirla en localidades, presumiblemente adecuadas, río abajo de la represa.
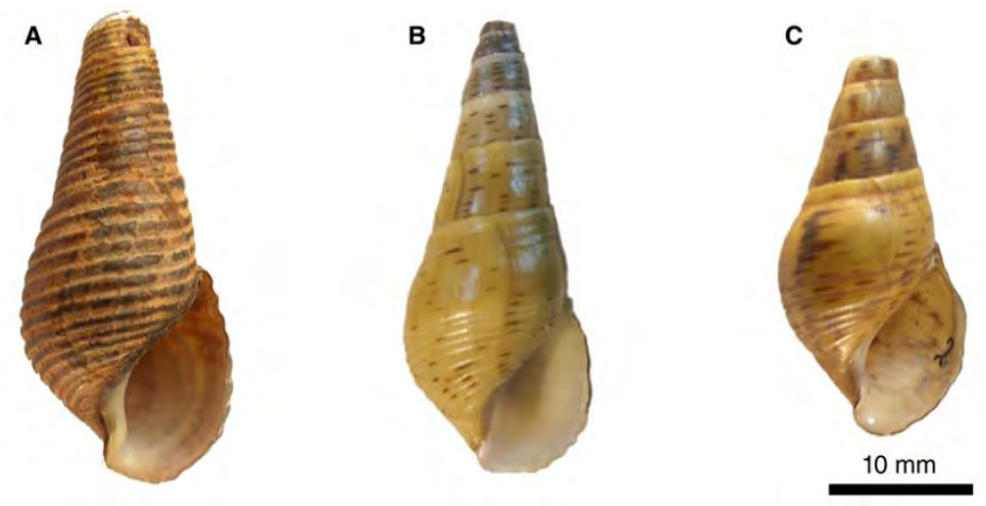

Figura 1. Especies de Aylacostoma Spix, 1827 descriptas por Hylton Scott para el Alto Paraná. A: A. guaraniticum; B: A. chloroticum, C: A. stigmaticum. 


\section{OBJETIVO GENERAL}

Efectuar un análisis filogeográfico enfocado en comprender la estructura genética e historia de las poblaciones de las especies endémicas y amenazadas del género Aylacostoma del río Paraná (Argentina), que aporte información fundamental para el desarrollo de estrategias de conservación y manejo de las especies.

\section{OBJETIVOS ESPECÍFICOS}

a. Examinar caracteres diagnósticos de las conchillas y endosomáticos de las especies argentinas del género Aylacostoma. Los caracteres endosomáticos aún no están descriptos para estas especies.

b. Estimar los tiempos generacionales de las poblaciones en cautiverio utilizando como modelo a $A$. chloroticum.

c. Analizar la estructura y diversidad genética de las poblaciones naturales.

d. Reconstruir la historia filogeográfica de las especies utilizando genes presentes en el ADN mitocondrial (ADNmt).

e. Predecir patrones de distribución de especies utilizando modelado de nicho ecológico combinado con filogeografía molecular.

f. Evaluar la variabilidad genética y dinámica de las poblaciones naturales, en el marco del modelo ecológico "Frozen Niche Variation", utilizando como modelo a $A$. chloroticum.

g. Identificar número y rango geográfico de las ESUs. 


\section{HIPÓTESIS}

a. Las especies del género Aylacostoma están estructuradas filogeográficamente en clados genéticos diferentes, debido a la antigüedad de su separación, en tiempo geológico.

b. Cada clado probablemente presente un haplotipo ancestral y otros derivados.

c. Para las poblaciones relictuales alopátricas de A. chloroticum, se espera que la variabilidad genética se encuentre estructurada.

d. Aylacostoma chloroticum presenta una baja diversidad genética dentro de los clados, considerando el sistema reproductivo de la especie y que las poblaciones ocurren en áreas geográficas restrictas.

e. Para A. chloroticum los haplotipos compartidos entre las poblaciones actuales, explican un origen común como parte de una población ancestral.

f. Los individuos clonales de Aylacostoma presentan especificidad de hábitat respecto de especies generalistas como Melanoides tuberculatus (Thiaridae invasor). 


\section{CAPÍTULO I: ANÁLISIS DE LA FORMA DE LAS Aylacostoma DESCRIPTAS PARA EL ALTO PARANÁ A TRAVÉS DE MORFOMETRÍA GEOMÉTRICA}

\section{I.1 INTRODUCCIÓN}

La cuantificación de fenómenos por medio de modelos matemáticos y métodos estadísticos es una práctica establecida en diversas ramas de la biología, como la genética, ecología, inmunología y fisiología (Monteiro \& Reis, 1999). En sus comienzos, las comparaciones entre organismos estaban basadas en el análisis de las diferencias de sus dimensiones lineales y la forma era considerada una cualidad de la estructura, la cual aunque describible de manera detallada, no podía ser analizada cuantitativamente (Toro et al., 2010).

A partir de la década de 1930, y con el objetivo de describir patrones de variación de la forma dentro y entre muestras de organismos, se desarrollaron métodos estadísticos tales como los multivariados (e.g. análisis de componentes principales, de variables canónicas, función discriminante) que se comenzaron a aplicar a grupos de variables cuantitativas (e.g. largo, ancho, alto, ángulos; Toro et al., 2010). Este enfoque es referido en la literatura como morfometría tradicional o clásica (Rohlf \& Marcus, 1993), aunque el término morfometría ha sido utilizado indiscriminadamente para referir a cualquier estudio enfocado al análisis cuantitativo de la variación morfológica encontrada en los organismos (Monteiro \& Reis, 1999).

Durante la década de 1980, una revolución metodológica en el área de la morfometría favoreció la creación de un área de investigación en la frontera entre la biología, la estadística y la geometría, la morfometría geométrica, con la cual se desarrollaron métodos que lograron reunir el carácter geométrico de las formas biológicas y permitieron un tratamiento estadístico adecuado de la variación registrada (Monteiro \& Reis, 1999; Adams et al., 2004). Mientras que en los estudios morfométricos tradicionales se utilizan distancias como variables, en morfometría geométrica la manera habitual de capturar la geometría de los organismos bajo estudio es a partir de la selección y digitalización de una serie de puntos morfométricos homólogos o landmarks (Adams et al., 2004; Strauss, 2010). Estos son caracteres basados en coordenadas cartesianas y pueden ser definidos como puntos en un espacio bi o tridimensional que corresponden a la posición de un rasgo morfológico particular (Lele \& Richtsmeier, 2001). En este contexto, resulta oportuno aclarar que el concepto de homología puede ser 
puramente operacional (correspondencia biológica de la posición de los landmarks entre los organismos de la muestra) o corresponder a estructuras homólogas en un sentido evolutivo, dependiendo de cuál sea el objetivo del estudio (Monteiro \& Reis, 1999; Marani, 2010).

Una vez que se han obtenido las coordenadas de landmarks para un conjunto de organismos, éstas deben necesariamente ser estandarizadas (i.e. eliminar los efectos debido a escala, posición y orientación) para que puedan ser comparables (Strauss, 2010). Esto se realiza típicamente mediante métodos de sobreimposición, de los cuales el más frecuentemente utilizado es el Análisis Generalizado de Procrustes (GPA, del inglés Generalized Procrustes Analysis). Posteriormente, para caracterizar y visualizar la dirección de las diferencias de forma, las coordenadas alineadas de landmarks, a menudo, son ajustadas a una función de interpolación como Thin-Plate Splines -TPS- (Bookstein, 1989). Los métodos de deformaciones como el TPS son cada vez más utilizados en investigación morfométrica, dado que: a) permiten la completa separación del tamaño y la forma en variables distintas, b) permiten la segregación de la forma en componentes uniformes y no uniformes, c) permiten visualizar las diferencias morfológicas, d) posibilitan la incorporación de las variables de forma derivadas de los análisis de morfometría geométrica en análisis multivariados de uso común, e) son económicos y, f) emplean software "amigables" para el usuario (Anderson \& Roopnarine, 2005; Carvajal-Rodríguez et al., 2005).

Los diferentes abordajes en morfometría geométrica han demostrado ser de utilidad en numerosas disciplinas como arqueología, geología, biología evolutiva, medicina y sistemática (Marani, 2010). En relación con los moluscos, la aplicación de métodos de morfometría geométrica ha demostrado ser muy útil para la determinación de grupos tanto al nivel intra (Palmer et al., 2004; Krapivka et al., 2007; Márquez et al., 2010; Valladares et al., 2010, entre otros) como interespecífico (Ferson et al., 1985; Innes \& Bates, 1999; Dommergues et al., 2003; Aguirre et al., 2006; Rufino et al., 2006). Al igual que los bivalvos, los gasterópodos poseen conchillas duras que los convierten en excelentes candidatos para el análisis de forma mediante morfometría geométrica (e.g. Carvajal-Rodríguez et al., 2005, 2006), dado que no se producen deformaciones durante su manipulación.

Bajo la premisa que la morfología puede reflejar adaptaciones especiales a características ambientales, el objetivo del presente capítulo fue examinar la forma de las tres especies de Aylacostoma del Alto Paraná a partir de sus conchillas (objetivo específico a, en 
parte) a los efectos de: complementar su diagnosis específica, evaluar la capacidad diagnóstica de los abordajes morfogeométricos en la discriminación de las especies, e intentar responder la pregunta ¿por qué sólo una de las especies persistió en la naturaleza? 


\section{I.2 MATERIALES Y MÉTODOS}

\section{I.2.1 MATERIAL DE ESTUDIO}

Se analizaron treinta y dos conchillas de Aylacostoma spp. de Argentina y Paraguay depositadas en el Museo Argentino de Ciencias Naturales -MACN-; el Museo de La Plata MLP- y la Universidad Nacional de Misiones -UNaM- (Figura 2).

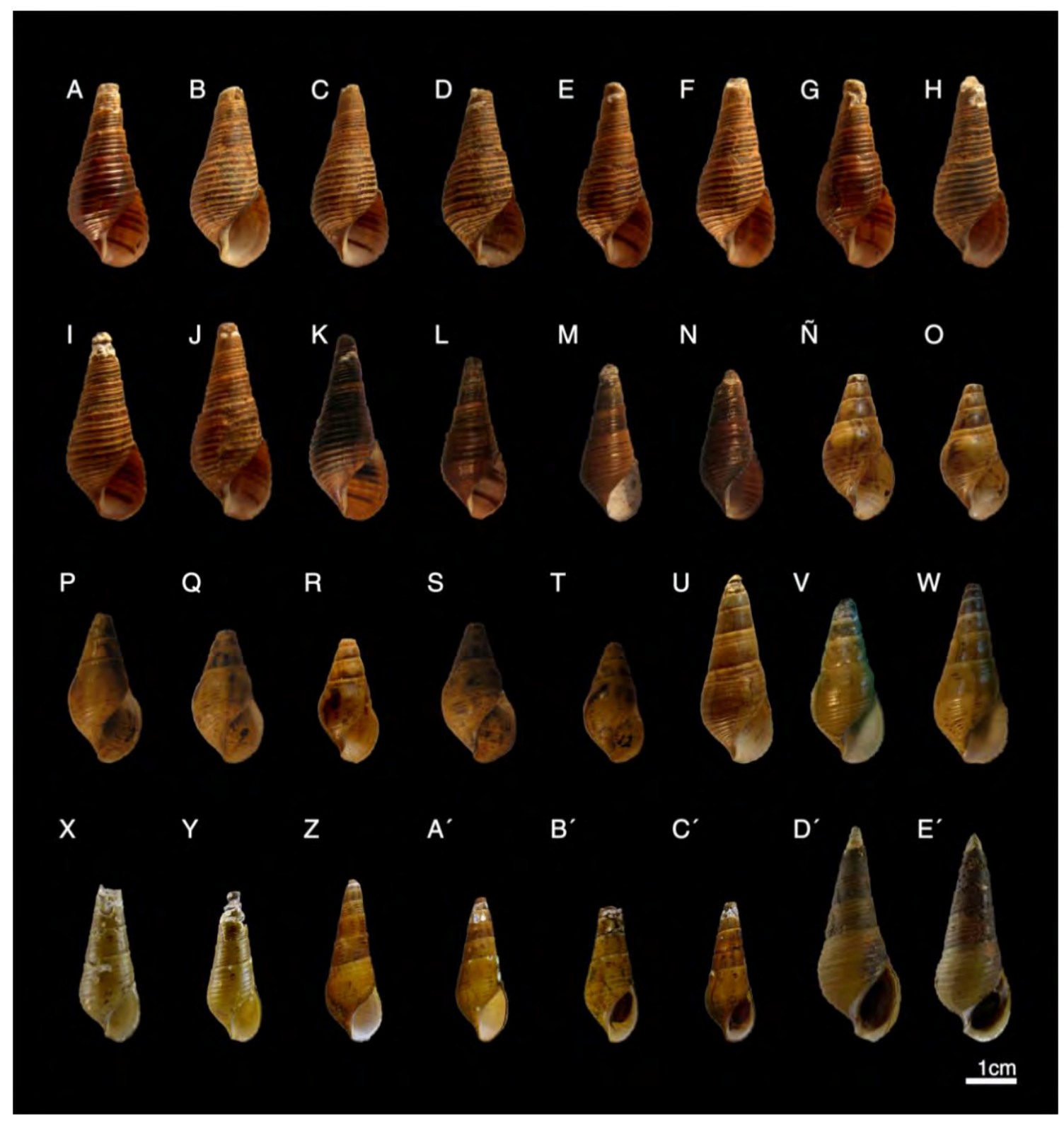

Figura 2. Ejemplares analizados de las tres especies endémicas de Aylacostoma del Alto Paraná. $A$. guaraniticum: A (Tipo, MLP 11213; Paraje Ombú, Argentina); B-J (Paratipos, MLP 11213; Paraje Ombú, Argentina), K (Paratipo, MACN-In 488-1; Paraje Ombú, Argentina), L-N (Referencia, UNaM CR; Paraje Ombú, Argentina); A. stigmaticum: Ñ-O (Paratipos, MLP 10964; Isla Ibicuy, Paraguay), P-Q (Paratipos, MACN-In 488-2; Isla Ibicuy, Paraguay), R (Paratipo, MLP 10965; Isla Ibicuy, Paraguay), S-T (Cotipos, MACN-In 488-2; Isla Ibicuy, Paraguay) ; A. chloroticum: U (Tipo, MLP 11596; Isla Ibicuy, Paraguay), V-E'(Referencia, UNaM CR; Candelaria, Argentina). 
La muestra incluyó material tipo, paratipos y especímenes adultos de referencia de $A$. guaraniticum (MACN-In 488-1; MLP 11213; UNaM CR; rango de longitud total de las últimas tres vueltas: 24,70 - 34,76 mm); A. stigmaticum (MACN-In No 488-2; MLP 10964/65; UNaM CR; rango de longitud total de las últimas tres vueltas: 21,89-27,88 mm) y A. chloroticum (MLP 11596; UNaM CR; rango de longitud total de las últimas tres vueltas: 23,17 - 33,76 mm). Los ejemplares se fotografiaron con cámara Samsung SL-76 utilizando como referencia una escala graduada de $5 \mathrm{~cm}$. En todos los casos se utilizó la misma orientación de la conchilla, con el eje de torsión y la abertura en el mismo plano que el objetivo de la cámara.

\section{I.2.2 ADQUISICIÓN DE DATOS}

En la literatura, se reconocen tres tipos de landmarks, cuya denominación depende del autor: Bookstein (1991) los llama tipo I, II y III; Lele \& Richtsmeier (2001) los denominan tradicionales, confusos y construidos; mientras que Dryden \& Mardia (1998) los designan como anatómicos, matemáticos y pseudolandmarks (Marani, 2010). Esta clasificación se basa en si la homología de un individuo con otro se encuentra sustentada por una sólida evidencia y/o posee significado biológico (tipo I, tradicionales o anatómicos); si se sustenta únicamente en la geometría (tipo II, confusos o matemáticos); o si los landmarks presentan una coordenada deficiente $\mathrm{y} / \mathrm{o}$ se localizan en cualquier lugar del contorno de una estructura o entre dos landmarks anatómicos o matemáticos (tipo III, construidos o pseudolandmarks). Un tipo adicional de landmark, es el semilandmark que representa un punto localizado sobre una curva al que se le permite deslizarse una distancia pequeña respecto de otra curva correspondiente (Dryden \& Mardia, 1998).

Con el objeto de capturar las diferencias de forma en todas las regiones de la conchilla, se seleccionaron 16 landmarks en torno al perímetro de la conchilla y abertura (Figura 3), siguiendo un criterio similar al de Conde-Padín et al. (2007) (Tabla I). Tal como lo expresaran Carvajal-Rodríguez et al. (2005) en un estudio del género Littorina Férussac, 1822, estos puntos no necesariamente representan landmarks homólogos (desde el punto de vista del

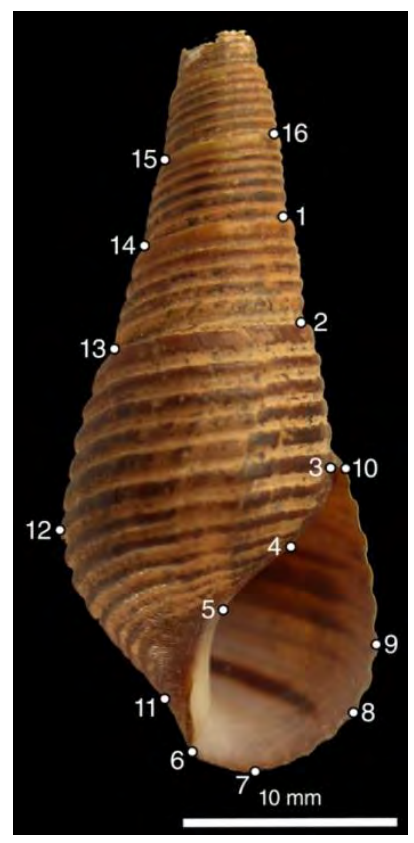

Figura 3. Posición de los landmarks seleccionados en las conchillas. 
desarrollo), aunque los mismos permiten capturar y analizar de manera objetiva y repetitiva la forma de la concha de los especímenes.

Los datos de landmarks fueron obtenidos digitalizando las imágenes de las conchillas tal como se muestra en la Figura 3, utilizando el programa TPSDIG 2.12 (Rohlf, 2008) para generar las coordenadas. Finalmente, seis landmarks (LM4, LM5, LM8, LM9, LM11, LM12) fueron tratados como semilandmarks deslizantes mediante el programa TPSUTIL 1.44 (Rohlf, 2009).

Tabla I. Descripción de la posición de los landmarks en la conchillas.

\begin{tabular}{|c|c|}
\hline & POSICIÓN \\
\hline LM1 & $\begin{array}{l}\text { Sobre el perfil derecho de la conchilla, en el extremo de la sutura } \\
\text { superior de la penúltima vuelta. }\end{array}$ \\
\hline LM2 & $\begin{array}{l}\text { Sobre el perfil derecho de la conchilla, en el extremo de la sutura } \\
\text { superior de la última vuelta. }\end{array}$ \\
\hline LM3 & Al final de la sutura, en la última vuelta. \\
\hline LM4 y LM5 & $\begin{array}{l}\text { Sobre los puntos más interno (LM4) y más externo (LM5) del } \\
\text { perfil izquierdo de la abertura de la conchilla, respecto de su } \\
\text { intersección con una línea perpendicular a la del eje del LM6. }\end{array}$ \\
\hline LM6 & Al final de la columela. \\
\hline LM7 & Sobre el punto más bajo de la base. \\
\hline LM8 & $\begin{array}{l}\text { En el punto más externo del perfil derecho de la última vuelta, } \\
\text { respecto de su intersección con una línea perpendicular a la del } \\
\text { eje desde el LM6. }\end{array}$ \\
\hline LM9 & En el punto más externo del labio externo. \\
\hline LM10 & $\begin{array}{l}\text { Sobre el contorno derecho de la conchilla, en el extremo de la } \\
\text { sutura inferior de la última vuelta. }\end{array}$ \\
\hline LM11 & En el punto más interno del contorno izquierdo de la última vuelta. \\
\hline LM12 & En el punto más externo del contorno izquierdo de la última vuelta. \\
\hline LM13 & $\begin{array}{l}\text { En el contorno izquierdo de la conchilla, sobre el extremo de la } \\
\text { sutura superior de la última vuelta. }\end{array}$ \\
\hline LM14 & $\begin{array}{l}\text { En el contorno izquierdo de la conchilla, sobre el extremo de la } \\
\text { sutura superior de la penúltima vuelta. }\end{array}$ \\
\hline LM15 & $\begin{array}{l}\text { En el contorno izquierdo de la conchilla, sobre el extremo de la } \\
\text { sutura superior de la antepenúltima vuelta. }\end{array}$ \\
\hline LM16 & $\begin{array}{l}\text { En el contorno derecho de la conchilla, sobre el extremo de la } \\
\text { sutura superior de la antepenúltima vuelta. }\end{array}$ \\
\hline
\end{tabular}




\section{I.2.3 ANÁLISIS DE DATOS}

Las configuraciones de coordenadas "crudas" de todos los ejemplares fueron alineadas utilizando GPA con el fin de eliminar la variación debida a diferencias en escala y orientación. El GPA establece una configuración "promedio" minimizando la suma de las distancias cuadradas entre las configuraciones de landmarks homólogos de los diferentes especímenes (Rohlf \& Slice, 1990; Cavalcanti et al., 1999; Rohlf, 1999). Esta configuración promedio resultante del GPA actúa como configuración de referencia en los cálculos subsiguientes (Cavalcanti et al., 1999), donde para cada especímen es posible obtener una variable para el tamaño, i.e. centroid size (CS), y un conjunto de variables para la forma, i.e. componentes uniformes y no-uniformes (Strauss, 2010). El CS se obtiene como un factor de escala durante el GPA y deriva de la raíz cuadrada de la sumatoria de las distancias cuadradas de cada landmark al centroide de la configuración (Bookstein, 1991; Cavalcanti et al., 1999). Los componentes uniformes describen las diferencias que afectan de la misma manera todas las partes de la estructura analizada (diferencias globales). En contraste, los componentes nouniformes dan cuenta de las deformaciones de forma locales respecto de la configuración de referencia a diferentes escalas espaciales (Conde-Padín et al., 2007).

Seguidamente, las coordenadas alineadas de todos los especímenes fueron analizadas mediante TPS y Relative Warps Analysis o RWA (Bookstein, 1991; Rohlf, 1993), a los efectos de analizar y visualizar la dirección de la diferencia de forma entre las especies. El método TPS permite representar cambios entre una forma y otra como una deformación continua y consiste en ajustar una función de interpolación a las coordenadas de landmarks de cada espécimen respecto de la configuración de referencia, de manera tal que exista coincidencia entre todos los landmarks homólogos (Cavalcanti et al., 1999; Toro et al., 2010). En este método, una placa metálica hipotética infinitamente delgada es montada sobre la configuración de referencia, la cual es posteriormente deformada hasta que coincide con la forma "target" (Bookstein, 1989, 1991; Rohlf et al., 1996), donde la deformación de la placa refleja la discrepancia entre landmarks homólogos (Bastir et al., 2004). En este punto, la forma se halla descompuesta en sus componentes uniformes y no uniformes (Strauss, 2010).

Con el objeto de caracterizar la variación de forma local, los componentes no uniformes pueden a su vez ser descompuestos en deformaciones parciales o partial warps, cada una siendo un componente de cambio en la forma (Conde-Padín et al., 2007). Estas deformaciones parciales están caracterizadas por ciertas cantidades de "energía de torsión”, la cual es utilizada en la 
derivación de los descriptores de forma, i.e. los puntajes de deformaciones parciales o partial warp scores (Bastir et al., 2004). Los puntajes de deformaciones parciales representan la contribución de cada deformación parcial al cambio total de la forma para un especímen (a partir de la configuración de referencia) y pueden ser usadas como variables nuevas en análisis estadísticos multivariados (Conde-Padín et al., 2007; Strauss, 2010), como por ejemplo el RWA. Este último es equivalente a un análisis de componentes principales, donde las deformaciones relativas o relative warps (RWs) constituyen los componentes principales de cualquier tipo de variables de forma (e.g. partial warp scores) reflejando las tendencias principales en la variación de la forma (Bastir et al., 2004; Rufino et al., 2006). Una descripción técnica y detallada de los numerosos abordajes de morfometría geométrica existentes puede consultarse en Zelditch et al. (2004).

El RWA y el cómputo de los puntajes de deformaciones parciales se realizó mediante TPSRELW 1.49 (Rohlf, 2010) con la opción de escala $\alpha=0$ que pondera todos los landmarks igualitariamente, lo cual es considerado más apropiado para estudios sistemáticos (Rohlf et al., 1996; Cavalcanti et al., 1999). Las primeras cuatro variables morfométricas derivadas analizadas (RWs 1-4) fueron incluidas en un MANOVA no paramétrico (NP-MANOVA) (Anderson, 2001) empleando distancia de Mahalanobis (9.999 permutaciones), con la finalidad de evaluar la significancia de la forma media de las especies. Consecutivamente, se realizó a los mismos RWs un Análisis Canónico de la Varianza (CVA, del inglés Canonical Variates Analysis), con el objeto de maximizar la separación entre los grupos (Zelditch et al., 2004), para estimar así las tasas de clasificación erróneas y para evaluar las diferencias de forma que mejor distinguen entre las tres especies (Márquez et al., 2010). Las retículas de deformación a lo largo de los ejes canónicos fueron generadas mediante TPSREGR 1.38 (Rohlf, 2011) y los análisis estadísticos fueron realizados con PAST 2.14 (Hammer et al., 2001). La mayoría de los programas utilizados se encuentran gratuitamente disponibles online $e^{2}$.

\footnotetext{
${ }^{2}$ http://life.bio.sunysb.edu/morph/
} 


\section{I.3 RESULTADOS}

El RWA mostró que aproximadamente el $85 \%$ de la variación local de las conchillas se explica por los primeros cuatro RWs (i.e. RW1 $=57,41 \%$; RW2 $=13,15 \%$; RW3 $=8,78 \%$; RW4=5,48\%). Asimismo, el NP-MANOVA realizado para evaluar la significación de la forma media de la conchilla de las tres especies fue altamente significativo $(\mathrm{F}=7,164 ; p=$ 0,0001). Mediante el CVA las diferencias de forma entre las especies fueron maximizadas, y las especies pudieron ser discriminadas (Tabla II, Figura 4).

Tabla II. Matriz de clasificación de los ejemplares.

\begin{tabular}{r|c|c|c|c} 
& A. chloroticum & A.guaraniticum & A. stigmaticum & $\%$ \\
A. chloroticum & 10 & 1 & 0 & 90,90 \\
A. guaraniticum & 1 & 13 & 0 & 92,85 \\
A. stigmaticum & 0 & 0 & 7 & 100 \\
TOTAL & 11 & 14 & 7 & 94,58
\end{tabular}

Se muestra el número y porcentaje de individuos correctamente clasificados.

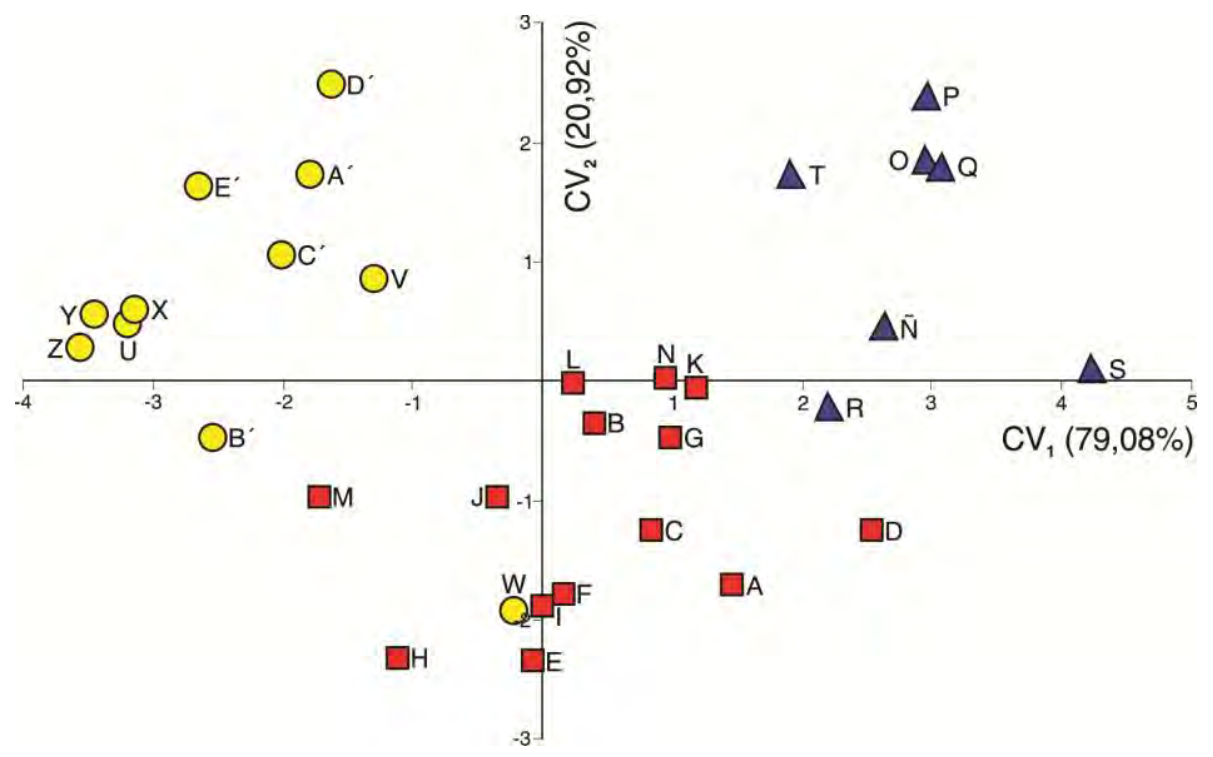

Figura 4. Análisis Canónico de la Varianza (CVA). Diagrama de dispersión de los puntajes individuales. •: A. chloroticum; $\mathbf{~ : ~ A . ~ g u a r a n i t i c u m ; ~} \mathbf{\Delta}$ : A. stigmaticum. Las etiquetas de los ejemplares corresponden a las presentadas en la Figura 2. 
La conexión por líneas de los landmarks externos y aquellos que representan la abertura facilitaron la visualización del significado de las deformaciones (Figura 5). Cuando el $\mathrm{CV}_{1}$ fue analizado desde los puntajes más bajos a los puntajes más altos, fue principalmente descripto como una expansión de la última vuelta y abertura, involucrando casi todos los landmarks en el área. También se observó una contracción antero-posterior de la espira, exhibiendo un desplazamiento hacia arriba del par de landmarks definiendo la sutura inferior de la penúltima vuelta (LM13-LM2), así como un desplazamiento hacia abajo y hacia adentro del par de landmarks localizado sobre la sutura superior de la antepenúltima vuelta (LM15LM16) (Figura 5, a y b).

En cambio, cuando el $\mathrm{CV}_{2}$ fue analizado desde los puntajes más bajos a los más altos, no reveló diferencias notables en la forma de la espira y la variación estuvo mayormente asociada a la última vuelta, que incluyó un desplazamiento hacia arriba del LM12 y un acercamiento del LM6 y LM7 (Figura 5, c y d).

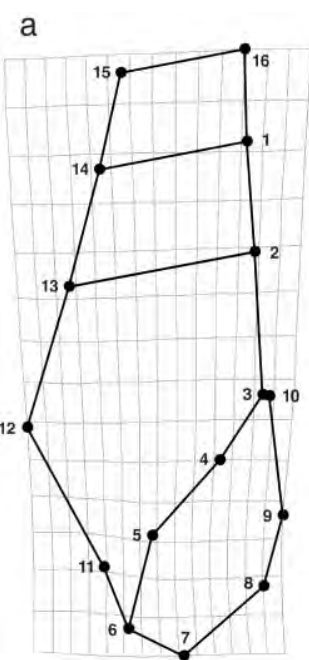

CV1- b

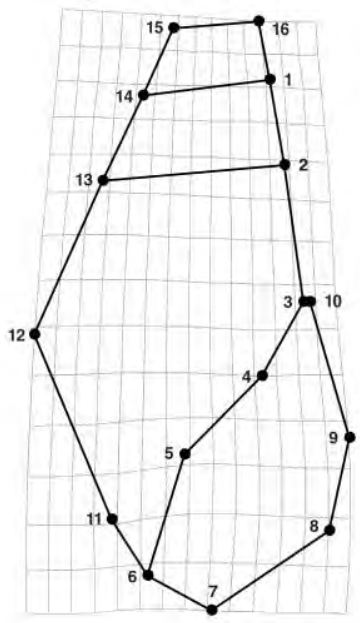

$\mathrm{CV} 1+$

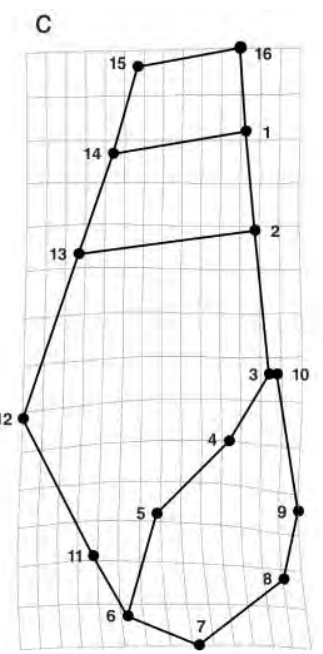

CV2- d

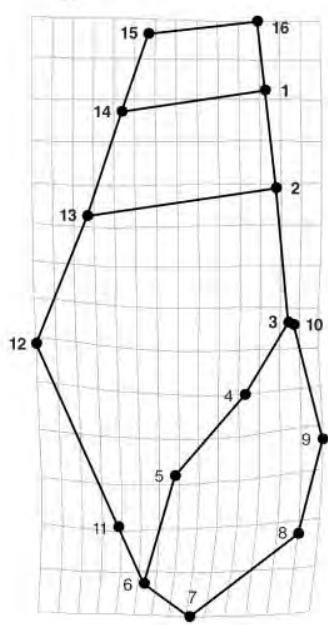

$\mathrm{CV} 2+$

Figura 5. Retículas de deformación a lo largo de los dos ejes canónicos. Se muestran los extremos más negativos y positivos. $\mathrm{CV}_{1}: \mathrm{a}, \mathrm{b} ; \mathrm{CV}_{2}: \mathrm{c}, \mathrm{d}$. 


\section{I.4 DISCUSIÓN}

En el análisis realizado, se encontraron diferencias significativas en la forma de la conchilla para el material de colección disponible para las tres especies del Alto Paraná, y prácticamente el 95\% de los especímenes fueron correctamente asignados a una de las tres especies. El éxito del método en revelar estas diferencias parece proveer una base robusta para examinar la variación morfológica en este grupo de moluscos. Esta sensibilidad geométrica había sido notada por otros autores al revelar diferencias de forma en poblaciones y especímenes de especies hermanas del género Littorina (Carvajal-Rodríguez et al., 2005; Conde-Padín et al., 2007), así como especies hermanas del género Nassarius Duméril, 1806 (Carvajal-Rodríguez et al., 2006).

En las especies estudiadas aquí, las principales diferencias de forma evidenciadas a lo largo de los ejes canónicos, pueden resumirse como cambios en la espira, última vuelta y abertura. Las diferencias discriminantes más notorias se concentraron en el $\mathrm{CV}_{1}$, donde la forma de la conchilla de las tres especies varía en un rango que va desde las más estilizadas en A. chloroticum a las más globosas en A. stigmaticum (Figura 4).

La detección de dos variables estadísticamente significativas, las cuales sintetizan las principales diferencias en la forma entre las tres especies, es interesante dado que estudios de morfometría geométrica previos sugieren que es posible una interpretación de la forma en términos biológicos simples (Carvajal-Rodríguez et al., 2005; Conde-Padín et al., 2007). Como ejemplo Conde-Padín et al. (2007) propusieron que la conchilla más globosa encontrada en un ecotipo de Littorina saxatilis (Olivi, 1792) está probablemente relacionada a la necesidad de resistir a los ataques de cangrejos, comunes donde habita ese ecotipo. Desafortunadamente, interpretaciones de esta naturaleza como podría ser la resistencia a peces molusquicívoros no pueden ser inferidas para las especies de Aylacostoma del Alto Paraná, debido a: i- la desaparición de los ambientes de rápidos donde estas especies eran registradas (Quintana \& Mercado Laczkó, 1997); ii- la extinción en la naturaleza de $A$. guaraniticum y A. stigmaticum (Quintana \& Mercado Laczkó, 1997; Mansur, 2000a, b), y iiila falta de estudios previos.

No obstante, considerando que las tres especies habitaban aguas poco profundas en ambientes altamente oxigenados como los rápidos del Apipé (Quintana \& Mercado Laczkó, 1997), es posible que las diferencias en lo que respecta a cambios en espira, última vuelta y 
abertura en las tres especies, puedan explicarse de alguna manera por el uso diferencial del hábitat y/o tal vez por diferentes grados de exposición a la corriente.

Como se ha demostrado previamente para otros gasterópodos de agua dulce (Greenwood \& Thorp, 2001), un pie más grande puede relacionarse con la habilidad de un gasterópodo de evitar ser desplazado por el oleaje de un río. Así, de este análisis surge como hipótesis que la conchilla más globosa y la abertura más oval encontrada en $\mathrm{A}$. stigmaticum, seguida en menor medida por A. guaraniticum, podría haber estado asociada a los hábitats y sustratos expuestos a mayores velocidades de corriente en los rápidos. Contrariamente, la conchilla estilizada presente en A. chloroticum podría estar relacionada con la preferencia por hábitats más protegidos como aquellos encontrados río arriba de la represa Yacyretá, donde hasta 2008 persistían dos poblaciones relictuales de A. chloroticum (Ostrowski de Nuñez \& Quintana, 2008), aunque estudios adicionales del tipo ecológico serían necesarios para corroborar esta hipótesis.

Finalmente, a partir de los resultados obtenidos se sugiere que los abordajes geométricos resultan muy útiles al momento de comparar y cuantificar la forma de diferentes especies, como en este caso las de Aylacostoma descriptas para Argentina y Paraguay. Sin embargo, esta metodología por sí sola no permite validar nuevas especies, más bien complementa a otros datos (e.g. anatómicos, morfológicos, ecológicos y genéticos) y contribuye a la mejor descripción de las entidades preexistentes. 


\section{CAPÍTULO II: CARACTERIZACIÓN MORFOLÓGICA DE Aylacostoma chloroticum Y DE UN NUEVO MORFOTIPO DEL ALTO PARANÁ}

\section{II.1 INTRODUCCIÓN}

La familia de gasterópodos Thiaridae Gill, 1871 comprende especies que han sido intensamente estudiadas como consecuencia de su modo de reproducción vivíparo y por su exitosa capacidad de colonización, habiendo sido muchas de ellas introducidas en diferentes partes del mundo (Strong et al., 2011). Aunque el conocimiento de Thiaridae se ha incrementado en tiempos recientes (e.g. Glaubrecht 1996, 1999, 2006; Michel, 2004; Gómez et al., 2011; Strong et al., 2011), prácticamente nada se sabe de casi todas las especies Sudamericanas, la mayoría de las cuales fueron descriptas basándose en conchillas durante el siglo XIX y principios del XX, y que han sido escasamente estudiadas desde sus descripciones formales (e.g. Reeve, 1860; Ihering, 1902, 1909).

Varios nombres genéricos se reconocen para Thiaridae en el Neotrópico, sin embargo aún es muy difícil efectuar análisis comparativos entre los taxa debido a la escasez de datos disponibles. Un primer intento por organizar este grupo -basado en algunas características anatómicas- fue realizado por Morrison (1954), el cual incluyó el género Aylacostoma Spix, 1827 dentro de Thiaridae, una concepción que no ha cambiado desde entonces. De acuerdo con Castellanos (1981), este género se define por las características de las conchas de los thiaridos sudamericanos sic: “oval cónica, alargada, algo turriteloide, de anfractos más bien planos. Con presencia de marcada escultura espiral, pocas veces faltando. Pueden existir estriaciones longitudinales. Son formas operculadas y el último anfracto representa la mitad de la concha".

Tal como se mencionara en la introducción general, la ocurrencia de especies de Aylacostoma en Argentina y Paraguay fue informada primeramente por Hylton Scott (1953, 1954). Esta investigadora describió A. guaraniticum (Hylton Scott, 1953), A. chloroticum Hylton Scott, 1954 y A. stigmaticum Hylton Scott, 1954, especies consideradas vivíparas, de reproducción partenogenética y sin machos informados al presente (Quintana \& MercadoLaczkó, 1997; Ostrowski de Núñez \& Quintana, 2008). De las tres especies argentinoparaguayas, sólo se cuenta con algunos datos anatómicos para A. guaraniticum (Hylton Scott, 1953), siendo el trabajo de Hylton Scott pionero en la descripción anatómica de una especie del género, mientras que las otras dos fueron descriptas sólo a partir de sus conchillas (Hylton 
Scott, 1954). En este contexto, es importante destacar un trabajo publicado a inicios de este siglo, donde Simone (2001) presenta el primer tratamiento anatómico para tres especies de Brasil, aportando así nuevos datos para la comparación de las formas.

En este capítulo, se propuso explorar los caracteres endosomáticos para las tres especies de Aylacostoma del Alto Paraná (objetivo específico a, en parte). Sin embargo, dada la extinción en la naturaleza de dos de ellas y a que no se encontraron partes blandas depositadas en colecciones malacológicas para ninguna de las especies del Alto Paraná, se aborda un primer examen de las partes blandas de A. chloroticum y una redescripción cualitativa de la conchilla, que complementan su descripción original estrictamente conquiliológica. Adicionalmente, se estiman algunos aspectos poblacionales para la especie (objetivo específico b) y a través de una revisión bibliográfica, se compilan sus principales aspectos conocidos, por lo que se consignan algunos datos no propios (ítems: hábitat, distribución, aspectos ecológicos y poblacionales). Por último, se caracteriza por primera vez a nivel morfológico un nuevo morfotipo recientemente registrado en el Alto Paraná. 


\section{II.2 MATERIALES Y MÉTODOS}

\section{II.2.1 MATERIAL ANALIZADO}

Aylacostoma chloroticum: Río Paraná. Se trabajó con 15 ejemplares provenientes de

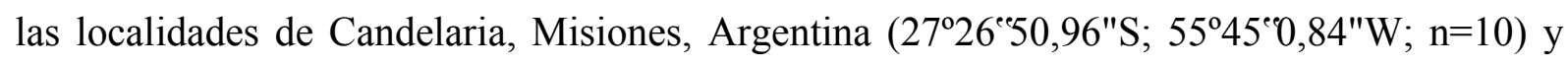
Río Beach, Itapúa, Paraguay $\left(27^{\circ} 24^{\prime} 29,83^{\prime \prime} S ; 5^{\circ} 49^{\prime} 32,94^{\prime \prime W}\right.$ n=5). Material blando y conchillas.

Nuevo morfotipo: Río Paraná. Se trabajó con 6 ejemplares provenientes de la localidad

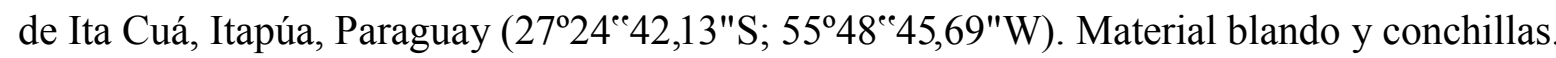

\section{II.2.2 PREPARACIÓN DEL MATERIAL MALACOLÓGICO}

El material vivo se relajó en solución de Nembutal sódico al 0,1\%, durante 8 a 10 horas. Seguidamente, se sumergieron los ejemplares en agua a $60-70^{\circ} \mathrm{C}$ por aproximadamente 30 segundos. Las partes blandas fueron extraídas de las conchillas y se fijaron en solución de Raillet-Henry modificada para organismos de agua dulce (agua destilada 93\%, ácido acético $2 \%$, formol 5\% y 6 gramos de cloruro de sodio por litro de solución). Para la disección y observación se empleó un microscopio binocular estereoscópico (LEICA MZ6) y, cuando necesario, una solución al $0,1 \%$ de rojo neutro para mejorar el contraste de los tejidos (e.g. órganos del manto). La preparación de las rádulas se realizó según la propuesta de Holznagel (1998): los bulbos faríngeos se colocaron en microtubos de $1,5 \mathrm{ml}$ y se agregaron $500 \mu 1 \mathrm{de}$ buffer NET (Apéndice I) y $10 \mu \mathrm{l}$ de Proteinasa K $(20 \mathrm{mg} / \mathrm{ml})$. Los bulbos fueron incubados a $37^{\circ} \mathrm{C}$ por aproximadamente 2-3 hs. hasta verificar la ausencia de tejido. Posteriormente, se recuperaron las rádulas que fueron enjuagadas con dos lavados de agua destilada. Cada rádula fue preservada separadamente en etanol al $25 \%$ hasta su montaje, el cual se realizó sobre tacos de aluminio. Finalmente, las rádulas fueron metalizadas y observadas en un Microscopio Electrónico de Barrido (MEB, JEOL 6360). La observación de huevos y conchillas de juveniles mediante MEB se realizó sin tratamiento previo.

\section{II.2.3 ESTRATEGIA DE ANÁLISIS DE CARACTERES DIAGNÓSTICOS}

Caracterización morfológica de las conchillas: Se incluyó una descripción cualitativa siguiendo a Simone (2001), ampliando la diagnosis disponible en Hylton-Scott (1954) y 
Castellanos (1981). Para la clasificación de las conchillas según el tamaño se siguió a Burch \& Cruz-Reyez (1987).

Rádula: Para la caracterización de los dientes radulares se contaron el número de filas de dientes y la fórmula radular se describió de acuerdo a Glaubrecht (1996) como se detalla a continuación: i- raquídeo (número de cúspides lado izquierdo / dentículo mediano / número de cúspides lado derecho), ii- dientes laterales (cúspides interiores / dentículo pronunciado / cúspides exteriores), iii- dientes marginales (número de cúspides en el diente marginal interno + número de cúspides en el diente marginal externo).

Anatomía: El formato descriptivo se realizó siguiendo a Simone (2001). Se examinaron cabeza-pie, opérculo, órganos del manto, sistema digestivo, sistemas circulatorio y excretor y sistema genital.

\section{II.2.4 ESTIMACIÓN DE ALGUNOS ASPECTOS POBLACIONALES}

A pesar de la especificidad de hábitat demostrada por A. chloroticum, fue posible realizar un seguimiento parcial desde marzo de 2009 hasta febrero de 2011 de los reclutamientos obtenidos a partir de un ejemplar adulto (Longitud total: 21,32 mm; Longitud del último anfracto: $15,50 \mathrm{~mm}$ ). Las condiciones experimentales consistieron de un acuario de $2.000 \mathrm{ml}$, conteniendo agua corriente declorinada, con circulación de agua mediante bomba, a $24^{\circ} \mathrm{C}$ y fotoperiodo controlado (12:12). La alimentación se realizó ad libitum con hojas de lechuga y alimento en escamas para peces. Los juveniles obtenidos en cada reclutamiento fueron medidos (Longitud total; Longitud del último anfracto) usando microscopio binocular estereoscópico (LEICA MZ6), con ocular micrométrico.

\section{II.2.5 DISTRIBUCIÓN}

La distribución de $A$. chloroticum y el nuevo morfotipo fue mapeada a partir de registros geoposicionados obtenidos en campo y cedidos por la Dra. Juana Peso (FCEQyN, $\mathrm{UNaM}$ ), en virtud de la vigencia del "Programa Aylacostoma" (Convenio FCEQyN-EBY) enfocado en la conservación ex situ de los gasterópodos objeto de estudio. Otros registros fueron obtenidos a partir de los antecedentes publicados en la literatura. La pertinencia de los registros a las provincias malacológicas fue considerada de acuerdo con Núñez et al. (2010). En este punto es importante destacar que a los efectos de evaluar la distribución histórica de las especies del Alto Paraná (i.e. antes de la construcción y llenado del embalse Yacyretá) se 
pretendía utilizar modelado de nicho ecológico (objetivo específico e), lo cual no fue posible como consecuencia del escaso número de registros históricos disponibles para análisis $(\mathrm{n}<$ 10) y la estrecha área de ocupación de estas especies. 


\section{II.3 RESULTADOS}

\section{II.3.1 SISTEMÁTICA}

Clase Gastropoda Cuvier, 1795

Subclase Orthogastropoda Ponder \& Lindberg, 1995

Superorden Caenogastropoda Cox, 1960

Orden Sorbeoconcha Ponder \& Lindberg, 1997

Superfamilia Cerithioidea Férussac, 1819

Familia Thiaridae Gill, 1871

Género Aylacostoma Spix, 1827

\section{II.3.2 DESCRIPCIONES}

\section{II.3.2.1 Aylacostoma chloroticum Hylton Scott, 1954}

\section{II.3.2.1.1 Descripción original}

Hylton Scott, M.I. 1954. Dos nuevos melánidos del Alto Paraná (Mol. Prosobr.) Neotropica $1(3): 45-48$.

Holotipo: MLP 11596 (Ejemplar U en Figura 2, Capítulo I). Sin especificación sobre lugar preciso de recolección, fecha de recolección ni nombre del colector (Martín \& César, 2004).

Paratipos: MACN-In 488-1. En la etiqueta que acompaña al material se informa: "compra Sr.

M. Rodríguez, IX-1934" (Figura 6). Se omite si el lote fue comprado al o por el Sr. Rodríguez. Hylton Scott (1954) informa en su trabajo que en el lote "no figura nombre de colector".

Localidad tipo: Isla Ibicuy. Alto Paraná. Paraguay.

Comentario: Según la descripción original el tipo y paratipos se encuentran depositados en el MACN con el $N^{\circ}$ 488-1. Tablado \& Mantinian (2004) informan que el holotipo no se halla entre el material de colección de ejemplares tipo del MACN. Por razones que se desconocen el holotipo se encuentra depositado en la colección de ejemplares tipo del MLP, inscripto bajo el número 11596. Este ejemplar corresponde al fotografiado y presentado en Hylton Scott (1954), el cual es a su vez ilustrado como holotipo en Simone (2006). 


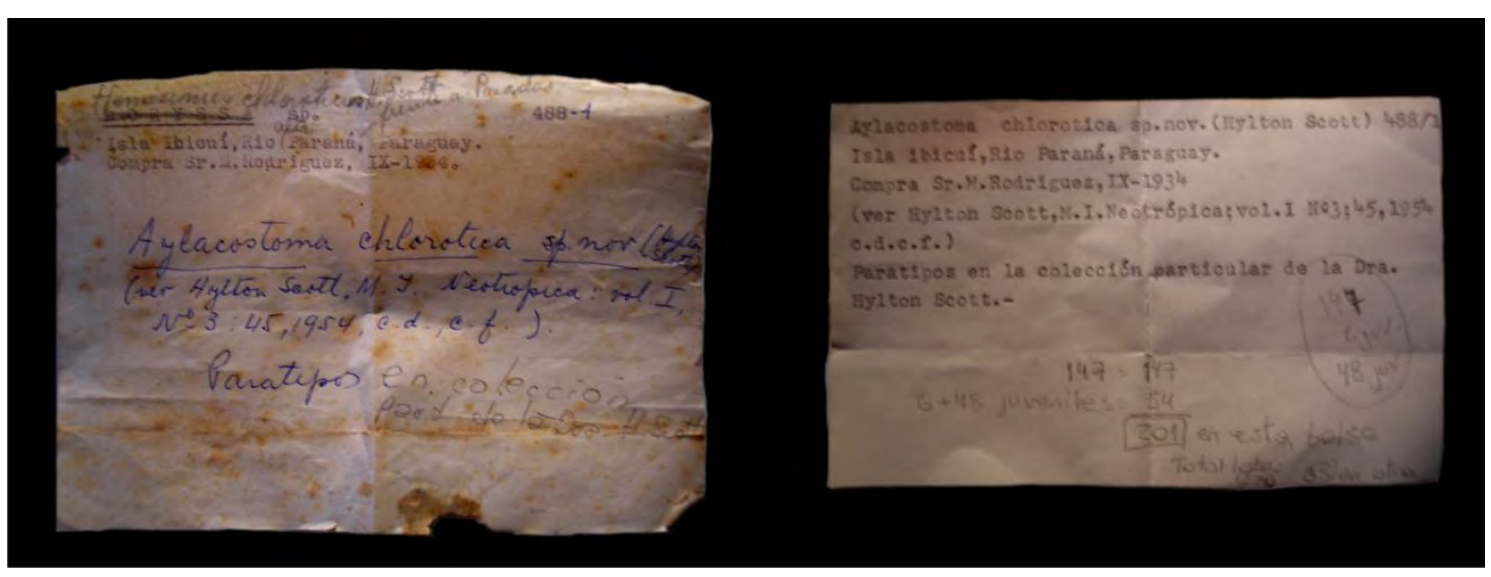

Figura 6. Etiquetas que acompañan a los paratipos de $A$. chloroticum depositados en el Museo Argentino de Ciencias Naturales.

\section{II.3.2.1.2 Sinonimia}

Aylacostoma chlorotica Hylton Scott, 1954: 45; Castellanos, 1981: 10, 11, 17; Quintana, 1982: 118; Castellanos \& Landoni, 1995: 774, 796; Rumi et al., 2004: 214; Simone, 2006: $12,79$.

Aylacostoma chloroticum: Cazzaniga, 1992: 303; Quintana \& Mercado Lazckó, 1997: 26; Mansur, 2000c; Quintana et al., 2001-2002: 110; Gutiérrez Gregoric et al., 2006: 54, 57; Rumi et al., 2006: 199, 204; Gutiérrez Gregoric et al., 2007: 109; Ostrowski de Núñez \& Quintana, 2008: 647, 648, 652-654; Rumi et al., 2008: 80; Núñez et al., 2010: 50, 58; Vogler, 2012: 43-45.

Hemisinus chloroticus: Martín \& César, 2004: 15.

Comentario: Aylacostoma chloroticum fue descripta por Hylton Scott como Aylacostoma chlorotica. La autora consideró el nombre genérico como femenino, pero la terminación -stoma lo hace neutro (Cazzaniga, 2011). Esta falta de concordancia fue corregida por Cazzaniga (1992). El nombre Hemisinus chloroticus Hylton Scott que mencionan Martín \& César (2004) nunca fue publicado como nombre válido, sino que responde al rótulo manuscrito que acompaña al material tipo.

\section{II.3.2.1.3 Conchilla}

Cónico fusiforme desgastada en el ápice, a veces con espira totalmente truncada (Figura 2, U a E'), de gran tamaño (Tabla III), pudiendo alcanzar hasta $42 \mathrm{~mm}$ (J.G. Peso, 
Tabla III. Medidas relevadas a partir de 15 conchillas de A. chloroticum.

\begin{tabular}{r|c|c|c|c|c|c|c|c|c|c|} 
& LT & AT & LUA & LE & LPA & AE & LA & AA & NV & ProcEDENCIA \\
$\mathbf{1}$ & 33,59 & 11,20 & 17,08 & 16,51 & 5,19 & 8,11 & 12,86 & 5,66 & 7 & Candelaria, Misiones, AR \\
$\mathbf{2}$ & 32,07 & 12,12 & 17,90 & 14,17 & 4,60 & 8,35 & 13,17 & 6,20 & 6 & Candelaria, Misiones, AR \\
$\mathbf{3}$ & 30,11 & 14,05 & 19,29 & 10,82 & 5,25 & 9,33 & 14,88 & 6,55 & 4 & Candelaria, Misiones, AR \\
$\mathbf{4}$ & 29,54 & 10,20 & 15,92 & 13,62 & 3,45 & 7,26 & 12,17 & 5,26 & 6 & Candelaria, Misiones, AR \\
$\mathbf{5}$ & 29,29 & 10,40 & 16,63 & 12,66 & 4,04 & 7,14 & 13,01 & 5,10 & 6 & Candelaria, Misiones, AR \\
$\mathbf{6}$ & 29,20 & 11,47 & 17,64 & 11,56 & 4,56 & 8,34 & 12,52 & 5,29 & 5 & Candelaria, Misiones, AR \\
$\mathbf{7}$ & 26,72 & 9,82 & 15,89 & 10,83 & 4,02 & 6,97 & 11,76 & 5,01 & 5 & Candelaria, Misiones, AR \\
$\mathbf{8}$ & 24,96 & 10,19 & 15,38 & 9,58 & 4,04 & 7,20 & 11,30 & 5,68 & 5 & Candelaria, Misiones, AR \\
$\mathbf{9}$ & 24,68 & 8,65 & 14,02 & 10,66 & 3,86 & 6,49 & 9,81 & 4,67 & 5 & Candelaria, Misiones, AR \\
$\mathbf{1 0}$ & 23,70 & 8,72 & 13,80 & 9,90 & 3,58 & 6,33 & 10,06 & 4,72 & 5 & Candelaria, Misiones, AR \\
$\mathbf{1 1}$ & 22,84 & 10,28 & 15,27 & 7,57 & 4,08 & 6,87 & 11,42 & 5,80 & 4 & Río Beach, Itapúa, PY \\
$\mathbf{1 2}$ & 22,20 & 10,14 & 14,88 & 7,32 & 3,81 & 6,82 & 10,74 & 5,80 & 3 & Río Beach, Itapúa, PY \\
$\mathbf{1 3}$ & 21,45 & 9,60 & 14,08 & 7,37 & 4,09 & 6,50 & 10,45 & 5,43 & 4 & Río Beach, Itapúa, PY \\
$\mathbf{1 4}$ & 21,01 & 9,14 & 14,40 & 6,61 & 3,60 & 6,22 & 10,99 & 5,27 & 3 & Río Beach, Itapúa, PY \\
$\mathbf{1 5}$ & 20,90 & 8,95 & 13,67 & 7,23 & 3,73 & 6,33 & 10,64 & 5,13 & 4 & Río Beach, Itapúa, PY
\end{tabular}

Todas las medidas están en mm. LT: Longitud total; AT: Ancho total; LUA: Longitud del último anfracto; LE: Longitud de la espira; LPA: Longitud del penúltimo anfracto; AE: Ancho de la espira; LA: Longitud de la abertura; AA: Ancho de la abertura; NV: Número de vueltas.AR: Argentina; PY: Paraguay.

com. pers.). Color pardo claro a pardo verdoso (Hylton Scott, 1954; Castellanos, 1981). Diminutas manchas lineales dispuestas en espiral en algunos ejemplares adultos, de color marrón oscuro rojizo (e.g. Figura 1B). Protoconcha únicamente presente en especímenes juveniles aún no emergidos de la bolsa incubadora o marsupio. Presenta dos vueltas lisas, convexas y redondeadas, la escultura espiral comienza gradualmente llegando a ser marcada en las siguientes vueltas (Figura 7). Los ejemplares juveniles presentan, desde estadíos embrionales, muy delicadas manchas lineales de color rojo vinoso, exceptuando la banda subsutural que no lleva decoración (Figura 8; Hylton Scott, 1954).

Teleoconcha de hasta ocho vueltas, la mayoría de las veces sólo con tres a cuatro vueltas persistentes. Espira alta de anfractos plano-convexos, última vuelta moderadamente convexa. Superficie esculturada con cordones espirales planos y surcos estrechos, algo irregulares en cada anfracto, seis cordones en la penúltima vuelta. Cordón subsutural algo más ancho, y algunas veces de color más claro. Algunos especímenes presentan escultura atenuada pudiendo presentar vueltas enteramente lisas. Sutura plana, rebajada no excavada (Hylton Scott, 1954). Abertura internamente blanca, larga, elíptica, angulada posteriormente y con un canal anterior poco profundo. 


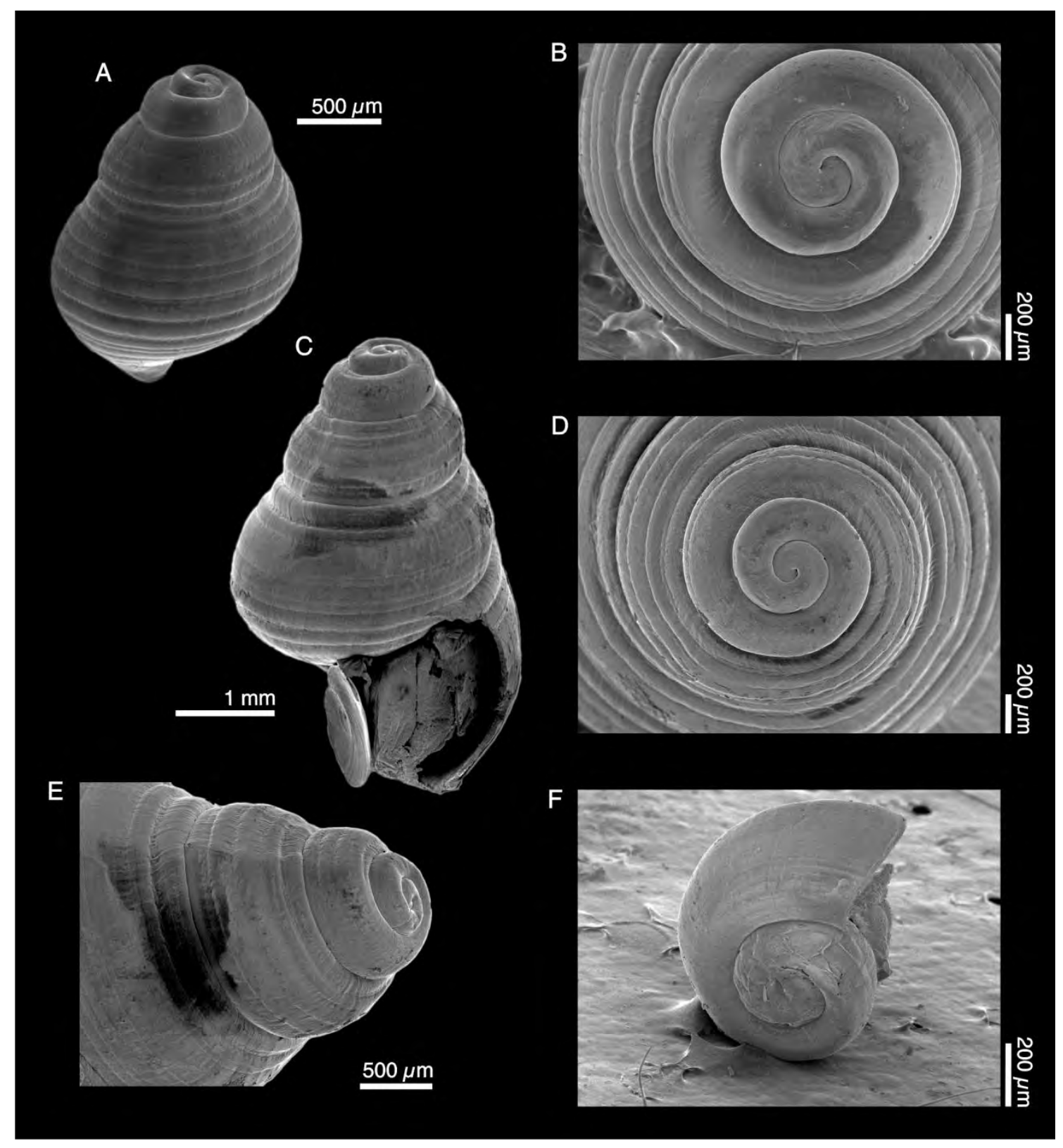

Figura 7. Detalle de la protoconcha de tres juveniles de $A$. chloroticum al MEB. A-B: Juvenil 1; C-E: Juvenil 2; F: Juvenil 3. 


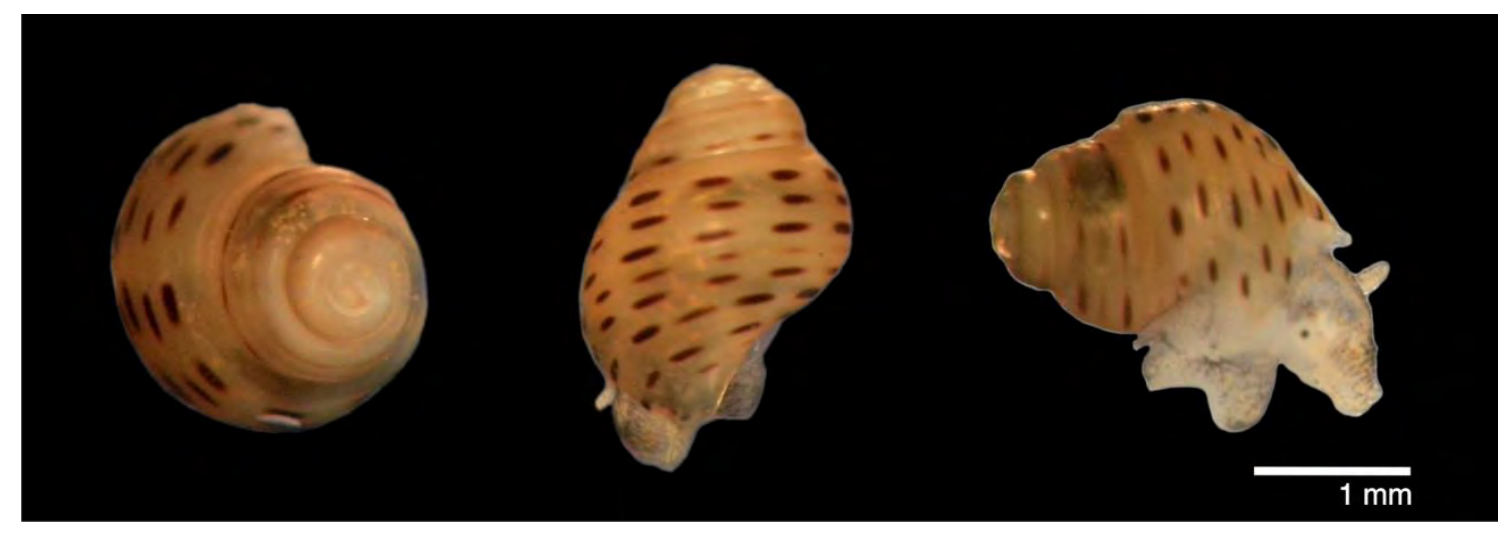

Figura 8. Diseño de la conchilla de un juvenil de $\boldsymbol{A}$. chloroticum. Obtenido en la disección de la bolsa incubadora de un ejemplar adulto.

\section{II.3.2.1.4 Cabeza-Pie}

Bandas transversales oscuras alrededor de la trompa, los tentáculos y en la región dorsal del pie. Trompa grande, aplanada dorsoventralmente y con el margen anterior algo bilobado. Tentáculos largos y gruesos, con un pequeño ensanchamiento basal sobre el cual se ubican los ojos del lado externo (Figura 9). Pie de tamaño medio sin divisiones, con un surco presente en el margen anterior de la glándula pedal anterior. Bolsa incubadora en la región posterior de la cabeza; en varios ejemplares se la observó abultada por la presencia de embriones en desarrollo en su interior. La abertura de la bolsa incubadora es un pequeño orificio situado ventralmente cerca de la fusión derecha del manto al cefalopodio. Músculo columelar de aproximadamente una vuelta y media.

\section{II.3.2.1.5 Opérculo}

Oval, córneo y de crecimiento paucispiral, con núcleo sub-terminal externamente lamelado. Cubre parcialmente la abertura y presenta una impronta muscular elíptica, cercana al margen interno (Figura 10A-C).

\section{II.3.2.1.6 Órganos del manto}

Borde del manto con pequeños tentáculos lobulados (Figura 9), más desarrollados en ambos extremos. Cavidad del manto de casi dos vueltas. Osfradio conspicuo, como reborde (ridge-like sensu Simone, 2001, 2011), sobre el margen izquierdo de la cavidad paleal, ocupando menos de la mitad de la longitud de la branquia y con el extremo anterior situado posteriormente al extremo anterior de la branquia (Figura 10D). 


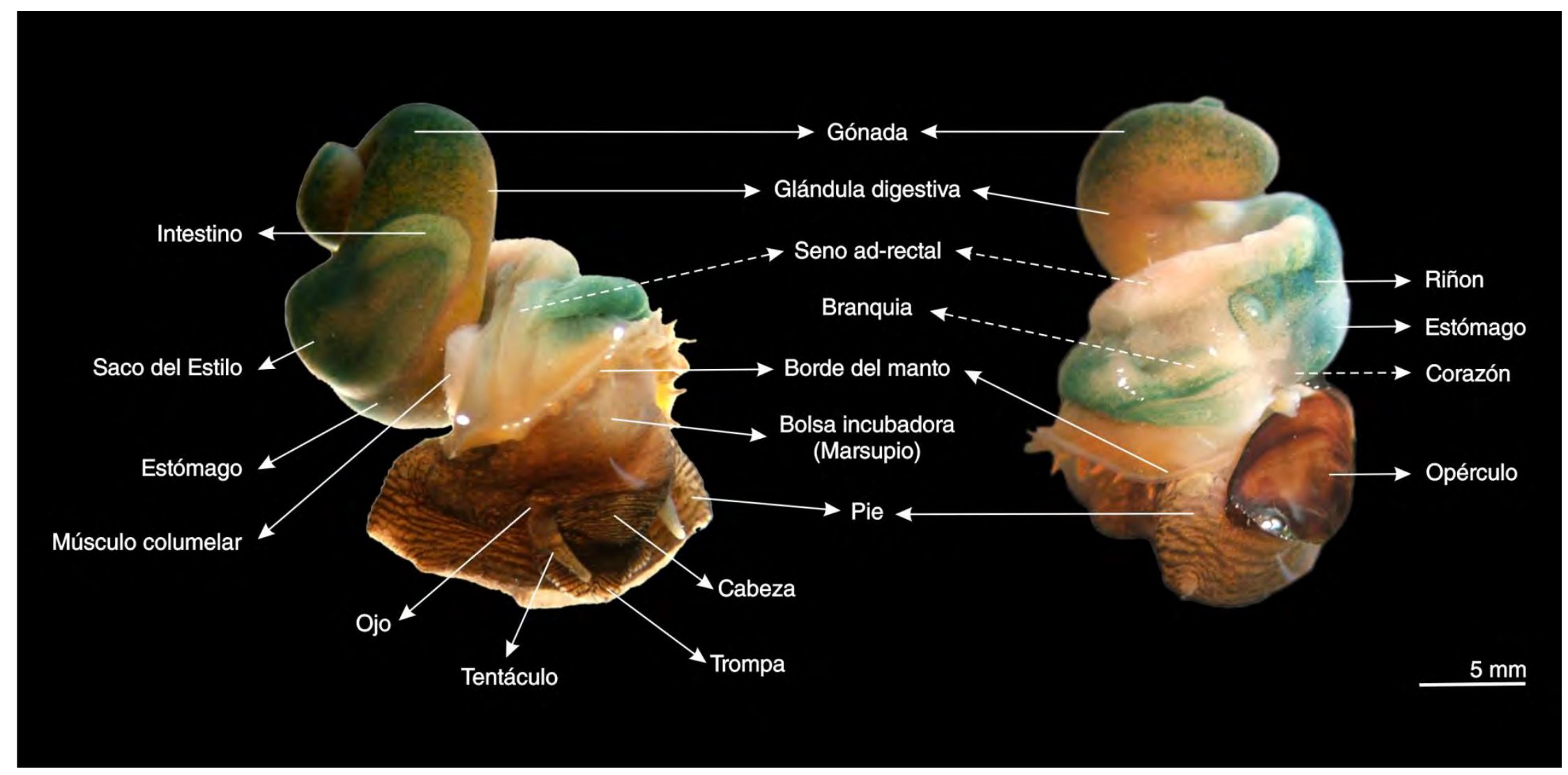

Figura 9. Anatomía externa de $\boldsymbol{A}$. chloroticum. Las flechas en líneas de puntos hacen referencia a estructuras internas. 


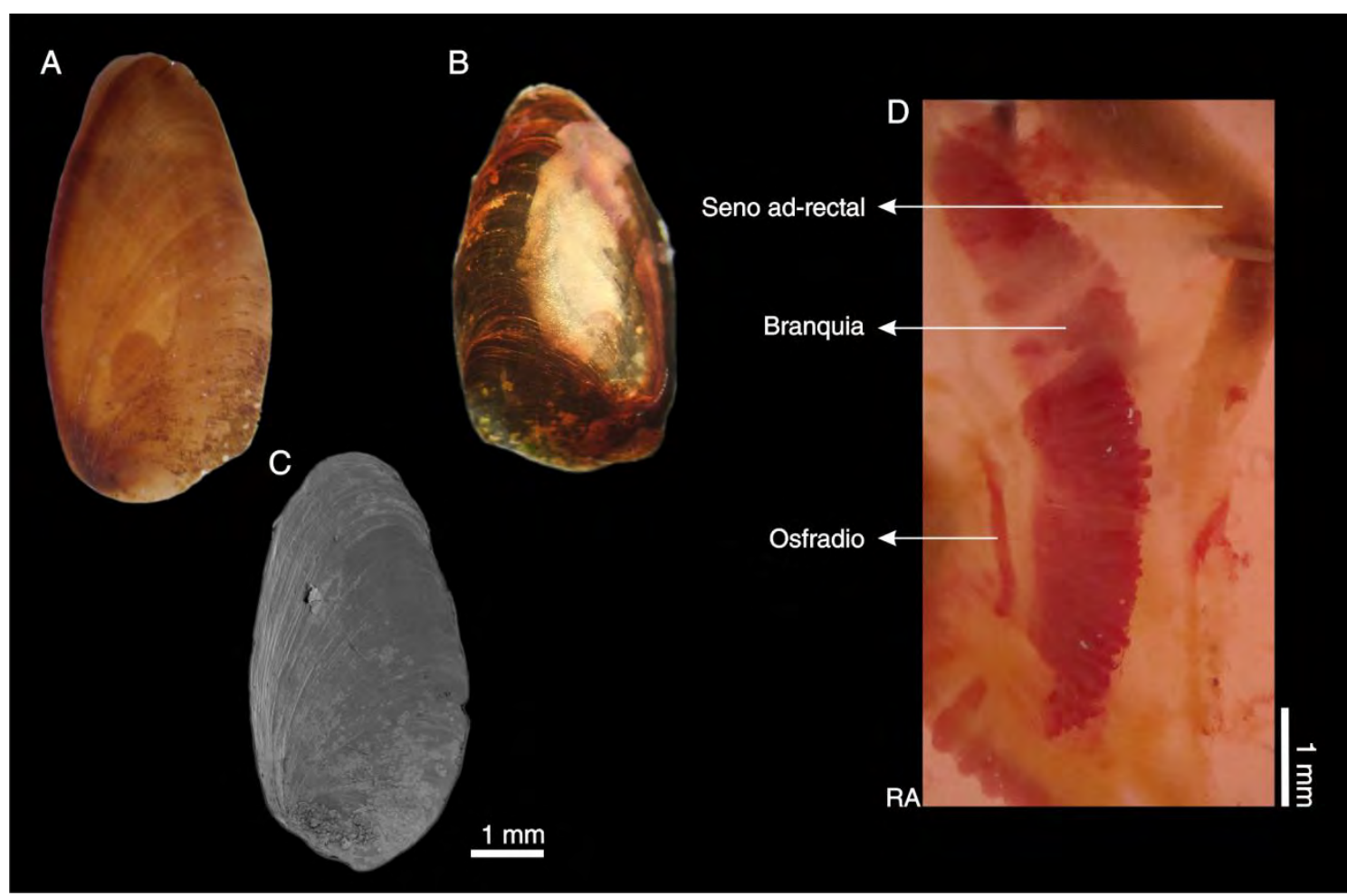

Figura 10. Detalle del opérculo (A-C) y del área entre la branquia y el seno ad-rectal (D) de $A$. chloroticum. A: Anverso, B: Reverso; vista al MO. C: Anverso; vista al MEB. RA: región anterior.

Branquia muy larga, aproximadamente de igual longitud que la cavidad paleal, con filamentos triangulares y vaso ctenidial bien desarrollado. Entre la branquia y el recto, se observa un área proporcionalmente amplia en la mitad anterior y estrecha en la mitad posterior, con vascularización poco evidente (Figura 10D). El seno ad-rectal es proporcionalmente grande, con el recto corriendo libre en su interior. Ano sifonado, en el extremo derecho del borde del manto y posterior al extremo anterior del oviducto paleal. El oviducto paleal corre por el lado derecho de la cavidad paleal.

\section{II.3.2.1.7 Sistema digestivo}

Boca ubicada en la extremidad anterior de la trompa. Masa bucal dentro de la trompa justo detrás de la boca, esófago dorsal, odontóforo ventral. Rádula tenioglosa, corta, formando una "S", con 93 hileras de dientes $(\mathrm{n}=6)$. Diente raquídeo pentagonal, aproximadamente dos veces más ancho que alto, con borde dorsal cóncavo y base en forma de "V" (Figura 11). Cúspide central lanceolada, de longitud notoria, con 3 a 4 cúspides puntiagudas de cada lado (3-4/1/4-3). Presencia de dos dentículos basales en cada vértice exterior. Dientes laterales largos con 6-7 cúspides puntiagudas siendo la segunda más grande, de forma algo rectangular. Dientes marginales similares, largos, espatulados, de base estrecha. 


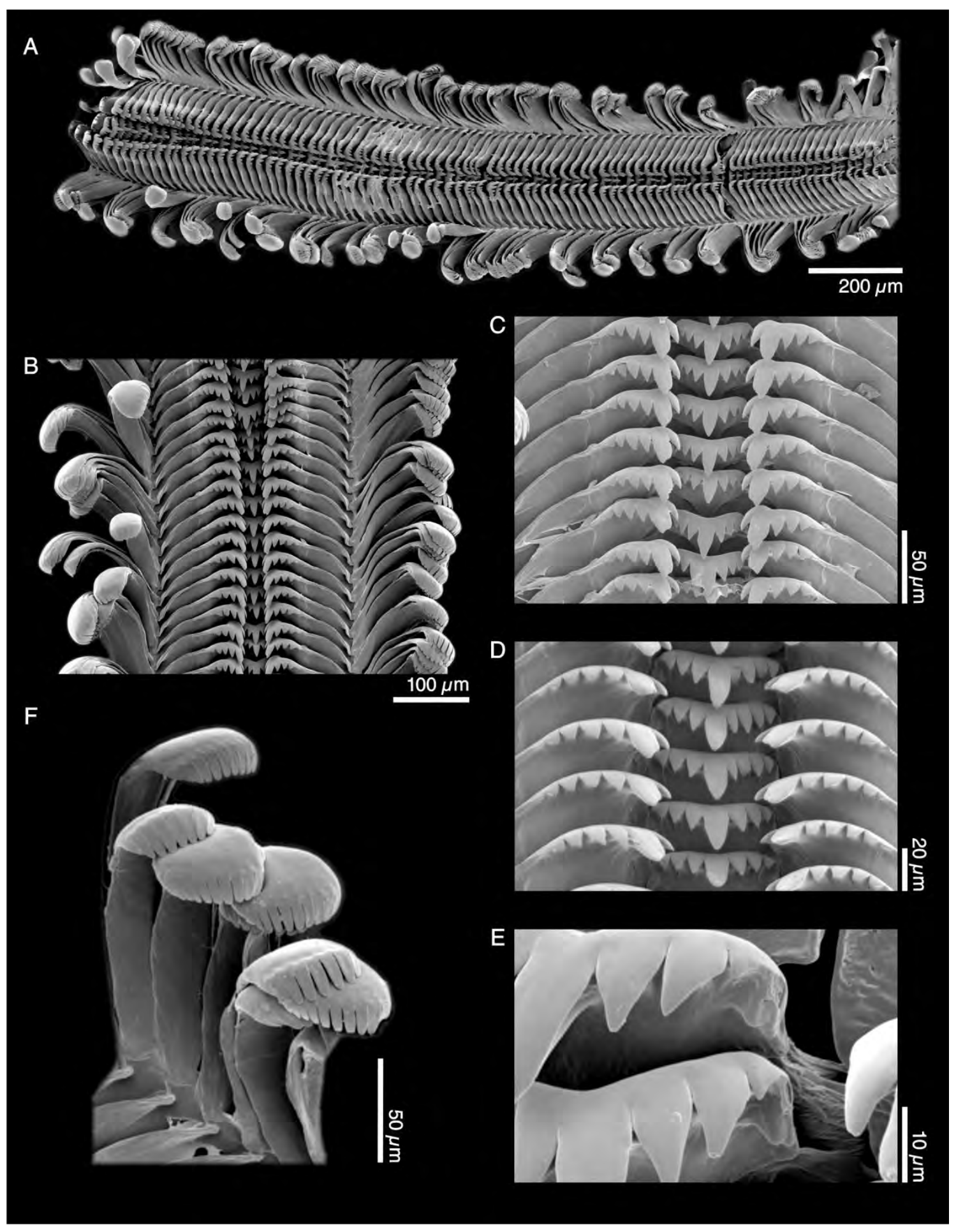

Figura 11. Rádula de $\boldsymbol{A}$. chloroticum al MEB. A-B: Vista general, C-D: Raquídeo y dientes laterales. E: Detalle de los dentículos basales del raquídeo. F: Detalle de los dientes marginales. 
Diente marginal interno con 7-8 cúspides digitiformes largas de forma redondeada, a excepción de la primera y última, más pequeñas. Diente marginal externo con 10-11 cúspides, más delgadas respecto del marginal interno.

Estómago grande y complejo, separa casi por completo la glándula digestiva y gónada del pericardio y estructuras paleales, ocupa aproximadamente media vuelta. Saco del estilo grande, aproximadamente la mitad de tamaño del estómago. Estilo elíptico, transparente. La glándula digestiva rodea la mitad posterior de la superficie ventral del estómago y continúa casi dos vueltas posteriormente al mismo. Intestino largo, estrecho, rodea ventralmente el saco del estilo, dando una vuelta en la región dorsal-anterior de éste, después se dirige hacia la parte anterior bordeando el margen derecho de la cavidad paleal; después del riñón se ensancha ligeramente. El recto presenta pliegues internos sucesivos anchos, oblicuos, algo uniformes en su superficie dorsal. Pueden observarse partículas fecales en el interior del recto (estatoconias), alineadas y compactadas en paralelo a los pliegues. Ano sifonado, posterior desde el borde del manto.

\section{II.3.2.1.8 Sistemas circulatorio y excretor}

Corazón situado posteriormente en la cavidad paleal por detrás de la branquia, en cámara pericárdica, aurícula grande y anterior, ventrículo esférico, pequeño y posterior. Riñón proporcionalmente grande, alcanzando la base de la cavidad del manto entre el intestino y la branquia, limitado atrás por la glándula digestiva y el saco del estilo.

\section{II.3.2.1.9 Sistema genital}

Sólo se han encontrado hembras. El ovario se observó desarrollado sólo en los especímenes grandes, ocupando las regiones superiores de cada vuelta sobre la glándula digestiva. Oviducto paleal complejo, terminando posterior al ano, cerca de la abertura de la bolsa incubadora. La bolsa incubadora es un gran saco abultado ubicado en la región nucal detrás de la cabeza, con la superficie interior lisa, sin grandes pliegues. Se llegó a observar hasta trece especímenes en diferentes etapas de crecimiento dentro de la bolsa incubadora, los cuales presentaban conchillas con una a tres vueltas. Moco no visible en torno a los juveniles en la bolsa incubadora. Sin embargo, una membrana transparente rodea los especímenes de una a dos vueltas (Figura 12A-C). Abertura de la bolsa incubadora en forma de esfínter (Figura 12D). 


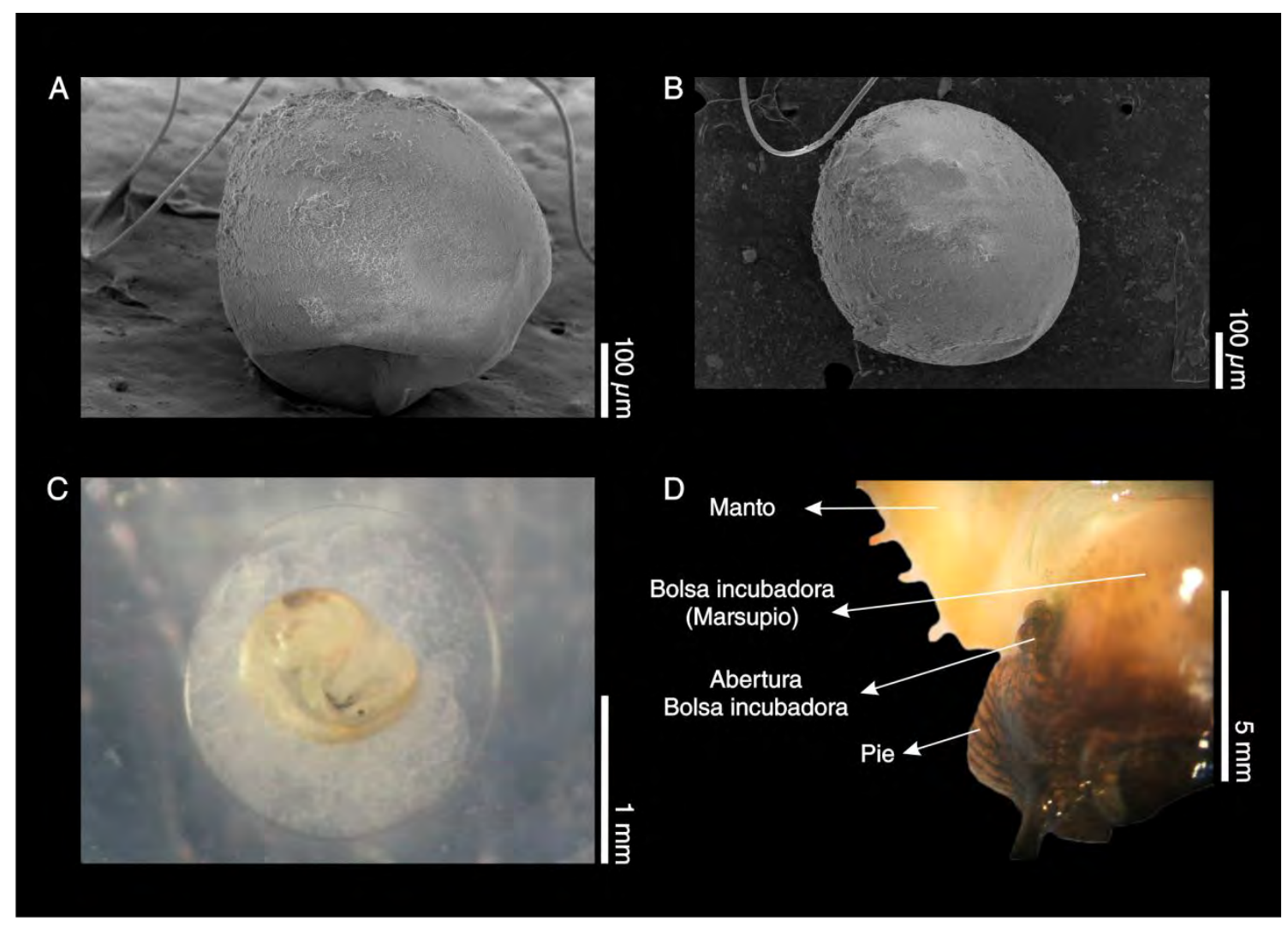

Figura 12. Ejemplares de menos de dos vueltas (A-C) y abertura de la bolsa incubadora (D). A-B: Fotografía al Microscopio Electrónico de Barrido; C: Vista al Microscopio Estereoscópico. D: Región anterior derecha de un ejemplar adulto.

\section{II.3.2.1.10 Distribución}

Aylacostoma chloroticum es una especie neotropical que se distribuye en el río Paraná, en la región conocida como Alto Paraná, entre Argentina y Paraguay. La distribución de la especie está incluida en la provincia malacológica Misionera. La especie es endémica de la región, con un rango de distribución que abarcaba poco menos de $150 \mathrm{~km}$ de río, entre los $56^{\circ} 50^{\prime} \mathrm{W}$ y $\operatorname{los} 55^{\circ} 40^{\prime} \mathrm{W}$ de longitud (Tabla IV, Figura 13), en un área donde abundaban islas, islotes, rápidos y correderas (Quintana \& Mercado Lackzó, 1997). La construcción de la Represa Binacional Yacyretá (Argentina-Paraguay) y posterior llenado de su embalse (desde 1993 hasta 2011) impactó negativamente en la distribución de la especie, que actualmente se restringe a una única población conocida en la localidad argentina de Candelaria, Misiones.

\section{II.3.2.1.11 Hábitat}

Aylacostoma chloroticum es una especie dulceacuícola. Habita ambientes de alta energía, como los rápidos de Apipé en el río Paraná (actualmente inundados por el embalse Yacyretá). 
Tabla IV. Registros de $A$. chloroticum en el Alto Paraná (Argentina-Paraguay).

\begin{tabular}{|c|c|c|c|c|c|c|}
\hline & ID & LOCALIDAD & AÑo & LATITUD & LONGITUD & REFERENCIAS \\
\hline \multirow[t]{8}{*}{ Argentina } & 1 & Isla Apipé Grande & 1981 & $-27,5015$ & $-56,7293$ & Castellanos, 1981 \\
\hline & 2 & Rápidos de Apipé & 1994 & $-27,4826$ & $-56,7335$ & Quintana \& Mercado Lackzó,1997 \\
\hline & 3 & Puerto de Posadas & 2006 & $-27,361972$ & $-55,884777$ & J.G. Peso com. pers. \\
\hline & 4 & Laguna San José & 2008 & $-27,369833$ & $-55,880455$ & J.G. Peso com. pers. \\
\hline & 5 & Des. $A^{\circ}$ San Juan & 2009 & $-27,416930$ & $-55,713022$ & J.G. Peso com. pers. \\
\hline & 6 & Candelaria & 2006 & $-27,447488$ & $-55,750233$ & J.G. Peso com. pers. \\
\hline & & & 2008 & $-27,447488$ & $-55,750233$ & Este trabajo \\
\hline & & & 2011 & $-27,447488$ & $-55,750233$ & Este trabajo \\
\hline \multirow[t]{4}{*}{ Paraguay } & 7 & Isla Ibicuy* & 1954 & $-27,2991$ & $-56,0579$ & Hylton Scott, 1954 \\
\hline & & & 1982 & $-27,2991$ & $-56,0579$ & Quintana, 1982 \\
\hline & 8 & Campichuelo & 1982 & $-27,4389$ & $-55,7884$ & Quintana, 1982 \\
\hline & 9 & Río Beach & 2007 & $-27,408286$ & $-55,825816$ & J.G. Peso com. pers. \\
\hline
\end{tabular}

*Localidad Tipo. Coordenadas en grados decimales. La georeferenciación de las localidades 1, 2, 7 y 8, es sólo una aproximación dado que en las referencias consultadas sólo se informa el nombre de la localidad sin precisiones sobre la ubicación de las poblaciones.

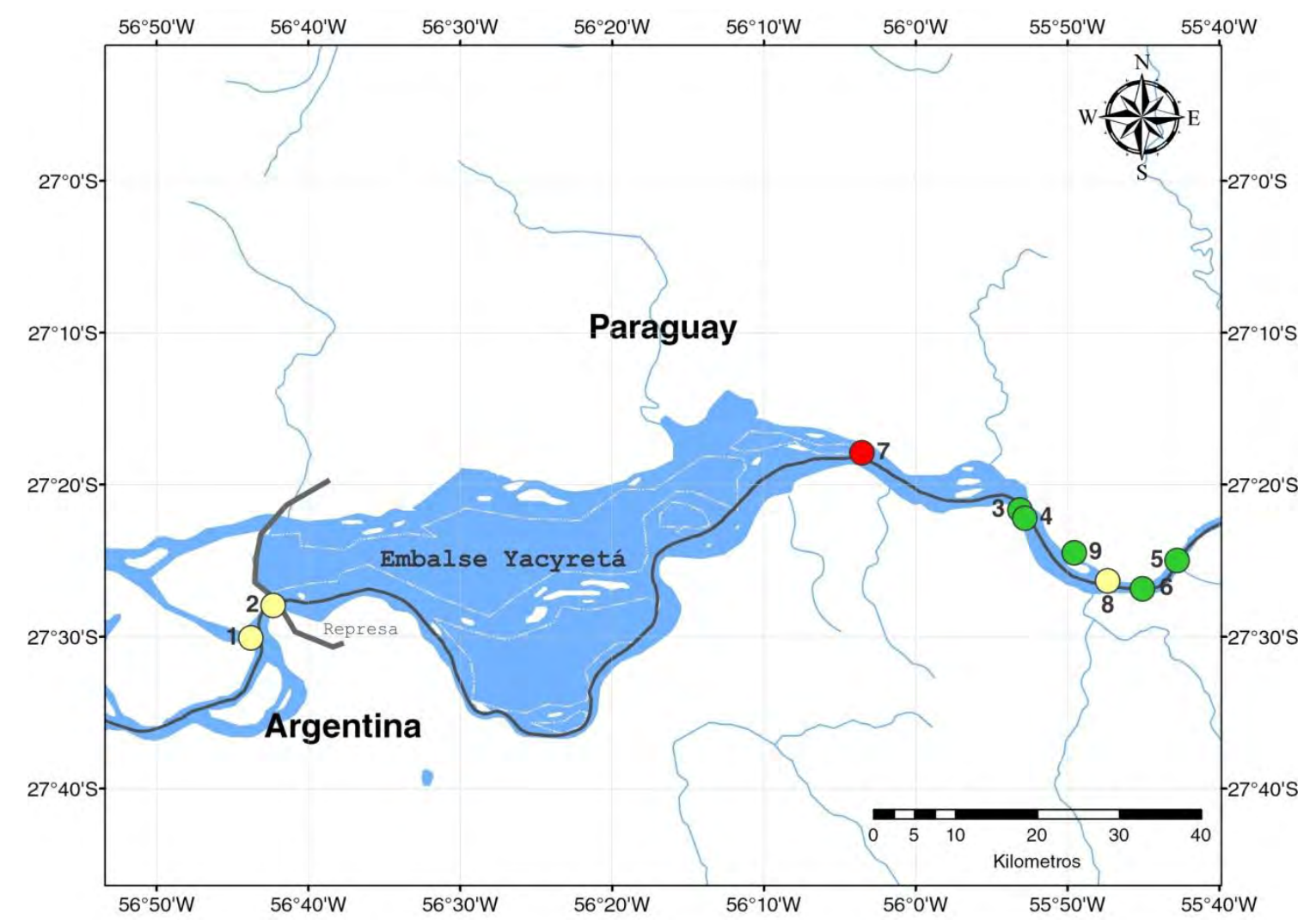

Figura 13. Distribución de $A$. chloroticum en el Alto Paraná. La localidad tipo se muestra en rojo. Localidades 1, 2, 7 y 8: registros históricos previos a la construcción y llenado del embalse Yacyretá. Localidades 3, 4, 5, 6, 9: registros durante diferentes etapas del llenado del embalse. Localidad 6: única población conocida después del alcance de cota definitiva en el año 2011. Las referencias a las localidades se presentan en la Tabla IV. 
En Apipé, la especie había sido registrada a escasa profundidad junto a otras dos especies del género, y dos morfotipos no determinados (Quintana \& Mercado Lazckó, 1997). También se han registrado ejemplares habitando sustrato limoso y arenoso, en ambientes más protegidos del río Paraná (e.g. Candelaria), con una menor velocidad de la corriente del agua.

\section{II.3.2.1.12 Aspectos ecológicos y poblacionales}

Según Quintana et al. (2001-2002), A. chloroticum es una especie estenoica intolerante a niveles bajos de oxígeno disuelto. Su dieta conocida incluye microalgas (Chlorophyta, Rhodophyta) y su ciclo de vida se asocia con los primitivos pulsos de crecida y estiaje del río Paraná (Quintana et al., 2001-2002). Asimismo los autores informaron una longevidad superior a 7 años para ejemplares criados en acuarios. Su reproducción es por partenogénesis, e incuban a sus crías en un marsupio adventicio o bolsa de cría; la liberación anual de crías sucede en dos eventos reproductivos estacionales (Quintana et al., 2001-2002). Al respecto, en nuestro seguimiento en laboratorio de una hembra adulta desde 2009 hasta 2011, detectamos dos reclutamientos, en Agosto y Octubre de 2009, con la presencia de siete y tres crías respectivamente con largo total promedio del orden de los $4 \mathrm{~mm}$ (Tabla V). Durante 2010 y hasta la muerte del ejemplar adulto en Febrero de 2011, no se observaron más reclutamientos. En relación con el parasitismo, A. chloroticum resulta el primer hospedador intermediario de una especie de tremátodo recientemente descripta, Stephanoprora aylacostoma Ostrowski de Núñez \& Quintana, 2008.

Tabla V. Medidas de los reclutamientos a partir de una hembra de A. chloroticum.

\begin{tabular}{|c|c|c|c|c|}
\hline \multirow[b]{2}{*}{ CRÍA } & \multicolumn{2}{|c|}{$\begin{array}{l}\text { PRIMER RECLUTAMIENTO } \\
\text { (Agosto- 2009) }\end{array}$} & \multicolumn{2}{|c|}{$\begin{array}{l}\text { SEGUNDO RECLUTAMIENTO } \\
\text { (Octubre - 2009) }\end{array}$} \\
\hline & LT & LUA & LT & LUA \\
\hline 1 & 5,78 & 4,62 & 4,17 & 3,45 \\
\hline 2 & 5,63 & 4,43 & 3,95 & 3,05 \\
\hline 3 & 4,38 & 3,52 & 3,96 & 3,12 \\
\hline 4 & 4,39 & 3,44 & - & - \\
\hline 5 & 3,19 & 2,64 & - & - \\
\hline 6 & 3,17 & 2,94 & - & - \\
\hline 7 & 3,29 & 2,84 & - & - \\
\hline Promedio & 4,26 & 3,49 & 4,02 & 3,20 \\
\hline DS & 1,12 & 0,77 & 0,12 & 0,21 \\
\hline
\end{tabular}

Todas las medidas están en mm. Las mismas corresponden a los tamaños registrados cuando las crías fueron detectadas por primera vez. LT: Longitud total. LUA: Longitud del último anfracto. 


\section{II.3.2.2 Nuevo morfotipo del Alto Paraná}

Lote: MLP 13613 (6 ejemplares). Todos de la localidad tipo.

Localidad tipo: Ita Cuá, Alto Paraná, Itapúa, Paraguay (Marzo 2007; Peso, J.G. col.).

\section{II.3.2.2.1 Diagnosis}

Bandas transversales oscuramente pigmentadas en la región cefalopedal. Osfradio conspicuo de casi la mitad de la longitud de la branquia; branquia larga de filamentos altos, área entre la branquia y el seno ad-rectal con vasos transversales distintivos.

\section{II.3.2.2.2 Conchilla}

Cónico-oval, sólida, desgastada en el ápice, a veces totalmente truncada, de tamaño mediano, alcanzando hasta por lo menos $28 \mathrm{~mm}$ (Tabla VI). Periostraco persistente, color marrón oscuro con bandas alternantes más claras. Manchas lineares espirales de color marrón oscuro rojizo regularmente espaciadas en todos los ejemplares (Figura 14). Protoconcha sólo presente en ejemplares juveniles (de la bolsa embrionaria), con dos vueltas casi lisas, convexas y redondeadas, la escultura espiral comienza gradualmente desde la tercera vuelta, presentando manchas lineares oscuras, espaciadas bastante regularmente (Figura 15).

Teleoconcha con hasta cuatro vueltas, en la mayoría de los casos con tres vueltas persistentes; espira de vueltas subplanas, última vuelta moderadamente convexa; superficie casi completamente lisa, última vuelta esculturada por cordones espirales anchos y bajos, uniformes en tamaño con surco angosto y poco profundo entre ellos; sutura angosta y poco profunda, no excavada; un pequeño surco corriendo paralelo a la sutura limitando muy claramente un cordón o banda subsutural algo ancha. Abertura verticalmente alargada, angulada posteriormente, con canal anterior definido. Labio externo con forma de " $\mathrm{D}$ " desde su eje mayor, con curvatura proyectándose hacia la base y la derecha. En el interior de la abertura se destacan manchas lineares de color oscuro dispuestas en hileras espirales; algunos ejemplares presentan dos bandas más oscuras asemejando listones, terminando un poco antes del borde. 


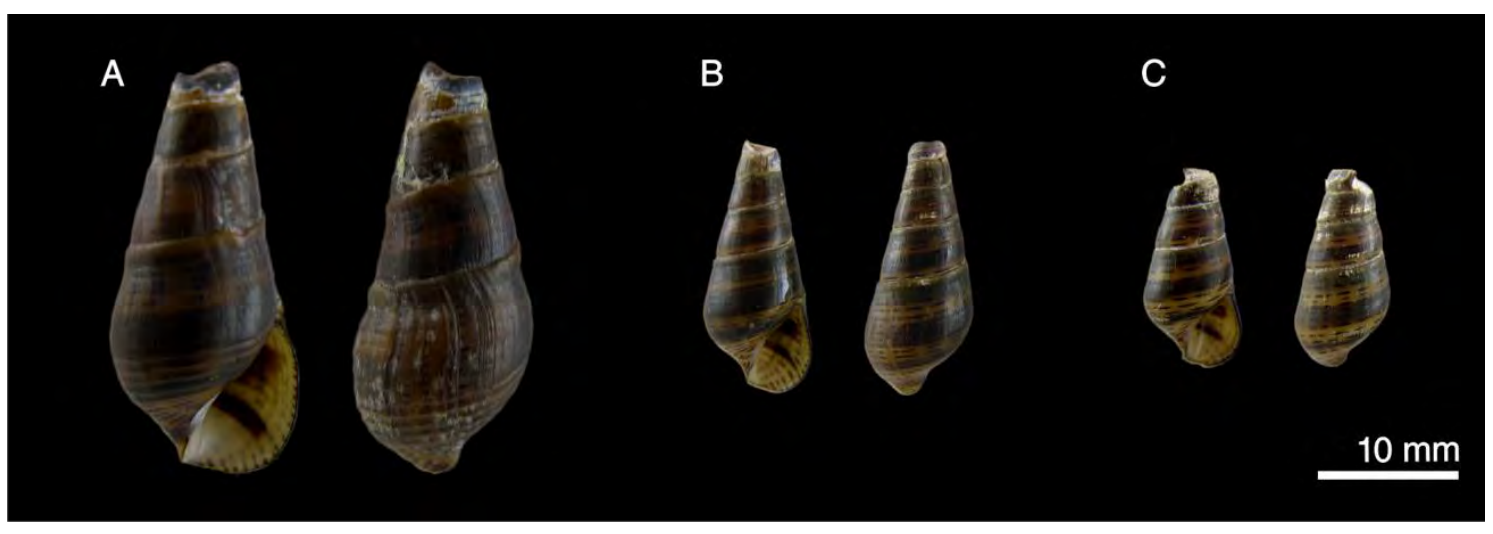

Figura 14. Nuevo morfotipo del Alto Paraná. A: Adulto; B-C: Juveniles.

Tabla VI. Medidas relevadas a partir de 6 conchillas del nuevo morfotipo (MLP 13613).

\begin{tabular}{|c|c|c|c|c|c|c|c|c|c|c} 
& $\mathbf{L T}$ & $\mathbf{A T}$ & $\mathbf{L U A}$ & $\mathbf{L E}$ & $\mathbf{L P A}$ & $\mathbf{A E}$ & $\mathbf{L A}$ & $\mathbf{A A}$ & $\mathbf{N V}$ & PROCEDENCIA \\
$\mathbf{1}$ & 27,89 & 12,38 & 18,41 & 9,48 & 4,39 & 9,24 & 13,72 & 6,51 & 4 & Ita Cuá, Itapúa, PY \\
$\mathbf{2}$ & 26,95 & 11,28 & 17,41 & 9,54 & 4,70 & 8,09 & 12,61 & 5,80 & 4 & Ita Cuá, Itapúa, PY \\
$\mathbf{3}$ & 23,63 & 11,47 & 17,33 & 6,30 & 4,57 & 7,90 & 11,99 & 5,56 & 3 & Ita Cuá, Itapúa, PY \\
$\mathbf{4}$ & 23,56 & 11,80 & 17,25 & 6,31 & 4,47 & 8,47 & 11,56 & 6,50 & 3 & Ita Cuá, Itapúa, PY \\
$\mathbf{5}$ & 18,03 & 9,29 & 13,99 & 4,59 & 3,99 & 6,66 & 10,03 & 5,10 & 3 & Ita Cuá, Itapúa, PY \\
$\mathbf{6}$ & 13,47 & 6,32 & 9,52 & 3,95 & 2,15 & 4,66 & 6,80 & 3,61 & 3 & Ita Cuá, Itapúa, PY
\end{tabular}

Todas las medidas están en mm. LT: Longitud total; AT: Ancho total; LUA: Longitud del último anfracto; LE: Longitud de la espira; LPA: Longitud del penúltimo anfracto; AE: Ancho de la espira; LA: Longitud de la abertura; AA: Ancho de la abertura; NV: Número de vueltas. PY: Paraguay.

\section{II.3.2.2.3 Cabeza-Pie}

Características similares a la especie anterior. Las bandas transversales son comparativamente más oscuras en la región cefálica.

\section{II.3.2.2.4 Opérculo}

Características similares a la especie anterior.

\section{II.3.2.2.5 Órganos del manto}

Características similares a la especie anterior. Comparativamente, manto más transparente. Longitud del osfradio de aproximadamente la mitad de la longitud de la branquia. Área entre la branquia y el seno ad-rectal con vasos transversales distintivos (Figura 16). 


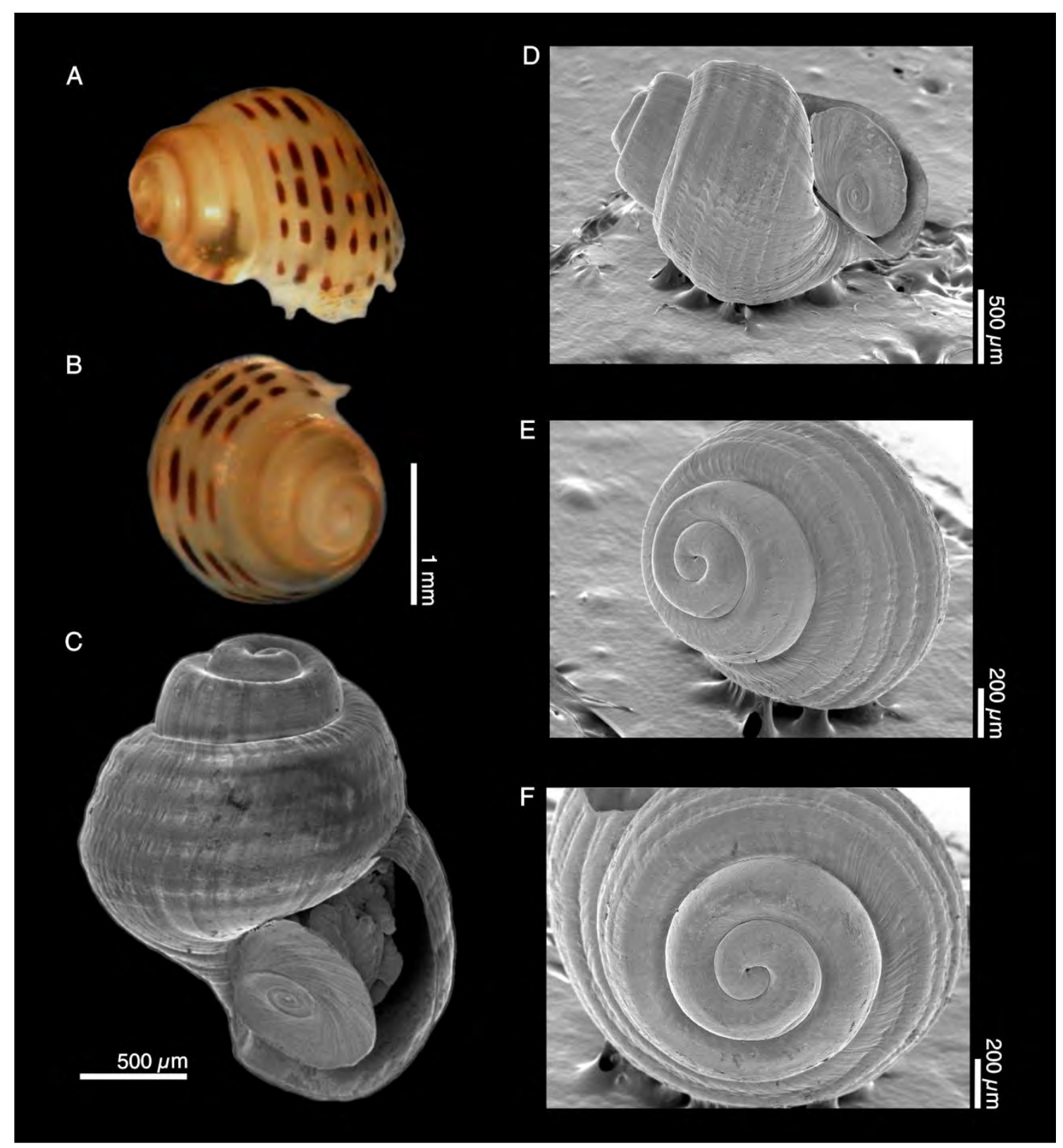

Figura 15. Juvenil del nuevo morfotipo. A-B: Vista al MO; C-F: Vista al MEB. 


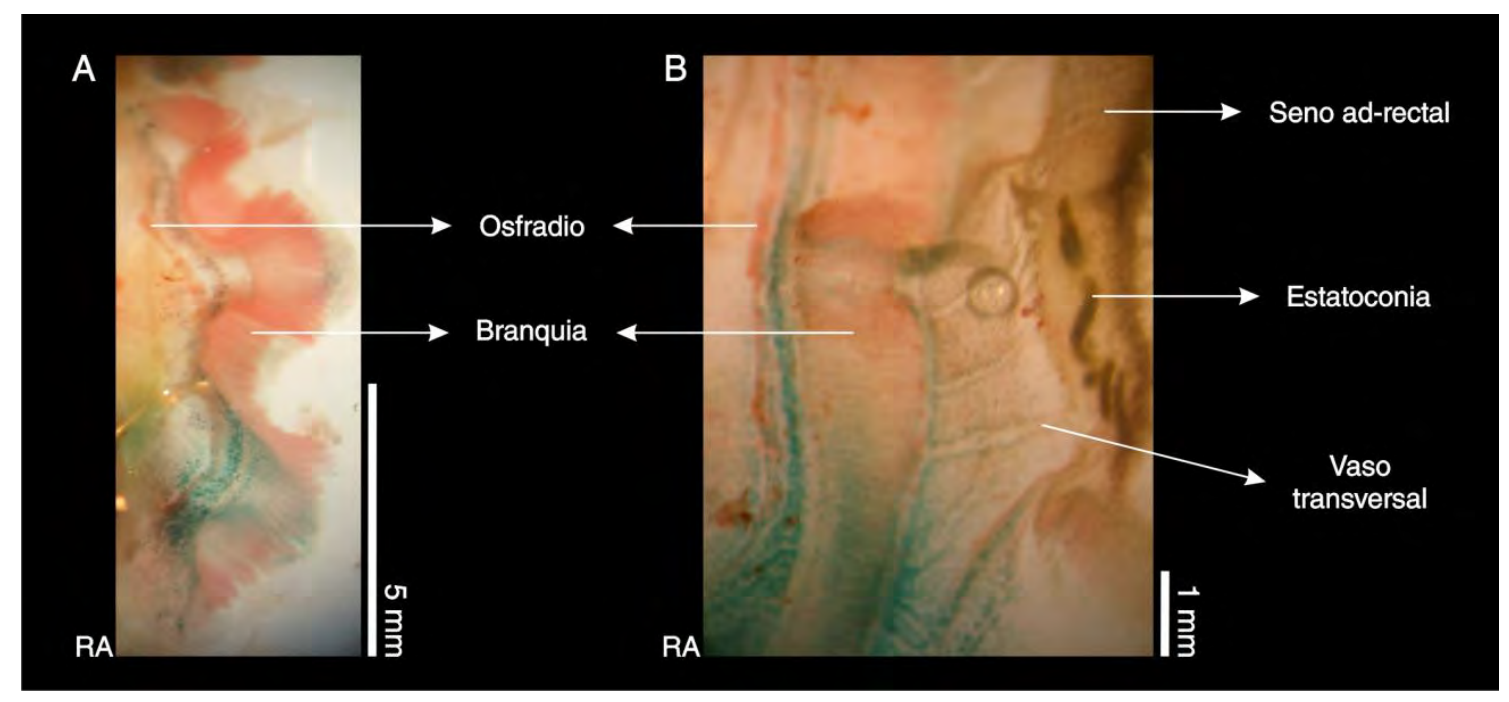

Figura 16. Detalle de la branquia (A) y de los vasos transversales entre la branquia y el seno adrectal (B) en el nuevo morfotipo. RA: región anterior.

\section{II.3.2.2.6 Sistema digestivo}

Caracteres similares a la especie anterior. Rádula tenioglosa, corta, formando una "S", con 94 hileras de dientes ( $\mathrm{n}=3$ ). Diente raquídeo pentagonal, aproximadamente dos veces más ancho que alto, con borde dorsal cóncavo y base en forma de "V" (Figura 17). Cúspide central lanceolada, de longitud notoria, con una pequeña proyección anterior; 3 a 4 cúspides puntiagudas de cada lado (3-4/1/4-3). Presencia de dos dentículos basales en cada vértice exterior. Dientes laterales largos, asimétricos, en general con 6-7 cúspides puntiagudas siendo la segunda más grande, algo más rectangular con proyección anterior. Laterales con tendencia a presentar las cúspides interiores aserradas (cúspides bífidas o trífidas). Dientes marginales similares, largos, espatulados, de base estrecha. Diente marginal interno con 7-8 cúspides digitiformes largas de forma redondeada, a excepción de la primera y última, más pequeñas. Diente marginal externo con 10-11 cúspides, más delgadas respecto del marginal interno.

\section{II.3.2.2.7 Sistemas circulatorio y excretor}

Caracteres y ubicación del corazón y riñón similares a la anterior especie.

\section{II.3.2.2.8 Sistema genital}

Sistema genital similar a la anterior especie. Sólo se han encontrado hembras. Se observaron hasta cuatro especímenes dentro de bolsa incubadora. 


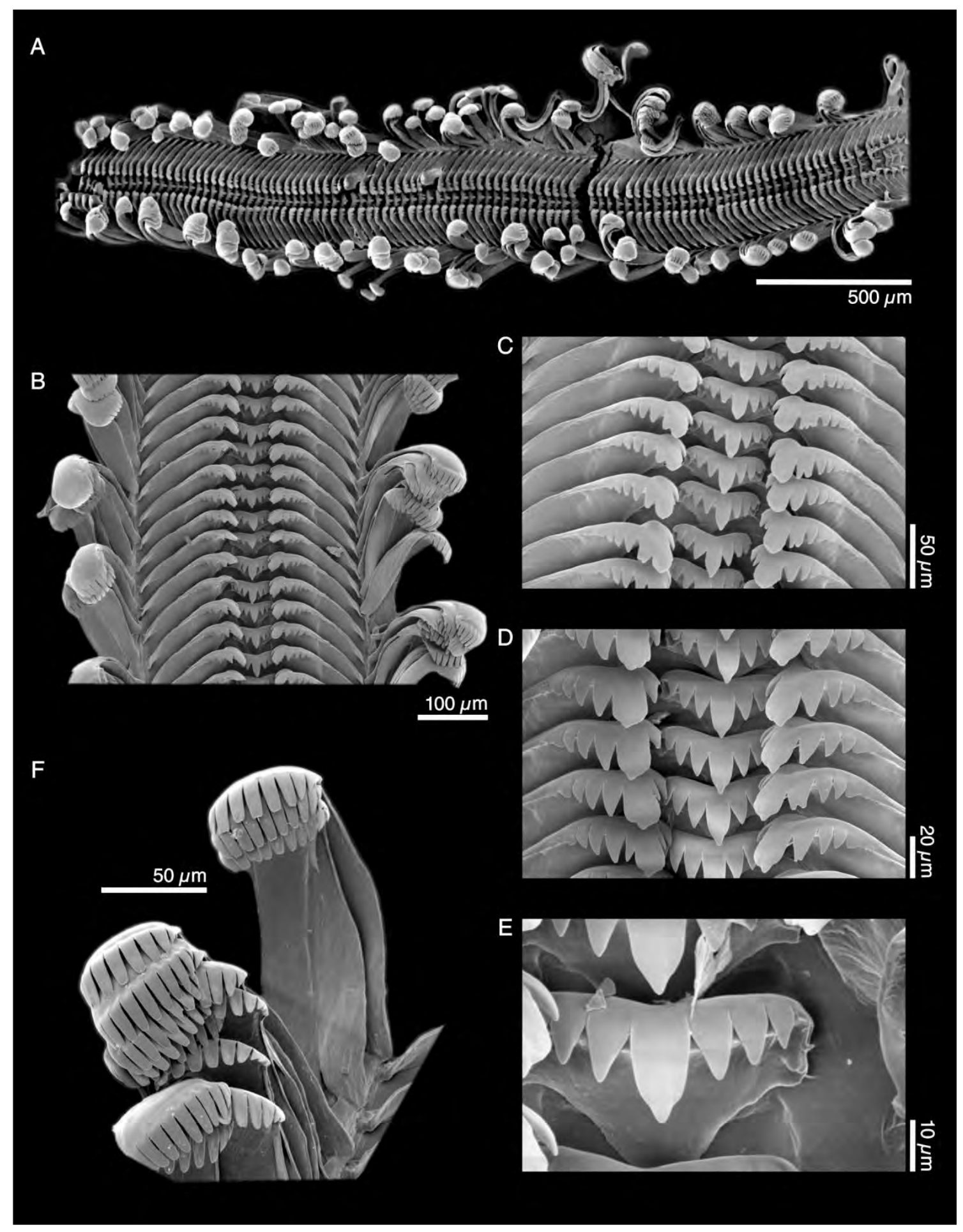

Figura 17. Rádula del nuevo morfotipo al MEB. A-B: Vista general, C-D: Raquídeo y dientes laterales. E: Detalle de los dentículos basales del raquídeo. F: Detalle de los dientes marginales. 


\section{II.3.2.2.9 Distribución}

Al igual que $A$. chloroticum este morfotipo se distribuye en el Alto Paraná, dentro de la provincia malacológica Misionera. La presencia de esta forma se conoce desde 2007 a partir de únicamente dos registros geográficos (J.G. Peso, com. pers.; Figura 18): Ita Cuá, Itapúa, Paraguay $\left(27^{\circ} 24^{e} 42,13 " S ; 55^{\circ} 48^{e} 45,69 " \mathrm{~W}\right)$ y Río Beach, Itapúa, Paraguay $\left(27^{\circ} 24^{\prime} 29,83^{\prime \prime S} ; 5^{\circ} 49^{\prime} 32,94^{\prime \prime W}\right)$. Estos sitios actualmente se encuentran modificados por el llenado del embalse Yacyretá a su cota definitiva.

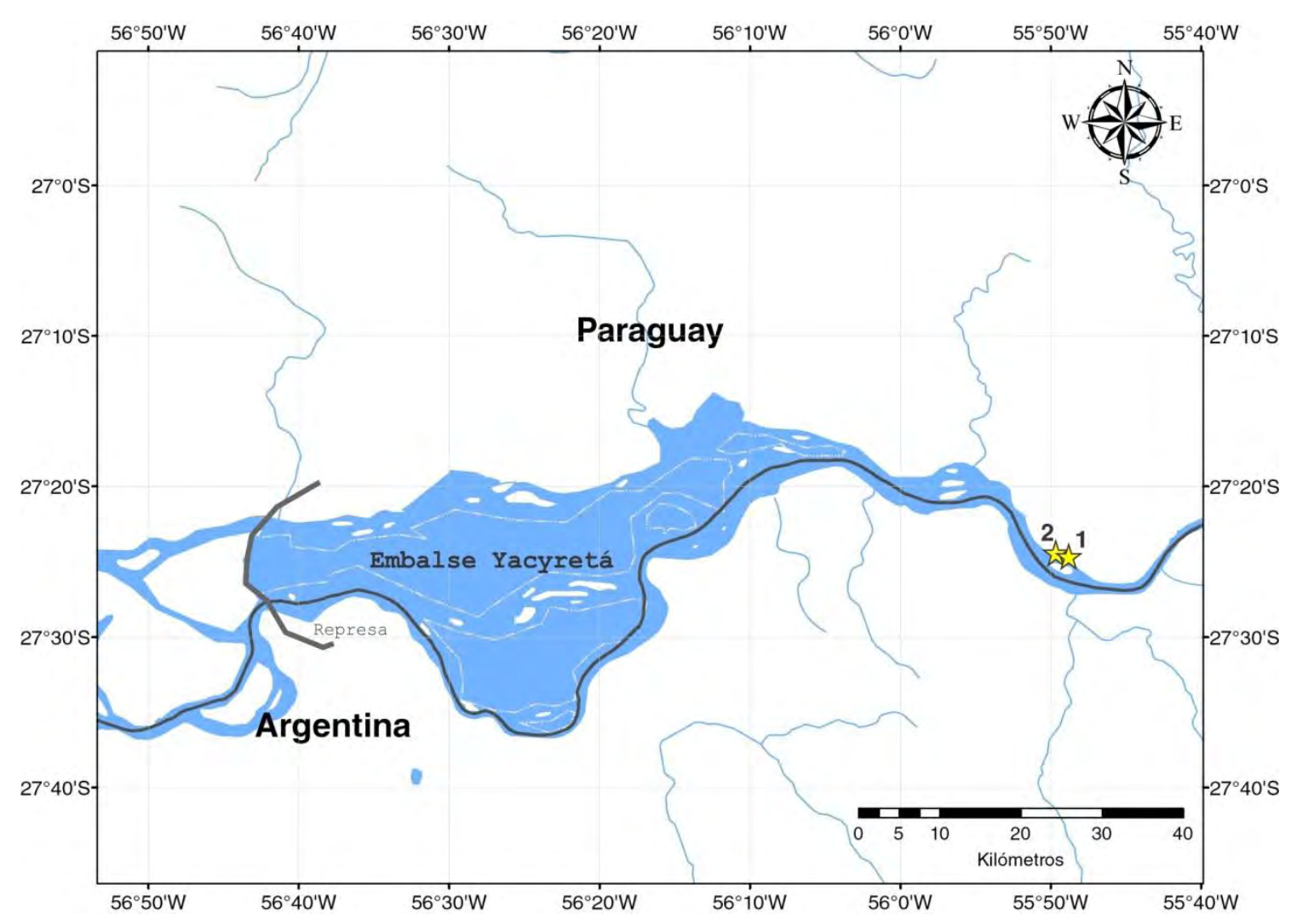

Figura 18. Distribución conocida del nuevo morfotipo en el Alto Paraná. 1: Ita Cuá, 2: Río Beach. 


\section{II.3 DISCUSIÓN}

En este estudio se describen por primera vez caracteres morfológicos para dos formas provenientes del Alto Paraná, A. chloroticum y el nuevo morfotipo. Las diferencias más notorias entre ambas estuvieron concentradas en patrones de coloración de la conchilla. Asimismo, el nuevo morfotipo se diferencia de A. chloroticum y A. guaraniticum en la espira de vueltas lisas, y en el menor número de vueltas. Adicionalmente, por su espira relativamente baja y la inflación de la última vuelta, el nuevo morfotipo se asemeja más a A. stigmaticum, aunque se distingue de esta especie por no evidenciar la coloración amarillo cuerno y por la ausencia de sus manchas negras típicas (Hylton Scott, 1954).

A nivel anatómico, el esquema general de la organización interna de A. chloroticum y el nuevo morfotipo se ajusta bien al presentado para A. guaraniticum en Castellanos (1981). El nuevo morfotipo difirió de $A$. chloroticum en la presencia de vasos distintivos en el área entre las branquias y el seno ad-rectal. En este sentido, A. chloroticum se asemeja a Aylacostoma ci Simone 2001, por no presentar vascularización evidente en esa área, y el nuevo morfotipo se asemeja a $A$. exoplicata Simone, 2001, aunque ambas formas del Alto Paraná difieren respectivamente de las de Brasil en sus conchillas, así como en la presencia de dos dentículos basales en cada vértice exterior del diente raquídeo, los cuales están ausentes en las especies brasileñas (Simone, 2001, 2011). Estos dentículos, a su vez, diferencian las formas aquí estudiadas de $A$. guaraticum para quien se ha informado la presencia de sólo un dentículo basal en cada vértice exterior del raquídeo (Hylton Scott, 1953).

En este contexto, si bien fue posible discriminar las dos entidades del Alto Paraná aquí estudiadas de aquellas otras para las cuales se cuenta con datos anatómicos, es pertinente mencionar que no existen grandes diferencias a nivel endosomático que permitan una diagnosis precisa de las formas de Aylacostoma basada sólo en caracteres anatómicos. Evidencia de ello se encuentra en un trabajo reciente de anatomía comparada, en el que Simone (2011) analiza 305 especies de Caenogastropoda a partir de la codificación de 676 caracteres morfológicos con 2.291 estados, donde se incluyeron las tres especies de Aylacostoma tratadas anatómicamente por el mismo autor en 2001 (i.e. A. ci; A. exoplicata, A. tenuilabris). A partir del análisis de la matriz de caracteres presentada en Simone (2011), se observa que sólo seis de los 676 caracteres fueron codificados con diferentes estados para las especies brasileñas (Simone, 2011). Así, pareciera que el abordaje tipológico basado en 
caracteres de conchillas es el que mejor permitiría discriminar entre las formas de Aylacostoma. Sin embargo, es sabido que este tipo de enfoque ha llevado a una plétora de sinónimos en gasterópodos dulceacuícolas, lo cual representa más un indicativo de una disparidad fenotípica que una diversidad de verdaderas especies (Köhler \& Glaubrecht, 2001). Por ello, para desarrollar una visión integral que permita tomar decisiones acertadas respecto del estatus específico de los miembros del género Aylacostoma, sugerimos que es necesario contar con evidencias provenientes de otros abordajes metodológicos (e.g. citogenética, biología molecular) que complementen los datos anatómicos y conquiliológicos. En este mismo sentido, los datos sobre la ecología e historia de vida de las entidades podrían auxiliar en esta toma de decisiones. No obstante, y tal como se observa en la compilación presentada para A. chloroticum, este tipo de información es aún escasa, y no sólo representa una particularidad de esta especie, sino más bien constituye una generalidad para todas las especies actualmente incluidas en el género.

Finalmente, respecto de la distribución de las entidades aquí analizadas, sus registros en el Alto Paraná representan los más australes para Aylacostoma en el Neotrópico. De acuerdo con el registro fósil de Aylacostoma y Hemisinus en el noroeste de América del Sur y el Caribe, se ha indicado que la distribución moderna de ambos géneros constituye un pequeño remanente de una distribución neotropical que otrora fue amplia (Wesselingh \& Salo, 2006; Wesselingh \& Ramos, 2010). Es así, que la presencia del género Aylacostoma en el Alto Paraná puede entenderse entonces como un relicto de esa distribución ancestral. 


\section{CAPÍTULO III: FILOGEOGRAFÍA DE POBLACIONES DE Aylacostoma sp. DEL ALTO PARANÁ Y SU APLICACIÓN EN CONSERVACIÓN}

\section{III.1 INTRODUCCIÓN}

\section{III.1.1 EL CONCEPTO DE FILOGEOGRAFÍA}

El término "filogeografía" fue acuñado a finales de la década de 1980 por John Avise y colaboradores para referirse al "estudio de los principios y procesos que gobiernan la distribución geográfica de los linajes genealógicos, especialmente dentro y entre especies cercanamente relacionadas" (Avise et al., 1987; Avise, 2000). A partir de entonces, la filogeografía se ha transformado de manera extraordinaria en una disciplina integradora en la que confluyen conceptos y técnicas de la genética molecular y otros campos de estudio de procesos macroevolutivos, como la filogenética, la paleontología y la biogeografía; y microevolutivos, como la genética de poblaciones, la autoecología, la demografía y la etología (Avise, 2000; Lanteri \& Confalonieri, 2003; Piñero et al., 2008; Domínguez-Domínguez \& Vázquez-Domínguez, 2009).

Esta disciplina parte del concepto de que la gran mayoría de las especies en la naturaleza exhiben cierto grado de estructuración genética asociada con la geografía, y su principal objetivo es entender cómo los acontecimientos históricos han contribuido a dar forma a la actual dispersión geográfica de genes, poblaciones y especies (Freeland, 2005; Domínguez-Domínguez \& Vázquez-Domínguez, 2009). En otras palabras, los estudios filogeográficos proveen información detallada sobre cómo los eventos geológicos, las influencias ambientales y los factores geográficos en interacción con aspectos de la ecología e historia natural, modelan la evolución de una especie (Knowles, 2009).

En un estudio filogeográfico típico, los individuos de una especie son muestreados a lo largo de su rango geográfico, para los cuales se caracteriza su genoma mitocondrial (ADNmt), ya sea a partir del análisis de fragmentos de restricción o por secuenciación directa. Posteriormente, los haplotipos resultantes (i.e. variantes genéticas del ADNmt) son utilizados para inferir una filogenia, o árbol de genes, que refleje las relaciones evolutivas de los individuos y poblaciones muestreadas. Al combinar los árboles de genes resultantes con la localización geográfica de cada individuo muestreado, es posible elucidar las distribuciones geográficas de los linajes genéticos mayores que comprenden el árbol de genes, y realizar 
interpretaciones de eventos y procesos asociados a esas distribuciones (Arbogast \& Kenagy, 2001; Domínguez-Domínguez \& Vázquez-Domínguez, 2009).

En la actualidad, coexisten dos abordajes metodológicos en filogeografía (Nielsen \& Beaumont, 2009). El primero y más convencional, está fundamentalmente basado en un enfoque gráfico-descriptivo, en donde se analizan hipótesis de la historia biogeográfica de los organismos a partir de la reconstrucción de árboles de genes o de redes de haplotipos (Lanteri \& Confalonieri, 2003; Nielsen \& Beaumont, 2009; Templeton, 2009). El segundo, denominado "fílogeografía estadística", se sustenta en fundamentos estadísticos y matemáticos de demografía y estructura poblacional. Estos se basan en la Teoría de la Coalescencia, factores estocásticos y estadística computacional, donde los modelos de análisis incluyen hipótesis que se ponen a prueba utilizando métodos basados en verosimilitud o inferencia bayesiana (Knowles \& Maddison, 2002; Domínguez-Domínguez \& VázquezDomínguez, 2009; Knowles, 2009; Nielsen \& Beaumont, 2009). Finalmente, vale aclarar que ambos abordajes no resultan mutuamente excluyentes, y cada vez con más frecuencia son utilizados de forma combinada y complementaria (Domínguez-Domínguez \& VázquezDomínguez, 2009).

\section{III.1.2 EL ADN MITOCONDRIAL EN FILOGEOGRAFÍA}

Desde sus inicios, el marcador molecular más utilizado en estudios filogeográficos en especies animales ha sido el ADNmt (Avise, 2009a; Domínguez-Domínguez \& VázquezDomínguez, 2009). El genoma mitocondrial animal constituye una molécula circular covalentemente cerrada típicamente de menos de 20 kilobases $(\mathrm{Kb})$ de longitud, el cual está caracterizado por un contenido génico altamente conservado (13 genes codificantes para proteínas, 2 genes ribosomales, y 22 genes de ARN de trasferencia; Boore, 1999; Avise, 2004). En relación con los moluscos, y a diferencia de los genomas de ADNmt de vertebrados, sus genomas mitocondriales presentan una extraordinaria variación en el orden de sus genes (Lydeard \& Lindberg, 2003), que posibilitan estudios más allá del alcance de la filogeografía (e.g. Grande et al., 2002, 2008).

La preferencia por el análisis del ADNmt en filogeografía se fundamenta en varios aspectos de la molécula, entre los que pueden citarse: i- el ADNmt exhibe un extenso polimorfismo y una tasa elevada de mutación, por lo que evoluciona más rápidamente que el ADN nuclear de copia simple; ii- la mayoría de las variantes de ADNmt involucran 
sustituciones nucleotídicas y son pocos los casos en que se observan cambios en la longitud de la molécula; iii- la herencia del ADNmt es casi siempre materna y normalmente no presenta recombinación genética intermolecular; y iv) la mayoría de los individuos son homoplásmicos para un ADNmt prevalente (Avise et al., 1987, Lanteri \& Confalonieri, 2003; Ballard \& Whitlock, 2004). Asimismo, debe agregarse que, para animales, se encuentran disponibles cebadores mitocondriales universales, lo cual constituye una de las razones por las que históricamente se encuentran muchos más estudios filogeográficos en animales que en vegetales (e.g. Folmer et al., 1994; Palumbi, 1996).

\section{III.1.2.1 Genes frecuentemente utilizados en filogeografía de gasterópodos}

\section{III.1.2.1.1 El gen ribosomal 16S (ARNr 16S)}

Este gen corresponde a la subunidad ribosomal grande en el ADNmt, y al igual que el gen $12 \mathrm{~S}$ su secuencia nucleotídica y estructura secundaria se encuentran conservadas. Según Palumbi (1996), este gen pareciera evolucionar más lentamente que el genoma mitocondrial en su conjunto. La calibración de la tasa evolutiva de las secuencias del gen ARNr 16S, de acuerdo con Reid et al. (1996) en el prosobranquio del género Littorina, sugiere una divergencia en secuencia por pares de bases del 0,2\% por millón de años. Douris et al. (1998), en estudios efectuados en caracoles terrestres del género Albinaria estimaron una tasa evolutiva aproximada del 1\% por millón de años. Otras estimaciones confiables en función de datos de varios invertebrados suponen hasta una tasa del 2,2\% por millón de años (Stätdler et al., 2005). Wilson et al. (2004) refieren a varios autores que consideraron el uso del gen mitocondrial ARNr 16S, como así también el gen de la Citocromo Oxidasa subunidad I (COI), como poderosas herramientas en la elucidación de relaciones filogenéticas de gasterópodos a niveles de superfamilia, familia y género. Adicionalmente, Palumbi (1996) propone que el gen ARNr 16S, dependiendo de las especies, exhibe variación suficiente que lo transforma en una herramienta útil aún en reconstrucciones filogenéticas a nivel de poblaciones.

\section{III.1.2.1.2 El gen ribosomal 12S (ARNr 12S)}

Este gen corresponde a la subunidad ribosomal pequeña codificada por el genoma mitocondrial. Del mismo modo que la mayoría de los genes ribosomales está altamente conservado entre diferentes taxa. Parece evolucionar a la misma tasa que el genoma 
mitocondrial como un todo (Simon et al., 1990), exhibiendo regiones que presentan un número amplio de sustituciones de secuencia. Su estructura secundaria se encuentra altamente conservada. De igual manera que el gen $\mathrm{ARNr} 16 \mathrm{~S}$, el $\mathrm{ARNr} 12 \mathrm{~S}$ es útil en estudios filogenéticos a nivel de familias, géneros y especies (Palumbi, 1996).

\section{III.1.2.1.3 El gen Citocromo Oxidasa subunidad I (COI)}

Este gen codifica para una subunidad del complejo citocromo oxidasa que es parte de la cadena transportadora de electrones (Palumbi, 1996). La secuencia parcial de este gen, no sólo resulta de utilidad para estudios filogeográficos, sino que también se ha estandarizado como la región para la obtención de códigos de barra genéticos (DNA barcoding) para la identificación de especies, por lo cual existen protocolos y condiciones de amplificación estandarizados que garantizan la amplificación del gen con alto grado de éxito (DeWaard et $a l ., 2008)$. Las tasas de evolución para este gen serán presentadas y discutidas más adelante en este capítulo.

\section{III.1.3 EL RELOJ MOLECULAR COMO ESTIMADOR DE DIVERGENCIA}

La noción de que las diferencias genéticas tienden a incrementarse con el tiempo ha prevalecido desde los inicios del enfoque molecular de la evolución en 1960 (Dickerson, 1971; Avise, 2009b). En 1963, Margoliash obtuvo los primeros datos empíricos para la proteína citocromo $c$, demostrando una diferencia en sólo tres posiciones para la secuencia de aminoácidos entre caballo y cerdo, 19 sustituciones aminoacídicas entre caballo y atún, y 44 cambios entre caballo y levadura, entre otras comparaciones. A partir de tales observaciones, Margoliash (1963) concluyó que "especies relacionadas y relativamente cercanas exhiben pocas diferencias [genéticas]... y especies filogenéticamente distantes exhiben mayores diferencias" (Avise, 2009b).

En 1962, Zuckerland \& Pauling obtuvieron resultados similares al analizar las cadenas $\alpha$ y $\beta$ de hemoglobina de mamíferos señalando que la cantidad de diferencias de aminoácidos entre linajes estaría aproximadamente relacionada con los tiempos de divergencia, en virtud de que esos linajes presentaban un ancestro común (Zuckerland \& Pauling, 1962; Schneider, 2007; Wilke et al., 2009). Posteriormente, en 1965, estos investigadores generalizaron sus observaciones acuñando el término "reloj molecular" para explicar que las secuencias de proteínas parecen divergir con cierta regularidad a lo largo del tiempo evolutivo (Zuckerland 
\& Pauling, 1965; Avise, 2009b). Esta regularidad condujo a la hipótesis de la acumulación de sustituciones de aminoácidos a nivel molecular a tasa constante, reconociéndose de inmediato su utilidad para estimar los tiempos de divergencia entre especies, especialmente para aquellos organismos con registro fósil escaso o inexistente (Martin, 2007; Battistuzzi et al., 2011).

Continuando con la propuesta y discusión de los relojes moleculares de proteínas en la década de 1960, fue natural cuestionarse si esta idea podía ser extendida al ADN (revisión histórica en Kumar, 2005). En 1968, Kimura observó que los errores espontáneos raros en la replicación del ADN causan las mutaciones que dirigen la evolución molecular, y que la acumulación de esas diferencias evolutivamente neutras entre dos secuencias podían ser usadas para medir el tiempo (Schneider, 2007). Sin embargo, la comparación directa de secuencias de ADN sólo fue posible a partir de mediados de la década de 1970 con el desarrollo de las técnicas de secuenciación del ADN. Es así como a principios de la década de 1980 se obtienen las secuencias nucleotídicas de muchos genes para los cuales, a su vez, las secuencias aminoacídicas que codificaban ya habían sido analizadas con anterioridad. Al mismo tiempo, la Teoría Neutral de evolución molecular proveyó el marco para estimar la tasa de mutación a partir de la tasa de sustituciones neutrales (Kumar, 2005).

De igual forma que el reloj molecular de proteínas, el reloj molecular de ADN ha sido objeto de debates y controversias en la literatura especializada dado que en muchos casos genes y/o linajes no parecen estar evolucionando de acuerdo con un reloj molecular (Kumar, 2005). Esta controversia a su vez ha acompañado en muchos casos el debate seleccionistaneutralista (revisión en Avise, 2004). No obstante las controversias, al presente, se asume que ciertos genes o secuencias pueden evolucionar a tasas constantes a lo largo del tiempo. En este sentido, se han desarrollado pruebas para examinar si las tasas de evolución molecular varían significativamente entre los grupos taxonómicos o linajes filogenéticos (Martin, 2007). Existen dos tipos de pruebas principales: aquellas basadas en comparaciones de distancias genéticas entre dos especies (o grupos de especies) en relación con un grupo externo; y las que comparan valores de máxima verosimilitud para la misma filogenia calculada asumiendo o no una tasa constante. Para aquellos casos donde se infringe el supuesto de tasa constante, se están aplicando relojes moleculares modernos que incorporan la tasa heterogénea en el proceso de estimación del tiempo (Battistuzzi et al., 2011). 


\section{III.1.4 LA INFERENCIA FILOGEOGRÁFICA APLICADA A CONSERVACIÓN}

La biología de la conservación ha sido descripta como una "disciplina de crisis", en virtud del gran número de especies extintas y en inminente peligro de extinción (Frankham et al., 2002; Pullin, 2002). Esta disciplina ha incorporado diversas tecnologías para acelerar y aumentar la precisión de la toma de decisiones en conservación, y particularmente los avances en genómica, sistemática y biología de poblaciones han sido un factor clave en la integración de la genética a la biología de la conservación (DeSalle \& Amato, 2004). En este contexto, la genética de la conservación puede ser entendida como la aplicación de la genética evolutiva y molecular a la conservación de la biodiversidad (Frankham et al., 2002; Frankham 2010a).

El conocimiento de la diversidad genética resulta de fundamental importancia en conservación, pues es la base de la variación orgánica y por lo general tiene una estrecha correlación con el ajuste de las especies al medio (Lanteri et al., 2002). Sin embargo, con el transcurso del tiempo y en forma creciente, la variabilidad genética de muchas poblaciones naturales se ha visto erosionada por factores tales como la destrucción y fragmentación de las áreas naturales, el cambio climático y/o la introducción de especies exóticas (Lande, 1988; Lydeard et al., 2004; Rubidge et al., 2012).

Las aplicaciones más importantes de la genética en conservación se derivan de su capacidad para auxiliar en la generación de una imagen más precisa de los patrones y procesos genéticos-evolutivos de las especies en peligro, los cuales son relevantes para el conocimiento, gestión y conservación de sus poblaciones (DeSalle \& Amato, 2004; Domínguez-Domínguez \& Vázquez-Domínguez, 2009). Entre las principales contribuciones de la genética a la conservación biológica se destacan: la definición de unidades evolutivas divergentes dentro de las especies para su gestión separada, la resolución de incertidumbres taxonómicas, la gestión genética de las poblaciones pequeñas y el uso de análisis moleculares en casos forenses (revisión en Frankham, 2010a).

En lo referido a conservación al nivel intraespecífico, área donde la filogeografía constituye una importante herramienta (Domínguez-Domínguez \& Vázquez-Domínguez, 2009), un objetivo general de la mayoría de los esfuerzos conservacionistas es maximizar la preservación de la variación genética adaptativa de una especie, de manera tal que las poblaciones puedan responder ecológica y evolutivamente a los diversos desafíos ambientales que pueden experimentar a través de sus áreas de distribución nativas (Avise, 2005). En este 
sentido, una tarea importante es caracterizar, cuantificar e interpretar correctamente el significado adaptativo de tal variación (Crandall et al., 2000; Moritz, 2002). Para ello, el enfoque general consiste en identificar poblaciones geográficas o grupos de poblaciones que en virtud de un flujo génico restricto resulten inusualmente distintivas en su composición genética y/o que sean independientes en su demografía, de manera tal que justifiquen una consideración especial en los esfuerzos de conservación (Avise, 2005).

A los efectos de priorizar la conservación de unidades de manejo que reflejen la importancia evolutiva de los linajes dentro de las especies, se han acuñado diversos conceptos, entre los cuales el más utilizado en estudios filogeográficos enmarcados en un contexto de conservación es el de Unidades Evolutivas Significativas (ESUs, del inglés Evolutionary Significan Units). El primer concepto de ESU se originó con Ryder (1986), quien lo definió como un grupo de organismos que han estado aislados de otros grupos de la misma especie por un periodo de tiempo suficiente como para haber desarrollado divergencias genéticas significativas entre ellos (Domínguez-Domínguez \& Vázquez-Domínguez, 2009). Actualmente, el concepto más popularizado es el propuesto por Moritz (1994), según el cual una ESU debe ser recíprocamente monofilética para marcadores mitocondriales y evidenciar divergencias significativas en las frecuencias alélicas de loci nucleares; aunque esta manera de delimitar ESUs no está exenta de críticas (revisión en Moritz, 2002). En la actualidad, no existe un consenso generalizado para definir las ESUs (Frankham, 2010b), sin embargo la noción general es que una ESU es una o un conjunto de poblaciones de una especie con una historia evolutiva diferente de la de otras unidades (Avise, 2005). Tales "grupos naturales" pueden ser morfológicamente crípticos pero contienen no sólo la impronta de su historia pasada, sino la posibilidad de respuestas diferentes a cambios ambientales futuros (Ladle \& Whittaker, 2011).

A modo de ejemplo, se puede citar un estudio efectuado por Holland \& Hadfield (2002). Los investigadores evaluaron la estructura filogeográfica dentro y entre las poblaciones de tres especies de gasterópodos endémicos del género Achatinella Swaison, 1828, críticamente amenazados de extinción en Hawai, priorizando la conservación de $A$. mustelina Mighels, 1845. Las especies focales tenían habilidades de dispersión limitadas, ocupando poblaciones fragmentadas restrictas a un territorio de montaña por encima de los $600 \mathrm{~m}$ de elevación, presentando las mismas un estado de declinación acentuada debido a impactos antrópicos y a la presencia de especies invasoras. A pesar de la ausencia de una clara 
diferenciación morfológica, fueron identificadas seis ESUs aisladas a partir de datos de secuencias de ADNmt, lo que permitió el desarrollo de estrategias de conservación y recuperación para A. mustelina (Hadfiel et al., 2004).

Finalmente y considerando que para contribuir al desarrollo de estrategias de conservación de las especies de Aylacostoma del Alto Paraná en un contexto evolutivo es vital primero adquirir información sobre lo que ha acontecido en tiempos pretéritos, en este capítulo se abordan, mediante análisis genéticos, gran parte de los objetivos particulares planteados (i.e. c, d, f y g). Es importante destacar, que en forma similar a lo expresado en el capítulo anterior, en el presente se pretendía el análisis de todas las formas de Aylacostoma descriptas para el Alto Paraná, aunque la extinción en la naturaleza de dos de las formas y la inexistencia de partes blandas depositadas en colecciones malacológicas para las especies extintas, limitaron los abordajes moleculares al material disponible. No obstante, los resultados obtenidos no sólo permitieron dar respuesta a las hipótesis planteadas, sino también caracterizar y delimitar linajes evolutivos, un paso importante para la conservación del grupo. 


\section{III.2 MATERIALES Y MÉTODOS}

\section{III.2.1 MATERIAL DE ESTUDIO}

Durante el período comprendido entre abril 2008 y diciembre 2011 se realizaron cuatro campañas exploratorias y de recolección del material bajo estudio (una en 2008, una en 2010 y dos en 2011), en diferentes localidades del área de distribución histórica del género Aylacostoma en el Alto Paraná, comprendiendo las provincias argentinas de Misiones y Corrientes, y el departamento Itapúa de Paraguay. Las campañas fueron coordinadas con la Dra. Juana Peso (FCEQyN, UNaM) y con el Lic. Diego Pérez (EBY), dada la vigencia del "Programa Aylacostoma" (Convenio FCEQyN-EBY) enfocado en la conservación ex situ de los gasterópodos objeto de estudio.

La búsqueda y recolección de ejemplares adultos se realizó a través de diversos métodos y en una variedad de sustratos: mediante buceo autónomo, muestreador tipo surber y “copos” en el Embalse Yacyretá, Río Paraná y desembocadura de arroyos; y de forma manual en hábitats de las zonas ribereñas. Resulta oportuno resaltar que durante las campañas no fue posible muestrear en la mayoría de las localidades con registros históricos para Aylacostoma spp., debido a la modificación de los ambientes como consecuencia de los sucesivos incrementos de los niveles de cota del Embalse Yacyretá. No obstante, fue posible obtener muestras de algunos ejemplares, los que fueron gentilmente cedidos por la Dra. Peso, y que oportunamente habían sido rescatados y mantenidos en cautiverio en el marco del "Programa Aylacostoma" procedentes de localidades que en la actualidad son inexistentes. De la misma manera, el Dr. Jean Pierre Pointier de la Universidad de Perpignan (Francia), cedió muestras en alcohol pertenecientes a tres especies de Thiaridae s.l. las que fueron incluidas como grupo externo en los análisis filogenéticos realizados en el presente trabajo.

La colección final contó con tejidos de 63 individuos, 40 procedentes de los muestreos efectuados, y 23 derivados del "Programa Aylacostoma". Estos últimos procedentes de: 1) Rápidos Apipé, Laguna San José, Puerto Posadas -Argentina-; Río Beach, Ita Cuá Paraguay-, localidades inexistentes después del alcance de cota definitiva del embalse y 2) desembocadura del $\mathrm{A}^{\circ}$ San Juan, ambiente actualmente negativo para Aylacostoma spp. La procedencia del material de estudio, sus coordenadas geográficas y el número de ejemplares analizados por localidad se resume en la Tabla VII. 
Tabla VII. Procedencia del material de estudio.

\begin{tabular}{|c|c|c|c|c|c|}
\hline & PaÍS & LOCALIDAD & $\mathbf{N}$ & LAT. LONG. & AÑo COLECTA \\
\hline \multirow[t]{8}{*}{ Aylacostoma spp. } & \multirow[t]{6}{*}{ Argentina } & $\mathrm{A}^{\mathrm{o}}$ San Juan (Mis.) & $2^{*}$ & $27,416930 \mathrm{~S} ; 55,713022 \mathrm{~W}$ & 2009 \\
\hline & & Candelaria (Mis.) & 15 & $27,447488 \mathrm{~S} ; 55,750233 \mathrm{~W}$ & 2008 \\
\hline & & & 15 & & 2011 \\
\hline & & Laguna San José (Mis.) & 10 & $27,369833 \mathrm{~S} ; 55,880455 \mathrm{~W}$ & 2008 \\
\hline & & Puerto Posadas (Mis.) & $3^{*}$ & $27,361972 \mathrm{~S} ; 55,884777 \mathrm{~W}$ & 2006 \\
\hline & & Rápidos Apipé (Corr.) & $5^{*}$ & $27,482613 \mathrm{~S} ; 56,733588 \mathrm{~W}$ & 1994 \\
\hline & \multirow[t]{3}{*}{ Paraguay } & Ita Cuá (Ita.) & $5^{*}$ & $27,411702 \mathrm{~S} ; 55,812691 \mathrm{~W}$ & 2003 \\
\hline & & Río Beach (Ita.) & $8^{*}$ & $27,408286 \mathrm{~S} ; 55,825816 \mathrm{~W}$ & 2007 \\
\hline Total & & & 63 & & \\
\hline \multirow[t]{3}{*}{ Thiaridae s.l. } & \multirow{4}{*}{$\begin{array}{c}\text { Cuba } \\
\text { Venezuela }\end{array}$} & Río Ochoa & 1 & $22,400530 \mathrm{~N} ; 79,926177 \mathrm{~W}$ & 1997 \\
\hline & & Rio Tocoma & 1 & $7,9141388 \mathrm{~N} ; 63,090027 \mathrm{~W}$ & 2010 \\
\hline & & La Macanilla & 1 & $10,111583 \mathrm{~N} ; 66,517527 \mathrm{~W}$ & 2010 \\
\hline Total & & & 3 & & \\
\hline
\end{tabular}

N: número de individuos; Lat. Long.: coordenadas en grados decimales. Corr.: Provincia de Corrientes; Ita: Departamento Itapúa; Mis.: Provincia de Misiones; "individuos cedidos por el "Programa Aylacostoma".

\section{III.2.2 PREPARACIÓN DEL MATERIAL MALACOLÓGICO}

Los ejemplares se relajaron mediante modificación de la técnica de "Fijación de Gasterópodos Límnicos" (Ministério da Saúde, Secretaria de Vigilância em Saúde, Departamento de Vigilância Epidemiológica, 2007). Para la extracción de pequeñas porciones de tejido muscular sin ocasionar la muerte de los ejemplares, las condiciones de relajación óptimas consistieron en la exposición de los individuos a una solución $0,05 \%$ del anestésico Nembutal durante $6-8$ hs a $30^{\circ} \mathrm{C}$, y posterior exposición en acuarios conteniendo el antibiótico Tripaflavina hasta su recuperación total.

De cada ejemplar se extrajeron dos porciones pequeñas de tejido muscular de pie $(\sim 1$ $\mathrm{mm}^{3}$ ). La primer porción de cada uno de los tejidos se colocó en microtubos de 1,5 ml conteniendo $500 \mu \mathrm{l}$ de solución fisiológica y se conservaron a $-20^{\circ} \mathrm{C}$ hasta el momento de proceder con la extracción de ADN. La segunda porción se colocó en microtubos de 1,5 ml conteniendo $500 \mu \mathrm{l}$ de etanol absoluto y se depositaron como vouchers en la colección malacológica de la División Invertebrados del Museo de La Plata (FCNyM, UNLP).

Todos los ejemplares se documentaron mediante fotografía (Figura 19) y se midieron con calibre digital, incluyéndose esta información en una base de datos. Las medidas registradas fueron: longitud total (LT), ancho total (AT), longitud del último anfracto (LUA), 
longitud del penúltimo anfracto (LPA), longitud de la espira (LE), ancho de la espira (AE), largo y ancho de la abertura (LA y AA). Finalmente, los ejemplares se marcaron adhiriendo a su conchilla una vuelta de masilla epoxi comercial (en la cual se inscribió su codificación) y se remitieron al "Programa Aylacostoma" para su conservación ex situ.

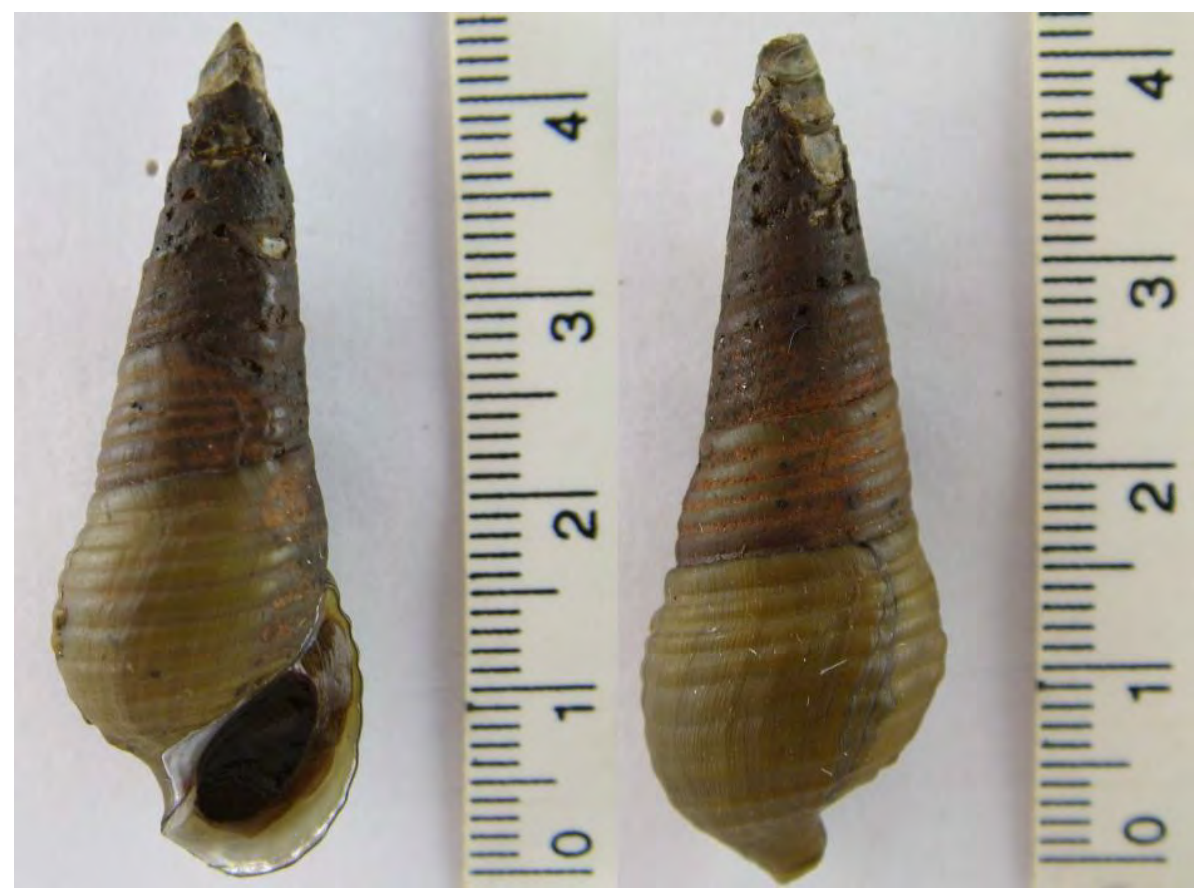

Figura 19. Vista frontal y dorsal de un ejemplar de Aylacostoma chloroticum.

\section{III.2.3 EXTRACCIÓN DE ADN GENÓMICO TOTAL}

Para la extracción de ADN genómico total se ensayaron tres protocolos a partir de tejido fresco obtenido de un individuo de prueba a los efectos de evaluar su rendimiento y calidad.

\section{III.2.3.1 Protocolo I (modificado de Aljanabi \& Martínez, 1997)}

El tejido se colocó en un microtubo de $1,5 \mathrm{ml}$ y se agregaron $400 \mu 1$ de buffer BHS (ver Apéndice I), $80 \mu 1$ de SDS 10\% y 4,6 $\mu 1$ de Proteinasa K $(10 \mathrm{mg} / \mathrm{ml})$. Esta solución se incubó a $60^{\circ} \mathrm{C}$ overnight (de aquí en más ON). Posteriormente, se agregaron $300 \mu 1$ de $\mathrm{NaCl} 6$ M. La muestra se agitó con vórtex durante 30 segundos y se centrifugó a $10.000 \mathrm{~g}$ durante 30 minutos. El sobrenadante se transfirió a un nuevo microtubo, y se le agregó un volumen de alcohol isopropílico igual al de la muestra. El contenido fue homogeneizado por inversión y llevado a $-20^{\circ} \mathrm{C}$ durante 1 hora. Posteriormente, la muestra fue centrifugada a $4^{\circ} \mathrm{C}$ durante 30 
minutos a $10.000 \mathrm{~g}$ descartando el sobrenadante. El precipitado obtenido se lavó con etanol $70 \%$, se dejó secar a temperatura ambiente y fue resuspendido en Tris/HCl 10 mM.

\section{III.2.3.2 Protocolo II (modificado de Vogler et al., 2006)}

El tejido se colocó en un microtubo de $1,5 \mathrm{ml}$ y se agregaron $500 \mu \mathrm{l}$ de buffer TEC/SDS (ver Apéndice I) y $2 \mu 1$ de Proteinasa K $(10 \mathrm{mg} / \mathrm{ml})$. Esta solución fue incubada a $56^{\circ} \mathrm{C}$ durante 2 horas con inversión manual del tubo cada 15 minutos. Posteriormente, la muestra fue tratada con solventes orgánicos: una vez con fenol y otra con cloroformo/alcohol isoamílico (24:1) centrifugando a $12.000 \mathrm{~g}$ durante 10 minutos y recuperando cada vez la fase acuosa. El ADN se precipitó mediante el agregado 2/3 volúmenes de alcohol isopropílico. El contenido fue homogeneizado por inversión y llevado a $-20^{\circ} \mathrm{C}$ durante 1 hora. Finalmente, la muestra fue centrifugada durante 10 minutos a $12.000 \mathrm{~g}$ descartando el sobrenadante. El precipitado se dejó secar a temperatura ambiente y fue resuspendido en Tris/HCl $10 \mathrm{mM}$.

\section{III.2.3.3 Protocolo III (estandarizado en el Laboratorio de Citogenética y Genética Humana-FCEQyN, UNaM)}

El tejido se colocó en un microtubo de $1,5 \mathrm{ml}$ y se agregaron $500 \mu 1$ de buffer CTAB (ver Apéndice I) y $2 \mu \mathrm{l}$ de Proteinasa K $(10 \mathrm{mg} / \mathrm{ml})$. La muestra se incubó $60^{\circ} \mathrm{C} \mathrm{ON}$. Posteriormente, se realizaron tres lavados orgánicos con cloroformo/alcohol isoamílico (24:1), alternados con centrifugaciones de 10 minutos a $10.000 \mathrm{~g}$. El ADN se precipitó mediante el agregado de $2 / 3$ volúmenes de alcohol isopropílico. El contenido fue homogeneizado por inversión y llevado a $-20^{\circ} \mathrm{C}$ durante 12 horas. Finalmente, la muestra fue centrifugada durante 10 minutos a $12.000 \mathrm{~g}$, descartando el sobrenadante. El precipitado se dejó secar a temperatura ambiente y fue resuspendido en Tris/ $\mathrm{HCl} 10 \mathrm{mM}$.

Una vez definido el protocolo más conveniente se procedió a la extracción de ácidos nucleicos a partir de la colección de tejidos conservados en solución fisiológica. El rendimiento de las extracciones fue verificado mediante electroforesis horizontal $(5 \mathrm{~V} / \mathrm{cm})$ en geles de agarosa al $1 \%(\mathrm{p} / \mathrm{v})$ teñidos con bromuro de etidio $(0,5 \mathrm{mg} / \mathrm{ml})$. Los geles fueron visualizados y fotografiados bajo luz UV en transiluminador UVP-TM-20 (Upland, CA). Las imágenes se documentaron digitalmente con cámara Kodak Easyshare Z7590, utilizando lente close up y filtro para luz UV así como para bromuro de etidio (Byodinamics S.R.L.). A los efectos de semicuantificar el ADN obtenido, los geles se corrieron conjuntamente con ADN 
de fago lambda (533 $\mu \mathrm{g} / \mathrm{ml}$, Promega). Asimismo, en cada corrida se incorporó como referencia un marcador de peso molecular $1 \mathrm{Kpb}$ Ladder (Productos Bio-Lógicos).

\section{III.2.4 AMPLIFICACIÓN DE GENES MITOCONDRIALES}

Para el presente trabajo, en función de los antecedentes disponibles en la literatura para la familia Thiaridae, se seleccionaron los dos genes ribosomales mitocondriales (ARNr $12 \mathrm{~S}$ y $16 \mathrm{~S}$ ) y el gen mitocondrial Citocromo Oxidasa subunidad I (COI).

\section{III.2.4.1 Amplificación de los genes ribosomales ARNr 12S y 16S}

Teniendo en cuenta que en las bases de datos mundiales (GenBank, EMBL) no existían al momento secuencias de referencia para el género Aylacostoma que permitieran el diseño de cebadores específicos, la amplificación de los genes ribosomales se realizó en primera instancia a partir de: a) cebadores desarrollados para otras especies, siguiendo la estrategia de amplificación interespecífica, y b) cebadores universales descritos en la literatura.

Para la amplificación interespecífica se obtuvieron los cebadores descritos por Facon et al. (2003) para los genes ribosomales mitocondriales 12S y $16 \mathrm{~S}$ del thiárido Melanoides tuberculata (Müller, 1774) (Tabla VIII). Los cebadores universales fueron obtenidos a partir de la descripción efectuada en Palumbi (1996). Dado que estos últimos fueron propuestos a partir de la comparación de secuencias de diversos organismos (incluyendo vertebrados e invertebrados), el ajuste de las posiciones nucleotídicas fue realizado mediante BLASTn (Altschul et al., 1990) utilizando secuencias de gasterópodos como referencia. Por consiguiente, cada sitio ambiguo fue reemplazado por el nucleótido de mayor frecuencia entre las diferentes especies comparadas.

Adicionalmente, y en la búsqueda de secuencias de referencia en GenBank se encontró una secuencia única para la región ribosomal mitocondrial mayor LSU (del inglés Large Subunit) de otro thiárido americano del género Hemisinus (i.e. H. cubanianus, GenBank $\mathrm{N}^{\circ} \mathrm{AY}$ 010516). Dado que esta región contiene gran parte del gen ARNr 16S, a partir de ella se diseñaron cebadores para Aylacostoma asumiendo la estrategia de transferencia de secuencias. El diseño se efectuó con auxilio del programa Primer-BLAST (Ye et al., 2012). En todos los casos la síntesis de los cebadores fue realizada por la empresa Operon a través de Tecnolab S.A. 
Tabla VIII. Detalle de los cebadores utilizados para la amplificación de los genes ribosomales 12 y $16 \mathrm{~S}$.

\begin{tabular}{|c|c|c|c|c|}
\hline & SECUENCIA & $T m$ & TEF & REFERENCIA \\
\hline \multicolumn{5}{|l|}{ ARNr 12S } \\
\hline $12 \mathrm{SF}$ & 5'-AAC TCA AAG GAC TTG GCG GTG C-3' & $60^{\circ} \mathrm{C}$ & \multirow{2}{*}{$300 \mathrm{pb}$} & Facon et al. (2003) \\
\hline $12 \mathrm{SR}$ & 5'-GTT TTT TTA CTT TCA AGT CCT CC-3' & $62^{\circ} \mathrm{C}$ & & Facon et al. (2003) \\
\hline 12Sai & 5'-AAA CTA GGA TTA GAT ACC CTA TTA T-3' & $64^{\circ} \mathrm{C}$ & \multirow{2}{*}{$450 \mathrm{pb}$} & Palumbi (1996) \\
\hline $12 \mathrm{Sbi}$ & 5'-GAG AGC GAC GGG CGA TGT GT-3' & $62^{\circ} \mathrm{C}$ & & Palumbi (1996) \\
\hline \multicolumn{5}{|l|}{ ARNr 16S } \\
\hline 16SAr & 5'-CGC CTG TTT AAC AAA AAC AT-3' & $52^{\circ} \mathrm{C}$ & \multirow{2}{*}{$550 \mathrm{pb}$} & Palumbi (1996) \\
\hline $16 \mathrm{SBr}$ & 5'-CCG GTC TGA ACT CAG ATC ACG T-3' & $68^{\circ} \mathrm{C}$ & & Palumbi (1996) \\
\hline $16 \mathrm{SF}$ & 5'-TAG CAT GAA TGG TCT GAC GAA AGC-3' & $49^{\circ} \mathrm{C}$ & \multirow{2}{*}{$300 \mathrm{pb}$} & Facon et al. (2003) \\
\hline $16 \mathrm{SR}$ & 5'-AAG GAG ATT ATG CTG TTA TCC C-3' & $62^{\circ} \mathrm{C}$ & & Facon et al. (2003) \\
\hline AYLA2F & 5'-ACG GCC GCG GTA CTT TGA CC -3' & $66^{\circ} \mathrm{C}$ & \multirow{2}{*}{$450 \mathrm{pb}$} & Este trabajo \\
\hline AYLA2R & 5'-ACC TTC GAA GAC GTC TGC ACC T-3' & $68^{\circ} \mathrm{C}$ & & Este trabajo \\
\hline
\end{tabular}

TEF: Tamaño esperado del producto de amplificación.

Para definir los perfiles térmicos iniciales, se calculó manualmente para cada cebador su temperatura de hibridación o $T m$, de acuerdo a la fórmula: $T m=4(\mathrm{G}+\mathrm{C})+2(\mathrm{~A}+\mathrm{T})$. Para la amplificación de los genes ribosomales, se ensayaron condiciones diversas, entre las que podemos citar: a) diferentes composiciones de mezclas de reacción, introduciendo modificaciones en cuanto a composición y concentración de sus componentes (Tabla IX) y, b) diferentes perfiles térmicos (Tabla X). La combinación de los perfiles y mezclas de reacción ensayados para los diferentes pares de cebadores se presenta en la Tabla XI.

En todos los casos las amplificaciones se realizaron en un termociclador Techne PHC3 Dri-Block ${ }^{\circledR}$ cycler en un volumen final de $50 \mu$ l. Los productos de amplificación fueron verificados electroforéticamente $(5 \mathrm{~V} / \mathrm{cm})$ en geles de agarosa al 1,5\% teñidos con bromuro de etidio $(0,5 \mathrm{mg} / \mathrm{ml})$, utilizando como referencia el marcador $100 \mathrm{pb}$ Ladder (Productos BioLógicos) y fotodocumentados digitalmente como se detalló más arriba.

\section{III.2.4.2 Amplificación del gen Citocromo Oxidasa subunidad I (COI)}

La amplificación parcial del gen COI se realizó utilizando cebadores universales para invertebrados (Folmer et al., 1994) los cuales han sido ampliamente utilizados en estudios de gasterópodos de agua dulce: LCO1490 (5'-GGT CAA CAA ATC ATA AAG ATA TTG G3') y HCO2198 (5'-TAA ACT TCA GGG TGA CCA AAA AAT CA-3'). Su síntesis fue realizada por la empresa Integrated DNA Technologies (IDT) a través de Biodynamics S.R.L. 
Tabla IX. Detalle de la composición de las diferentes mezclas de reacción ensayadas en la amplificación de los genes ribosomales (A-J).

\begin{tabular}{|c|c|c|c|c|c|c|c|c|c|c|}
\hline & $\mathbf{A}$ & B & C & D & $\mathbf{E}$ & $\mathbf{F}$ & G & $\mathbf{H}$ & I & $\mathbf{J}$ \\
\hline Buffer & $\mathrm{SO}_{4}\left(\mathrm{NH}_{4}\right)_{2}[1 \mathrm{X}]^{\mathrm{I}}$ & $\mathrm{SO}_{4}\left(\mathrm{NH}_{4}\right)_{2}[1 \mathrm{X}]^{\mathrm{I}}$ & $\mathrm{SO}_{4}\left(\mathrm{NH}_{4}\right)_{2}[1 \mathrm{X}]^{\mathrm{I}}$ & $\mathrm{SO}_{4}\left(\mathrm{NH}_{4}\right)_{2}[1 \mathrm{X}]^{\mathrm{I}}$ & {$[1 \mathrm{X}]^{\mathrm{II}}$} & {$[1 \mathrm{X}]^{\mathrm{II}}$} & {$[1 \mathrm{X}]^{\mathrm{II}}$} & {$[1 \mathrm{X}]^{\mathrm{II}}$} & {$[1 \mathrm{X}]^{\mathrm{II}}$} & {$[1 \mathrm{X}]^{\mathrm{III}}$} \\
\hline $\mathrm{Cl}_{2} \mathrm{Mg}$ & {$[1,5 \mathrm{mM}]^{\mathrm{I}}$} & {$[1 \mathrm{mM}]^{\mathrm{I}}$} & {$[1,2 \mathrm{mM}]^{\mathrm{I}}$} & {$[1,5 \mathrm{mM}]^{\mathrm{I}}$} & {$[1,5 \mathrm{mM}]^{\mathrm{II}}$} & {$[2,5 \mathrm{mM}]^{\mathrm{II}}$} & {$[1,5 \mathrm{mM}]^{\mathrm{II}}$} & {$[2,5 \mathrm{mM}]^{\mathrm{II}}$} & {$[2 \mathrm{mM}]^{\mathrm{II}}$} & {$[2 \mathrm{mM}]^{\mathrm{III}}$} \\
\hline Mix dNTPs & {$[0,2 \mathrm{mM}]$} & {$[0,2 \mathrm{mM}]$} & {$[0,2 \mathrm{mM}]$} & {$[0,125 \mathrm{mM}]$} & {$[0,2 \mathrm{mM}]$} & {$[0,05 \mathrm{mM}]$} & {$[0,2 \mathrm{mM}]$} & {$[0,2 \mathrm{mM}]$} & {$[0,2 \mathrm{mM}]$} & {$[0,2 \mathrm{mM}]$} \\
\hline Cebador forward & {$[0,5 \mu \mathrm{M}]$} & {$[0,5 \mu \mathrm{M}]$} & {$[0,5 \mu \mathrm{M}]$} & {$[0,5 \mu \mathrm{M}]$} & {$[0,5 \mu \mathrm{M}]$} & {$[0,1 \mu \mathrm{M}]$} & {$[0,5 \mu \mathrm{M}]$} & {$[0,2 \mu \mathrm{M}]$} & {$[0,2 \mu \mathrm{M}]$} & {$[0,5 \mu \mathrm{M}]$} \\
\hline Cebador reverse & {$[0,5 \mu \mathrm{M}]$} & {$[0,5 \mu \mathrm{M}]$} & {$[0,5 \mu \mathrm{M}]$} & {$[0,5 \mu \mathrm{M}]$} & {$[0,5 \mu \mathrm{M}]$} & {$[0,1 \mu \mathrm{M}]$} & {$[0,5 \mu \mathrm{M}]$} & {$[0,2 \mu \mathrm{M}]$} & {$[0,2 \mu \mathrm{M}]$} & {$[0,5 \mu \mathrm{M}]$} \\
\hline Taq Polimerasa & {$[1,5 \mathrm{U}]^{\mathrm{I}}$} & {$[1,5 \mathrm{U}]^{\mathrm{I}}$} & {$[1,5 \mathrm{U}]^{\mathrm{I}}$} & {$[1,5 \mathrm{U}]^{\mathrm{I}}$} & {$[1,5 \mathrm{U}]^{\mathrm{II}}$} & {$[1,2 \mathrm{U}]^{\mathrm{II}}$} & {$[1,5 \mathrm{U}]^{\mathrm{II}}$} & {$[1,2 \mathrm{U}]^{\mathrm{II}}$} & {$[1,2 \mathrm{U}]^{\mathrm{II}}$} & {$[1,25 \mathrm{U}]^{\mathrm{III}}$} \\
\hline Trehalosa & - & - & - & - & - & - & $5 \%(\mathrm{v} / \mathrm{v})$ & - & - & - \\
\hline $\mathrm{ADN}$ & {$[50-100 \mathrm{ng}]$} & {$[50-100 \mathrm{ng}]$} & {$[50-100 \mathrm{ng}]$} & {$[50-100 \mathrm{ng}]$} & [50-100 ng] & {$[50-100 \mathrm{ng}]$} & [50-100 ng] & {$[50-100 \mathrm{ng}]$} & {$[50-100 \mathrm{ng}]$} & {$[50-100 \mathrm{ng}]$} \\
\hline $\mathrm{H} 2 \mathrm{O}$ ultrapura & c.s.p. & c.s.p. & c.s.p. & c.s.p. & c.s.p. & c.s.p. & c.s.p. & c.s.p. & c.s.p. & c.s.p. \\
\hline
\end{tabular}


Tabla X. Detalle de los perfiles térmicos (PT) ensayados en la amplificación de los genes ribosomales.

\begin{tabular}{|c|c|c|c|c|c|c|c|c|c|c|c|}
\hline & PT1 & PT2 & PT3 & PT4 & PT5 & PT6 & PT7 & PT8 & PT9 & PT10 & PT11 \\
\hline Desnaturalización inicial & - & - & - & $94^{\circ} \mathrm{C}\left(1^{\prime}\right)$ & $94^{\circ} \mathrm{C}\left(1^{\prime}\right)$ & $94^{\circ} \mathrm{C}\left(1^{\prime}\right)$ & $94^{\circ} \mathrm{C}\left(1^{\prime}\right)$ & $94^{\circ} \mathrm{C}\left(1^{\prime}\right)$ & $94^{\circ} \mathrm{C}\left(1^{\prime}\right)$ & $95^{\circ} \mathrm{C}\left(3^{\prime}\right)$ & $95^{\circ} \mathrm{C}\left(3^{\prime}\right)$ \\
\hline & $\underline{40 \text { ciclos }}$ & 1 ciclo & 1 ciclo & $\underline{40 \text { ciclos }}$ & $\underline{5 \text { ciclos }}$ & 35 ciclos & $\underline{40 \text { ciclos }}$ & $\underline{40 \text { ciclos }}$ & $\underline{40 \text { ciclos }}$ & $\underline{40 \text { ciclos }}$ & 35 ciclos \\
\hline Desnaturalización & $92^{\circ} \mathrm{C}\left(20^{\prime \prime}\right)$ & $94^{\circ} \mathrm{C}\left(30^{\prime \prime}\right)$ & $94^{\circ} \mathrm{C}\left(3^{\prime}\right)$ & $94^{\circ} \mathrm{C}$ (30") & $94^{\circ} \mathrm{C}\left(30^{\prime \prime}\right)$ & $94^{\circ} \mathrm{C}\left(30^{\prime \prime}\right)$ & $94^{\circ} \mathrm{C}\left(30^{\prime \prime}\right)$ & $94^{\circ} \mathrm{C}\left(30^{\prime \prime}\right)$ & $94^{\circ} \mathrm{C}\left(30^{\prime \prime}\right)$ & $94^{\circ} \mathrm{C}\left(1^{\prime}\right)$ & $95^{\circ} \mathrm{C}\left(30^{\prime \prime}\right)$ \\
\hline Hibridación & $48^{\circ} \mathrm{C}\left(40^{\prime \prime}\right)$ & $48^{\circ} \mathrm{C}\left(40^{\prime \prime}\right)$ & $53^{\circ} \mathrm{C}\left(40^{\prime \prime}\right)$ & $48^{\circ} \mathrm{C}\left(40^{\prime \prime}\right)$ & $45^{\circ} \mathrm{C}\left(40^{\prime \prime}\right)$ & $55^{\circ} \mathrm{C}\left(30^{\prime \prime}\right)$ & $51^{\circ} \mathrm{C}(40 ")$ & $54^{\circ} \mathrm{C}\left(30^{\prime \prime}\right)$ & $55^{\circ} \mathrm{C}\left(30^{\prime \prime}\right)$ & $51^{\circ} \mathrm{C}\left(1^{\prime}\right)$ & $60^{\circ} \mathrm{C}\left(30^{\prime \prime}\right)$ \\
\hline Extensión & $68^{\circ} \mathrm{C}\left(1^{\prime}\right)$ & $72^{\circ} \mathrm{C}\left(1^{\prime}\right)$ & $68^{\circ} \mathrm{C}\left(1^{\prime}\right)$ & $72^{\circ} \mathrm{C}\left(30^{\prime \prime}\right)$ & $72^{\circ} \mathrm{C}\left(1^{\prime}\right)$ & $72^{\circ} \mathrm{C}\left(1^{\prime}\right)$ & $72^{\circ} \mathrm{C}\left(30^{\prime \prime}\right)$ & $72^{\circ} \mathrm{C}\left(1^{\prime}\right)$ & $72^{\circ} \mathrm{C}\left(1^{\prime}\right)$ & $72^{\circ} \mathrm{C}\left(1^{\prime}\right)$ & $72^{\circ} \mathrm{C}\left(1^{\prime}\right)$ \\
\hline Desnaturalización & - & $\frac{39 \text { ciclos }}{92^{\circ} \mathrm{C}\left(20^{\prime \prime}\right)}$ & $\frac{39 \text { ciclos }}{92^{\circ} \mathrm{C}\left(20^{\prime}\right)}$ & - & $\frac{35 \text { ciclos }}{94^{\circ} \mathrm{C}\left(30^{\prime \prime}\right)}$ & - & - & - & - & - & - \\
\hline Hibridación & - & $48^{\circ} \mathrm{C}\left(40^{\prime \prime}\right)$ & $53^{\circ} \mathrm{C}\left(40^{\prime \prime}\right)$ & - & $51^{\circ} \mathrm{C}\left(40^{\prime \prime}\right)$ & - & - & - & - & - & - \\
\hline Extensión & - & $72^{\circ} \mathrm{C}\left(1^{\prime}\right)$ & $68^{\circ} \mathrm{C}\left(1^{\prime}\right)$ & - & $72^{\circ} \mathrm{C}\left(1^{\prime}\right)$ & - & - & - & - & - & - \\
\hline Extensión final & - & - & - & $72^{\circ} \mathrm{C}\left(7^{\prime}\right)$ & $72^{\circ} \mathrm{C}\left(10^{\prime}\right)$ & - & $72^{\circ} \mathrm{C}\left(7^{\prime}\right)$ & - & - & $72^{\circ} \mathrm{C}\left(10^{\prime}\right)$ & $72^{\circ} \mathrm{C}\left(5^{\prime}\right)$ \\
\hline
\end{tabular}


Tabla XI. Resumen de las combinaciones de mezclas de reacción y perfiles térmicos ensayados en la optimización de las reacciones de amplificación de los genes ribosomales.

\begin{tabular}{|c|c|c|c|c|c|c|c|c|c|c|}
\hline & A & B & $\mathrm{C}$ & D & $\mathbf{E}$ & $\mathbf{F}$ & G & H & I & $\mathbf{J}$ \\
\hline PT1 & $\begin{array}{l}16 \mathrm{SF}-16 \mathrm{SR} \\
12 \mathrm{SF}-12 \mathrm{SR}\end{array}$ & $16 \mathrm{SF}-16 \mathrm{SR}$ & $16 \mathrm{SF}-16 \mathrm{SR}$ & - & - & - & - & - & - & - \\
\hline PT2 & $16 \mathrm{SF}-16 \mathrm{SR}$ & - & - & $16 \mathrm{SF}-16 \mathrm{SR}$ & - & - & - & - & - & - \\
\hline PT3 & $16 \mathrm{SF}-16 \mathrm{SR}$ & - & - & - & - & - & - & - & - & - \\
\hline PT4 & - & - & - & - & $\begin{array}{l}16 \mathrm{SF}-16 \mathrm{SR} \\
12 \mathrm{SF}-12 \mathrm{SR}\end{array}$ & - & - & - & - & - \\
\hline PT5 & - & - & - & - & $12 \mathrm{SF}-12 \mathrm{SR}$ & $16 \mathrm{SF}-16 \mathrm{SR}$ & - & - & - & - \\
\hline PT6 & - & - & - & - & $12 \mathrm{SF}-12 \mathrm{SR}$ & - & - & - & - & - \\
\hline PT7 & - & - & - & - & $12 \mathrm{SF}-12 \mathrm{SR}$ & - & - & - & - & - \\
\hline PT8 & - & - & - & - & $12 \mathrm{SF}-12 \mathrm{SR}$ & - & $12 \mathrm{SF}-12 \mathrm{SR}$ & - & - & - \\
\hline PT9 & - & - & - & - & $12 \mathrm{SF}-12 \mathrm{SR}$ & - & - & - & - & - \\
\hline PT10 & - & - & - & - & - & - & - & $\begin{array}{c}\text { 16SAr-16SBr } \\
\text { 12Sai-12Sbi }\end{array}$ & 12Sai-12Sbi & - \\
\hline PT11 & - & - & - & - & - & - & - & - & - & AYLA2F-AYLA2R \\
\hline
\end{tabular}


Dado que esta región se ha estandarizado mundialmente como la región de elección para la obtención de códigos de barras de ADN o DNA barcodes en animales, la mezcla de reacción (Tabla XII) y el perfil de ciclado se ajustaron a partir de los protocolos descriptos por Ivanova \& Grainger (2006) disponibles en la página del Canadian Centre for DNA Barcoding $^{3}$.

En todos los casos las amplificaciones se realizaron en un volumen final de $50 \mu \mathrm{l}$, en el termociclador descrito previamente bajo el siguiente perfil: desnaturalización inicial de $94^{\circ} \mathrm{C}$ durante 1 minuto; 5 ciclos de $94^{\circ} \mathrm{C}$ ( 1 minuto), $45^{\circ} \mathrm{C}$ (40 segundos), $72^{\circ} \mathrm{C}$ (1 minuto); 35 ciclos de $94^{\circ} \mathrm{C}$ (30 segundos), $51{ }^{\circ} \mathrm{C}(40$ segundos $), 72^{\circ} \mathrm{C}$ (1 minuto) y una extensión final de $72^{\circ} \mathrm{C}$ durante 10 minutos. Los amplicones de un tamaño esperado de aproximadamente 700 $\mathrm{pb}$ fueron verificados electroforéticamente como se detalló previamente.

Tabla XII. Composición de la mezcla de reacción utilizada en la amplificación del gen COI.

\begin{tabular}{r|r} 
Componente & CONCENTRACIÓN FINAL \\
Buffer & {$[1 \mathrm{X}]$} \\
$\mathrm{Cl}_{2} \mathrm{Mg}$ & {$[1,5 \mathrm{mM}]$} \\
Mix dNTPs & {$[0,05 \mathrm{mM}]$} \\
Cebador forward & {$[0,1 \mu \mathrm{M}]$} \\
Cebador reverse & {$[0,1 \mu \mathrm{M}]$} \\
Taq Polimerasa* & {$[1,2 \mathrm{U}]$} \\
& {$[50-100 \mathrm{ng}]$} \\
ADN & c.s.p. \\
\hline H2O ultrapura & \\
\hline Platinum & \\
\hline
\end{tabular}

\section{III.2.5 PURIFICACIÓN}

Con el objeto de remover potenciales contaminantes que pudieran interferir durante el proceso de secuenciación se realizó la purificación de los amplicones obtenidos. Para tal efecto se utilizó el kit GFX $X^{T M} P C R D N A$ and Gel Band Purification (GE Healthcare, \#27-

\footnotetext{
${ }^{3} \mathrm{http}: / /$ www.dnabarcoding.ca
} 
9602-01) siguiendo las recomendaciones del fabricante. Este kit puede ser aplicado para purificar productos de PCR tanto a partir de geles de agarosa, como en solución. De esta manera, se procedió a la purificación a partir de productos en solución para aquellos casos donde electroforéticamente se verificó la presencia de una banda única, y a partir del soporte en los casos donde se registró presencia de bandas inespecíficas que podrían interferir con la reacción de secuenciación.

\section{III.2.6 SECUENCIACIÓN}

Los productos de PCR correspondientes a las amplificaciones de los genes ARNr 12S y $16 \mathrm{~S}$, conjuntamente con COI fueron enviados para su secuenciación a MACROGEN Inc, Corea. Los productos fueron secuenciados en ambos sentidos para cada individuo. Los electroferogramas obtenidos se analizaron mediante Chromas Lite 2.01 (Technelysium Pty Ltd.) y Clustal X 2.02 (Larkin et al., 2007) para la obtención de las secuencias consenso. La valoración de la calidad y especificidad de las secuencias se realizó mediante inspección visual, a partir de los valores de calidad (QV scores) provistos por el servicio de secuenciación y por comparación con secuencias depositadas en GenBank mediante el algoritmo BLASTn (Altschul et al., 1990).

\section{III.2.7 ANÁLISIS BIOINFORMÁTICO}

El análisis bioinformático fue realizado sobre las secuencias obtenidas para la región parcial del gen COI y para la totalidad de individuos estudiados. Esta elección estuvo basada en la excelente calidad de los electroferogramas obtenidos, situación que no fue posible reproducir para el caso de las secuencias obtenidas a partir de los genes ribosomales $12 \mathrm{~S} \mathrm{y}$ 16S (mayor detalle en el apartado Resultados). Para los análisis bioinformáticos se confeccionaron dos matrices de datos, una conteniendo únicamente las secuencias de las muestras procedentes del Alto Paraná, y otra incluyendo las secuencias del grupo externo, el cual estuvo constituido por el material de Thiaridae s.l. cedido por el Dr. Pointier: Pachychilus nigratus, P. laevissimus y Doryssa sp.

\section{III.2.7.1 Caracterización de las secuencias a partir de descriptores típicos}

A partir de la matriz de datos conteniendo las secuencias provenientes del Alto Paraná, se realizó un alineamiento múltiple en Clustal X 2.02 (Larkin et al., 2007), con los parámetros por defecto. El contenido informativo del alineamiento múltiple se representó mediante su 
sequence logos a través de Weblogo 2.8.2 (Schneider \& Stephens, 1990; Crooks et al., 2004), para determinar de manera gráfica las posiciones variables y su frecuencia (en bits).

Asimismo, el alineamiento se utilizó para la identificación manual de los haplotipos presentes en la muestra, los cuales fueron caracterizados a partir de aspectos composicionales (cantidad de cada una de las bases, frecuencia relativa, contenido de $\mathrm{G}+\mathrm{C}$ y $\mathrm{A}+\mathrm{T}$ ) mediante BioEdit 7.0.9 (Hall, 1999). Como las secuencias de ADN analizadas codifican secuencias aminoacídicas, la búsqueda de marcos de lectura (ORF, del inglés Open Reading Frame) se realizó utilizando el código genético mitocondrial para invertebrados mediante la herramienta gráfica de análisis en línea ORF Finder ${ }^{4}$.

\section{III.2.7.2 Caracterización de las secuencias a partir de descriptores adicionales}

Las secuencias son moléculas informativas por excelencia; las mismas pueden ser analizadas en búsqueda de particularidades comunes a una colección de secuencias, a través de los llamados descriptores adicionales. Entre éstos se incluyen, por ejemplo, las frecuencias y abundancias relativas di-, tri- o $n$-nucleotídicas y/o las repeticiones nucleotídicas (Ghiringhelli \& Cerrudo, 2007).

En el presente capítulo las secuencias fueron caracterizadas a través de dos descriptores adicionales: a) complejidad de composición local (LCC, del inglés Local Compositional Complexity), y b) asimetrías composicionales.

\section{III.2.7.2.1 Complejidad de composición local}

La complejidad de composición local puede ser definida como una medida numérica de la repetitividad de una secuencia de símbolos a partir de un alfabeto finito, donde secuencias altamente repetidas son consideradas simples, mientras que secuencias no repetidas son consideradas complejas (mayor detalle en Konopka, 2005). Una forma de análisis basada en LCC, consiste en generar un gráfico de complejidad composicional, el cual representa una función que asigna un valor de complejidad a una zona determinada de una secuencia llamada ventana. Al moverse esta ventana a lo largo de la secuencia, es posible obtener una representación gráfica de la secuencia, que aunque con un patrón complejo, se puede analizar de forma más sencilla que la secuencia en bruto (Ghiringhelli \& Cerrudo, 2007). De acuerdo a Konopka \& Owens (1990), el cálculo de complejidad informativa en

\footnotetext{
${ }^{4}$ http://www.ncbi.nlm.nih.gov/gorf/gorf.html
} 
forma local, a partir de ventanas definidas por el usuario, está dado por la ecuación:

$$
\mathrm{LCC}=(1 / L) *\left[\mathrm{~N}^{1} * \log _{4}\left(\mathrm{~N}^{1} / L\right)+\mathrm{N}^{2} * \log _{4}\left(\mathrm{~N}^{2} / L\right)+\mathrm{N}^{3} * \log _{4}\left(\mathrm{~N}^{3} / L\right)+\mathrm{N}^{4} * \log _{4}\left(\mathrm{~N}^{4} / L\right)\right]
$$

Donde $L$ representa la longitud de la ventana, $\mathrm{N}^{1}$ la cantidad de $\mathrm{A}, \mathrm{N}^{2}$ la cantidad de $\mathrm{C}$, $\mathrm{N}^{3}$ la cantidad de $\mathrm{G}, \mathrm{N}^{4}$ la cantidad de T. Los autores utilizan el logaritmo en base 4 para que los resultados sean siempre positivos.

Esta ecuación se encuentra implementada en la rutina computacional CALCLCC (P.D. Ghiringhelli, no publicada), la cual fue empleada para el cálculo de la complejidad informativa de los haplotipos del gen COI provenientes del Alto Paraná, utilizando arbitrariamente una ventana de 21 bases (en lugar de los 51 nucleótidos recomendados en la rutina) para que resultara lo suficientemente informativa, teniendo en cuenta la corta longitud de las secuencias bajo análisis.

\section{III.2.7.2.2 Asimetrías composicionales}

A partir de la comparación de genomas se ha demostrado que las variaciones en el contenido de GC afectan la composición de las proteínas codificadas (Foster et al., 1997). No obstante, en genomas con contenidos de GC comparables pueden, sin embargo, existir diferencias en la distribución de los nucleótidos G y $\mathrm{C}$ entre las dos cadenas de ADN. Esta distribución desigual de nucleótidos entre ambas cadenas es referida en la literatura como asimetría GC (GC skew). De igual modo, secuencias con contenidos similares de AT pueden presentar una distribución asimétrica de A y $\mathrm{T}$ entre cadenas de $\mathrm{ADN}$, la cual es referida como asimetría AT (AT skew) (Min \& Hickey, 2007). Vale aclarar que las asimetrías no afectan al mismo subconjunto de aminoácidos que aquel afectado por la variación en el contenido de GC (mayor detalle en Min \& Hickey, 2007; Wang et al., 2008).

Con el fin de caracterizar la asimetría composicional de los tres haplotipos del Alto Paraná, se realizaron los cálculos de los sesgos en la composición de nucleótidos a partir de la cadena “+” (la hebra codificante usada para la anotación de genes en GenBank). La asimetría se calculó de acuerdo a las ecuaciones de Perna \& Kocher (1995):

$$
\begin{aligned}
& \text { Asimetría } A T=(A-T) /(A+T) \\
& \text { Asimetría } G C=(G-C) /(G+C)
\end{aligned}
$$


El cálculo de las asimetrías fue realizado manualmente a partir de los contenidos de nucleótidos obtenidos en la caracterización de los haplotipos. Asimismo, las secuencias correspondientes a los tres haplotipos fueron analizadas utilizando una estrategia de ventanas mediante las rutinas computacionales STRANDAT-STRANDCG (P.D. Ghiringhelli, no publicadas), que incluyen las ecuaciones antes mencionadas, para elaborar gráficos a partir de los valores numéricos obtenidos. Teniendo en cuenta la longitud total de las secuencias se consideró que una ventana conformada por 50 nucleótidos junto a un desplazamiento de 5 bases sería lo suficientemente informativa.

\section{III.2.7.3 Calidad de los datos}

De acuerdo a Schneider (2007), antes de iniciar el análisis de datos moleculares, se debe verificar la calidad de la información contenida en ella. Existen una serie de pruebas descritas en la literatura que pueden ser agrupadas en dos tipos: i- verificación del nivel de saturación de las secuencias, y ii- verificación de estructura genética o señal filogenética en los datos.

\section{III.2.7.3.1 Verificación de la saturación}

Normalmente, entre dos o más secuencias, la tasa de cambios del tipo transiciones $(\mathrm{A} \leftrightarrow \mathrm{G} ; \mathrm{C} \leftrightarrow \mathrm{T}$ ) es mayor que la del tipo transversiones (A o $\mathrm{G} \leftrightarrow \mathrm{C}$ o $\mathrm{T}$ ). Sin embargo, a medida que aumenta la divergencia genética entre las secuencias, el número de transiciones observadas con relación a las transversiones puede decrecer en función de la saturación. Para verificar esta situación, se puede utilizar un diagrama del número de transiciones y transversiones $v s$. divergencia de las secuencias, el cual proporciona un indicativo del nivel de saturación de las sustituciones (Schneider, 2007). Otra manera de efectuarlo es a partir de pruebas estadísticas, entre las que se destaca la prueba de Xia et al. (2003). En esta prueba se calcula un índice de saturación de sustituciones $\left(\mathrm{I}_{\mathrm{SS}}\right)$ y su valor crítico ( $\left.\mathrm{I}_{\mathrm{SS} . \mathrm{C}}\right)$, a partir del cual las secuencias empezarían a fallar en recuperar la topología verdadera de un árbol filogenético (mayor detalle en Xia \& Lemey, 2009).

La verificación de la saturación de las secuencias del presente trabajo se realizó empleando DAMBE 5.3.8 (Xia \& Xie, 2001), a partir de la prueba de Xia et al. (2003). Adicionalmente, se graficó la distribución de las transiciones y transversiones contra la distancia genética empleando el modelo de sustitución nucleotídica Felsenstein 84 (F84). El 
análisis se corrió en dos oportunidades, difiriendo sólo en la inclusión del grupo externo antes mencionado.

\section{III.2.7.3.2 Verificación de señal filogenética}

La prueba de permutación PTP (del inglés Permutation Tail Probability Test; Archie, 1989) utiliza los puntajes de los árboles más parsimoniosos como una medida de correlación jerárquica. La prueba compara el puntaje del árbol más parsimonioso obtenido a partir de los datos originales, con los puntajes de árboles obtenidos a través de permutaciones al azar. La ausencia de señal filogenética (hipótesis nula) es verdadera cuando el puntaje del árbol más parsimonioso, obtenido de los datos reales, cae dentro de la curva de distribución de los valores obtenidos a través de la permutación al azar de la matriz de datos (Schneider, 2007).

Para verificar la señal filogenética, se realizó el alineamiento múltiple de las secuencias mediante Clustal X 2.02 (Larkin et al., 2007), con los parámetros por defecto, el cual fue optimizado visualmente y editado mediante TextPad 6.1 (Helios Software Solutions). Posteriormente, a partir de esta matriz de datos, se corrió la prueba PTP en PAUP*4.0b10 (Swofford, 2002) utilizando búsqueda heurística y 1.000 permutaciones.

\section{III.2.7.4 Estimación de las distancias genéticas}

Cuando dos secuencias derivan de una secuencia ancestral común, las secuencias descendientes gradualmente divergen por sustituciones de nucleótidos (Nei \& Kumar, 2000). Una medida simple de la cantidad de divergencia está dada por la proporción $(p)$ de sitios nucleotídicos en las cuales ambas secuencias son diferentes. Esta proporción puede ser calculada a partir de la ecuación:

$$
p=n_{d} / \mathrm{n}
$$

Donde $n_{d} y n$ son, respectivamente, el número de nucleótidos diferentes entre las dos secuencias y el número total de nucleótidos examinados. Esta medida de la divergencia entre secuencias es llamada distancia $p$.

Dado que los cambios mutacionales del ADN no necesariamente ocurren de manera azarosa (e.g. en secuencias codificantes los patrones de sustitución en la primera, segunda o tercera posición del codón no son los mismos; Nei \& Kumar, 2000), otra manera de calcular la divergencia entre secuencias es a partir del uso de modelos matemáticos de sustitución de 
nucleótidos. Estos modelos asumen diferentes posibilidades para las sustituciones de nucleótidos, incluyendo por ejemplo tasas transicionales (cambio entre bases púricas i.e. $\mathrm{A} \leftrightarrow \mathrm{G}$, o pirimidinicas i.e. $\mathrm{T} \leftrightarrow \mathrm{C}$ ) y transversionales (purina $\leftrightarrow$ pirimidina). Entre estos modelos se encuentran el de Jukes-Cantor (JC) o el de Kimura dos Parámetros (K2P), por mencionar algunos simples (mayor detalle en Nei \& Kumar, 2000). A partir del uso de modelos de sustitución nucleotídica, es posible calcular distancias genéticas corregidas.

Para el caso de las secuencias obtenidas de individuos procedentes del Alto Paraná, el cálculo de las distancias se realizó mediante la comparación de pares de haplotipos, utilizando en primera instancia la distancia $p$, y posteriormente los siguientes modelos de sustitución nucleotídica: Jukes-Cantor (JC), Kimura dos Parámetros (K2P), Tajima \& Nei (TN84), F84 y Tamura \& Nei (TN93). Los cálculos de las distancias fueron ejecutados en DAMBE 5.3.8 (Xia \& Xie, 2001).

\section{III.2.7.5 Parámetros genético-poblacionales}

\section{III.2.7.5.1 Variabilidad genética}

La variabilidad genética de las secuencias obtenidas a partir de los individuos procedentes del Alto Paraná se caracterizó a través del cálculo de tres índices en el programa DnaSP v5.10 (Librado \& Rozas, 2009): diversidad haplotípica, diversidad nucleotídica y estimador de Watterson. La diversidad haplotípica $\left(\mathrm{H}_{\mathrm{D}}\right)$ considera la probabilidad de que dos haplotipos elegidos al azar en una población sean diferentes (Nei, 1987). La diversidad nucleotídica ( $\mathrm{pi}, \pi$ ) computa el número promedio de diferencias nucleotídicas por sitio entre dos secuencias elegidas al azar (Nei \& Li, 1979). El estimador de Watterson (teta, $\theta$ ) da cuenta del número de sitios segregantes (= polimórficos) en una muestra de secuencias por sitio (Watterson, 1975).

\section{III.2.7.5.2 Análisis demográfico}

Durante décadas la genética de poblaciones se ha ocupado del problema de cuantificar la contribución relativa de la selección natural en el modelado de la variación genética observada entre los organismos vivos (Nielsen, 2005). Para la Teoría Neutral de Evolución Molecular la mayor parte de la variación molecular dentro y entre las especies es selectivamente neutral, i.e. no afecta la aptitud de los organismos (Kimura, 1968, 1983; Nei et al., 2010). Así, el destino evolutivo de esta variación en la población puede ser explicado 
adecuadamente a través de factores estocásticos, aun cuando no proporcionan ninguna ventaja a la aptitud de sus portadores. En este contexto, el proceso por el cual cambian las frecuencias alélicas en las poblaciones debido a factores aleatorios es referido como deriva genética. Una segunda Teoría, la Seleccionista, sostiene que una gran proporción de la variación observada si afecta la aptitud de los organismos y está sujeta a selección Darwiniana (Gillespie, 1991).

Suponiendo un modelo poblacional clásico con dos alelos $A$ y $a$, se habla de selección si la aptitud (W) de los tres posible genotipos $\left(\mathrm{W}_{\mathrm{AA}}, \mathrm{W}_{\mathrm{Aa}}, \mathrm{W}_{\mathrm{aa}}\right)$ no es igual. Ejemplo de ello serían: $\mathrm{W}_{\mathrm{AA}}>\mathrm{W}_{\mathrm{Aa}}>\mathrm{W}_{\mathrm{aa}} ; \mathrm{W}_{\mathrm{AA}}<\mathrm{W}_{\mathrm{Aa}}<\mathrm{W}_{\mathrm{aa}} \mathrm{O} \mathrm{W}_{\mathrm{AA}}<\mathrm{W}_{\mathrm{Aa}}>\mathrm{W}_{\text {aa. }}$. En organismos haploides, se habla de selección si $\mathrm{W}_{\mathrm{A}} \neq \mathrm{W}_{\mathrm{a}}$. Contrariamente, si una nueva mutación no afecta la aptitud del individuo en el que surge $\left(\mathrm{W}_{\mathrm{AA}}=\mathrm{W}_{\mathrm{Aa}}=\mathrm{W}_{\mathrm{aa}}\right.$; en el caso de haploides $\left.\mathrm{W}_{\mathrm{A}}=\mathrm{W}_{\mathrm{a}}\right)$, se dice que es neutra. En términos generales, la neutralidad describe la condición donde los loci en consideración no se ven afectados por la selección (Nielsen, 2005). Un método estadístico destinado a rechazar un modelo de evolución neutral es denominado prueba de neutralidad (Nielsen, 2005). Al presente, un número creciente de pruebas de neutralidad han sido desarrolladas y se ha demostrado que los desvíos de la hipótesis nula no sólo pueden ser consecuencia de selección sino también de eventos demográficos, dado que los cambios de tamaño poblacional pueden dejar huellas particulares que podrían, eventualmente, ser detectadas (Ramírez-Soriano et al., 2008).

Existen varios estimadores frecuentemente utilizados en filogeografía para detectar huellas de posibles eventos demográficos, entre ellos las pruebas de neutralidad de Tajima (D $\mathrm{D}_{T}$; Tajima, 1989), Fu ( $F_{S} ; \mathrm{Fu}$ 1997). $\mathrm{R}_{2}$ (Ramos-Onsis \& Rozas, 2002) y el análisis de distribución de discrepancias pareadas (pairwise mismatch distribution, Rogers \& Harpending, 1992; Ramos-Onsis \& Rozas, 2002; Ramírez-Soriano et al., 2008).

\section{III.2.7.5.2.1 Prueba de Tajima (Tajima, 1989)}

Se basa en la detección de las diferencias entre los estimadores $\pi$ y $\theta$ con la determinación de la $\mathrm{D}$ de Tajima, calculada a partir de la siguiente ecuación:

$$
D=\frac{\pi-\theta}{\sqrt{\operatorname{Var}(\pi-\theta)}}
$$

Si $\mathrm{D}_{T}$ es igual a cero, no existe diferencia alguna entre ambos estimadores indicando evolución neutral (Tajima, 1989). Los valores negativos de $\mathrm{D}_{T}$ sugieren un exceso de 
variantes de baja frecuencia o alelos raros y son comúnmente interpretados como evidencia de barrido selectivo reciente, selección purificadora, migración, expansión poblacional, o cuello de botella severo (Schmidt \& Pool, 2002; Pool \& Aquadro, 2006). Contrariamente, valores positivos indican un exceso de variantes intermedias y son interpretados como evidencia de alguna forma de selección equilibradora, reducción poblacional, subdivisión poblacional, cuello de botella reciente o migración (Schmidt \& Pool, 2002).

En el presente trabajo el cálculo de la prueba de Tajima se realizó mediante DNAsp 5.10 (Librado \& Rozas, 2009). La significancia estadística de la D de Tajima se obtuvo en este programa a partir del método analítico original de Tajima (1989) y utilizando simulaciones coalescentes (5.000 réplicas) basándose en el número de sitios segregantes $(S)$. A partir de estas simulaciones, se obtuvo el intervalo de confianza del 95\% para el valor de $\mathrm{D}_{T}$.

\section{III.2.7.5.2.2 Prueba $F_{S}$ de Fu (Fu, 1997)}

Fu (1997) propuso un estadístico que se basa en la probabilidad de observar una muestra al azar con un número de alelos igual o menor que el valor observado de $\pi$, bajo la suposición de que todos los alelos son selectivamente neutrales. Es decir, se evalúa la probabilidad de observar no menos de $k$ haplotipos en una muestra de $n$ secuencias dado un cierto valor de $\theta$, estimado a través de $\pi$. Si se denomina a esta probabilidad $\hat{\mathrm{S}}$, entonces:

$$
\mathrm{F}_{\mathrm{S}}=\left(\frac{\hat{\mathrm{S}}}{1-\hat{\mathrm{S}}}\right)
$$

Un valor negativo de $\mathrm{F}_{\mathrm{S}}$ indica un número de alelos raros excesivo, y es interpretado como evidencia de expansión poblacional (e.g. Pilkington et al., 2008) o selección, mientras que valores positivos sugieren poblaciones estables (Bell et al., 2010). Simulaciones realizadas por $\mathrm{Fu}$, sugieren que el estimador $\mathrm{F}_{\mathrm{S}}$ es más sensible a la expansión poblacional y hitchhiking que la prueba de Tajima. Asimismo y a partir de simulaciones se demostró que $\mathrm{F}_{\mathrm{S}}$ debe ser considerado como significativo si $p<0,02$.

El cálculo de la prueba $\mathrm{F}_{\mathrm{S}}$ de $\mathrm{Fu}$, en el presente trabajo, se realizó mediante DNAsp 5.10 (Librado \& Rozas, 2009). La significancia estadística se obtuvo utilizando simulaciones coalescentes (5.000 réplicas) sobre la base del número de sitios segregantes $(S)$. 


\section{III.2.7.5.2.3 Prueba $R_{2}($ Ramos Onsis \& Rozas, 2002)}

Esta prueba fue desarrollada por Ramos Onsis \& Rozas (2002), y se basa en la diferencia entre el número de mutaciones únicas y el promedio de las diferencias de nucleótidos. La misma se utiliza para detectar un escenario demográfico de expansión poblacional severa y reciente (indicado por un valor significativamente bajo de $R_{2}$ ).

La prueba se define como:

$$
=\underline{\left(\sum_{=1}(-\overline{2})^{2} /\right)^{1 / 2}}
$$

Donde $n$ es el tamaño de la muestra, $S$ es el número total de sitios segregantes, $k$ es el promedio de diferencias de nucleótidos entre dos secuencias, y $U i$ es el número de mutaciones únicas en la secuencia $i$.

El cálculo de la prueba de $R_{2}$ para las secuencias analizadas en el presente trabajo se realizó mediante DNAsp 5.10 (Librado \& Rozas, 2009) a partir del número de diferencias pareadas, asumiendo un tamaño poblacional constante. La significación estadística de $R_{2}$ se obtuvo mediante simulaciones coalescentes (5.000 réplicas) sobre la base del número de sitios segregantes $(S)$.

\section{III.2.7.5.2.4 Distribución de discrepancias pareadas o pairwise mismatch distribution (Rogers \& Harpending, 1992)}

Las distribuciones de discrepancias pareadas o mistmatch distributions son histogramas que muestran el patrón de diferencias de nucleótidos entre pares de individuos en una muestra (Harpending, 1994; Rogers et al., 1996). Rogers \& Harpending (1992) describieron los efectos del crecimiento poblacional en la distribución de las discrepancias genéticas pareadas de muestras de $\mathrm{ADN}$ no recombinante, demostrando que los eventos demográficos dejan una impronta en esta distribución. Diversos estudios han demostrado que en aquellos casos donde las poblaciones han experimentado un crecimiento poblacional reciente, se espera una distribución unimodal de las discrepancias pareadas (con el pico de frecuencias del lado de pocas discrepancias), mientras que para aquellas poblaciones que se encuentran en equilibrio demográfico (tamaño estable) o que están declinando se espera una 
distribución multimodal (Rogers \& Harpending, 1992; Rogers et al., 1996).

Para las secuencias obtenidas de los individuos procedentes del Alto Paraná, la representación gráfica de la distribución de las discrepancias pareadas observadas respecto de los valores esperados, se obtuvo en DNAsp 5.10 (Librado \& Rozas, 2009), siguiendo la propuesta de Rozas (2009): en primer lugar se asumió un tamaño poblacional constante para estimar parámetros poblacionales, los cuales fueron posteriormente utilizados para el cálculo de las discrepancias pareadas bajo la suposición de crecimiento-decrecimiento poblacional (Slatkin \& Hudson, 1991; Rogers \& Harpending, 1992).

Adicionalmente, la distribución de las discrepancias pareadas fue calculada con el programa Arlequin 3.5.1.3 (Excoffier \& Lischer, 2010), el cual permite evaluar la hipótesis de expansión poblacional bajo los modelos de expansión súbita reciente y expansión espacial (Zainudin et al., 2010). Para ambas hipótesis se estimó el índice de raggedness de Harpending (Hri; Harpending, 1994) a partir de 1.000 réplicas de bootstrap (Felsenstein, 1985). Un valor significativo de este índice $(p<0,05)$ es tomado usualmente como evidencia para rechazar expansión poblacional, permitiendo distinguir así entre poblaciones de tamaño constante y aquellas bajo expansión (Santos et al., 2011).

En todos los casos los cálculos fueron realizados de dos maneras: 1) abordando $A$. chloroticum como un todo, sin discriminar las localidades (atendiendo así la falta de variación genética de gran parte de los registros geográficos de la especie), y 2) incluyendo al nuevo morfotipo como parte de A. chloroticum.

\section{III.2.7.6 Distribución espacial de la variabilidad genética}

En la actualidad existen numerosos métodos estadísticos disponibles para medir el grado de diferenciación espacial, los patrones espaciales de variación genética, y el significado de la variación entre las poblaciones. La medición de los patrones espaciales tiene una amplia gama de aplicaciones para probar hipótesis tales como si la variación genética se encuentra idénticamente distribuida entre las poblaciones o si por el contrario existe aislamiento genético a consecuencia de la distancia geográfica, entre otros muchos procesos (Epperson, 2003). A continuación se detallan algunos de estos métodos utilizados en el presente trabajo para entender cómo está distribuida la variación genética en el material de estudio y evaluar la existencia de asociación entre distancia genética y distancia geográfica en 
las poblaciones analizadas.

\section{III.2.7.6.1 Análisis de la varianza molecular (AMOVA)}

El análisis de la varianza molecular o AMOVA (del inglés Analysis of Molecular Variance) es un procedimiento estadístico que permite un particionamiento jerárquico de la variación genética entre poblaciones y regiones (Peakall \& Smouse, 2009a) así como la estimación de los estadísticos $F$ (y/o sus análogos los estadísticos $\Phi$ ) ampliamente utilizados en genética de poblaciones (Excoffier et al., 1992). Los estadísticos $F$ (i.e. $F_{I S}, F_{I T}, F_{S T}$ ) fueron presentados primeramente por Wright (1951) como una manera de describir la estructura genética poblacional en organismos diploides (Avise, 2004). En la actualidad estos estadísticos son ampliamente utilizados para caracterizar la estructura genética de las poblaciones y existen numerosas aproximaciones matemáticas (e.g. Nei, 1973, 1977; Weir \& Cockerham, 1984) para su cálculo a partir de diversos datos empíricos.

En términos generales, en un AMOVA la variación genética se descompone en los siguientes niveles jerárquicos:

$\Phi_{\mathrm{CT}}$ : diferenciación genética entre regiones (grupos) en relación con la población total.

$\Phi_{\mathrm{SC}}$ : diferenciación genética entre poblaciones dentro de las regiones (grupos).

$\Phi_{\mathrm{ST}}$ : diferenciación entre los individuos dentro de las poblaciones.

Vale aclarar que los valores de los estadísticos $\Phi$ en el AMOVA son variables aleatorias y pueden tomar tanto valores positivos como negativos, caso este último en el que deben ser interpretados como 0 (Tzeng et al., 2004).

En cualquiera de los niveles, es importante tener en cuenta cuales son las hipótesis evaluadas, siendo $\mathrm{H}_{0}=$ ausencia de diferencias genéticas (e.g. $\left.\Phi_{\mathrm{ST}}=0\right)$ y $\mathrm{H}_{1}=$ diferenciación genética (e.g. $\left.\Phi_{\mathrm{ST}}>0\right)$. Así, para un AMOVA si se definieran en principio varias subpoblaciones (e.g. por localidades geográficas) sin considerar regionalización, la hipótesis nula será que las subpoblaciones pueden ser consideradas como parte de una gran población genética. De ser verdadera la $\mathrm{H}_{0}$, cualquier grupo subpoblacional definido será arbitrario y representará meramente una muestra del pool génico, por lo que se encontrarán pocas diferencias genéticas entre las subpoblaciones arbitrarias (Peakall \& Smouse, 2009a). Al aleatorizar las muestras para el conjunto de datos y calcular el AMOVA para cada 
aleatorización, se obtienen valores cercanos a los esperados por azar. Al realizar múltiples aleatorizaciones se puede obtener una buena estimación del valor esperado si la $\mathrm{H}_{0}$ fuera cierta y es la razón por la que la significancia estadística del AMOVA es evaluada mediante permutaciones al azar (Peakall \& Smouse, 2009a).

La existencia de estructuración genética entre poblaciones de Aylacostoma se infirió mediante un AMOVA realizado en el programa Arlequin 3.5.1.3 (Excoffier \& Lischer, 2010). Este análisis se corrió primeramente para las poblaciones de A. chloroticum $(\mathrm{n}=6)$, y posteriormente incorporando y tratando al nuevo morfotipo como parte de A. chloroticum ( $\mathrm{n}=$ 7). En ambos casos, se realizó una comparación pareada entre todas las poblaciones (localidades geográficas) utilizando el estadístico $\Phi_{\mathrm{ST}}$ a los efectos de determinar las poblaciones con mayor diferenciación genética. Finalmente, se realizó un análisis considerando tres niveles jerárquicos: entre regiones $\left(\Phi_{\mathrm{CT}}\right)$, entre las poblaciones dentro de las regiones $\left(\Phi_{\mathrm{SC}}\right)$ y dentro de las poblaciones $\left(\Phi_{\mathrm{ST}}\right)$, utilizando como criterio de regionalización el canal principal del Río Paraná, agrupando así las poblaciones de Argentina separadamente de las de Paraguay. En todos los casos la significancia estadística se evaluó utilizando 16.000 permutaciones (Guo \& Thompson, 1992).

\section{III.2.7.6.2 Prueba de Mantel}

Dada una escala geográfica amplia, la ausencia de diferenciación genética entre las poblaciones a lo largo de la geografía es bastante improbable y en su lugar, frecuentemente se espera encontrar una correlación positiva entre la distancia genética y la geográfica, i.e. aislamiento por distancia (Peakall \& Smouse, 2009b). Entre las herramientas estadísticas para probar esta hipótesis, se puede citar la prueba de correspondencias de Mantel, la cual permite evaluar la relación estadística entre los elementos de dos matrices de distancia con entradas coincidentes (Mantel, 1967). Este método obtiene un coeficiente de correlación para las dos matrices de datos (con un rango de $-1 \mathrm{a}+1$ ), cuya significancia es evaluada mediante permutaciones al azar (Miller, 2005).

En el caso de la prueba de Mantel las hipótesis nula $\left(\mathrm{H}_{0}\right)$ y alternativa $\left(\mathrm{H}_{1}\right)$ son:

$\mathrm{H}_{0}=$ Inexistencia de relación entre los elementos de las matrices $\mathrm{X}$ e $\mathrm{Y}\left(r_{\mathrm{xy}}=0\right)$

$\mathrm{H}_{1}=$ Existencia de relación entre los elementos de las matrices X e Y $\left(\mathrm{r}_{\mathrm{xy}}>0\right)$; la relación puede ser tanto positiva como negativa. 
Si la hipótesis nula es cierta, se deduce que al aleatorizar los datos $\mathrm{Y}$, manteniendo $\mathrm{X}$ sin cambios, $\mathrm{y}$ al recalcular el estadístico de Mantel $\mathrm{r}_{\mathrm{xy}}$ se debería obtener un $\mathrm{r}_{\mathrm{xy}}$ cercano a 0 (como cabría esperar por azar bajo la hipótesis nula). Al realizar múltiples aleatorizaciones se obtiene la estimación del valor esperado si la hipótesis nula fuera cierta, por lo que si el valor observado es mayor que los valores permutados el 95\% de las veces o más, el resultado se declara significativo al nivel del 5\%. En otras palabras, si existe una relación significativa entre los dos conjuntos de datos el valor de correlación observado será más extremo (más cercano a +1 o -1 ) que los valores generados por permutación al azar, por lo menos el 5\% de las veces (Peakall \& Smouse, 2009b).

Considerando que entre las localidades muestreadas la de Apipé es la más distante geográficamente del resto de las poblaciones (ver distribución en el capítulo anterior), se realizó un análisis de correlación entre las distancias genéticas y geográficas por medio de la prueba de Mantel implementada en el programa Alleles In Space (Miller, 2005) a los efectos de verificar la hipótesis de aislamiento por distancia para A. chloroticum. Ambas distancias fueron computadas a partir de las opciones incluidas en el programa. Para el cálculo de las distancias geográficas las coordenadas de las localidades fueron previamente convertidas al sistema de coordenadas UTM (Universal Transverse Mercator) mediante un conversor de coordenadas disponible on line ${ }^{5}$. El cálculo de la distancia genética en este análisis fue computado a partir de la proporción de diferencias pareadas entre las secuencias. Al igual que en el AMOVA, este análisis se corrió primeramente para A. chloroticum, y posteriormente incorporando y tratando al nuevo morfotipo como parte de A. chloroticum.

\section{III.2.7.7 Abordajes filogenéticos}

\section{III.2.7.7.1 Árboles filogenéticos}

Antes del advenimiento de las tecnologías de análisis molecular, los árboles filogenéticos se utilizaban casi exclusivamente para describir las relaciones entre especies en sistemática y taxonomía. Sin embargo, en la actualidad las filogenias se utilizan en casi todas las ramas de la biología. Además de representar las relaciones entre las especies en el árbol de la vida, las filogenias se utilizan por ejemplo para describir la historia de las poblaciones, la dinámica evolutiva-epidemiológica de patógenos y la evolución del lenguaje, por citar algunas de sus numerosas aplicaciones (Yang \& Rannala, 2012).

\footnotetext{
${ }^{5} \mathrm{http} / /$ www.atlascajamarca.info/conversor/
} 
Una filogenia puede ser representada gráficamente como un árbol que contiene nodos conectados por ramas. Cada rama representa la persistencia de un linaje genético a través del tiempo, y cada nodo representa el nacimiento de un nuevo linaje. La interpretación del árbol depende del contexto en el que es analizado. Así, por ejemplo, el árbol puede representar la relación entre un grupo de especies, donde los nodos entonces constituyen eventos de especiación; en cambio, en un árbol de genes construido a partir de secuencias obtenidas de individuos pertenecientes a una población, los nodos representarán eventos de nacimiento de individuos ancestrales a la muestra (Yang \& Rannala, 2012).

Existen varias formas en que la filogenia puede ser reconstruida a partir de datos genéticos, pero la mayoría puede ser enmarcado dentro de una de las siguientes cuatro categorías de métodos: distancia, parsimonia, verosimilitud (likelihood) e Inferencia Bayesiana (Freeland, 2005).

Los métodos de distancia están basados en las distancias evolutivas entre todos los pares de taxa analizados. Estas métricas pueden ser calculadas a partir de la diferencia de nucleótidos si los datos son secuencias de ADN, o a partir de estimadores basados en frecuencias alélicas si los datos provienen de marcadores moleculares tales como alozimas o microsatélites (Freeland, 2005). Existen diversos algoritmos que pueden ser empleados para reconstruir árboles a partir de la distancia genética, de los cuales el más comúnmente empleado es el método de Neighbour Joining (NJ), también referido como método de agrupamiento de vecinos (sensu Schneider, 2007). Este método fue desarrollado por Saitou \& Nei (1987) y se basa en el principio de evolución mínima (i.e. el mejor árbol es aquél que minimiza la longitud total del árbol). El método no examina todas las topologías posibles, sino que busca encontrar secuencialmente "vecinos" que minimicen la longitud total del árbol (Schneider, 2007). Entre las fortalezas del método de NJ se resalta su eficiencia computacional, dado que el algoritmo es extremadamente rápido. Entre sus debilidades se destaca el mal desempeño frente a grados de divergencia elevados (Yang \& Rannala, 2012).

Un árbol de Máxima Parsimonia (MP) es aquel que contiene el menor número de pasos posibles, en otras palabras el menor número de mutaciones que puedan explicar la distribución de los linajes en el árbol (Fitch, 1971). El fundamento filosófico del método se encuentra en la Navaja de Ockham, principio propuesto por William de Ockham en el siglo $\mathrm{XIV}$, que afirma que la mejor hipótesis para explicar un proceso es la que requiere la menor 
cantidad de supuestos (Freeland, 2005). El método se basa en el principio de homología, por lo que si dos taxa comparten una característica se asume que esta fue heredada del último ancestro común de ambos (Schneider, 2007). Una fortaleza de la parsimonia es su simplicidad, por cuanto facilita su comprensión y simultáneamente es plausible de un análisis matemático riguroso. Entre las debilidades se destacan la falta de supuestos explícitos, que hacen que sea casi imposible incorporar ningún conocimiento del proceso de evolución de secuencias en la reconstrucción del árbol (Yang \& Rannala, 2012).

La tercera y cuarta categorías de análisis filogenético incluyen los llamados métodos estadísticos: Máxima Verosimilitud (ML, del inglés Maximum Likelihood) e Inferencia Bayesiana (IB). Ambos métodos están basados en modelos específicos de evolución molecular (Peña, 2011). Los modelos son típicamente complejos, e incluyen por ejemplo diferentes tasas de transiciones y transversiones y heterogeneidad en las tasas de sustitución en una determinada fracción de la secuencia de ADN (Freeland, 2005).

Bajo el enfoque probabilístico de likelihood, se examina qué tan bien un árbol explica los datos observados. El likelihood es la probabilidad condicional de obtener los datos observados dado un árbol si fuera verdadero (Felsenstein, 1981), lo cual puede resumirse como:

\section{$\operatorname{Pr}[$ Datos $\mid$ Árbol]}

Entonces, una vez que se establecen los supuestos, ML determina la probabilidad de que un árbol en particular sea el mejor representante del conjunto de datos, a partir del cálculo del likelihood de cada árbol filogenético posible dentro del modelo evolutivo especificado (Felsenstein, 1981).

Contrariamente, en un enfoque Bayesiano se maximiza la probabilidad de que un árbol en particular sea el correcto dado un modelo evolutivo más los datos objeto de análisis (Huelsenbeck et al., 2001; Freeland, 2005). La Inferencia Bayesiana está basada en una cantidad denominada probabilidad a posteriori de un árbol, donde se utiliza el Teorema de Bayes para combinar la probabilidad a priori de una filogenia (Pr [Árbol]) con el likelihood (Pr [Datos | Árbol]) para producir una distribución de probabilidades a posteriori sobre los árboles (Pr [Árbol | Datos]), según la siguiente ecuación:

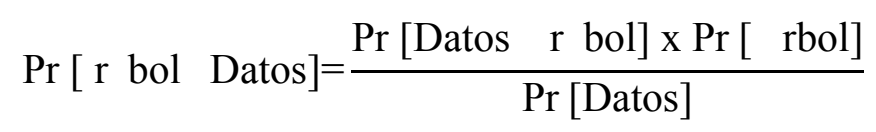


La probabilidad a posteriori de un árbol puede ser interpretada como la probabilidad de que un árbol sea correcto o cuántas veces es más probable que lo sea (Huelsenbeck et al., 2001).

Tanto ML como IB utilizan la función de likelihood, por consiguiente ambos métodos comparten muchas propiedades estadísticas. Sin embargo, ambos métodos representan filosofías opuestas de la inferencia estadística (Yang \& Rannala, 2012). Una ventaja del método de ML es que todas las suposiciones de su modelo son explícitas, por lo que pueden ser evaluadas y mejoradas. Asimismo, la disponibilidad de un amplio repertorio de modelos evolutivos sofisticados en el ML (y en IB) es una de sus grandes ventajas frente a MP. El principal inconveniente de ML es que el cálculo del likelihood y, en particular la búsqueda del árbol bajo el criterio de likelihood es computacionalmente exigente. Otro inconveniente es que el método tiene propiedades estadísticas potencialmente pobres si el modelo de evolución está mal especificado, lo cual es también cierto para IB.

Para el material procedente del Alto Paraná, la reconstrucción filogenética se realizó como se describe: el alineamiento múltiple de las secuencias fue realizado mediante Clustal X 2.02 (Larkin et al., 2007), con los parámetros por defecto, el cual fue optimizado visualmente y editado mediante un procesador de textos. La longitud total de la matriz fue de $658 \mathrm{pb}$. Posteriormente, los datos fueron sometidos a cuatro análisis filogenéticos empleando: Distancia, Máxima Parsimonia, Máxima Verosimilitud e Inferencia Bayesiana. Los análisis fueron realizados con MEGA 5.05 (Tamura et al., 2011) para el análisis de distancia y PAUP*4.0b10 (Swofford, 2002) para el análisis de MP. El análisis de ML se realizó utilizando el programa PhyML 3.0 (Guindon \& Gascuel, 2003) disponible en el servidor público Phylemon $2^{6}$ (Sánchez et al., 2011). El análisis de IB fue realizado con Mr. Bayes 3.2 (Ronquist et al., 2012). El grupo externo para los diferentes abordajes estuvo constituido por Pachychilus nigratus, P. laevissimus y Doryssa sp. Los árboles fueron editados en TreeGraph 2 (Stöver \& Müller, 2010).

\section{III.2.7.7.1.1 Análisis de distancia}

El análisis de distancia se realizó mediante el algoritmo de Neighbor-Joining (Saitou \& Nei, 1987) empleando el modelo Maximum Composite Likelihood (Tamura et al., 2004)

\footnotetext{
${ }^{6} \mathrm{http} / / /$ phylemon.bioinfo.cipf.es
} 
para el cálculo de las distancias evolutivas. Los valores de confiabilidad de los nodos se obtuvieron mediante bootstrapping (Felsenstein, 1985) basado en 1.000 réplicas.

\section{III.2.7.7.1.2 Análisis de parsimonia}

El análisis de MP se realizó mediante una búsqueda heurística, utilizando parsimonia de Fitch (Fitch, 1971). En este análisis, los caracteres fueron tratados como "no ordenados" (unordered characters) con iguales "pesos" (equal weights). La búsqueda heurística fue realizada con el algoritmo de construcción de árboles TBR (tree bisection and reconnection branch swapping), obteniendo el árbol inicial a través de adición secuencial (stepwise addition). La adición secuencial de los taxa se realizó al azar con 10 réplicas. La optimización del estado de los caracteres se realizó mediante ACCTRAN y el soporte estadístico para los nodos inferidos fue obtenido por bootstrapping (Felsenstein, 1985) basado en 1.000 réplicas.

\section{III.2.7.7.1.3 Análisis de Máxima Verosimilitud o Maximum Likelihood}

Para el análisis de ML, el modelo óptimo de sustitución nucleotídica fue evaluado mediante el test LR (Likelihood Ratio) y seleccionado según un Criterio de Información de Akaike corregido (AICc) con Jmodeltest 0.1.1 (Posada, 2008). La topología de ML fue obtenida en PhyML (Guindon \& Gascuel, 2003) después de una búsqueda heurística. Los valores de bootstrap (Felsenstein, 1985) fueron obtenidos utilizando 100 réplicas.

\section{III.2.7.7.1.4 Análisis de Inferencia Bayesiana}

El análisis de IB fue realizado mediante dos corridas simultáneas con 4 cadenas de Markov, que fueron corridas por $10^{6}$ generaciones, con una frecuencia de muestreo cada 100 generaciones. Las salidas fueron evaluadas en Tracer 1.5.0 (Rambaut \& Drummond, 2009), determinándose un burnin de 100.000 generaciones, por lo cual el consenso final estuvo basado en 18.000 árboles. El valor de soporte de nodos fue expresado como probabilidad $a$ posteriori (credibilidad).

\section{III.2.7.7.2 Red de haplotipos}

En los estudios donde se explora la variación en secuencias de ADN a nivel intraespecífico, otro tipo de representación gráfica diferente a los árboles filogenéticos son las redes de haplotipos, también llamadas networks (Mardulyn, 2012). Una red de haplotipos es 
una generalización de árboles filogenéticos que permite la representación de varios árboles simultáneamente en un único diagrama (Eslahchi et al., 2010), que a menudo representan las relaciones entre las secuencias más claramente que los árboles, en parte porque no limitan las conexiones al modo de visualización lineal y bifurcante que se utiliza en los árboles (Posada \& Crandall, 2001). Las redes tienen la ventaja, respecto de los árboles, que en ellas se muestra el número de cambios de bases entre las secuencias (Teacher \& Griffiths, 2012). Actualmente existen diversos algoritmos para la construcción de redes de haplotipos (Cassens et al., 2005; Makarenkov et al., 2006), pero en todos los casos una red está constituida básicamente de nodos y sus conexiones. Los nodos representan las secuencias analizadas o bien secuencias hipotéticas requeridas para conectar las secuencias analizadas (vectores medios), y las conexiones representan las diferencias mutacionales entre los nodos.

Para evidenciar las relaciones genealógicas entre los haplotipos hallados en las poblaciones provenientes del Alto Paraná se construyó una red de haplotipos mediante el algoritmo "median joining network" implementado en el programa Network 4.6 (Bandelt et al., 1999) con las opciones por defecto.

\section{III.2.7.8 Estimación de tiempos de divergencia}

\section{III.2.7.8.1 Evaluación del reloj molecular}

Dado que en muchos casos los genes o linajes parecen no estar de acuerdo con la hipótesis del reloj molecular, para poder estimar tiempos de divergencia es fundamental verificar primeramente si las secuencias de ADN están evolucionando de acuerdo con esta hipótesis (Schneider, 2007). Existen varias pruebas para ello (Wilke et al., 2009; Battistuzzi et al., 2011), dos de las cuales fueron aplicadas a las secuencias halladas en la muestras derivadas del Alto Paraná.

\section{III.2.7.8.1.1 Prueba de razón de verosimilitud global (Global likelihood ratio test)}

Como la hipótesis del reloj molecular asume que las tasas de sustitución entre las ramas de una filogenia son homogéneas, es factible aplicar una prueba de razón de verosimilitud (del inglés Likelihood Ratio -LR- o Likelihood Ratio Test -LRT-) para comparar valores generados por un análisis de máxima verosimilitud (ML) en dos situaciones diferentes, relajando y forzando el reloj molecular. Los modelos de sustitución, en ambos casos, serán los mismos difiriendo sólo en la opción del reloj molecular (Schneider, 2007). 
Así, dado un árbol filogenético de secuencias y un modelo de sustitución nucleotídica, se computa el likelihood asociado al árbol. Esto se realiza independientemente para cada sitio, y requiere sumar todos los posibles estados ancestrales (desconocidos) en los nodos internos del árbol. Posteriormente, el likelihood promedio del árbol es obtenido, bajo la suposición de sitios independientes, al multiplicar el likelihood (o, equivalentemente, sumando los loglikelihood) para todos los sitios (Battistuzzi et al., 2011). Este cálculo se realiza dos veces, permitiendo diferentes tasas entre las ramas del árbol y bajo la suposición de tasa constante, indistintamente de cual se compute primero. Finalmente, se calcula el LR, que sigue aproximadamente una distribución de $\chi$-cuadrado con $m$ (número de taxa en la filogenia) menos dos grados de libertad (Felsenstein, 1981), de acuerdo a la siguiente fórmula:

$$
L R=2\left|\ln L-\ln L_{C}\right|
$$

Donde $L_{C}$ representa el valor obtenido para la hipótesis nula bajo la suposición de tasa constante (i.e. reloj forzado) y $L$ el valor de likelihood bajo la hipótesis alternativa (i.e. reloj relajado). Vale aclarar que como la suposición de un reloj molecular sólo asume una única tasa de sustitución, esta constituye la hipótesis nula por ser la opción más simple.

Para el análisis del reloj molecular mediante la prueba de razón de verosimilitud global, se utilizaron las 46 secuencias provenientes del alineamiento múltiple (43 de Aylacostoma y 3 del grupo externo). Mediante PAUP*4.0b10 (Swofford, 2002) se realizaron dos corridas de ML, relajando y forzando el reloj molecular, respectivamente. Para el análisis el modelo óptimo de sustitución nucleotídica fue evaluado con Jmodeltest 0.1.1 (Posada, 2008) mediante el test LR y seleccionado según un Criterio de Akaike corregido (AICc). Finalmente, a partir de los valores de likelihood obtenidos se realizó el cálculo de la razón de verosimilitud "a mano" de acuerdo a la fórmula mencionada más arriba. El valor crítico a un nivel de significancia $p=0,05$ fue obtenido utilizando el recurso Chi Square Calculator ${ }^{7}$. Adicionalmente, se estimó el valor de $p$ utilizando el cálculo del LRT (LRT Calculator) disponible en Jmodeltest 0.1.1 (Posada, 2008).

\section{III.2.7.8.1.2 Prueba de tasas relativas de Tajima (Tajima's relative rate test)}

En 1993 Tajima presentó un marco global para evaluar la hipótesis del reloj molecular tanto para secuencias de ADN como proteínas denominadas "pruebas de tasas relativas". Su

\footnotetext{
${ }^{7}$ http://www.stat.tamu.edu/ west/applets/chisqdemo.html
} 
prueba (no paramétrica) permite rechazar la hipótesis nula de una tasa constante a partir del estudio de tres secuencias, una de ellas un grupo externo al problema (Battistuzzi et al., 2011).

La prueba está basada en la igualdad esperada del número de mutaciones únicas que han ocurrido en dos linajes (supóngase A y B) respecto de un grupo externo (C). Ahora bien, si se considera un sitio en las secuencias $\mathrm{A}, \mathrm{B}$ y $\mathrm{C}$, se dice que el sitio ha sufrido una mutación única en el linaje A si el residuo aminoacídico o el nucleótido en ese sitio de la secuencia A es diferente respecto de $\mathrm{B}$ y $\mathrm{C}$, los cuales son, a su vez, idénticos entre sí. Si se denota el número de sitios exhibiendo una mutación única en A como $m_{\mathrm{A}}$, y de manera similar, se considera el número de mutaciones únicas en el linaje $\mathrm{B}$, a través de $m_{\mathrm{B}}$, bajo la suposición de reloj molecular, se espera que $m_{\mathrm{A}}=m_{\mathrm{B}}$ (Battistuzzi et al., 2011). Esta expectativa puede ser evaluada por medio de una prueba de $\chi$-cuadrado con un grado de libertad, de acuerdo con la siguiente ecuación propuesta por Tajima (1993):

$$
\chi^{2}=\left(m_{A}-m_{B}\right)^{2} /\left(m_{A}+m_{B}\right)
$$

La prueba de tasas relativas de Tajima fue incluida en el programa MEGA 5.05 (Tamura et al., 2011). Para el análisis del reloj molecular mediante esta prueba se realizaron comparaciones de las secuencias COI entre los dos linajes de A. chloroticum, y entre el linaje más frecuente de $A$. chloroticum (H1) y el nuevo morfotipo. El grupo externo utilizado en la prueba fue Pachychilus nigratus (la elección de este grupo externo fue al azar).

\section{III.2.7.8.2 Calibración del reloj molecular}

En una situación ideal, el reloj molecular debe ser calibrado utilizando evidencia independiente, tales como la fecha de eventos de especiación inferidas del registro fósil o estimadas a partir de eventos biogeográficos particulares (Arbogast et al., 2002). Sin embargo, sin fósiles o eventos biogeográficos razonables para calibrar la tasa de evolución, todavía es posible estimar los tiempos de divergencia a partir del uso de una tasa de divergencia externa para la región génica en estudio, a través de la ecuación:

$$
T=\mathrm{Da} / 2 \mu
$$

Donde $T$ representa el tiempo de divergencia, Da constituye la divergencia neta entre los linajes (Nei \& Li, 1979), y $2 \mu$ indica la tasa de divergencia. Esta aproximación resulta simple respecto de otros métodos disponibles más complejos (revisión en Rutschmann, 2006), 
no obstante esta ecuación es comúnmente empleada en estudios filogeográficos (e.g. Brunhoff et al., 2003; Chen et al., 2010; Loaiza et al., 2010; Vega et al., 2010).

Para el conjunto de datos obtenidos en el presente trabajo, se emplearon tasas de divergencias para el gen COI propuestas para protostomados por Wilke et al. (2009) calculadas según diferentes distancias genéticas, las cuales a su vez han sido empleadas para la estimación de tiempos de divergencia en gasterópodos de agua dulce (e.g. Wilke et al., 2009; Kroll et al., 2012). Particularmente se utilizaron las siguientes tasas:

Tasa según distancia JC: 1,22 $\pm 0,27 \%$ por cada millón de años.

Tasa según distancia K2P: 1,23 $\pm 0,26 \%$ por cada millón de años.

El cálculo de las distancias netas entre los linajes de $A$. chloroticum, y de $A$. chloroticum respecto del nuevo morfotipo se realizó asumiendo (separadamente) los modelos de sustitución nucleotídica JC y K2P. La distancia neta fue calculada como:

$$
\mathrm{Da}=\mathrm{XY}-\left(\frac{\mathrm{X}+\mathrm{Y}}{2}\right)
$$

Donde $d \mathrm{XY}$ es la distancia media entre los linajes $\mathrm{X}$ e $\mathrm{Y}, \mathrm{y} d \mathrm{X}$ y $d \mathrm{Y}$ representan las distancias dentro de los linajes (Liu et al., 2011). Los errores estándares (ES) fueron estimados mediante bootstrap usando 1.000 réplicas. Estos cálculos fueron realizados en MEGA 5.05 (Tamura et al., 2011). El tiempo de divergencia entre dos linajes fue estimado a partir de la primera ecuación presentada en este apartado. El intervalo de confianza (IC) del 95\% para los tiempos de divergencia fue calculado como $\pm 1,96$ ES de las distancias netas (Brunhoff et al., 2003).

Adicionalmente, los tiempos de divergencia fueron estimados mediante Inferencia Bayesiana (IB) empleando Mr. Bayes 3.2 (Ronquist et al., 2012). El análisis de IB fue realizado mediante dos corridas simultáneas con 4 cadenas de Markov durante $2 \times 10^{6}$ generaciones, descartándose 20 mil generaciones como burnin. Para esta estimación se asumió un modelo evolutivo GTR $+\mathrm{I}+\Gamma$ y una tasa de divergencia de 1,76 $\pm 0,66 \%$ cada millón de años (Wilke et al., 2009); este análisis fue ensayado tres veces. 


\title{
III.3 RESULTADOS
}

\section{III.3.1 CAMPAÑAS EXPLORATORIAS Y RECOLECCIÓN DE EJEMPLARES}

Durante la realización de las campañas, y particularmente en 2011, se verificó que los sitios de emplazamiento de las poblaciones de interés y en especial las localidades de Posadas (Argentina) y Encarnación (Paraguay) sufrieron importantes alteraciones, que incluyeron inundación y modificación de la línea de costa, consecuencia de alcanzarse la cota definitiva prevista para el embalse Yacyretá $(83 \mathrm{msnm}$ ) y la construcción del último tramo de la costanera de ambas ciudades, actividades que dificultaron las tareas en el área (Figura 20).
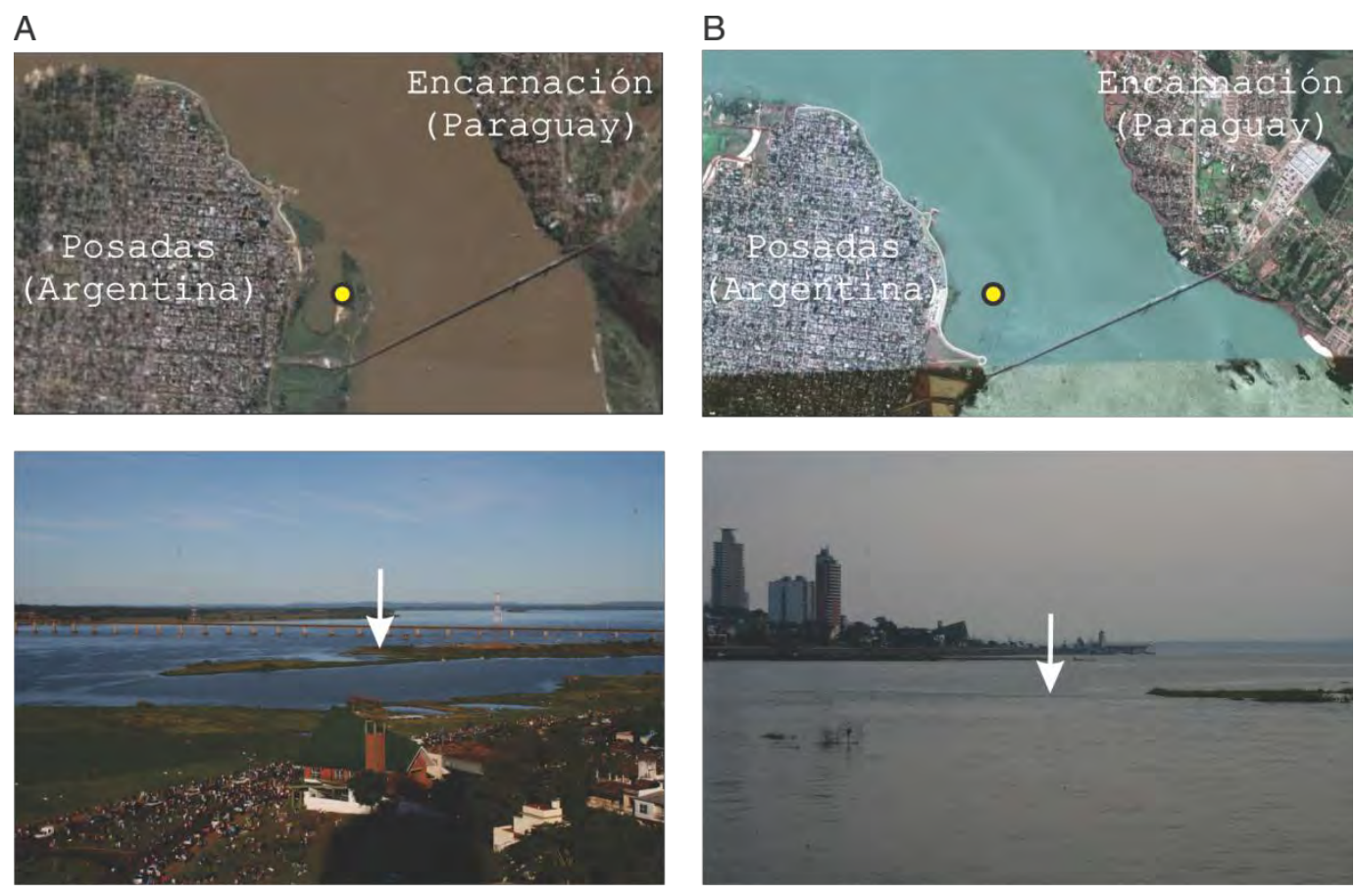

\begin{abstract}
Figura 20. Modificación del río Paraná entre Posadas (Argentina) y Encarnación (Paraguay) antes del llenado del embalse Yacyretá a su cota definitiva en 2011. A: Año 2005: Imagen satelital de Google Earth (superior) y fotografía del área (inferior); B: Año 2010: Imagen satelital de Google Earth (superior) y fotografía del área (inferior). La flecha destaca la inundación del terreno conocido como Península Heller desde diferentes vistas. Con $\mathbf{O}$ se indica el sitio de recolección de A. chloroticum durante 2008 (i.e. Laguna San José), inaccesible para el año 2011.
\end{abstract}

La exploración de otros tres ambientes (i.e. desembocadura del Arroyo San Juan, Ituzaingó y Paraje Ombú) fue negativa para poblaciones de Aylacostoma spp, y sólo un sitio fue positivo para una población de $A$. chloroticum, en el antiguo puerto de la localidad de Candelaria, Argentina (Figura 21). 

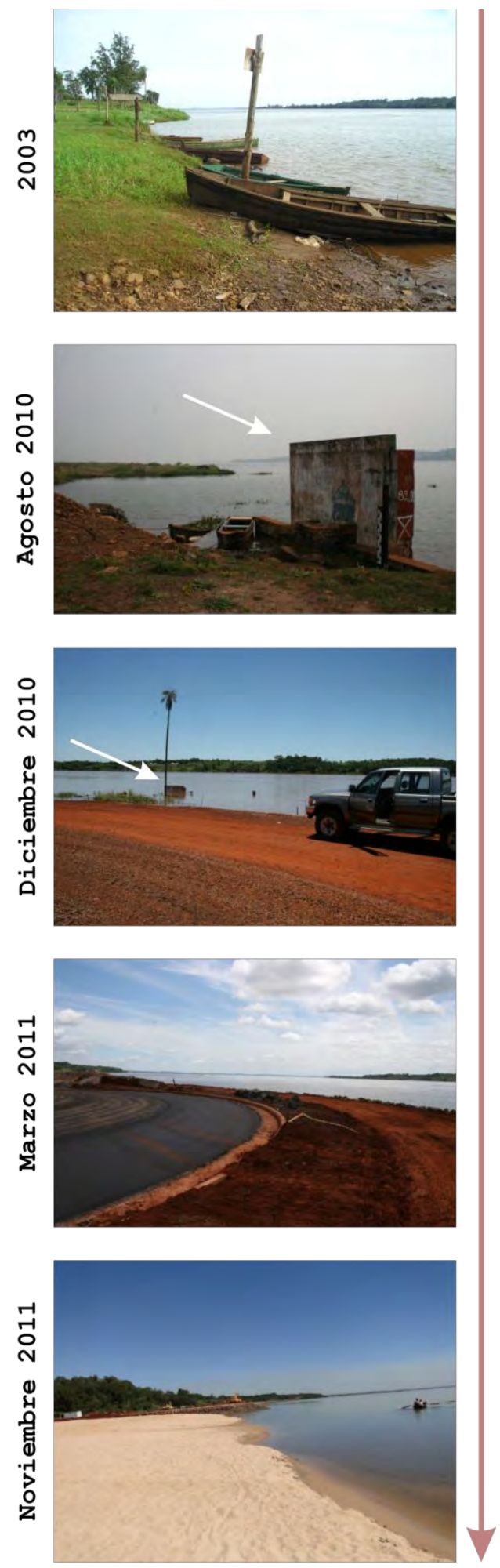

Figura 21. Antiguo puerto de la localidad de Candelaria. Se verifica la drástica modificación del ambiente entre 2003 y Noviembre 2011, con la construcción de una playa artificial para uso recreativo. La flecha blanca resalta el incremento del nivel del agua entre Agosto y Diciembre de 2010.
El municipio de Candelaria cuenta con una población de 26.713 habitantes, según censo 2010, parte de los cuales utilizan la zona del puerto viejo, actual costanera, con fines recreativos. La población de A. chloroticum de Candelaria (Figura 22; $27^{\circ} 26^{\prime} 50,96^{\prime \prime} \mathrm{S}$; 55 $\left.45^{\prime} 0,84^{\prime \prime} \mathrm{W}\right)$ se encuentra a $19 \mathrm{~km}$ aproximadamente del Puerto de Posadas siguiendo la línea de navegación (curvas, canal e islas).

Finalmente, es importante destacar que entre los ejemplares mantenidos en cautiverio cedidos por la Dra. Peso se contó con seis representantes de un nuevo morfotipo procedente de las localidades de Ita Cuá (27²4'29,83"S; 55²9'32,94"W) y Río Beach $\left(27^{\circ} 24^{\prime} 29,83^{\prime \prime} \mathrm{S} ; 55^{\circ} 49^{\prime} 32,94^{\prime \prime} \mathrm{W}\right)$, pertenecientes a la margen paraguaya del río.

\section{III.3.2 EXTRACCIÓN DE ADN}

Los tres protocolos ensayados resultaron adecuados para la obtención de ADN genómico total de alto peso molecular a partir del tejido seleccionado de los ejemplares. La semicuantificaciónen en gel de agarosa permitió estimar concentraciones de ADN en un rango aproximado de 150-200 $\mu \mathrm{g} / \mathrm{ml}$. Asimismo, el análisis electroforético respecto de la cantidad y calidad del ADN obtenido demostró que cualquiera de los protocolos ensayados resulta apropiado para obtener ADN plausible de ser utilizado en técnicas de Biología Molecular. De esta manera, fue el protocolo III (CTAB; Figura 23) el seleccionado para continuar con el procesado del resto del material de estudio por cuanto evita la utilización de fenol como solvente orgánico. 


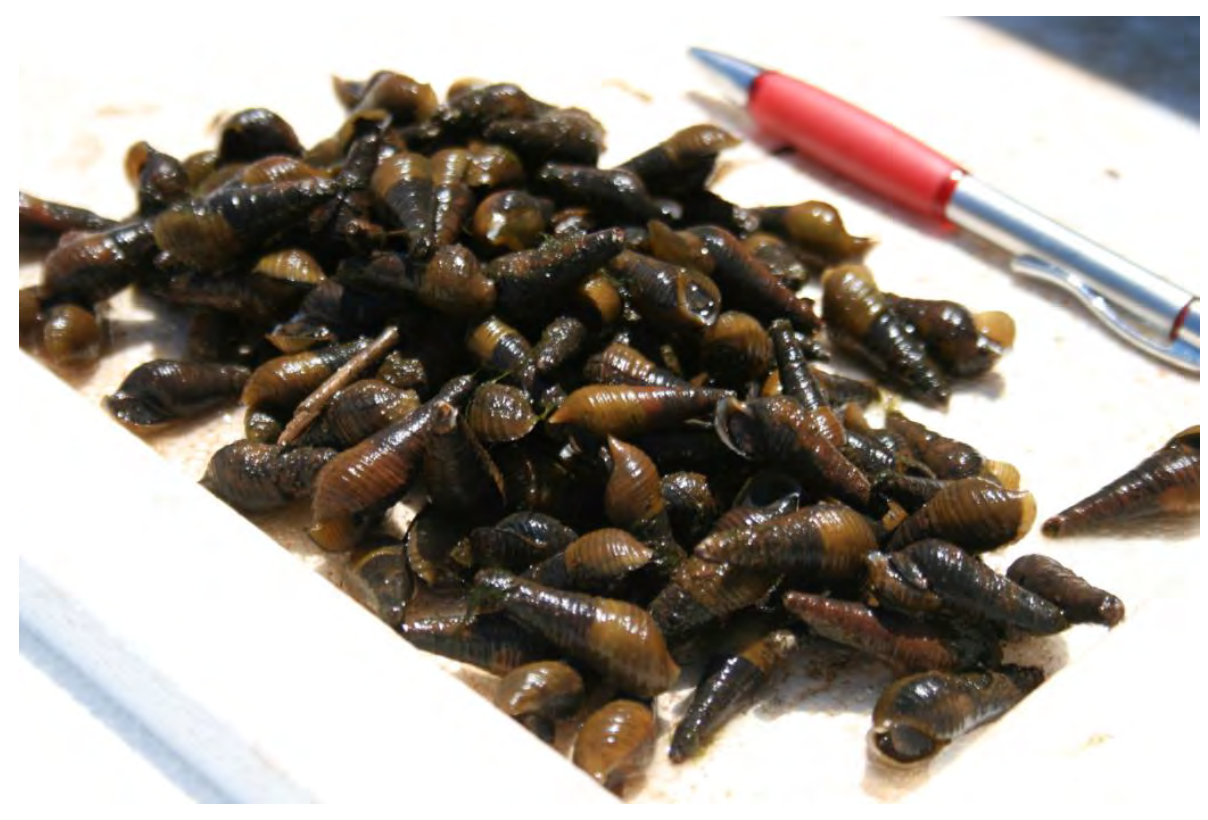

Figura 22. Ejemplares de Aylacostoma chloroticum colectados en la zona del antiguo puerto de la localidad argentina de Candelaria, Misiones.

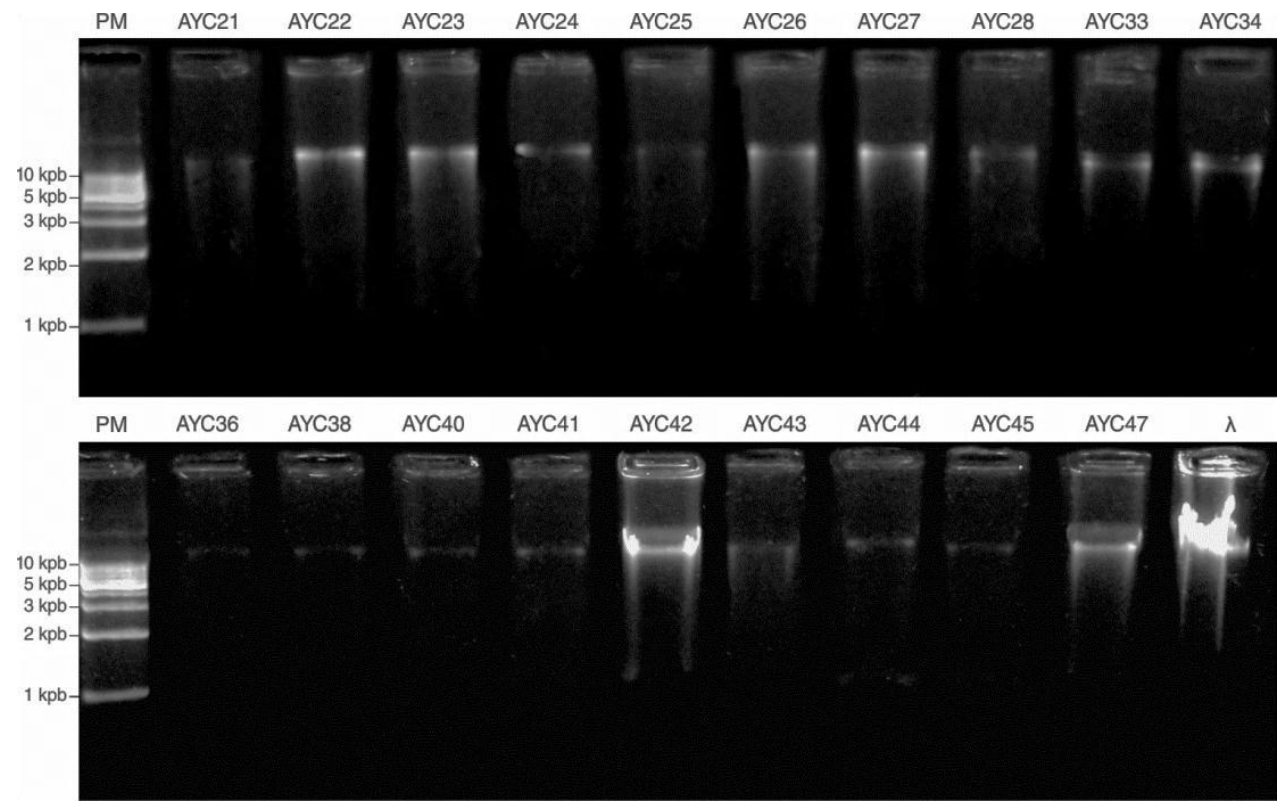

Figura 23. Obtención de ADN genómico total en ejemplares de $A$. chloroticum de diferentes localidades mediante el Protocolo III. Electroforesis en gel de agarosa 1\%. Ejemplares: AYC21-AYC22 (A ${ }^{\circ}$ San Juan); AYC23-AYC28 (R. Apipé); AYC33-AYC34 (Río Beach); AYC36-AYC44 (Lg. San José); AYC45-AYC47 (Pto. Posadas); PM: Ladder $1 \mathrm{kpb}$ (Productos Bio-Lógicos). $\lambda$ : ADN fago lambda $(533 \mu \mathrm{g} / \mathrm{ml}$, Fermentas). 


\section{III.3.3 AMPLIFICACIÓN DE LOS MARCADORES MITOCONDRIALES}

\section{III.3.3.1 Genes ribosomales}

\section{III.3.3.1.1 EI gen ribosomal 16S}

A partir del uso de los cebadores interespecíficos 16SF-16SR, según distintas combinaciones de mezclas de reacción y perfiles térmicos (Tabla XI, ver MyM), en la mayoría de las muestras amplificadas se verificó la presencia de bandas inespecíficas múltiples e incluso ausencia de producto (Tabla XIII). Una banda de aproximadamente 1.500 pb fue constante en todas las amplificaciones positivas (Figura 24), conviertiéndose en el producto de amplificación de elección para su purificación y posterior secuenciación. La amplificación de esta banda fue maximizada utilizando la mezcla de reacción E (Tabla IX, ver MyM) en combinación con el perfil térmico 4 (Tabla X, ver MyM).

A partir del uso de los cebadores universales 16SAr-16SBr, se observaron tres patrones de bandas en los diferentes individuos analizados (Figura 24): el primer patrón mostró la presencia de bandas dobles de $\approx 550$ y 900 pb; el segundo patrón exhibió bandas dobles de $\approx 550$ y $600 \mathrm{pb}$, y el tercero se caracterizó por la presencia de una banda única de $\approx 550 \mathrm{pb}$. En todos los casos, estos productos fueron obtenidos empleando la mezcla de reacción H (Tabla IX) y el perfil térmico 10 (Tabla X). Dado el carácter constante de la banda $\mathrm{de} \approx 550 \mathrm{pb}$, la misma fue seleccionada para su purificación y posterior secuenciación.

Finalmente, empleando los cebadores diseñados en el presente trabajo reconocidos como AYLA2F y AYLA2R en todas las muestras se visualizó la presencia de una banda única de $\approx 450 \mathrm{pb}$ (Figura 24), a partir de la mezcla de reacción J (Tabla IX) y el perfil térmico 11 (Tabla X).

\section{III.3.3.1.2 El gen ribosomal 12S}

A partir del uso de los cebadores interespecíficos 12SF-12SR, se visualizaron dos bandas de aproximadamente 300 y $400 \mathrm{pb}$, acompañadas por la presencia de producto inespecífico en la mayoría de las muestras amplificadas, para las distintas combinaciones de mezclas de reacción y perfiles térmicos (Tabla XI). Sin embargo, mediante la combinación de la mezcla de reacción E (Tabla IX) y el perfil térmico 9 (Tabla X), se optimizó la obtención de una banda única de $\approx 300 \mathrm{pb}$ en todas las muestras analizadas. 
Tabla XIII. Productos de amplificación obtenidos de los genes ribosomales mitocondriales a partir de diferentes cebadores, mezclas de reacción (AJ) y perfiles térmicos (PT1-PT11).

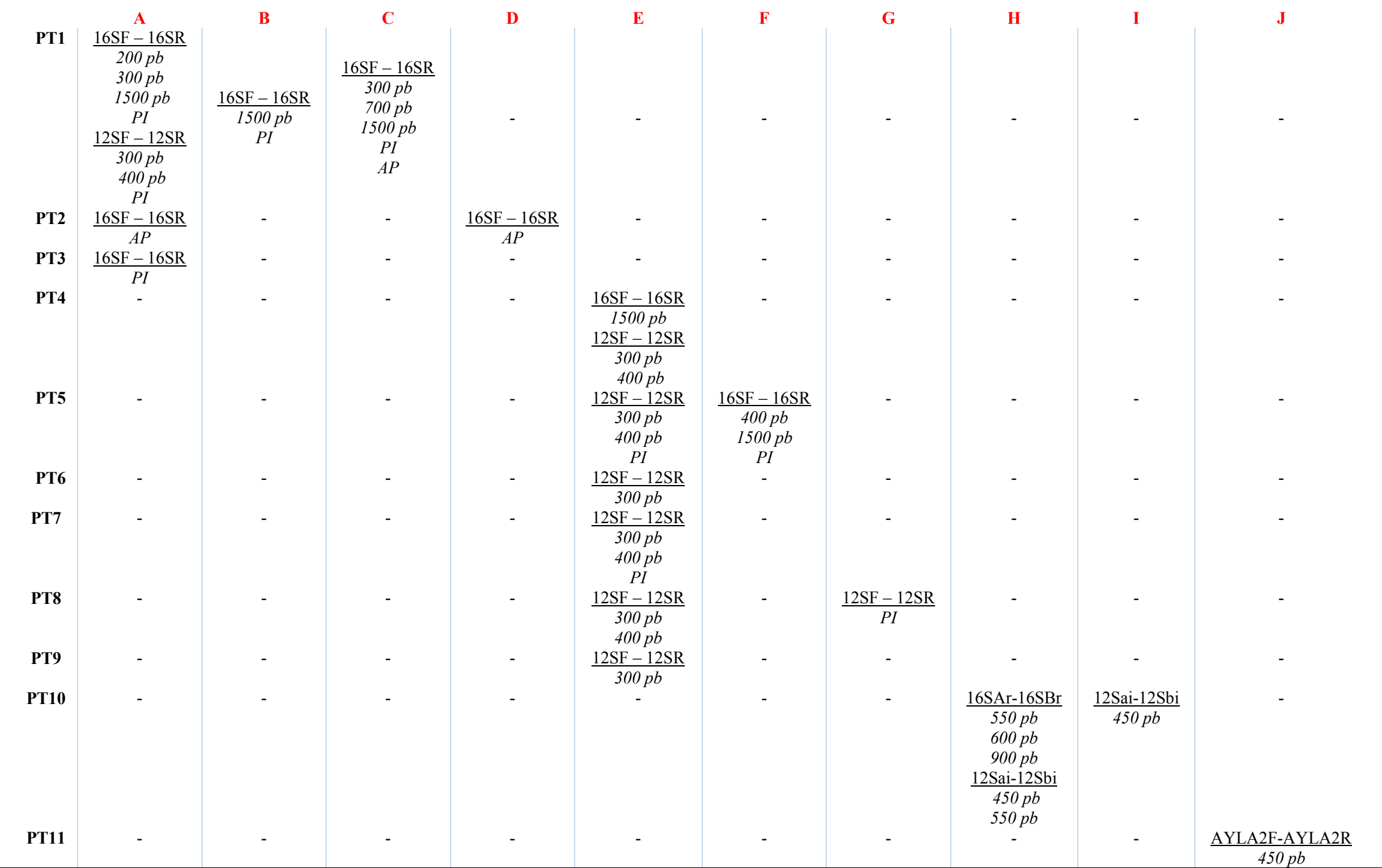

En cada caso se indican subrayados los cebadores utilizados. PI: producto inespecífico. AP: Ausencia de producto. 


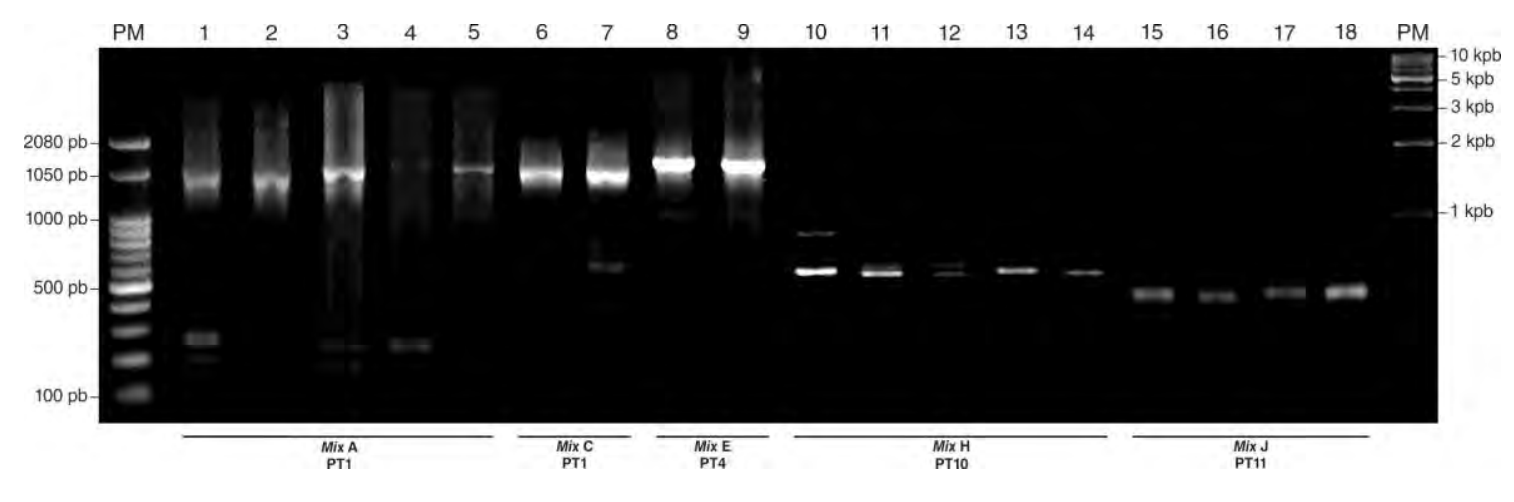

Figura 24. Amplificación del gen ribosomal mitocondrial 16S a partir de diferentes pares de cebadores. 1-9: 16SF-16SR; 10-14- 16SAr-16SBr; 15-18: AYLA2F-AYLA2R. PM (izq.): Ladder 100 pb (Productos Bio-Lógicos); PM (der.): Ladder 1kpb (Productos Bio-Lógicos). Las mezclas de reacción y perfiles térmicos empleados se indican debajo.

Al utilizar los cebadores universales identificados como 12Sai-12Sbi, en combinación con la mezcla de reacción H (Tabla IX) y el perfil térmico 10 (Tabla X) se observaron en principio dos patrones de bandas (Figura 25): el primero caracterizado por la presencia de bandas dobles de un tamaño aproximado de $\approx 550$ y 600 pb acompañadas de producto inespecífico, y el segundo caracterizado por bandas únicas de $\approx 450 \mathrm{pb}$. Sin embargo, mediante el uso de la mezcla de reacción I (Tabla IX) y el perfil térmico 10 (Tabla X) se obtuvo finalmente especificidad en la amplificación para la totalidad de las muestras, con la presencia uniforme de banda única de $\approx 450 \mathrm{pb}$, siendo la de elección para su purificación y posterior secuenciación.

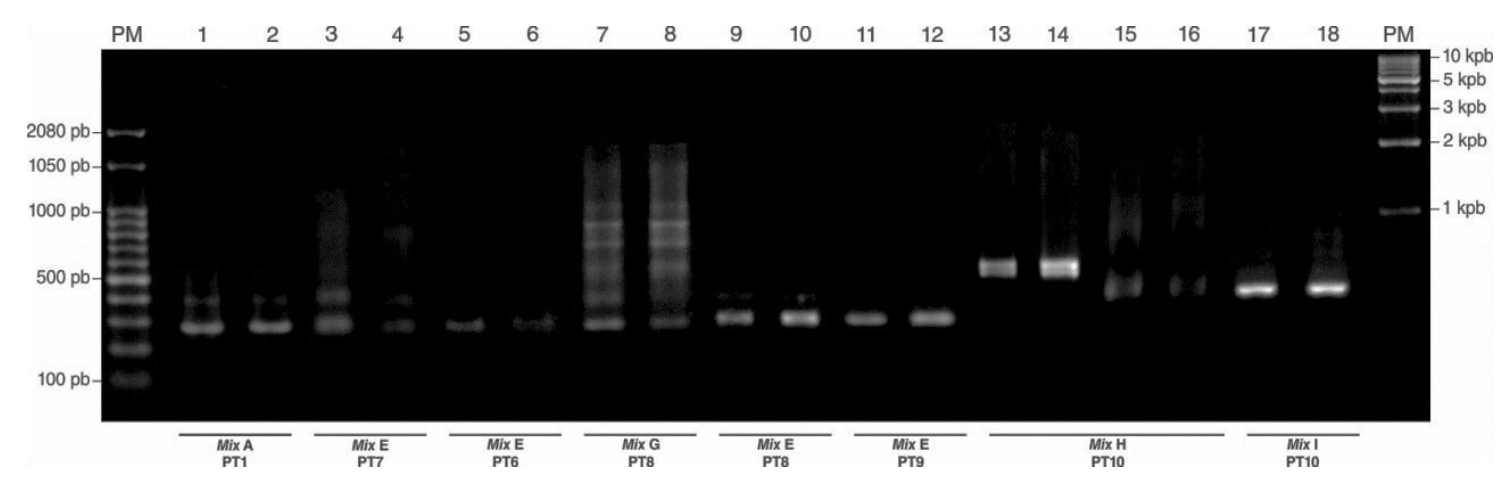

Figura 25. Amplificación del gen ribosomal mitocondrial 12S a partir de diferentes pares de cebadores. 1-12: 12SF-12SR; 13-18: 12Sai-12Sbi. PM (izq.): Ladder 100 pb (Productos Bio-Lógicos); PM (der.): Ladder $1 \mathrm{kpb}$ (Productos Bio-Lógicos). Las mezclas de reacción y perfiles térmicos empleados se indican debajo.

\section{III.3.3.2 Amplificación del gen COI}

Para esta región génica se logró la amplificación de fragmentos únicos de un tamaño 
aproximado de $700 \mathrm{pb}$ en la totalidad de los individuos con una densidad adecuada del amplicón obtenido (>50 ng), lo que permitió su ulterior secuenciación (Figura 26).
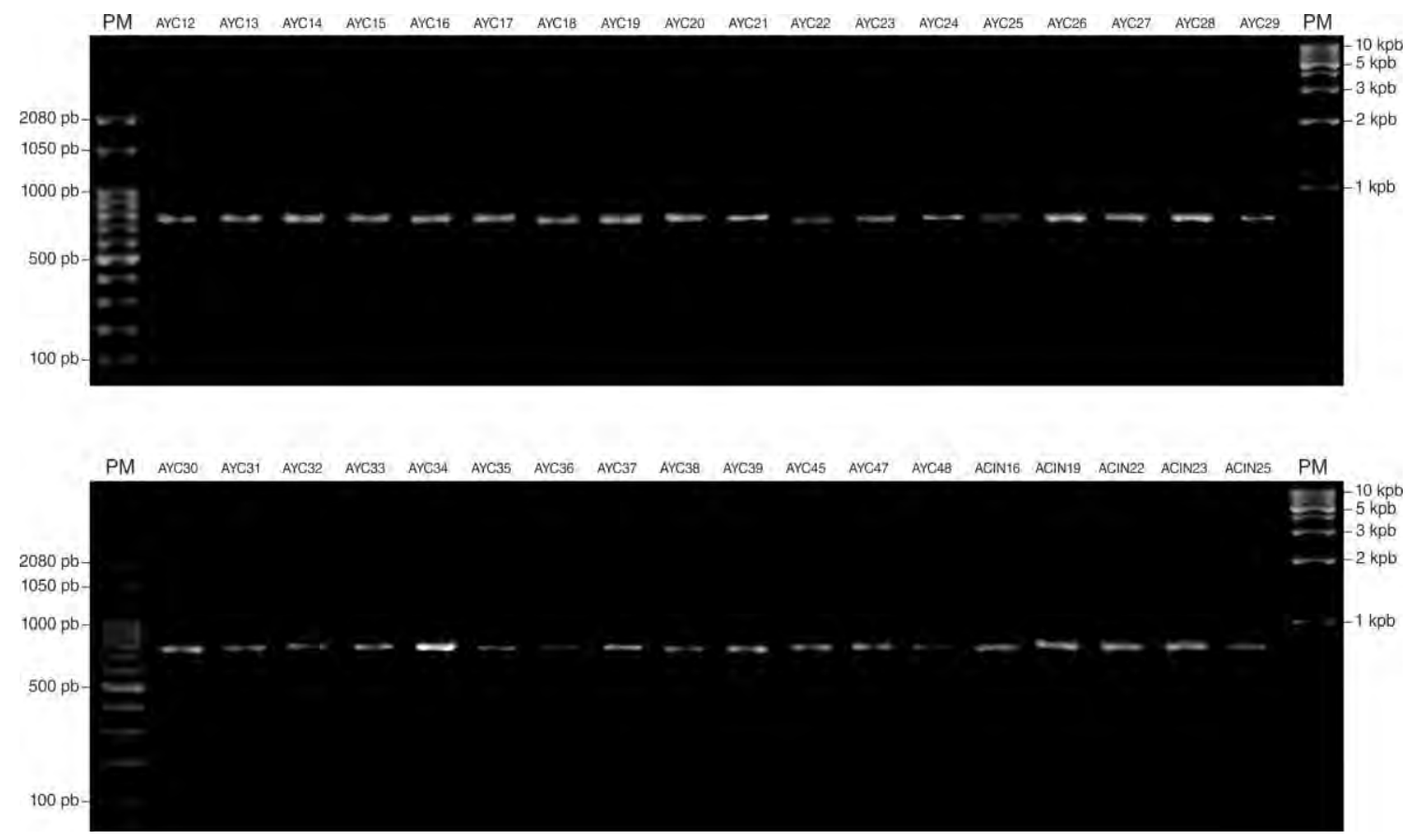

Figura 26. Amplificación parcial del gen COI. A. chloroticum: AYC12-AYC48; nuevo morfotipo: ACIN16-ACIN25. PM (izq.): Ladder 100 pb (Productos Bio-Lógicos); PM (der.): Ladder 1kpb (Productos Bio-Lógicos).

\section{III.3.4 SECUENCIACIÓN}

Todas las secuencias obtenidas para el gen ARNr 16S, presentaron valores de calidad bajos (QV scores < 20), no detectándose complementariedad de bases en los pares de secuencias de cada individuo. Asimismo, las comparaciones mediante BLASTn evidenciaron una homología débil con relación a la identidad del gen, con valores de probabilidad análogos a los esperados por azar. Resultados similares se observaron al analizar las secuencias del gen ARNr 12S (Figura 27).

Las secuencias obtenidas para el gen COI (Figura 27) arrojaron una alta calidad (QV scores $>600$ ), con complementariedad del $100 \%$ entre los pares de secuencias obtenidos para cada individuo, así como altos valores de identidad al análisis con BLASTn. Este evidenció una similitud en composición y orden de nucleótidos de las secuencias obtenidas con aquellas otras pertenecientes a gasterópodos depositadas en GenBank. Las secuencias obtenidas para el gen COI, presentaron una longitud de $658 \mathrm{pb}$, las que fueron depositadas en GenBank una vez editadas y analizadas. Sus números de acceso y datos asociados se resumen en la Tabla XIV. 


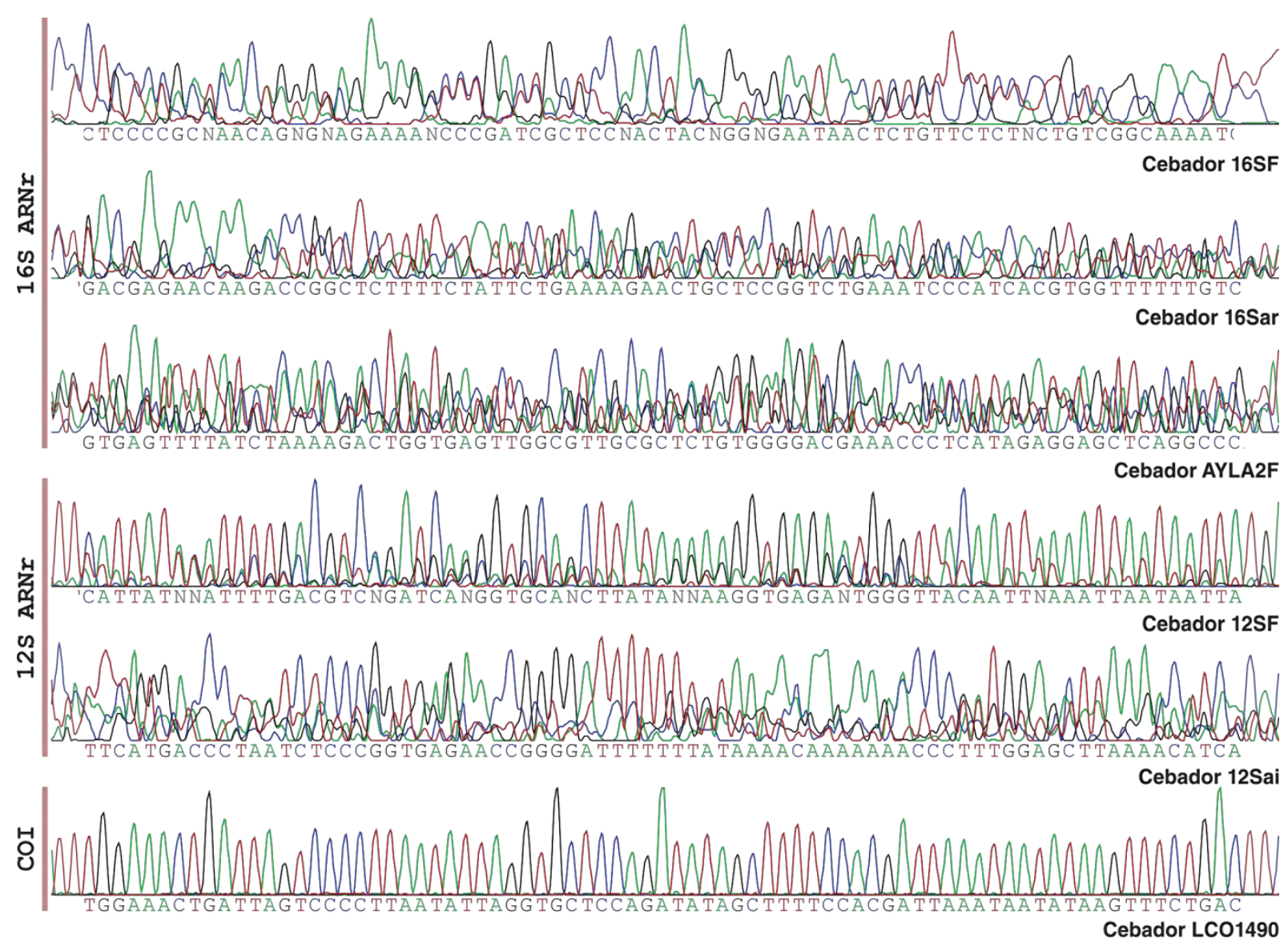

Figura 27. Comparación de la calidad de los electroferogramas obtenidos a partir de los cebadores sentido para los tres genes analizados en un individuo de $A$. chloroticum. Vista parcial.

\section{III.3.5 ANÁLISIS BIOINFORMÁTICO}

\section{III.3.5.1 Caracterización de las secuencias a partir de descriptores típicos}

La representación del contenido informativo del alineamiento múltiple (sequence logos) se presenta en la Figura 28. Se detectaron un total de tres haplotipos para el material procedente del Alto Paraná: dos en A. chloroticum, difiriendo en una mutación puntual correspondiente a una transición $\mathrm{G}>\mathrm{A}$ en la posición $\mathrm{N}^{\mathrm{o}} 466$, definidos como Haplotipo 1 (H1) y Haplotipo 2 (H2), portando G y A respectivamente; y uno en el nuevo morfotipo nominado Haplotipo 3 (H3), que exhibió 28 cambios nucleotídicos respecto del haplotipo más frecuente en A. chloroticum (H1), los cuales fueron en su mayoría transiciones. El análisis composicional se presenta en la Tabla XV y Figura 29.

Utilizando el código genético mitocondrial para invertebrados (Apéndice II), se identificó un marco de lectura en posición $+2(\mathrm{ORF}=+2)$ para los tres haplotipos. 
Tabla XIV. Datos de los ejemplares analizados y número de accesos a la región parcial del gen COI.

\begin{tabular}{|c|c|c|c|c|c|}
\hline OUTGROUP & INDIVIDUO & LOCALIDAD & LAT. LONG. & AÑO COLECTA & GENBANK \\
\hline Doryssa sp. & MLP 13445 & Venezuela & $7,9141388 \mathrm{~N} ; 63,090027 \mathrm{~W}$ & 2010 & JQ966087 \\
\hline Pachychilus laevissimus & MLP 13446 & Venezuela & $10,111583 \mathrm{~N} ; 66,517527 \mathrm{~W}$ & 2010 & JQ966088 \\
\hline Pachychilus nigratus & MLP 13447 & Cuba & $22,400530 \mathrm{~N} ; 79,926177 \mathrm{~W}$ & 1997 & JQ966089 \\
\hline INGROUP & & & & & \\
\hline \multirow[t]{37}{*}{ Aylacostoma chloroticum } & $\mathrm{AYC} 12$ & Candelaria, Arg. & $27,447488 \mathrm{~S} ; 55,750233 \mathrm{~W}$ & 2008 & JF346878 \\
\hline & $\mathrm{AYC13}$ & Candelaria, Arg. & $27,447488 \mathrm{~S} ; 55,750233 \mathrm{~W}$ & 2008 & JF346879 \\
\hline & AYC14 & Candelaria, Arg. & $27,447488 \mathrm{~S} ; 55,750233 \mathrm{~W}$ & 2008 & JF346880 \\
\hline & AYC15 & Candelaria, Arg. & $27,447488 \mathrm{~S} ; 55,750233 \mathrm{~W}$ & 2008 & JF346881 \\
\hline & AYC16 & Candelaria, Arg. & 27,447488S; 55,750233W & 2008 & JF346882 \\
\hline & $\mathrm{AYC} 17$ & Candelaria, Arg. & $27,447488 \mathrm{~S} ; 55,750233 \mathrm{~W}$ & 2011 & JQ236681 \\
\hline & AYC18 & Candelaria, Arg. & 27,447488S; 55,750233W & 2011 & JQ236682 \\
\hline & AYC19 & Candelaria, Arg. & 27,447488S; 55,750233W & 2011 & JQ236683 \\
\hline & $\mathrm{AYC} 20$ & Candelaria, Arg. & $27,447488 \mathrm{~S} ; 55,750233 \mathrm{~W}$ & 2011 & JQ236684 \\
\hline & $\mathrm{AYC} 21$ & $\mathrm{~A}^{\mathrm{o}}$ San Juan, Arg. & $27,416930 \mathrm{~S} ; 55,713022 \mathrm{~W}$ & 2009 & JQ236685 \\
\hline & $\mathrm{AYC} 22$ & A $^{o}$ San Juan, Arg. & $27,416930 \mathrm{~S} ; 55,713022 \mathrm{~W}$ & 2009 & JQ236686 \\
\hline & $\mathrm{AYC} 23$ & Rápidos Apipé, Arg. & $27,482613 \mathrm{~S} ; 56,733588 \mathrm{~W}$ & 1994 & JQ236687 \\
\hline & $\mathrm{AYC} 24$ & Rápidos Apipé, Arg. & $27,482613 \mathrm{~S} ; 56,733588 \mathrm{~W}$ & 1994 & JQ236688 \\
\hline & $\mathrm{AYC} 25$ & Rápidos Apipé, Arg. & $27,482613 \mathrm{~S} ; 56,733588 \mathrm{~W}$ & 1994 & JX244270 \\
\hline & AYC26 & Rápidos Apipé, Arg. & $27,482613 \mathrm{~S} ; 56,733588 \mathrm{~W}$ & 1994 & JQ236689 \\
\hline & $\mathrm{AYC} 27$ & Rápidos Apipé, Arg. & $27,482613 \mathrm{~S} ; 56,733588 \mathrm{~W}$ & 1994 & JQ236690 \\
\hline & $\mathrm{AYC} 28$ & Candelaria, Arg. & $27,447488 \mathrm{~S} ; 55,750233 \mathrm{~W}$ & 2011 & JQ236691 \\
\hline & AYC29 & Río Beach, Pgy. & $27,408286 \mathrm{~S} ; 55,825816 \mathrm{~W}$ & 2007 & JX203217 \\
\hline & AYC30 & Río Beach, Pgy. & $27,408286 \mathrm{~S} ; 55,825816 \mathrm{~W}$ & 2007 & JX244271 \\
\hline & AYC31 & Río Beach, Pgy. & $27,408286 \mathrm{~S} ; 55,825816 \mathrm{~W}$ & 2007 & JX203218 \\
\hline & AYC32 & Río Beach, Pgy. & $27,408286 \mathrm{~S} ; 55,825816 \mathrm{~W}$ & 2007 & JX203219 \\
\hline & AYC33 & Río Beach, Pgy. & $27,408286 \mathrm{~S} ; 55,825816 \mathrm{~W}$ & 2007 & JQ236692 \\
\hline & AYC34 & Río Beach, Pgy. & $27,408286 \mathrm{~S} ; 55,825816 \mathrm{~W}$ & 2007 & JQ236693 \\
\hline & AYC35 & Laguna San José, Arg. & $27,369833 \mathrm{~S} ; 55,880455 \mathrm{~W}$ & 2008 & JX203220 \\
\hline & AYC36 & Laguna San José, Arg. & $27,369833 \mathrm{~S} ; 55,880455 \mathrm{~W}$ & 2008 & JX203221 \\
\hline & AYC37 & Laguna San José, Arg. & $27,369833 \mathrm{~S} ; 55,880455 \mathrm{~W}$ & 2008 & JX244272 \\
\hline & AYC38 & Laguna San José, Arg. & $27,369833 \mathrm{~S} ; 55,880455 \mathrm{~W}$ & 2008 & JX203222 \\
\hline & AYC39 & Laguna San José, Arg. & $27,369833 \mathrm{~S} ; 55,880455 \mathrm{~W}$ & 2008 & JX203223 \\
\hline & $\mathrm{AYC} 40$ & Laguna San José, Arg. & $27,369833 \mathrm{~S} ; 55,880455 \mathrm{~W}$ & 2008 & JQ236694 \\
\hline & AYC41 & Laguna San José, Arg. & $27,369833 \mathrm{~S} ; 55,880455 \mathrm{~W}$ & 2008 & JQ236695 \\
\hline & $\mathrm{AYC} 42$ & Laguna San José, Arg. & $27,369833 \mathrm{~S} ; 55,880455 \mathrm{~W}$ & 2008 & JQ236696 \\
\hline & $\mathrm{AYC} 43$ & Laguna San José, Arg. & $27,369833 \mathrm{~S} ; 55,880455 \mathrm{~W}$ & 2008 & JQ236697 \\
\hline & AYC44 & Laguna San José, Arg. & $27,369833 \mathrm{~S} ; 55,880455 \mathrm{~W}$ & 2008 & JX203224 \\
\hline & AYC45 & Puerto Posadas, Arg. & $27,361972 \mathrm{~S} ; 55,884777 \mathrm{~W}$ & 2006 & JQ236698 \\
\hline & $\mathrm{AYC} 47$ & Puerto Posadas, Arg. & $27,361972 \mathrm{~S} ; 55,884777 \mathrm{~W}$ & 2006 & JQ236699 \\
\hline & AYC48 & Puerto Posadas, Arg. & $27,361972 \mathrm{~S} ; 55,884777 \mathrm{~W}$ & 2006 & JX203225 \\
\hline & AYC50 & Río Beach, Pgy. & $27,408286 \mathrm{~S} ; 55,825816 \mathrm{~W}$ & 2007 & JX203226 \\
\hline \multirow[t]{6}{*}{ Nuevo morfotipo } & ACIN16 & Ita Cuá, Pgy. & $27,411702 \mathrm{~S} ; 55,812691 \mathrm{~W}$ & 2003 & JQ236700 \\
\hline & ACIN19 & Ita Cuá, Pgy. & $27,411702 \mathrm{~S} ; 55,812691 \mathrm{~W}$ & 2003 & JQ236701 \\
\hline & ACIN22 & Ita Cuá, Pgy. & $27,411702 \mathrm{~S} ; 55,812691 \mathrm{~W}$ & 2003 & JQ236702 \\
\hline & ACIN23 & Ita Cuá, Pgy. & $27,411702 \mathrm{~S} ; 55,812691 \mathrm{~W}$ & 2003 & JQ236703 \\
\hline & ACIN24 & Ita Cuá, Pgy. & $27,411702 \mathrm{~S} ; 55,812691 \mathrm{~W}$ & 2003 & JQ236704 \\
\hline & ACIN25 & Río Beach, Pgy. & $27,408286 \mathrm{~S} ; 55,825816 \mathrm{~W}$ & 2007 & JQ236705 \\
\hline
\end{tabular}




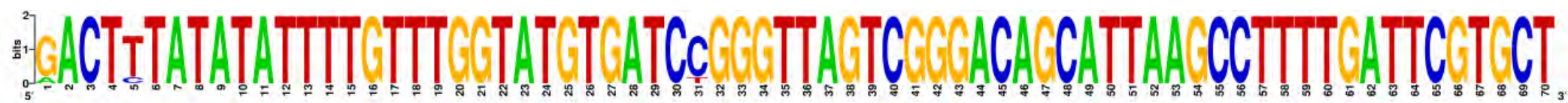

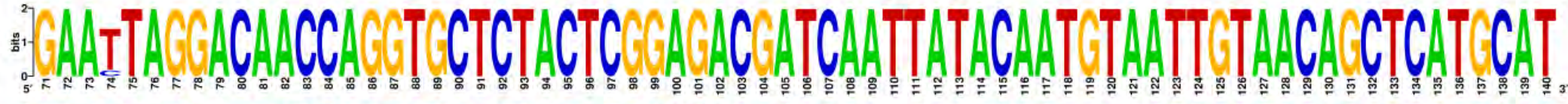

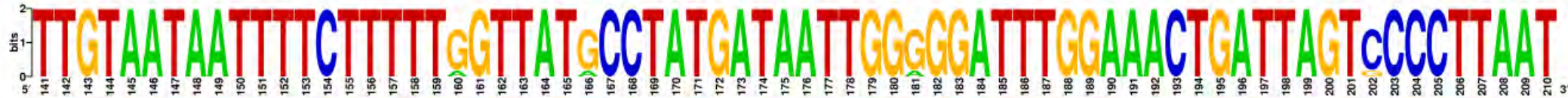

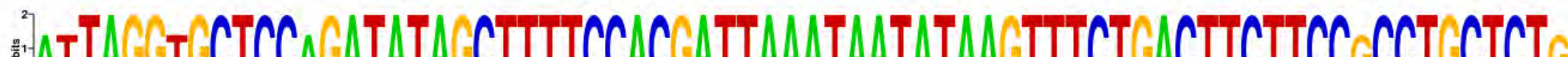

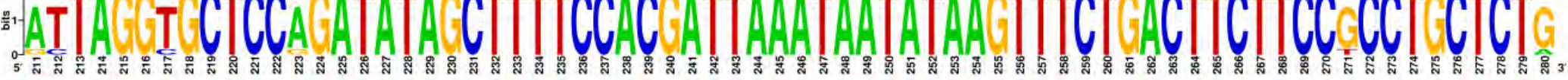
Th

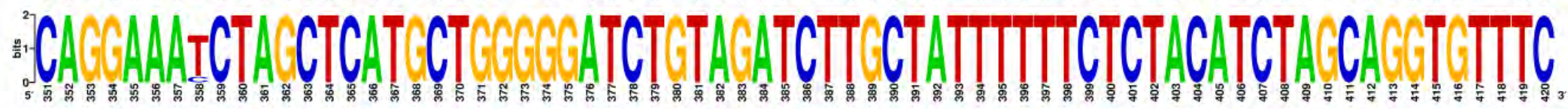

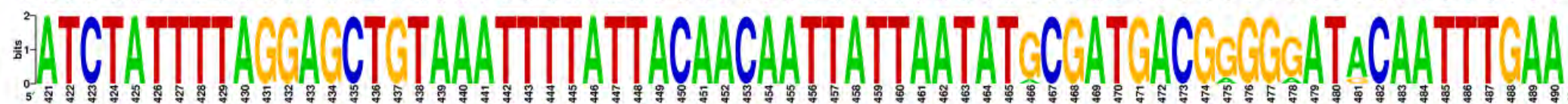

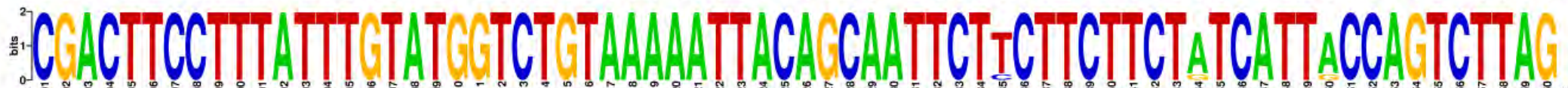

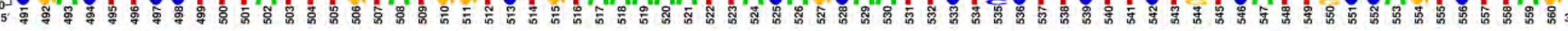

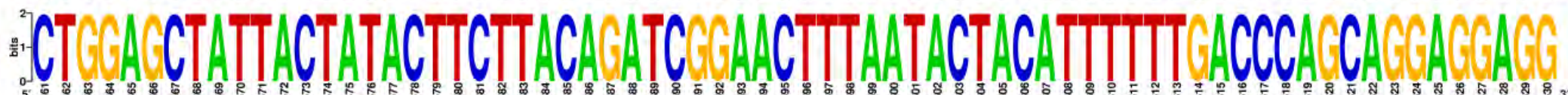

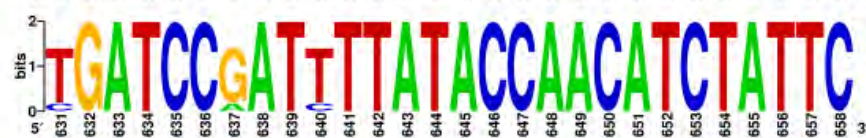

Figura 28. Sequence logos del alineamiento múltiple de las 43 secuencias obtenidas para ejemplares de Aylacostoma. 
Tabla XV. Composición de secuencia de los tres haplotipos identificados en Aylacostoma.

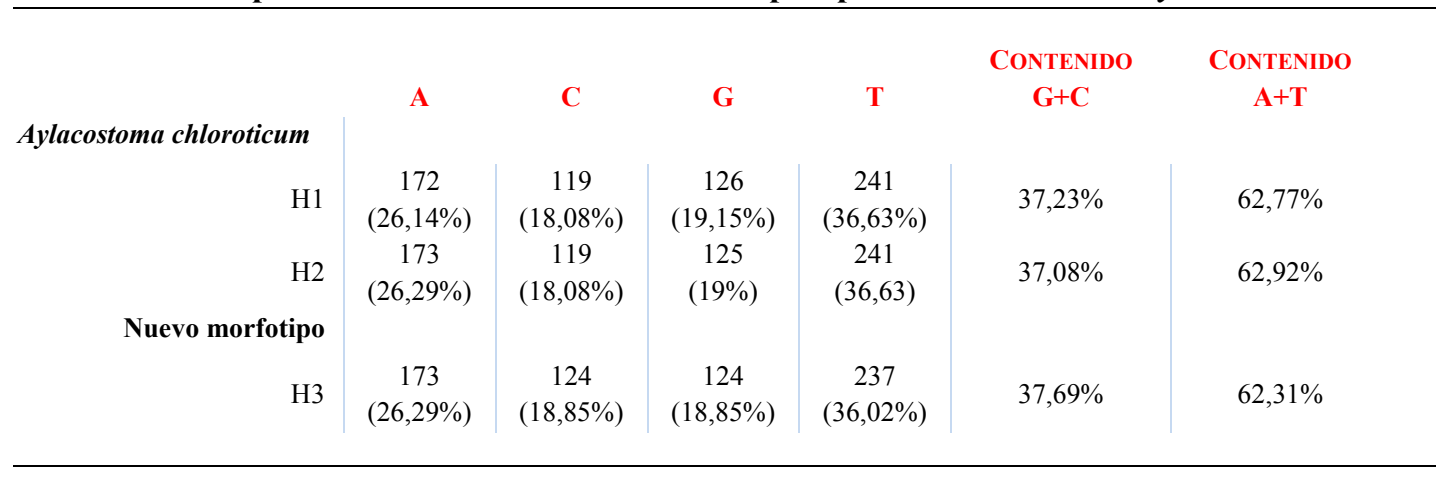

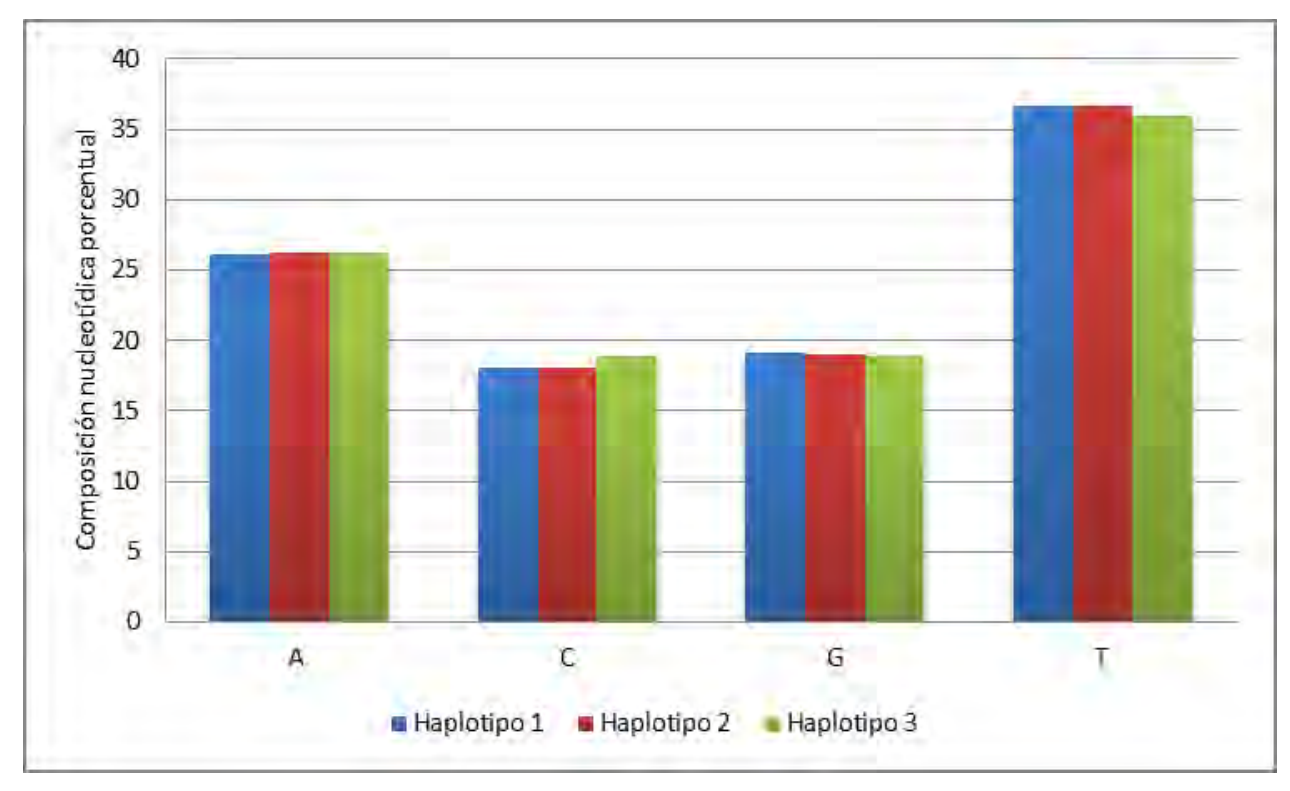

Figura 29. Composición nucleotídica porcentual por base y para cada uno de los tres haplotipos analizados. Mayor detalle en Tabla XV.

Al traducir las secuencias a proteínas se observó que se encuentra 100\% conservada la secuencia de aminoácidos, indicando que la totalidad de las mutaciones presentes fueron sinónimas. Al verificar la posición de los cambios dentro de los codones, el 89,28\% de las mutaciones ocurrieron en la tercera posición, mientras que el 10,72\% restante ocurrió en la primera posición, no detectándose sustituciones en la segunda base (Figura 30).

\section{III.3.5.2 Caracterización de las secuencias a partir de descriptores adicionales}

\section{III.3.5.2.1 Complejidad de composición local}

Mediante el análisis de complejidad de composición local, utilizando ventanas de 21 nucleótidos, el rango en el cual oscilaron los valores de LCC obtenidos fue alto para los tres haplotipos $(0,8-1)$, detectándose sólo algunas posiciones que alcanzaron valores medios 
B1 G ACU UUA UAU AUU UUG UUU GGU AUG UGA UCC GGG UUA GUC GGG ACA GCA UUA AGC CUU UUG AUU CGU GCU GAA UUA GGA CAA CCA GGU GCU CUA CUC GGA Thr Leu Tyr Ile Leu Phe Gly Met TIP Ser Gly Leu Val Gly Thr Ala Leu Ser Leu Leu Ile Arg Ala Glu Leu Gly Gin Pro Gly Ala Leu Leu GIY
G ACU UUA UAU AUU UDG UUU GGU AUG UGA UCC GGG UUA GUC GGG ACA GCA UUA AGC CUU UUG AUU CGU GCU GAA UUA GGA CAA CCA GGU GCU CDA CUC GGA Thr Leu Tyr Ile Leu Phe Gly Met Trp Ser Gly Leu Val GlY Thr Ala Leu Ser Leu Leu Ile Arg Ala Glu Leu Giy Gin Pro Gly Ala Leu Leu Gly
H3 A ACU CUA UAU AUU UUG UUU GGU AUG DGA UCU GGG UUA GUC GGG ACA GCA UUA AGC CUU UUG AUU CGU GCU GAA CUA GGA CAA CCA GGU GCU CUA CUC GGA

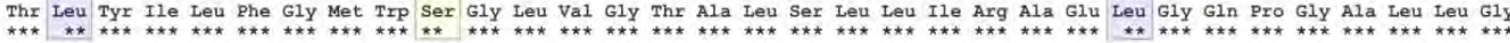

H1 GAC GAU CAA UUA UAC AAU GUA AUU GUA ACA GCU CAU GCA UUU GUA AUA AUU UUC UUU UUG GUU AUG CCU AUG AUA AUU GGG GGA UUU GGA AaC UGA UUA 19 Asp Asp Gln Leu TYr Asn Val Ile Val Thr Ala His Ala phe Val Met Ile phe phe Leu Val Met Pro Met Met Ile Gly Gly Phe Gly Asn Trp Le 2 GAC GAU CAA UUA UAC AAU GUA AUU GUA ACA GCU CAU GCA UUU GUA AUA AUU UUC UUU UUG GUU AUG CCU AUG AUA AUU GGG GGA UUU GGA AAC UGA UUA Asp Asp Gln Leu Tyr Asn Val Ile Val Thr Ala His Ala Phe Val Met Ile Phe Phe Leu Val Met Pro Met Met Ile Gly Gly Phe Gly Asn Trp Le GAC GAU CAA UUA UAC AAU GUA AUU GUA ACA GCU CAU GCA UUU GUA AUA AUU UUC UUU UUA GUU AUA CCU AUG AUA AUU GGA GGA UUU GGA AAC UGA UUA
Asp Asp GIn Leu Tyr Asn Val Ile Val Thr Ala His Ala phe Val Met Ile phe phe Leu Val Met Pro Met Met Ile G1y Gly Phe Gly Asn Trp Leu A

91 GUC CCC UUA AUA UUA GGU GCU CCA GAU AUA GCU UUU CCA CGA UUA AAU AAU AUA AGU UUC UGA CUU CUU CCG CCU GCU CUG UUA CUA CUU UUG UCU UCA 298 Val Pro Leu Met Leu Gly Ala Pro Asp Met Ala Phe Pro Arg leu Asn Asn Met Ser phe Trp Leu Leu Pro Pro Ala Leu Leu Leu Leu Leu Ser Ser Val Pro Leu Met Leu Gly Ala Pro Asp Met Ala Phe Pro Arg Leu Asn Asn Met Ser Phe Trp Leu Leu Pro Pro Ala Leu Leu Leu Leu Leu Ser Ser

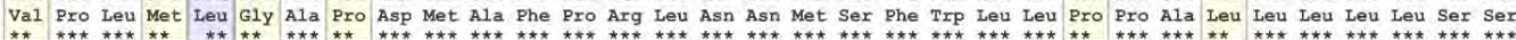

H1 GCU GCU GUU GAA AGA GGA GUC GGA ACA GGU UGA ACA GUU UAU CCA CCC UUA GCA GGA AAU CUA GCU CAU GCU GGG GGA UCU GUA GAD CUD GCU AUU UUU Ala Ala Val Glu Ser Gly Val Gly Thr Gly Trp Thr Val Tyr Pro Pro Leu Ala Gly Asn Leu Ala His Ala Gly Gly Ser Val Asp Leu Ala Ile Phe 2 GCU GCU GUU GAA AGA GGA GUC GGA ACA GGU UGA ACA GUU UAU CCA CCC UUA GCA GGA AAU CUA GCU CAU GCU GGG GGA UCU GUA GAU CUU GCU AUU UUD Ala Ala Val Glu Ser Gly Val Gly Thr Gly Trp Thr Val Tyr Pro Pro Leu Ala Gly Asn Leu Ala His Ala Gly Gly Ser Val Asp Leu Ala Ile Phe
GCU GCU GUU GAA AGA GGG GUU GGA ACA GGU UGA ACA GUU UAU CCC CCU UUA GCA GGA AAC CUA GCU CAU GCU GGG GGA UCU GUA GAU CUU GCU AUU UUD Ala Ala Val Glu Ser Gly Val Gly Thr Gly Trp Thr Val Tyr Pro Pro Leu Ala Gly Asn Leu Ala His Ala Gly G1Y Ser Val Asp Leu Ala Ile Phe

H1 UCU CUA CAU CUA GCA GGU GUU UCA UCU AUU UUA GGA GCU GUA AAU UUU AUU ACA ACA AUU AUU AAU AUG CGA UGA CGG GGG AUA CAA UUU GAA CGA CUU Ser Leu His Leu Ala Gly Val Ser Ser Ile Leu Gly Ala Val Asn Phe Ile Thr Thr Ile Ile Asn Met Arg Trp Arg Gly Met Gln Phe Glu Arg Leu

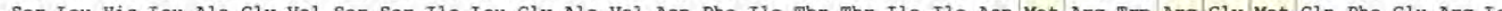
UCU CUA CAU CUA GCA GGU GUU UCA UCU AUU UUA GGA GCU GUA AAU UUU AUU ACA ACA AUU AUU AAU AUG CGA UGA CGA GGA AUG CAA UUD GAA CGA CUU Ser Leu His Leu Ala Gly Val Ser Ser Ile Leu GlY Ala Val Asn Phe Ile Thr Thr Ile Ile Asn Met Arg Trp Arg Gly Met Gln Phe Glu Arg Leu

1 CCU UUA UUU GUA UGG UCU GUA AAA AUU ACA GCA AUU CUU CUU CUU CUA UCA UUA CCA GUC UUA GCU GGA GCU AUU ACU AUA CUU CUU ACA GAD CGG AAC 595 2 CCU UUA UUU GUA UGG UCU GUA AAA AUO ACA GCA AUU CUU CUU CUU CUA UCA UUA CCA GUC UUA GCU GGA GCU AUU ACU AUA CUU CUU ACA GAU CGG AAC Pro teu phe Val Trp Ser Val hys Ile Thr Ala lle teu Leu Leu Leu Ser Leu pro Val ter 3 CCU UUA DUU GUA UGG UCU GUA AAA AUU ACA GCA AUU CUC CUU CUU CUG UCA UUG CCA GUC UUA GCU GGA GCU AUU ACU AUA CUU CUU ACA GAU CGG AAC

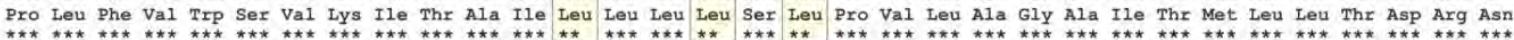

1 UUU AAU ACU ACA WUU UUU GAC CCA GCA GGA GGA GGU 658

UUU AAU ACU ACA UUU UUU GAC CCA GCA GGA GGA GGU GAU CCG AUU UUA UAC CAA CAU CUA UUC Phe Asn Thr Thr Phe Phe Asp Pro Ala G1Y G1Y G1Y Asp Pro Ile Leu TYr G1n His Leu Phe Phe Asn Thr Thr Phe Phe Asp Pro Ala Gly Gly Gly Asp Pro Ile Leu Tyr Gln His Leu Phe 33 VUU AAU ACU ACA UUU UUU GAC CCA GCA GGA GGA GGC GAU CCA AUC UUA UAC CAA CAU CUA UUC Phe Asn Thr Thr Phe Phe Asp Pro Ala G1Y G1Y G1Y Asp Pro Ile Leu Tyr Gin His Leu Phe

Figura 30. Conservación de la secuencia aminoacídica de los tres haplotipos. Se destacan en color las sustituciones en la primera (celeste) y tercera (amarillo) posición de los codones. ORF $=+2$. Código genético: mitocondrial de invertebrados (Apéndice II).

cercanos a 0,6 (Figura 31). De acuerdo a los perfiles obtenidos, las secuencias de los tres haplotipos pueden ser consideradas complejas.

\section{III.3.5.2.2 Asimetrías composicionales}

Los tres haplotipos procedentes del Alto Paraná mostraron una asimetría AT negativa. Respecto de la asimetría GC, los haplotipos 1 y 2 presentaron valores positivos, y el haplotipo 3 presentó un valor $=0$. Este comportamiento se vio reflejado asimismo en los gráficos generados utilizando una estrategia de ventanas (Figura 32, Figura 33, Tabla XVI). En otras palabras, las secuencias codificantes de la región COI para Aylacostoma resultaron ricas en G y $\mathrm{T}, \mathrm{y}$ correspondientemente pobres en $\mathrm{C}$ y A. 

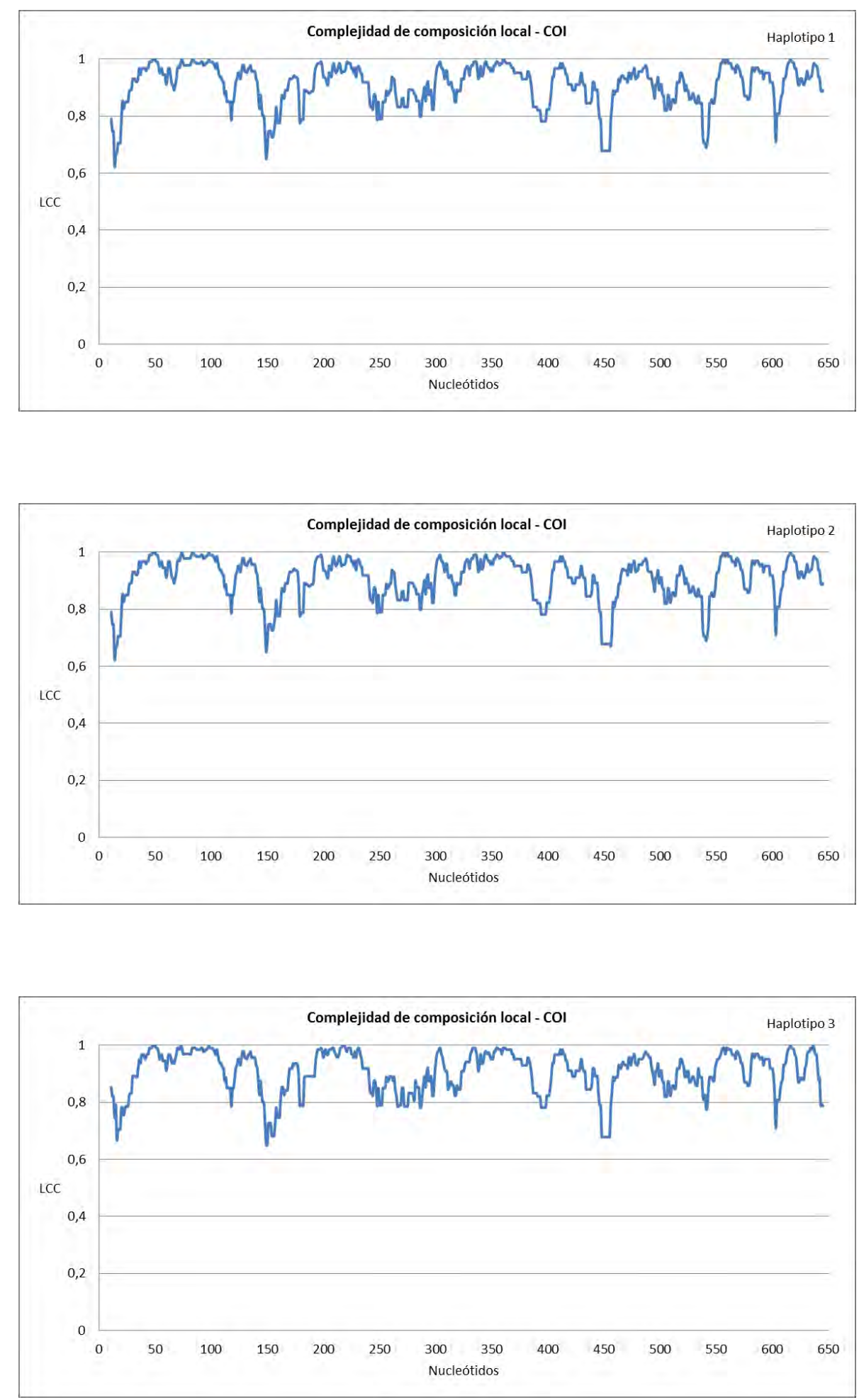

Figura 31. Gráficos comparativos de la complejidad del contenido informativo de la región parcial del gen COI en Aylacostoma. El haplotipo al que corresponde cada perfil se indica en el ángulo superior derecho de cada gráfico. 

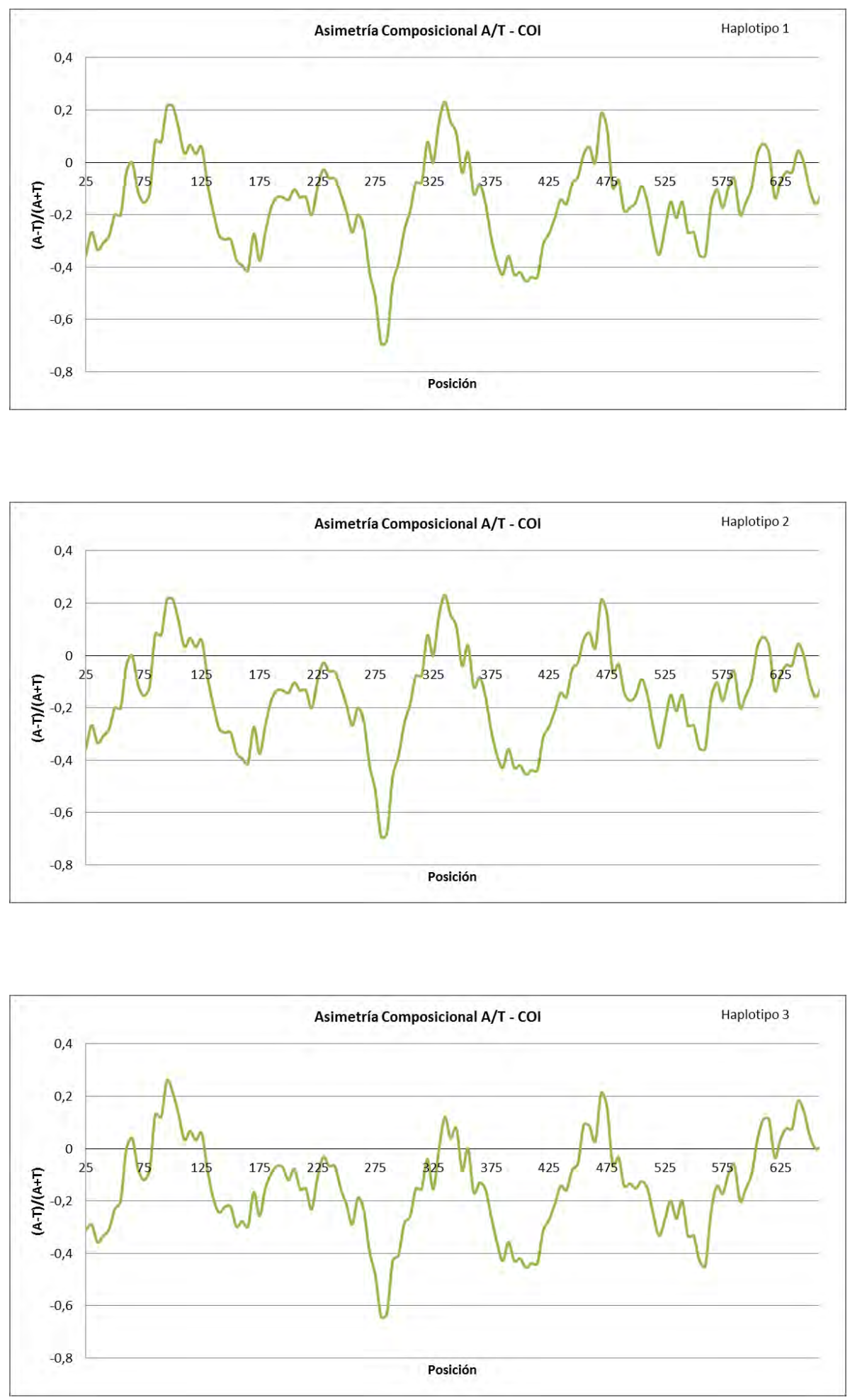

Figura 32. Análisis de asimetría composicional A vs. T de la región parcial del gen COI en Aylacostoma. El haplotipo al que corresponde cada perfil se indica en el ángulo superior derecho de cada gráfico. 

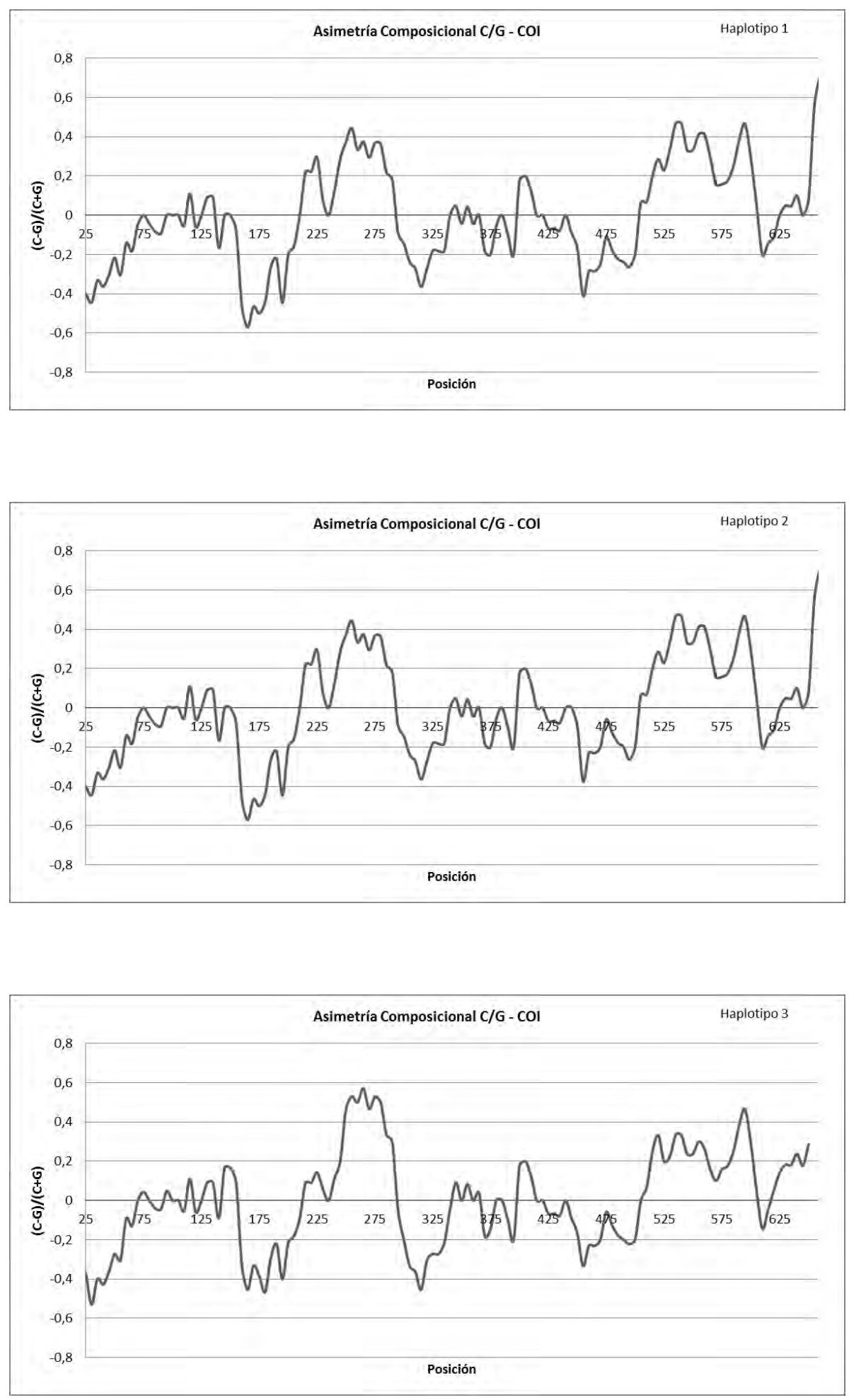

Figura 33. Análisis de asimetría composicional C vs. G de la región parcial del gen COI en Aylacostoma. El haplotipo al que corresponde cada perfil se indica en el ángulo superior derecho de cada gráfico. 
Tabla XVI. Valores de asimetrías composicionales calculados para los tres haplotipos del gen COI procedentes del Alto Paraná.

\begin{tabular}{|c|c|c|c|}
\hline & HAPLOTIPO 1 & HAPLOTIPO 2 & HAPLOTIPO 3 \\
\hline $\begin{array}{r}\text { Asimetría AT } \\
(\mathrm{A}-\mathrm{T}) /(\mathrm{A}+\mathrm{T})\end{array}$ & $\begin{array}{c}=(172-241) /(172+241) \\
=(-69) /(413) \\
-0,1670\end{array}$ & $\begin{array}{c}=(173-241) /(173+241) \\
=(-68) /(414) \\
-0,1642\end{array}$ & $\begin{array}{c}=(173-237) /(173+237) \\
=(-64) /(410) \\
-0,1560\end{array}$ \\
\hline $\begin{array}{r}\text { Asimetría GC } \\
(\mathrm{G}-\mathrm{C}) /(\mathrm{G}+\mathrm{T})\end{array}$ & $\begin{array}{c}=(126-119) /(126+119) \\
=(7) /(245) \\
0,028\end{array}$ & $\begin{array}{c}=(125-119) /(125+119) \\
=(6) /(244) \\
0,024\end{array}$ & $\begin{array}{c}=(124-124) /(124+124) \\
=(0) /(248) \\
0\end{array}$ \\
\hline
\end{tabular}

\section{III.3.5.3 Calidad de los datos}

\section{III.3.5.3.1 Verificación de la saturación}

El cálculo de la saturación mediante la prueba de Xia et al. (2003) mostró ausencia de saturación en los datos (Tabla XVII). Asimismo, la representación de las transiciones y transversiones con respecto a las distancias genéticas tanto para las secuencias alineadas sin los taxa del grupo externo (Figura 34), como para cuando se incluyó el grupo externo (Figura 35) fue consistente con el resultado de la prueba, evidenciando ausencia de saturación.

Tabla XVII. Niveles de saturación de acuerdo a la prueba de Xia et al. (2003).

\begin{tabular}{|c|c|c|c|c|}
\hline Sin grupo externo & Iss & Iss.C & $p$ & INTERPRETACIÓN \\
\hline $\begin{array}{l}\text { Para un árbol simétrico } \\
\text { Para un árbol extremamente asimétrico }\end{array}$ & 0,0376 & $\begin{array}{l}0,8109 \\
0,8034\end{array}$ & $\begin{array}{l}0,00 \\
0,00\end{array}$ & Ausencia o poca saturación [Iss $<$ Iss.c; $p<0,05]$ \\
\hline Con grupo externo & & & & \\
\hline $\begin{array}{l}\text { Para un árbol simétrico } \\
\text { Para un árbol extremamente asimétrico }\end{array}$ & 0,1859 & $\begin{array}{l}0,7743 \\
0,7017\end{array}$ & $\begin{array}{l}0,00 \\
0,00\end{array}$ & Ausencia o poca saturación [Iss $<$ Iss.c; $p<0,05]$ \\
\hline
\end{tabular}

\section{III.3.5.3.2 Verificación de señal filogenética}

Los valores obtenidos para la prueba de permutación PTP se grafican en la Figura 36 y se presentan en la Tabla XVIII. 


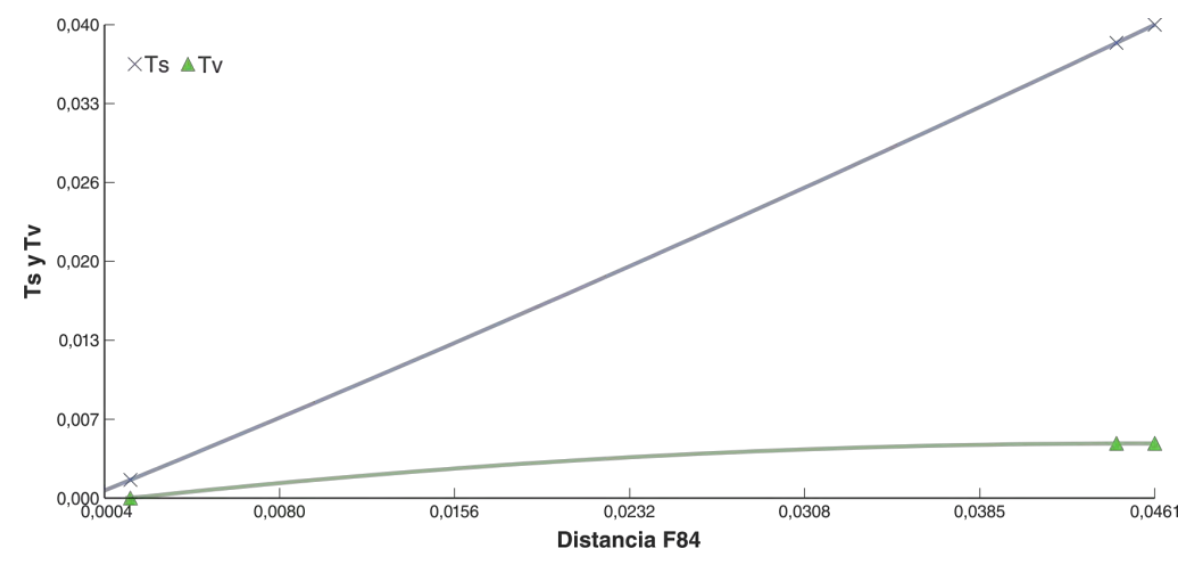

Figura 34. Comparación de las transiciones (Ts) y transversiones (Tv) respecto de la distancia genética sin incluir los taxa del grupo externo.

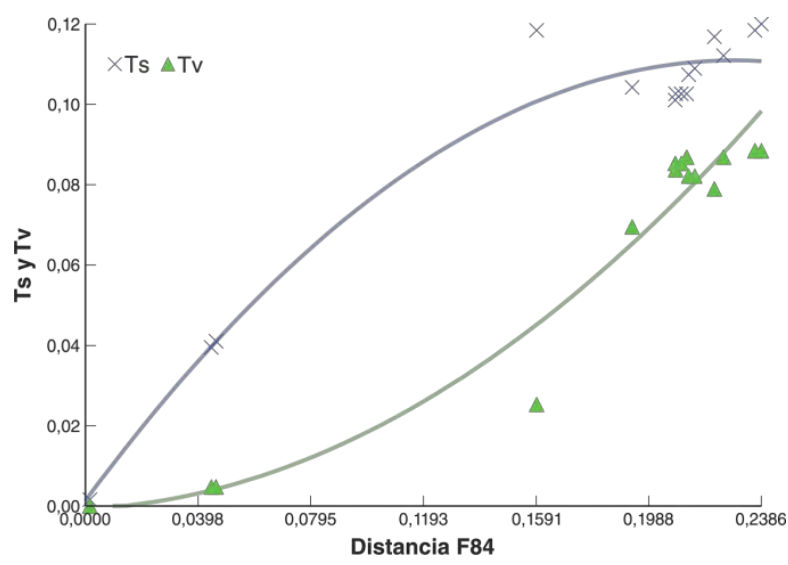

Figura 35. Comparación de las transiciones (Ts) y transversiones (Tv) respecto de la distancia genética al incluir los taxa del grupo externo.

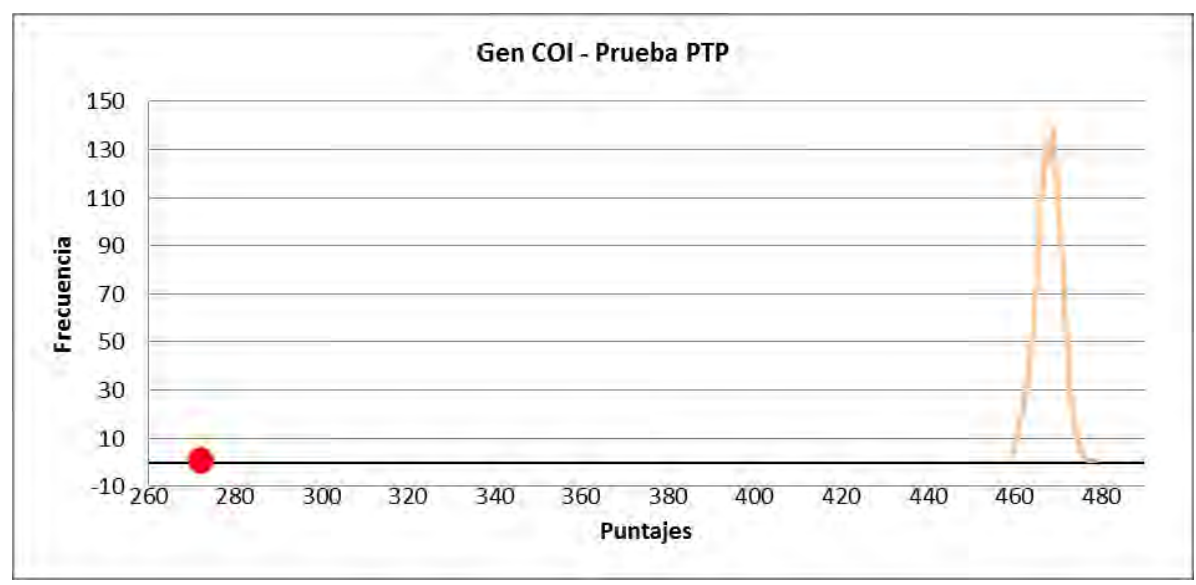

Figura 36. Distribución de puntajes de la prueba PTP en las secuencia COI. Se observa que el puntaje obtenido de los datos reales $(=272$; en rojo) se encuentra fuera de la distribución de los puntajes obtenidos por permutación (en naranja). 
Tabla XVIII. Resultados de la prueba PTP.

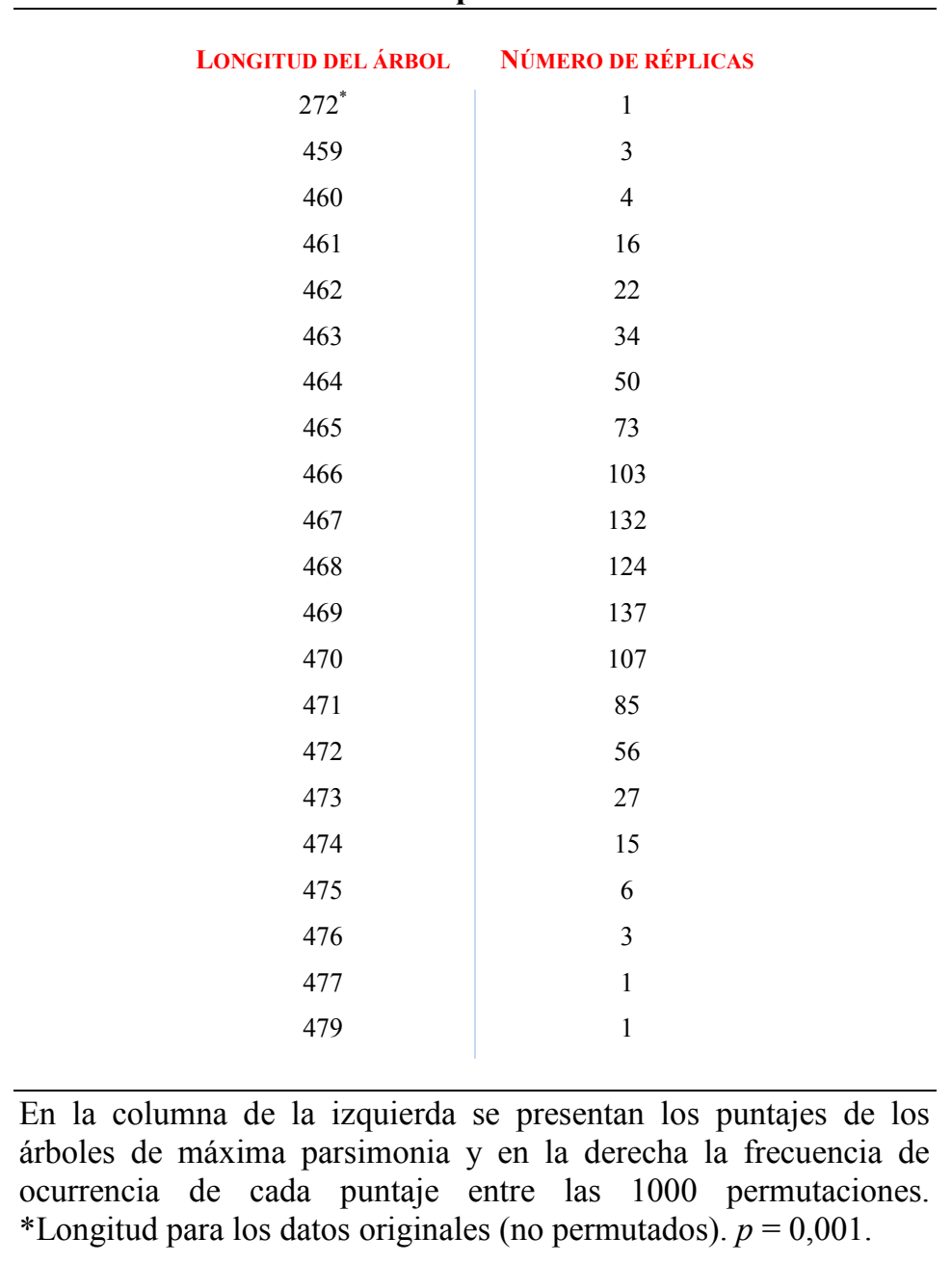

Los resultados indican que el mejor puntaje (más parsimonioso) difiere significativamente $(p=0,001)$ de los valores obtenidos por la permutación al azar de los datos. En el contexto de esta prueba los datos evidencian una fuerte señal filogenética.

\section{III.3.5.4 Distancias genéticas}

Para A. chloroticum se observó una distancia genética estrecha entre sus haplotipos (H1 y H2) independientemente del tipo de modelo de sustitución empleado (Tabla XIX). No obstante, ambos haplotipos evidenciaron individualmente una marcada divergencia respecto del nuevo morfotipo (H3), siendo levemente mayor la distancia entre $\mathrm{H} 2$ y H3 que entre $\mathrm{H} 1$ y H3. Al agrupar los haplotipos de A. chloroticum, y calcular la distancia respecto del nuevo morfotipo según diferentes modelos de sustitución (Tabla XX), se obtuvo una divergencia promedio entre A. chloroticum y el nuevo morfotipo del orden del 4,56\%. 
Tabla XIX. Distancia nucleotídica entre pares de haplotipos mitocondriales del gen COI según diferentes modelos de sustitución nucleotídica.

Distancia $p$

\begin{tabular}{|c|c|c|c|}
\hline & H1 & H2 & H3 \\
\hline H1 & - & & \\
\hline $\mathrm{H} 2$ & 0,001519 & - & \\
\hline $\mathrm{H} 3$ & 0,042553 & 0,044073 & - \\
\hline & \multicolumn{3}{|c|}{ Distancia de Jukes-Cantor (JC) } \\
\hline & H1 & H2 & H3 \\
\hline $\mathrm{H} 1$ & - & & \\
\hline $\mathrm{H} 2$ & 0,001521 & - & \\
\hline $\mathrm{H} 3$ & 0,043808 & 0,045421 & - \\
\hline
\end{tabular}

Distancia de Kimura dos Parámetros (K2P)

$\begin{array}{lll}\text { H1 H2 } & \text { H3 }\end{array}$

\begin{tabular}{c|c|c} 
H1 & - & \\
$\mathrm{H} 2$ & 0,001522 & - \\
$\mathrm{H} 3$ & 0,044278 & 0,045934
\end{tabular}

Distancia de Tajima \& Nei (TN84)

$\begin{array}{lll}\text { H1 H2 } & \text { H3 }\end{array}$

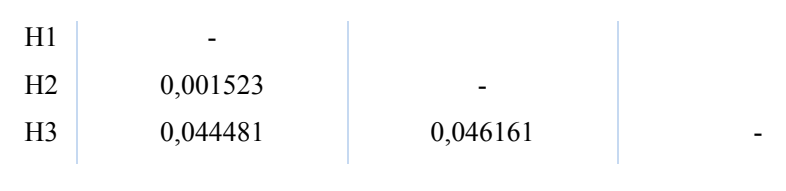

Distancia F84

\begin{tabular}{c|c|c|c} 
& H1 & H2 & H3 \\
H1 & - & & \\
H2 & 0,001524 & - & - \\
H3 & 0,044401 & 0,046069 & -
\end{tabular}

Distancia de Tamura \& Nei (TN93)
H1
H2
H3

\begin{tabular}{c|c|c} 
H1 & - & \\
H2 & 0,001527 & - \\
H3 & 0,044461 & 0,046160
\end{tabular}

H1 y H2: haplotipos de A. chloroticum; H3: haplotipo del nuevo morfotipo.

Tabla XX. Distancias genéticas entre $A$. chloroticum y el nuevo morfotipo según diferentes modelos de sustitución nucleotídica.

\begin{tabular}{|c|c|c|c|c|c|c|c|}
\hline & $P$ & JC & K2P & TN84 & F84 & TN93 & PROMEDIO \\
\hline Distancia & 0,04407 & 0,04542 & 0,04593 & 0,04616 & 0,04607 & 0,0461620 & 0,0456353 \\
\hline Porcentual & $4,407 \%$ & $4,542 \%$ & $4,593 \%$ & $4,616 \%$ & $4,607 \%$ & $4,61 \%$ & $4,56353 \%$ \\
\hline
\end{tabular}




\section{III.3.5.5 Estimación de los parámetros genético-poblacionales}

\section{III.3.5.5.1 Variabilidad genética}

Los valores de diversidad haplotípica $\left(\mathrm{H}_{\mathrm{D}}\right)$ y nucleotídica $(\pi)$ por población y total para A. chloroticum y el nuevo morfotipo se presentan en la Tabla XXI. Para A. chloroticum, los valores totales de diversidad obtenidos resultaron bajos a pesar de haber incluido muestras de seis localidades geográficas representando la distribución conocida para la especie en el Alto Paraná.

\section{III.3.5.5.2 Análisis demográfico}

Ninguna de las pruebas de neutralidad evaluadas (i.e. D de Tajima, $\mathrm{F}_{\mathrm{S}}$ de $\mathrm{Fu}$ y $\mathrm{R}_{2}$ ) resultó estadísticamente significativa, por lo cual no fue posible detectar huellas de posibles eventos demográficos a partir de estos estimadores. Los resultados de las pruebas se presentan en la Tabla XXI.

Por otra parte, el cálculo de la distribución de discrepancias pareadas, considerando $A$. chloroticum o incluyendo al nuevo morfotipo como parte de la especie, no permitió el rechazo de ninguno de los dos modelos evaluados (i.e. expansión súbita reciente y expansión espacial; Tabla XXII). El índice de Harpending resultó estadísticamente no significativo, indicando una interpretación unimodal de las discrepancias pareadas (Tabla XXII). La representación gráfica de la distribución de discrepancias pareadas se presenta en la Figura 37. Para A. chloroticum se observó una distribución unimodal; en contraste, al incluir al nuevo morfotipo como parte de la especie, la distribución de las distancias genéticas interindividuales fue bimodal.

\section{III.3.5.6 Distribución espacial de la variabilidad genética en el Alto Paraná}

\section{III.3.5.6.1 Análisis de la varianza molecular (AMOVA)}

Cuando se consideraron sólo los seis registros geográficos de A. chloroticum, el AMOVA para estas poblaciones condujo a un valor significativo de $\Phi_{\mathrm{ST}}=0,49368(p<0,01)$, indicando que al menos una de las poblaciones posee heterogeneidad significativa. Al explorar esta situación mediante las comparaciones pareadas, se observó que la única población que presentó diferenciación genética fue la de Río Beach (Tabla XXIII). 
Tabla XXI. Principales estadísticos obtenidos de las secuencias COI analizadas.

\begin{tabular}{|c|c|c|c|c|c|c|c|c|c|c|c|c|}
\hline & $\mathbf{N}$ & h & $\mathrm{HD} \pm \mathrm{DS}$ & $\pi \pm \mathrm{DS}$ & $\mathbf{S}$ & $\boldsymbol{\theta}_{\mathrm{S}} \pm \mathrm{DS}$ & $\mathbf{D}_{\mathrm{T}}$ & Prob. $\left(\left|\mathbf{D}_{\mathrm{T}}\right|\right)>0$ & $\mathrm{D}_{\mathrm{T}} \mathrm{IC} 95 \%$. & $F_{\mathrm{S}}$ & $\mathbf{R}_{\mathbf{2}}$ & $k \max$ \\
\hline Aylacostoma chloroticum & 37 & 2 & $0,198 \pm 0,08$ & $0,00030 \pm 0,00012$ & 1 & $0,00036 \pm 0,00036$ & $-0,25209^{*}$ & 0,5438 & $-1,13092 ; 1,65202$ & $0,2 *$ & 0,0991* & 1 \\
\hline $\mathrm{A}^{\mathrm{o}}$ San Juan & 2 & 1 & 0 & 0 & 0 & 0 & n.c. & n.c. & n.c. & n.c. & n.c. & 0 \\
\hline Candelaria & 10 & 1 & 0 & 0 & 0 & 0 & n.c. & n.c. & n.c. & n.c. & n.c. & 0 \\
\hline Lg. San José & 10 & 1 & 0 & 0 & 0 & 0 & n.c. & n.c. & n.c. & n.c. & n.c. & 0 \\
\hline Pto. Posadas & 3 & 1 & 0 & 0 & 0 & 0 & n.c. & n.c. & n.c. & n.c. & n.c. & 0 \\
\hline R. Apipé & 5 & 1 & 0 & 0 & 0 & 0 & n.c. & n.c. & n.c. & n.c. & n.c. & 0 \\
\hline Rio Beach & 7 & 2 & $0,571 \pm 0,119$ & $0,00087 \pm 0,00018$ & 1 & $0,00062 \pm 0,00062$ & $1,34164^{*}$ & 1 & $-1,00623 ; 1,34164$ & $0,856^{*}$ & $0,2857^{*}$ & 1 \\
\hline Morfotipo nuevo & 6 & 1 & 0 & 0 & 0 & 0 & n.c. & n.c. & n.c. & n.c. & n.c. & 0 \\
\hline Ita Cuá & 5 & 1 & 0 & 0 & 0 & 0 & n.c. & n.c. & n.c. & n.c. & n.c. & 0 \\
\hline Rio Beach & 1 & 1 & - & - & - & - & - & - & - & - & - & - \\
\hline Totalidad de la muestra & 47 & 3 & $0,392 \pm 0,084$ & $0,01072 \pm 0,00325$ & 29 & $0,01019 \pm 0,00340$ & $0,17921^{*}$ & 0,6522 & $-1,62834 ; 1,79389$ & $14,924 *$ & $0,1217^{*}$ & 29 \\
\hline
\end{tabular}


Tabla XXII. Significación estadística de las distribuciones pareadas bajo los modelos de expansión súbita y espacial.

\begin{tabular}{r|c|c|c|c}
\hline & \multicolumn{2}{c}{ EXPANSIÓN SÚBITA } & \multicolumn{2}{c}{ EXPANSIÓn ESPACIAL } \\
A. chloroticum & 0,3330 & 0,4036 & 0,0003 & 0,4036 \\
& $(p=0,1230)$ & $(p=0,1070)$ & $(p=0,2080)$ & $(p=0,5420)$ \\
& & & & SSD \\
A. chloroticum & 0,0642 & 0,3205 & 0,0429 & 0,3205 \\
$(+$ nuevo morfotipo $)$ & $(p=0,1350)$ & $(p=0,4690)$ & $(p=0,3050)$ & $(p=0,6440)$ \\
\hline
\end{tabular}

SDD: suma de cuadrados de los desvíos entre la distribución mismatch observada y esperada; Hri: índice de raggedness de Harpending.
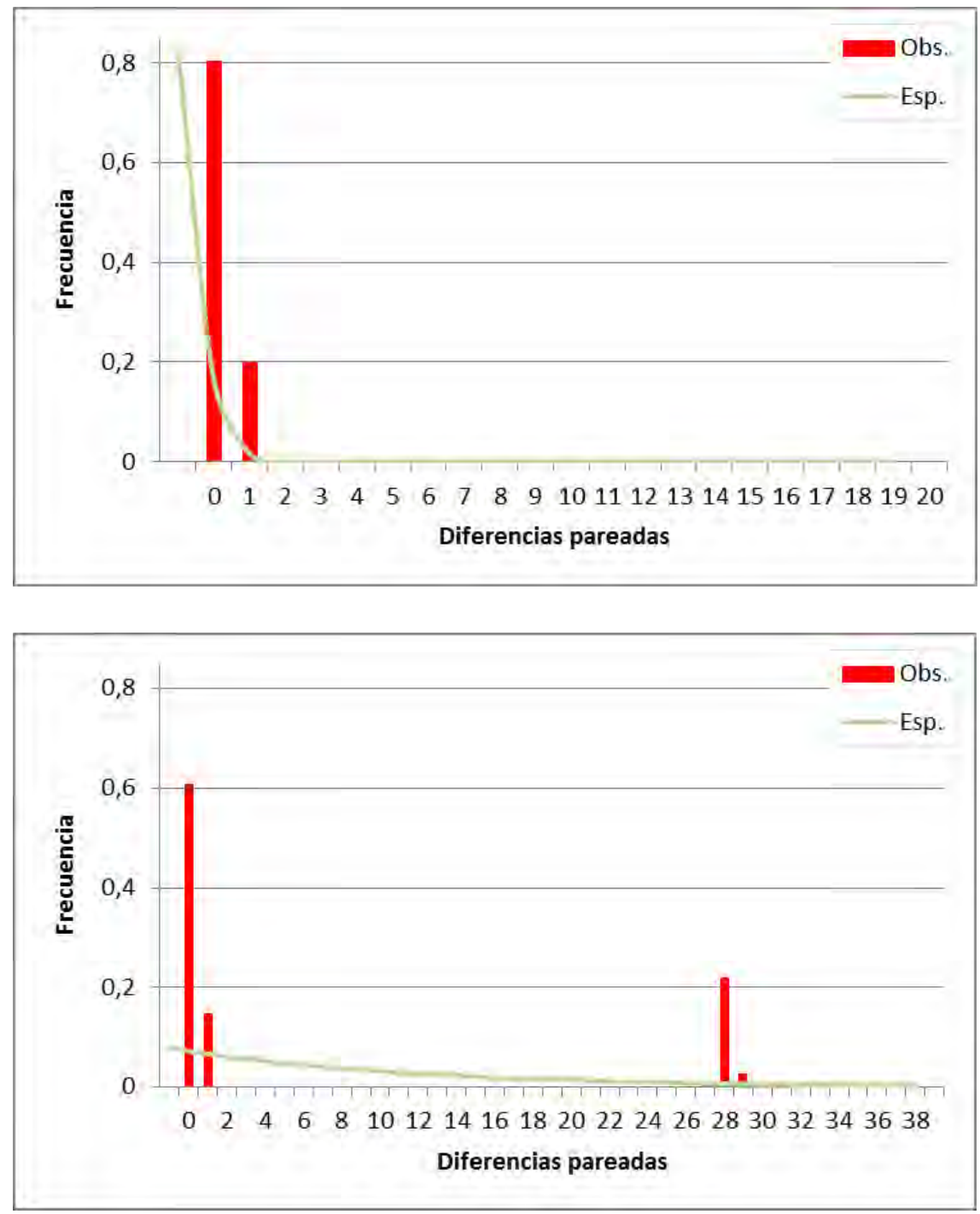

Figura 37. Distribución de discrepancias pareadas. Superior: A. chloroticum; Inferior: A. chloroticum incluyendo al nuevo morfotipo como parte de la especie. La línea verde indica los valores esperados bajo un modelo de expansión poblacional. En rojo se presenta la distribución observada en la muestra. 
Tabla XXIII. Valores de $\Phi_{\mathrm{ST}}$ de la comparación pareada de las seis poblaciones de $\boldsymbol{A}$. chloroticum.

\begin{tabular}{|c|c|c|c|c|c|c|}
\hline & $\mathbf{A}^{\circ}$ SAN JUAN & CANDELARIA & LG. SAN JOSÉ & PTo. Posadas & R. APIPÉ & RIO BEACH \\
\hline $\mathbf{A}^{\circ}$ San Juan & 0 & - & - & - & - & - \\
\hline Candelaria & 0 & 0 & - & - & - & - \\
\hline Lg. San José & 0 & 0 & 0 & - & - & - \\
\hline Pto. Posadas & 0 & 0 & 0 & 0 & - & - \\
\hline R. Apipé & 0 & 0 & 0 & 0 & 0 & - \\
\hline Río Beach & 0,25664 & $0,56656^{*}$ & $0,56656^{*}$ & 0,34375 & 0,43850 & 0 \\
\hline
\end{tabular}

Al realizar el análisis jerárquico de la variación utilizando el canal del río Paraná como criterio de regionalización, los dos grupos definidos fueron: a) Paraguay, que incluyó únicamente a la población de Río Beach, y b) Argentina, en el que se incluyeron las restantes poblaciones. Los resultados obtenidos (Tabla XXIV) indicaron la ausencia de diferencias genéticas significativas entre los registros geográficos a ambos lados del canal principal del río. Tampoco se evidenciaron diferencias entre las poblaciones dentro de las regiones, siendo significativa sólo la variación dentro de las poblaciones.

\begin{tabular}{r|c|c|c}
$\begin{array}{l}\text { Tabla XXIV. Análisis jerárquico } \\
\text { chloroticum. }\end{array}$ & por regiones de la variación genética en $\boldsymbol{A}$. \\
\hline FuENTE dE VARIACión & PORCENTAJE DE VARIACIÓN & ESTAdísticos $\Phi$ & $P$ \\
Entre regiones & 78,44 & $\Phi_{\mathrm{CT}}=0,7844$ & 0,1660 \\
Entre poblaciones dentro de las regiones & $-4,77^{\dagger}$ & $\Phi_{\mathrm{SC}}=-0,2214^{\dagger}$ & 1,000 \\
Dentro de las poblaciones & 26,33 & $\Phi_{\mathrm{ST}}=0,78441$ & 0,006
\end{tabular}

Argentina: A $^{\circ}$ San Juan, Candelaria, Laguna San José, Pto. Posadas, R. Apipé; Paraguay: Río Beach. $(\dagger)$ el valor debe interpretarse como 0 .

Al incorporar al nuevo morfotipo como parte de $A$. chloroticum, se analizaron un total de siete poblaciones, obteniéndose en el AMOVA un valor altamente significativo de $\Phi_{\mathrm{ST}}=$ $0,81821(p<0,0001)$. Mediante las comparaciones pareadas, se observó que las poblaciones que evidenciaron mayor diferenciación genética fueron las de Ita Cuá y Río Beach (Tabla $\mathrm{XXV}$ ). La población de Ita Cuá (constituida exclusivamente por representantes del nuevo morfotipo) fue claramente diferente respecto de la mayoría de las poblaciones de $A$. chloroticum obteniendo valores máximos de diferenciación $\left(\Phi_{\mathrm{ST}}=1\right)$. La excepción fue la población de Río Beach, donde el valor obtenido $\left(\Phi_{\mathrm{ST}}=0,81269\right)$ señaló la existencia de haplotipos compartidos con la población de Ita Cuá (Tabla XXVI). 
Tabla XXV. Valores de $\Phi_{\mathrm{ST}}$ de la comparación pareada de las poblaciones del Alto Paraná incluyendo el nuevo morfotipo como parte de A. chloroticum.

\begin{tabular}{|c|c|c|c|c|c|c|c|}
\hline & $\mathbf{A}^{\circ}$ SAN JuAn & CANDELARIA & ITA Cú́ & LG. SAN JOSÉ & Pto. Posadas & R. APIPÉ & RIO BEACH \\
\hline $\mathbf{A}^{\circ}$ San Juan & 0 & - & - & - & - & - & - \\
\hline Candelaria & 0 & 0 & - & - & - & - & - \\
\hline Ita Cuá & $1,000^{*}$ & $1,000^{*}$ & 0 & - & - & - & - \\
\hline Lg. San José & 0 & 0 & $1,000^{*}$ & 0 & - & - & - \\
\hline Pto. Posadas & 0 & 0 & $1,000^{*}$ & 0 & 0 & - & - \\
\hline R. Apipé & 0 & 0 & $1,000^{*}$ & 0 & 0 & 0 & - \\
\hline Río Beach & $-0,26379^{\dagger}$ & $0,08680^{*}$ & $0,81269^{*}$ & $0,08680^{*}$ & $-0,12666^{\dagger}$ & $-0,02021^{\dagger}$ & 0 \\
\hline
\end{tabular}

$(*) p<0,05 ;(\dagger)$ el valor debe interpretarse como 0 .

Tabla XXVI. Distribución de haplotipos por población.

\begin{tabular}{l|c|c|c|c|c|c|c}
\hline & A $^{\circ}$ San Juan & Candelaria & Ita Cú́ & Lg. San José & Pto. Posadas & R. Apipé & Rio Beach \\
H1 & 2 & 10 & - & 10 & 3 & 5 & 3 \\
H2 & - & - & - & - & - & - & 4 \\
H3 & - & - & 5 & - & - & - & 1 \\
\hline
\end{tabular}

Se indica el número de individuos que presentaron cada haplotipo

Para el análisis jerárquico de la variación utilizando el canal del río Paraná como criterio de regionalización, los dos grupos definidos fueron: a) Paraguay, que incluyó a las poblaciones de Río Beach e Ita Cuá, y b) Argentina, que incluyó a las poblaciones restantes. Los resultados obtenidos (Tabla XXVII) indicaron la ausencia de diferencias genéticas significativas entre ambas regiones. No obstante, bajo esta estructura genética se evidenciaron diferencias significativas entre y dentro de las poblaciones en las regiones definidas.

Tabla XXVII. Análisis jerárquico por regiones de la variación genética.

\begin{tabular}{r|c|c|c}
\hline FuENTE DE VARIACIÓN & PORCENTAJE DE VARIACión & ESTAdísticos $\Phi$ & $P$ \\
Entre regiones & 41,48 & $\Phi_{\mathrm{CT}}=0,4148$ & 0,1911 \\
Entre poblaciones dentro de las regiones & 44,02 & $\Phi_{\mathrm{SC}}=0,7512$ & 0,0039 \\
Dentro de las poblaciones & 14,50 & $\Phi_{\mathrm{ST}}=0,8549$ & 0,0000
\end{tabular}

Argentina: $\mathrm{A}^{\circ}$ San Juan, Candelaria, Laguna San José, Pto. Posadas, R. Apipé; Paraguay (Ita Cuá,

Río Beach. Se incluye al nuevo morfotipo como parte de A. chloroticum.

\section{III.3.5.6.2 Distancia geográfica vs. distancia genética: Test de Mantel}

Al considerar únicamente las poblaciones de A. chloroticum, la prueba de Mantel no evidenció diferencias significativas entre la distancia geográfica respecto de la distancia genética en la especie $(r=-0,1039, p=0,922)$. 
Más aún, al incorporar el nuevo morfotipo como parte de $A$. chloroticum, tampoco se evidenciaron diferencias significativas entre ambas matrices de distancias $(r=-0,1201, p=$ 0,994). Los correlogramas de Mantel para los registros considerando sólo las poblaciones de A. chloroticum, e incluyendo al nuevo morfotipo como parte de la especie se muestran en la Figura 38 (superior e inferior, respectivamente).

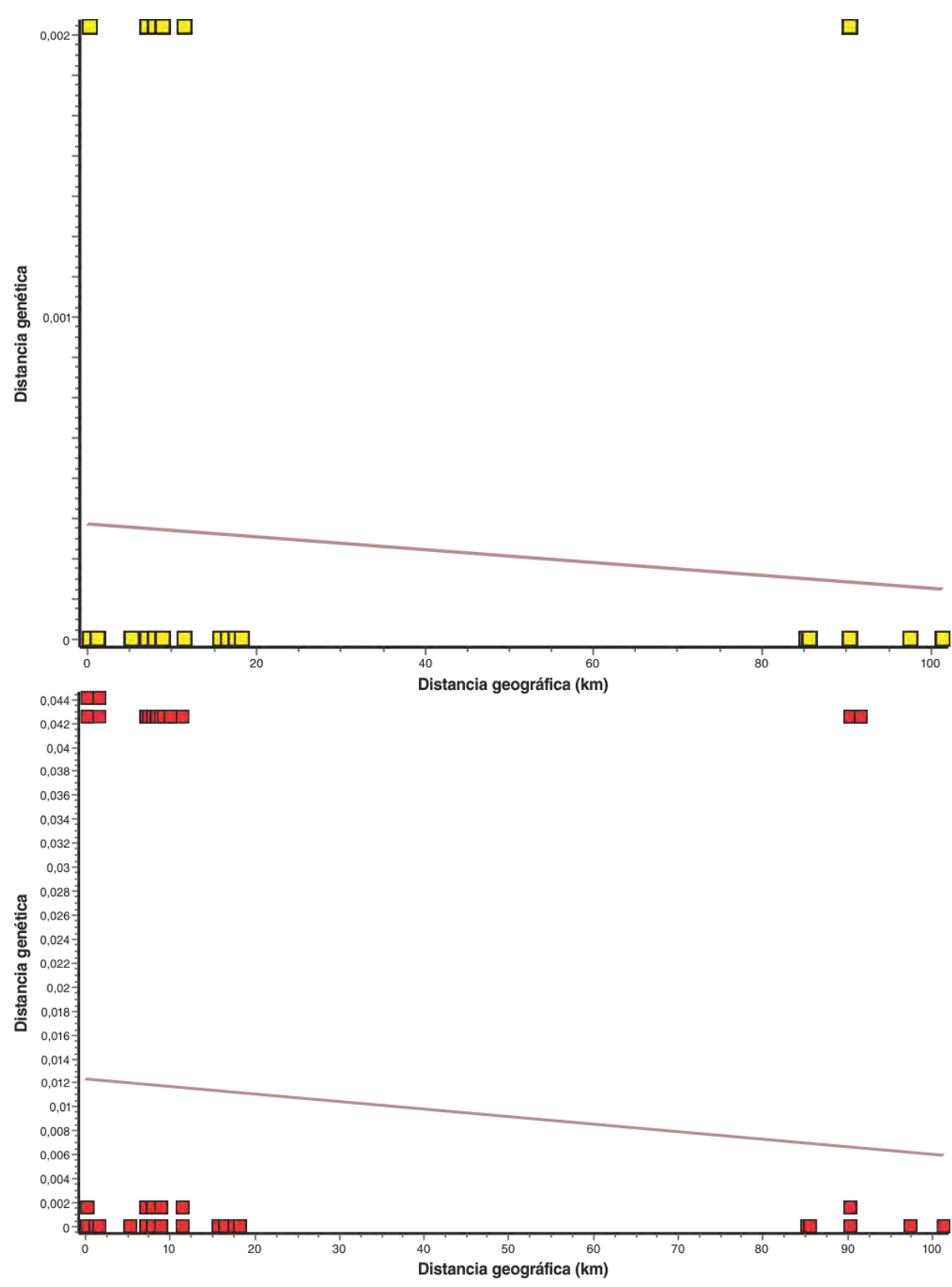

Figura 38. Correlogramas de Mantel a partir de 1000 permutaciones al azar entre las matrices de distancias genéticas y geográficas. Superior: considerando sólo las poblaciones de $A$. chloroticum. Inferior: tratando al nuevo morfotipo como parte de $A$. chloroticum. 


\section{III.3.5.7 Abordajes filogenéticos}

\section{III.3.5.7.1 Relaciones evolutivas entre las poblaciones del Alto Paraná}

Los árboles reconstruidos a partir de los cuatro métodos fueron congruentes en cuanto a los agrupamientos, difiriendo levemente en las topologías obtenidas. A continuación se detallan las particularidades de la reconstrucción para cada método.

Para el análisis de MP, de los 658 caracteres de la matriz, 120 resultaron informativos para parsimonia y 468 fueron constantes. En la búsqueda heurística se evaluaron un total de 81.690 árboles y se retuvieron un total de 3 árboles igualmente parsimoniosos, de 272 pasos de longitud. Respecto de los tres árboles más parsimoniosos obtenidos, en todos se recuperó la monofilia entre $A$. chloroticum y el nuevo morfotipo con un valor de soporte de $100 \%$. El análisis de MP evidenció la existencia de dos clados, uno conteniendo A. chloroticum y otro conteniendo al nuevo morfotipo (Figura 39). El clado de A. chloroticum estuvo dividido en dos subclados, uno mayor que incluyó la totalidad de los ejemplares procedentes de Candelaria, Arroyo San Juan, Rápidos del Apipé, Laguna San José, Puerto Posadas y algunos individuos procedentes de Río Beach; el segundo subclado estuvo constituido únicamente por individuos procedentes de Rio Beach. Respecto al clado del nuevo morfotipo, el mismo incluyó los ejemplares de Ita Cuá y un ejemplar procedente de Río Beach.

En el análisis de distancia mediante NJ se obtuvieron resultados similares al análisis de MP (Figura 40), donde se reconocieron los dos agrupamientos mayores con valores de soporte del $100 \%$, y los mismos dos subclados dentro de A. chloroticum con valores de soporte medios $(66 \%)$.

En el análisis de ML la topología difirió levemente de la evidenciada por los métodos anteriores (Figura 40), dado que se reconoció sólo un gran agrupamiento para el material procedente del Alto Paraná, que incluyó tanto las secuencias de A. chloroticum como las del nuevo morfotipo. Dentro de este gran grupo, se reconocieron a su vez dos grupos más pequeños, uno incluyendo a individuos de $A$. chloroticum procedentes de Rio Beach (con un bajo valor de soporte, 56\%) y otro agrupando los individuos del nuevo morfotipo (soporte del 100\%). Las secuencias de la totalidad de los ejemplares procedentes de Candelaria, Arroyo San Juan, Rápidos del Apipé, Laguna San José, Puerto Posadas y algunos individuos procedentes de Río Beach se presentaron como una politomía no resuelta. 


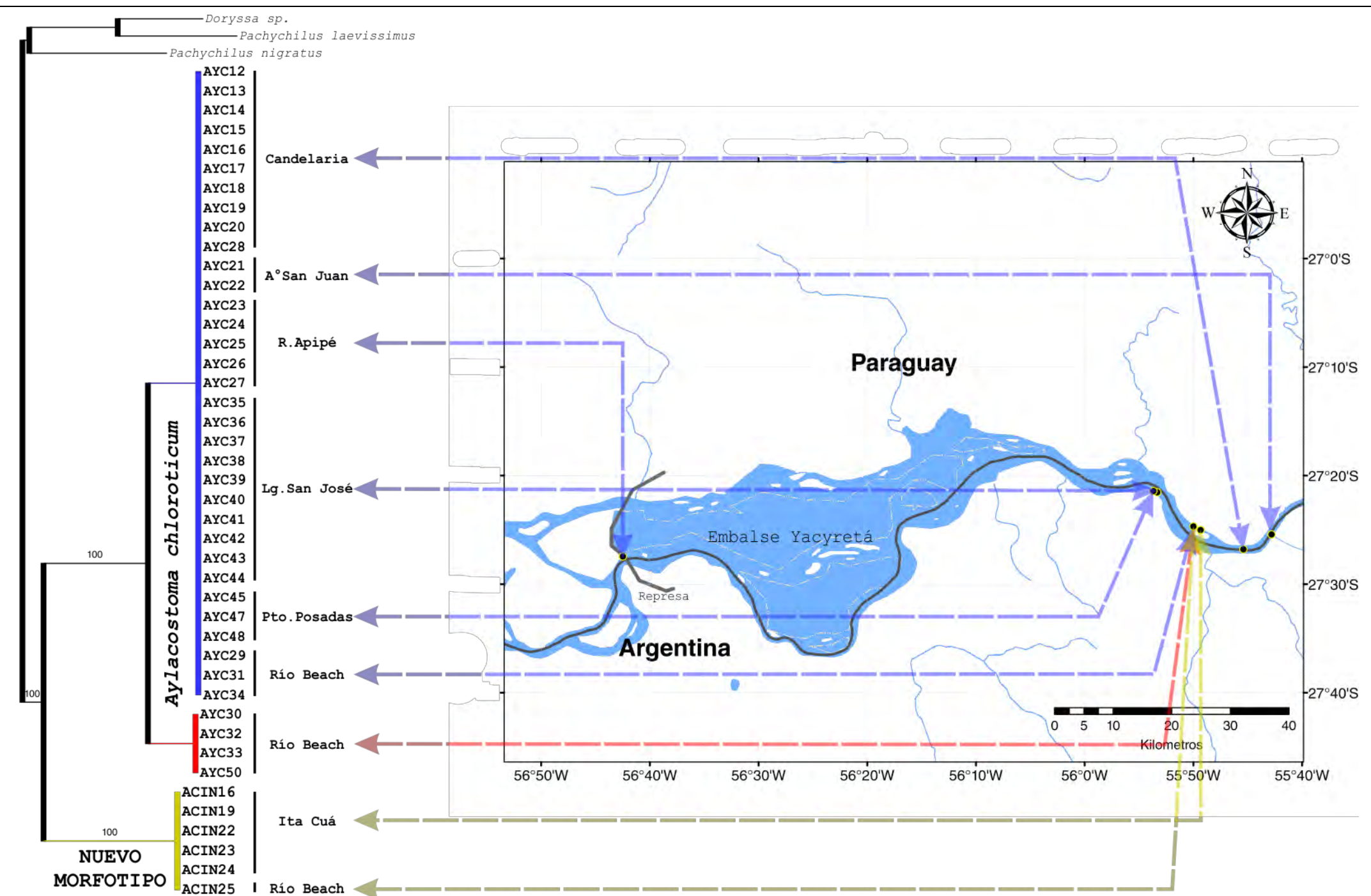

Figura 39. Reconstrucción filogenética de Aylacostoma spp. del Alto Paraná basada en 658 nucleótidos de la región parcial del gen COI. Se muestra uno de los tres árboles más parsimoniosos ( 120 caracteres informativos para parsimonia; longitud total: $272 ; \mathrm{CI}=0,8713 ; \mathrm{RI}=0,8856 ; \mathrm{RC}=0,7711)$ y la distribución en el espacio de los ejemplares analizados. Los valores de bootstrap mostrados sobre las ramas (>50\%) están basados en 1000 réplicas. 
A

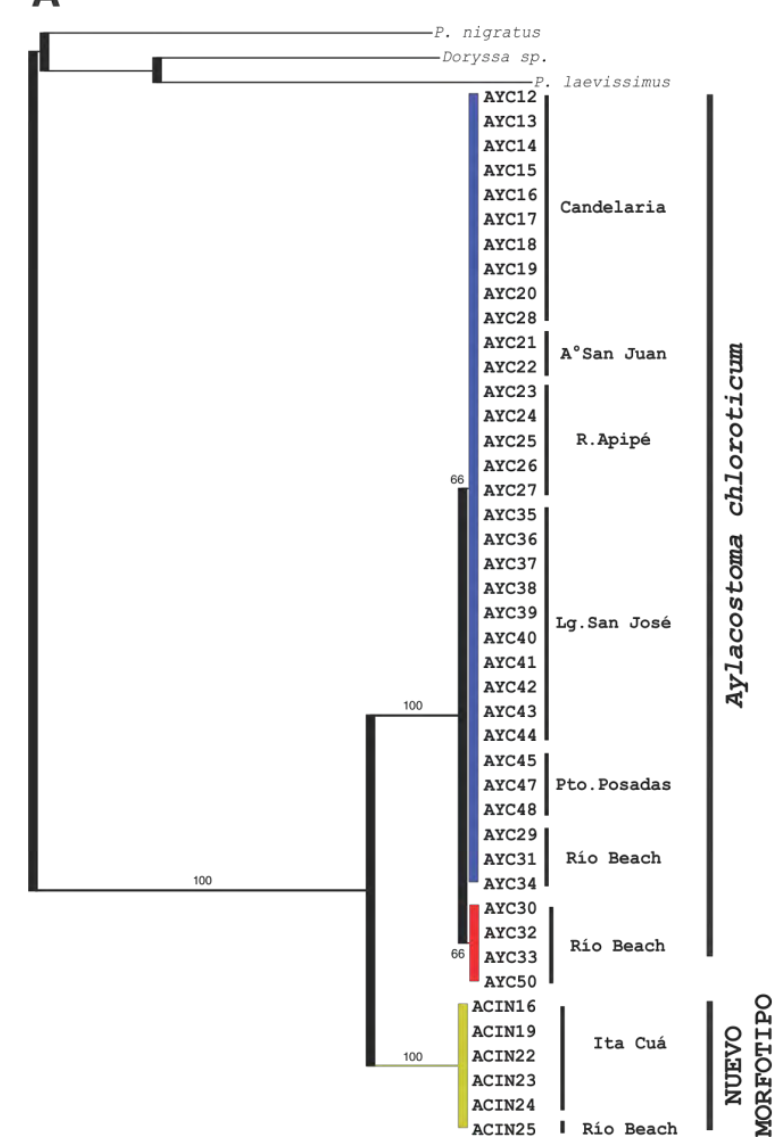

B

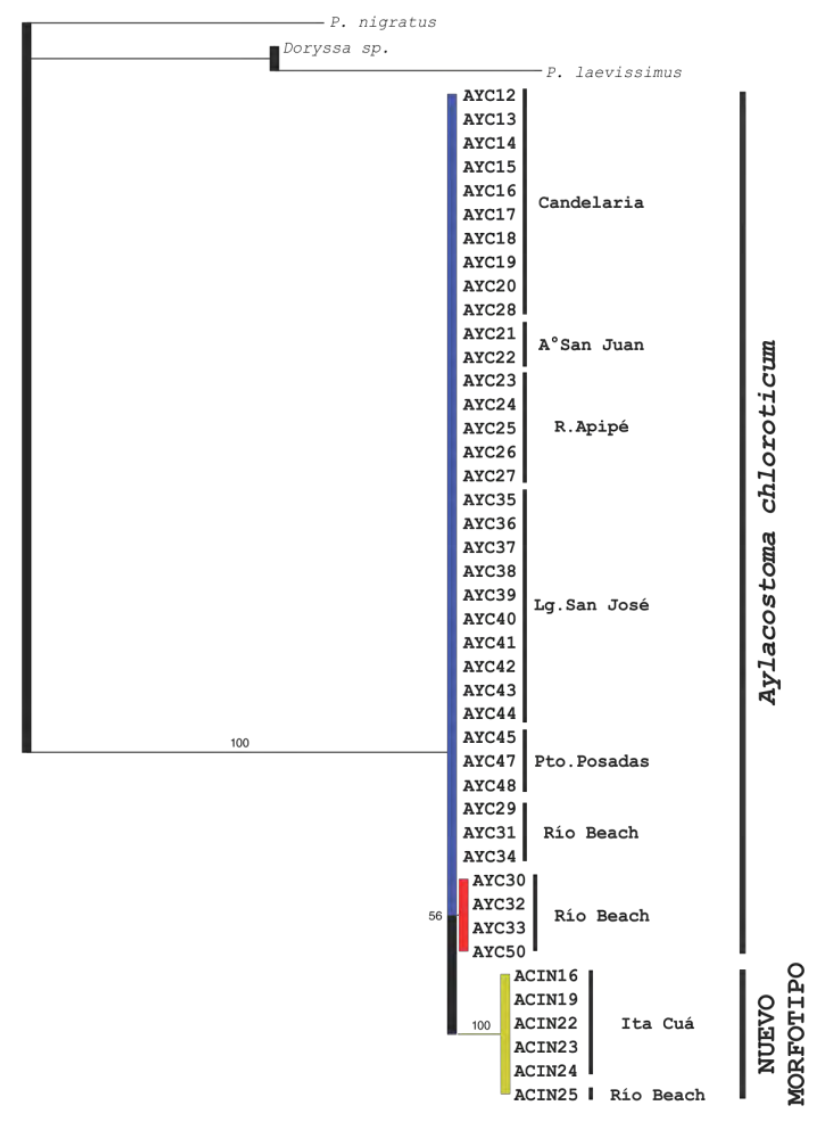

C

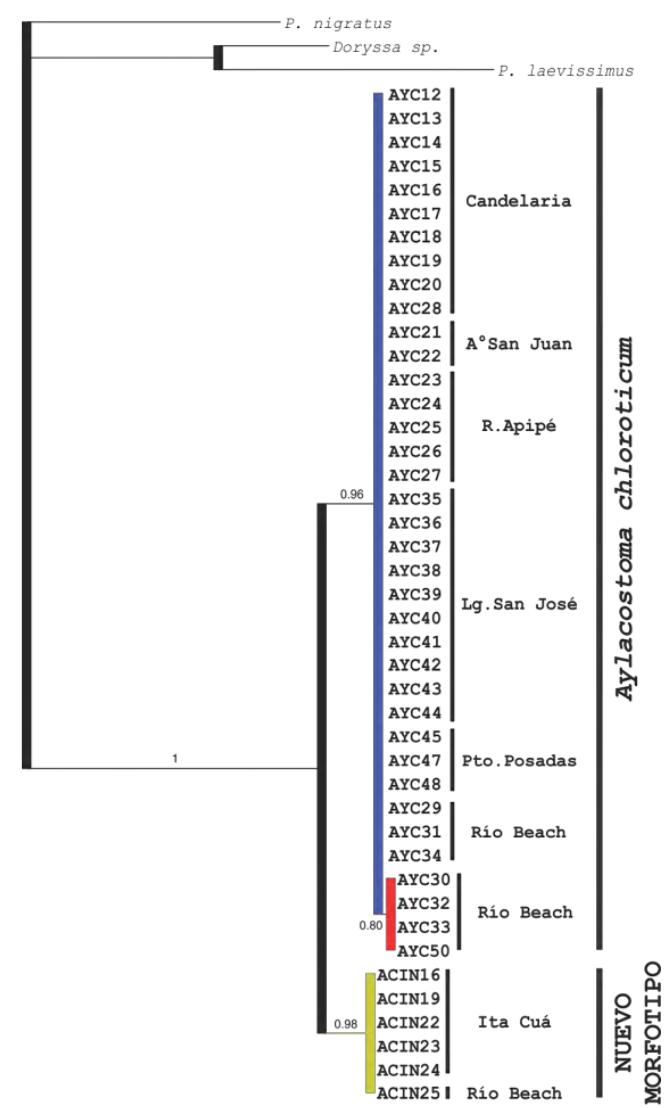

Figura 40. Reconstrucción filogenética basada en la región parcial del gen COI. A. Árbol de NJ. B. Mejor árbol de ML obtenido de PhyML (ln likelihood= -1.975,1317) basado en un modelo de sustitución TIM3+I. C. Árbol consenso de IB. Los valores de soporte se muestran sobre las ramas. Las referencias de las secuencias se presentan en la Tabla XIV. 
Finalmente, el análisis de IB evidenció una topología intermedia entre las obtenidas para MP-NJ y ML. En este análisis se observó que A. chloroticum y el nuevo morfotipo se encuentran asociados con una probabilidad a posteriori de 1, cada uno constituyendo un agrupamiento (equivalente a los dos clados mayores obtenidos mediante MP) con valores de credibilidad de 0,96 y 0,98 para A. chloroticum y el nuevo morfotipo, respectivamente. De forma similar a ML, dentro del grupo de $A$. chloroticum, un pequeño agrupamiento constituido por individuos de Rio Beach se diferenció con un valor de credibilidad de 0,80 , presentándose el resto de las secuencias dentro del grupo A. chloroticum como una politomía no resuelta en la base del grupo.

\section{III.3.5.7.2 Red de haplotipos}

La red de haplotipos obtenida a partir de las 43 secuencias del Alto Paraná (Figura 41) exhibió un haplotipo dominante (i.e. H1) presente en seis de los siete registros geográficos analizados, del cual derivó un haplotipo de baja frecuencia (i.e. H2) presente en una única localidad y separado a su vez por un único paso mutacional; ambos haplotipos hallados en ejemplares de A. chloroticum. Adicionalmente, se evidenció un haplotipo exclusivo para ejemplares del nuevo morfotipo (i.e H3) separado por 28 pasos mutacionales de $\mathrm{H} 1$.

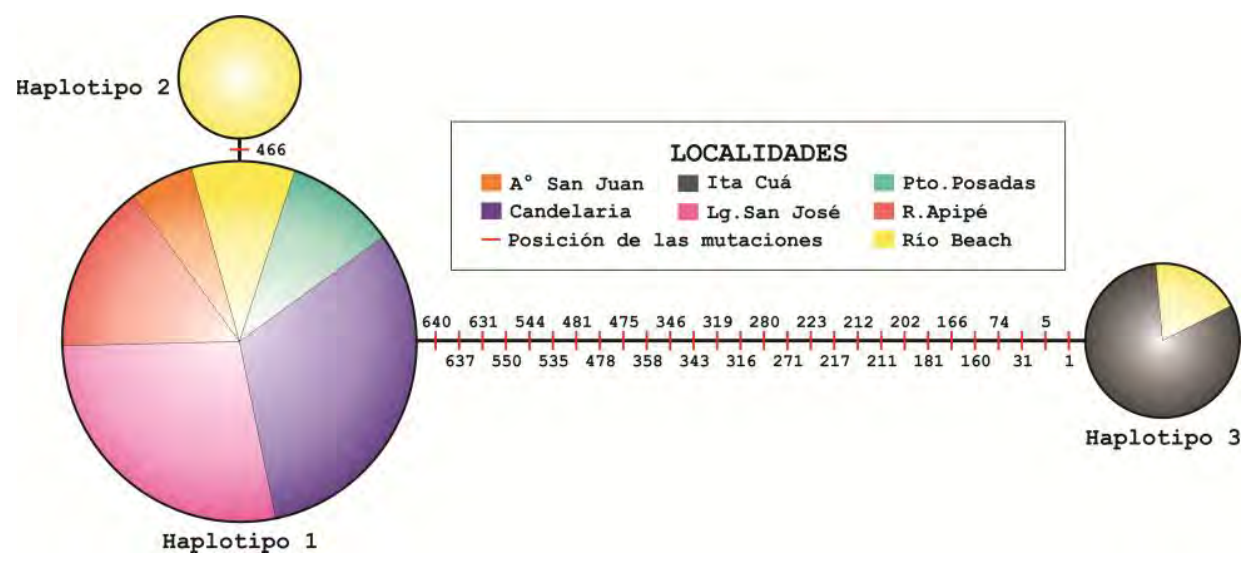

Figura 41. Red de haplotipos obtenida mediante el algoritmo "median joining network". El tamaño de la torta de cada haplotipo es proporcional a su frecuencia en la muestra analizada. Haplotipos 1 y 2: A. chloroticum Haplotipo 3: nuevo morfotipo. 


\section{III.3.5.8 Estimación de tiempos de divergencia}

\section{III.3.5.8.1 Evaluación del reloj molecular}

\section{III.3.5.8.1.1 Prueba de razón de verosimilitud global (Global likelihood ratio test)}

Para esta prueba, de acuerdo al criterio AICc empleado para la selección del mejor modelo de sustitución nucleotídica, TIM3+I proveyó el mejor ajuste a los datos con una frecuencia de bases: $\mathrm{A}=0,2708, \mathrm{C}=0,1808, \mathrm{G}=0,1649, \mathrm{~T}=0,3836$ y una proporción de sitios invariantes $(\mathrm{I})=0,67$.

Los puntajes de ML relajando y forzando el reloj molecular fueron:

$$
\begin{gathered}
\mathbf{H}_{\mathbf{0}}=\text { Reloj molecular forzado }\left(\mathrm{TIM} 3+\mathrm{I}+\text { Reloj }=L_{\mathrm{C}}\right): L n L=-1.981,0478 \\
\mathbf{H}_{\mathbf{1}}=\text { Reloj molecular relajado }(\mathrm{TIM} 3+\mathrm{I}=L): L n L=-1.975,1512
\end{gathered}
$$

El cálculo de la razón de verosimilitud a mano y mediante LRT Calculator, fue:

$$
\mathbf{L R}=2|(-1975,1512)-(-1981,0478)|=\mathbf{1 1 , 7 9 3 2}
$$

Grados de libertad $=m-2=46-2=44$

Valor crítico $(p=0,05)=\mathbf{6 0 , 4 8}$

Utilizando LRT Calculator:

$$
\text { LRT }=11.793201 ; p=1.0
$$

III.3.5.8.1.2 Comparación de linajes en Aylacostoma: prueba de tasas relativas de Tajima (Tajima's relative rate test)

Los resultados de las prueba de Tajima se presentan en la Tabla XXVIII. La comparación entre los dos linajes de $A$. chloroticum se realizó utilizando las secuencias: A: AYC20 (H1); B: AYC30 (H2); C: MLP 13447 (grupo externo). La comparación entre el linaje más frecuente de $A$. chloroticum (H1) y el nuevo morfotipo se realizó empleando las secuencias: A: AYC20 (H1); B: ACIN19 (H3); C: MLP 13447 (grupo externo). 
Tabla XXVIII. Resultados de la prueba de tasas relativas de Tajima.

\begin{tabular}{|c|c|c|}
\hline & ENTRE LINAJES & ENTRE $A$. chloroticum \\
\hline & DE $A$. chloroticum & Y NUEVO MORFOTIPO \\
\hline Sitios idénticos en las tres secuencias & 539 & 528 \\
\hline Sitios divergentes en las tres secuencias & 0 & 7 \\
\hline Diferencias únicas en la secuencia $\mathrm{A}$ & 1 & 10 \\
\hline Diferencias únicas en la secuencia B & 0 & 11 \\
\hline Diferencias únicas en la secuencia $\mathrm{C}$ & 118 & 102 \\
\hline$\chi^{2} ; p$ & $\chi^{2}=1 ; p=0,31731$ & $\chi^{2}=0.05 ; p=0,82726$ \\
\hline
\end{tabular}

\section{III.3.5.8.2 Estimación de los tiempos de divergencia: calibración del reloj}

La estimación de los tiempos de divergencia a partir de IB entre el nuevo morfotipo (NM) y A. chloroticum, así como entre los linajes de esta especie se presenta en la Tabla XXIX. Asimismo, los cálculos a partir de distancias genéticas netas asumiendo los modelos evolutivos JC y K2P se presentan en la Tabla XXX y Tabla XXXI. El filograma para el conjunto de datos analizados se presenta en la Figura 42. Es pertinente aclarar que el cálculo de la divergencia entre linajes de A. chloroticum (a diferencia del cálculo de la divergencia entre el nuevo morfotipo y A. chloroticum), se realizó a partir de la distancia genética neta $(\mathrm{Da}) \pm 1$ error estándar $(\mathrm{ES})$, dado que al utilizar $\pm 1,96$ ES la escasa diferencia entre los valores de Da y ES generó valores negativos para el límite inferior del intervalo de confianza del 95\%.

De acuerdo a los valores medios obtenidos según las diferentes tasas y modelos evolutivos ensayados, la divergencia de A. chloroticum y el nuevo morfotipo ocurrió entre 3,6 (JC-K2P) y $2(\mathrm{GTR}+\mathrm{I}+\Gamma)$ millones de años antes del presente, es decir entre mediados del Plioceno e inicios del Pleistoceno. Considerando tanto el error en la estimación de la divergencia genética, como la incertidumbre en las tasas de evolución, el máximo intervalo de tiempo calculado para esta divergencia fue de 6,34 y 0,61 Ma (i.e. fines del Mioceno a mediados del Pleistoceno). Asimismo, de acuerdo a los valores medios obtenidos dentro de $A$. chloroticum, la divergencia de sus haplotipos ocurrió entre $0,38(\mathrm{GTR}+\mathrm{I}+\Gamma)$ y $0,12(\mathrm{JC}-\mathrm{K} 2 \mathrm{P})$ millones de años antes del presente (finales del Pleistoceno). Considerando las fuentes de error, el máximo intervalo de tiempo calculado para esta divergencia fue de 0,84 y 0,008 millones de años, es decir entre mediados del Pleistoceno e inicios del Holoceno. 
Tabla XXIX. Estimación Bayesiana de los tiempos de divergencia entre $A$. chloroticum y el nuevo morfotipo, y entre linajes de $A$. chloroticum (bajo el modelo de evolución GTR+I+ $\Gamma$ del gen COI) asumiendo la tasa de divergencia para protostomados propuesta por Wilke et al. (2009).

\begin{tabular}{|c|c|c|c|c|}
\hline \multicolumn{5}{|c|}{ MODELO DE TIEMPO REVERSIBLE + I $+\Gamma($ GTR + I $+\Gamma)$} \\
\hline & Corrida I & Corrida II & Corrida III & Promedio \\
\hline \multicolumn{5}{|l|}{ A. chloroticum y nuevo morfotipo } \\
\hline Media & 2,053030 & 2,043548 & 1,905766 & 2,000781 \\
\hline Varianza & 1,717665 & 1,915267 & 1,513642 & - \\
\hline Mediana & 1,637369 & 1,648363 & 1,601710 & - \\
\hline IC $95 \% \mathrm{~T}$ & Mín: 0,637140 & Mín:0,624864 & Mín:0,580951 & Mín: 0,614318 \\
\hline RTS & Máx: 4,645630 & Máx: 4,601881 & Máx: 3,916187 & $\begin{array}{l}\text { Máx: 4,387899 } \\
\mathbf{0 , 6 1} \text { - 4,39 Ma }\end{array}$ \\
\hline \multicolumn{5}{|l|}{ Linajes de $A$. chloroticum } \\
\hline Media & 0,390944 & 0,383957 & 0,354946 & 0,376615 \\
\hline Varianza & 0,067284 & 0,076423 & 0,056026 & - \\
\hline Mediana & 0,310409 & 0,309942 & 0,292892 & - \\
\hline IC $95 \% \mathrm{~T}$ & Mín: 0,102358 & Mín: 0,108232 & Mín:0,096236 & Mín: 0,102275 \\
\hline RTS & Máx: 0,900306 & Máx: 0,872974 & Máx: 0,755542 & $\begin{array}{l}\text { Máx: } 0,842940 \\
\mathbf{0 , 1 0 - \mathbf { 0 , 8 4 }} \mathbf{M a}\end{array}$ \\
\hline
\end{tabular}

T: tiempo de divergencia; IC 95\% T: intervalo de confianza del 95\% de T; RTS: rango de tiempo sugerido (edad mínima: promedio del límite inferior del IC de las tres corridas; edad máxima: promedio del límite superior del IC de las tres corridas). Ma: tiempo expresado en millones de años. 
Tabla XXX. Estimación de los tiempos de divergencia entre $A$. chloroticum y el nuevo morfotipo (bajo los modelos de evolución JC y K2P del gen COI) asumiendo las tasas de divergencia para protostomados propuestas por Wilke et al. (2009).

\section{JUKES CANTOR (JC)}

[Tasa: 1,22 ( $\pm 0,27) \% \mathrm{Ma}^{-1}$ ]

Da

ES

IC $95 \% \mathrm{Da}$

\begin{tabular}{r|c|c|c}
$2 \mu$ & 0,95 & 1,22 & 1,49 \\
$\mathrm{~T}$ & 4,6139 & 3,5928 & 2,9417 \\
\hline IC 95\% T & Mín: 2,884831545 & Mín: 2,24638522 & Mín: 1,839322126 \\
& Máx: $\mathbf{6 , 3 4 2 8 9 0 6 1 7}$ & Máx: 4,939136136 & Máx: 4,04412489 \\
RTS & & $\mathbf{1 , 8 4}-\mathbf{6 , 3 4}$ Ma &
\end{tabular}

KiMURA-2-PARÁMETROS (K2P)

[Tasa: $1,23( \pm 0,26) \% \mathrm{Ma}^{-1}$ ]

0,0443064802106443

0,00825781496406842

$0,028121163-0,060491798$

\begin{tabular}{l|l|r}
0,97 & 1,23 & 1,49
\end{tabular}

4,5677

3,6022

2,9738

Mín: 2,899088957 Mín: 2,286273405 Mín: 1,887326368

Máx: 6,236267788 Máx: 4,91803232 Máx: 4,059852184

\section{$1,89-6,24$ Ma}

Tiempo de divergencia calculado según la fórmula $[\mathrm{T}=\mathrm{Da} / 2 \mu]$. T: tiempo de divergencia; Da: divergencia neta; $2 \mu$ : tasa de divergencia; $\mathrm{ES}$ : error estándar; IC 95\% Da: intervalo de confianza del 95\% de la divergencia neta (=Da $\pm 1,96 \mathrm{ES})$; IC 95\% T: intervalo de confianza del $95 \%$ del tiempo de divergencia ( $=\mathrm{Da} \pm 1.96 \mathrm{ES} / 2 \mu)$; RTS: rango de tiempo sugerido (edad mínima de acuerdo a la tasa de divergencia más rápida, edad máxima de acuerdo a la tasa de divergencia más lenta). Ma: tiempo expresado en millones de años. 
Tabla XXXI. Estimación de los tiempos de divergencia entre los linajes de $A$. chloroticum (bajo los modelos de evolución JC y K2P del gen COI) asumiendo las tasas de divergencia para protostomados propuestas por Wilke et al. (2009).

\section{JUKES CANTOR (JC) \\ [Tasa: $\left.1,22( \pm 0,27) \% \mathrm{Ma}^{-1}\right]$}

$\mathrm{Da}$

ES

IDa

$2 \mu$

$\mathrm{T}$

IT
0,00152129869604453

0,00133962656004421

$0,000181672136-0,002860925256$

0,95

0,160136705

Mín: 0,019123383

Máx: 0,301150027

\begin{tabular}{c|c}
1,22 & 1,49 \\
0,1247 & 0,102100584 \\
Mín: 0,014891159 & Mín: $\mathbf{0 , 0 1 2 1 9 2 7 6 1}$ \\
Máx: 0,23450207 & Máx: 0,192008406 \\
&
\end{tabular}

\begin{tabular}{|c|c|c|}
\hline \multicolumn{3}{|c|}{$\begin{array}{c}\text { KiMURA-2-PARÁMETROS (K2P) } \\
\text { [Tasa: } \mathbf{1 , 2 3}\left( \pm \mathbf{0 , 2 6} \% \mathbf{M a}^{-1}\right]\end{array}$} \\
\hline \multicolumn{3}{|c|}{0,00152207119061407} \\
\hline \multicolumn{3}{|c|}{0,0013984925648509} \\
\hline \multicolumn{3}{|c|}{$0,000123578626-0,002920563755$} \\
\hline 0,97 & 1,23 & 1,49 \\
\hline 0,1569 & 0,1248 & 0,102152429 \\
\hline Mín: 0,012740065 & Mín: 0,010129396 & Mín: 0,008293868 \\
\hline Máx: 0,301089047 & Máx: 0,239390472 & Máx: 0,19601099 \\
\hline & $0,008-0,30 \mathrm{Ma}$ & \\
\hline
\end{tabular}

Tiempo de divergencia calculado según la fórmula $[\mathrm{T}=\mathrm{Da} / 2 \mu]$. T: tiempo de divergencia; Da: divergencia neta; $2 \mu$ : tasa de divergencia; ES: error estándar; IDa: límites mínimo y máximo de la divergencia neta $(=\mathrm{Da} \pm 1 \mathrm{ES})$; IT: intervalo del tiempo de divergencia $(=\mathrm{Da} \pm 1 \mathrm{ES} / 2 \mu)$; RTS: rango de tiempo sugerido (edad mínima de acuerdo a la tasa de divergencia más rápida, edad máxima de acuerdo a la tasa de divergencia más lenta). Ma: tiempo expresado en millones de años. 

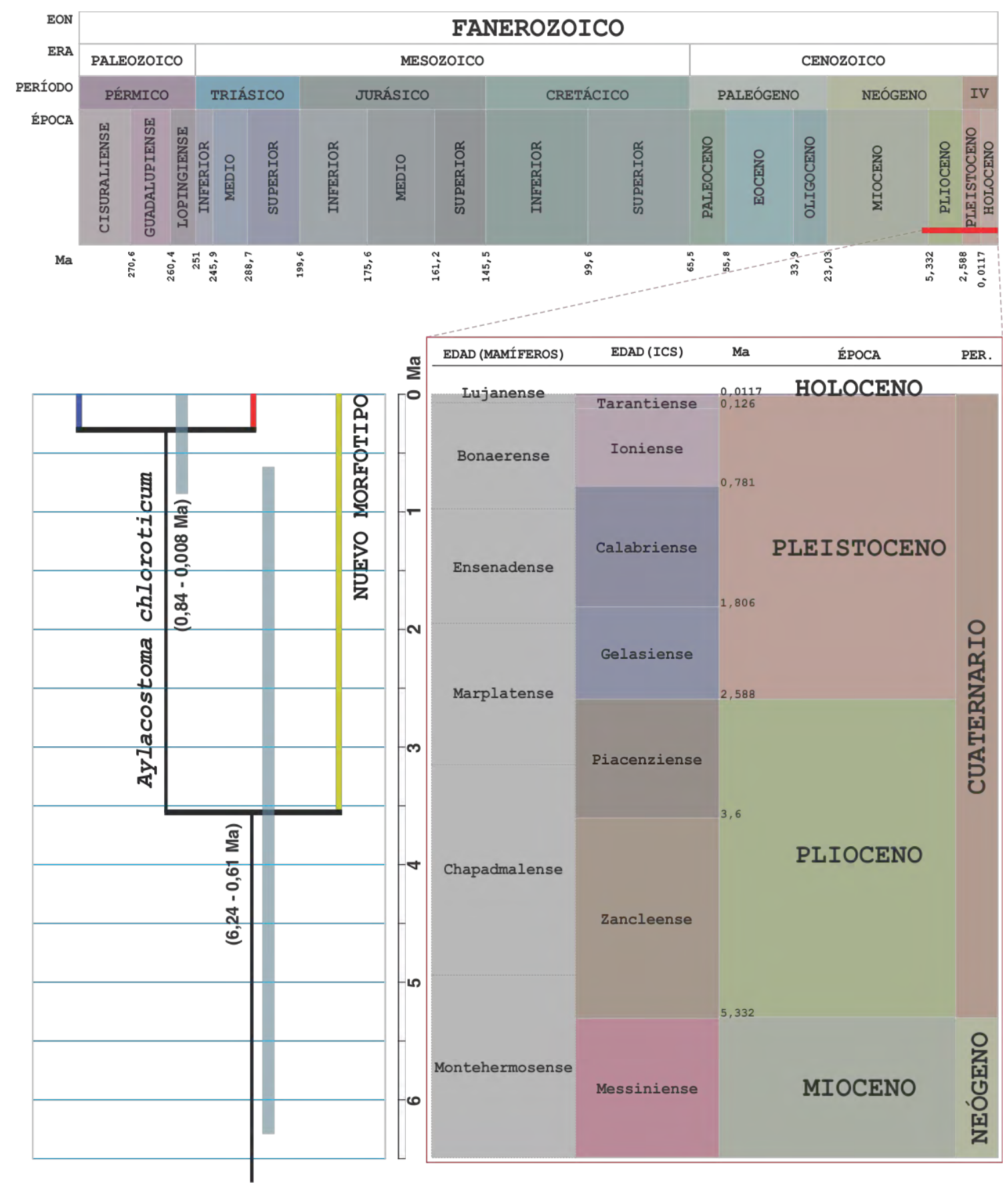

Figura 42. Tiempos de divergencia estimados para Aylacostoma procedente del Alto Paraná. Escala temporal adaptada a partir de la Escala Estratigráfica Internacional (International Commision on Stratigraphy -ICS- 2010). Las edades para mamíferos corresponden a las publicadas por Cione et al. (2007) para América del Sur. Los nodos en el filograma se presentan de acuerdo a la edad más antigua calculada (valor medio), asumiendo diferentes tasas de divergencia y modelos de sustitución. Edad del nodo $A$. chloroticum y nuevo morfotipo: 3,6022 Ma-K2P-. Edad del nodo para linajes de $A$. chloroticum: 0,3766 Ma $-\mathrm{GTR}+\mathrm{I}+\Gamma-$. Las barras en torno a cada nodo representan la edad mínima y máxima estimada para cada ancestro. Ma: millones de años. 


\section{III.4 DISCUSIÓN}

\section{III.4.1 DIFICULTADES AL UTILIZAR GENES RIBOSOMALES MITOCONDRIALES EN Aylacostoma}

En el presente estudio, las secuencias sentido y antisentido de los dos genes ribosomales mitocondriales ( $\mathrm{ARNr} 12 \mathrm{~S}$ y $16 \mathrm{~S}$ ) presentaron baja calidad, lo cual impidió su utilización en los abordajes bioinformáticos subsecuentes. A pesar de que se optimizaron condiciones de amplificación para los diferentes pares de cebadores ensayados -que permitieron el aislamiento de bandas discretas por PCR-, las secuencias obtenidas en la totalidad de los casos resultaron en electroferogramas con un elevado ruido de fondo y/o con presencia de posiciones ambiguas múltiples (Figura 27). Una primera explicación para estos resultados podría estar dada por una masa de templado insuficiente en la reacción de secuenciación. Sin embargo, esta opción resulta poco probable dado que las concentraciones de los templados superaron, en todos los casos, el mínimo recomendado por el servicio de secuenciación de $20 \mathrm{ng} / \mu \mathrm{l}$.

Una explicación alternativa es la contaminación con productos secundarios a consecuencia de una baja especificidad de los cebadores, tal como podría esperarse ante: a) más de una copia de los genes ribosómicos en la mitocondria; b) fragmentos ribosomales dispersos en el genoma mitocondrial, c) heteroplasmía; y d) pseudogenes mitocondriales nucleares o numts (nuclear mitochondrial DNA sequences; López et al., 1994). La primera de las opciones podría ser excluida dado que no existen al momento antecedentes de copias ribosomales múltiples en los genomas mitocondriales de moluscos (Grande et al., 2008; Simison \& Boore, 2008; Rawlings et al., 2010; Yuan et al., 2012). Respecto a la segunda opción, si bien la fragmentación y el reordenamiento de genes ribosomales en el ADNmt son relativamente comunes en procariotas y eucariotas unicelulares, en Metazoa este fenómeno sólo se ha informado para ostras del género Crassostrea (Milbury \& Gaffney, 2005; Milbury et al., 2010). En cuanto a la tercera alternativa, la heteroplasmía en moluscos se conoce a partir de una herencia doble uniparental o DUI (Doubly Uniparental Inheritance), informada exclusivamente para la clase Bivalvia (Hoeh et al., 1991; Rawson \& Hilbish, 1995; Passamonti \& Scali, 2001). Finalmente los numts, que constituyen copias no funcionales de ADNmt en el núcleo, han sido informados para casi todos los grupos eucarióticos, incluyendo invertebrados e incluso moluscos (Zhang \& Hewitt, 1996; Bensasson et al., 2001; 
Richly \& Leister, 2004; Groenenberg et al., 2009).

Los indicios de contaminación por numts incluyen, entre otros: bandas fantasmas en la amplificación por PCR; bandas extras en perfiles de restricción; ambigüedades en las secuencias; mutaciones que alteran el marco de lectura; y codones de stop (Sorenson \& Quinn, 1998; Bensasson et al., 2001; Groenenberg et al., 2009). Se han sugerido una variedad de estrategias para evitar la coamplificación de numts, entre ellas: utilizar ADNc como templado para la amplificación de ADNmt; utilizar sólo la fracción de ADNmt como templado (aislando las mitocondrias antes de la extracción de ADN); y excluir el ADN nuclear vía dilución del ADN templado, asumiendo que en los extractos de ADN genómico total existe un mayor número de copias del genoma mitocondrial respecto del nuclear (Sunnucks \& Hales, 1996; Sorenson \& Quinn, 1998; Bensasson et al., 2001; Williams \& Knowlton, 2001; Wolff et al., 2012). Esta última fue la estrategia utilizada en la presente tesis, sin que pudieran superarse las ambigüedades en las secuencias de los marcadores ribosomales.

La idea de potenciales numts en el material de estudio se sustenta en que: iexiste evidencia en invertebrados de integración al genoma nuclear de las regiones mitocondriales que codifican los ARNr (Zhang \& Hewitt, 1996), y ii- los numts pueden ser fácilmente coamplificados junto con el ADNmt ortólogo al utilizar cebadores universales conservados -tal es el caso en el presente trabajo- (Song et al., 2008). De confirmarse la presencia de numts, los mismos abrirían un abanico de oportunidades para estudios evolutivos en estos gasterópodos, ya que podrían ser utilizados para estudiar tasas relativas de evolución nuclear y mitocondrial, para reconstruir estados ancestrales del ADNmt, e incluso podrían ser de utilidad como marcadores genéticos intraespecíficos (Zhang \& Hewitt, 1996; Bensasson et al., 2001). De esta manera y sobre la base de la literatura disponible parecería que la presencia de numts sería la más probable. Para confirmar esta hipótesis o desestimarla, por alguna de las posibles alternativas previamente descritas, resulta necesario el diseño de nuevos ensayos.

Finalmente, en contraposición a lo acontecido con los marcadores ribosomales, todas las secuencias obtenidas para el gen COI carecieron de ambigüedades y mostraron un marco de lectura abierto, tal como se espera para un gen funcional, lo cual sugiere que es improbable que estas secuencias representen pseudogenes mitocondriales nucleares (Hurt, 2004; Kokshoorn \& Gittenberger, 2012). 


\section{III.4.2 VARIABILIDAD NUCLEOTÍDICA DEL GEN COI EN Aylacostoma}

La composición de nucleótidos de la región parcial del gen COI amplificada en el material proveniente del Alto Paraná mostró abundancia de bases A + T (62,66\%), siguiendo el patrón esperado para genes mitocondriales de gasterópodos (Hershler et al., 2003; Simison \& Boore, 2008). Sin embargo, la distribución de nucleótidos entre ambas cadenas de ADN fue desigual, la secuencia codificante mostró mayor riqueza de bases G y $\mathrm{T}$ a expensas de $\mathrm{C}$ y A, respectivamente. Estos resultados concuerdan con el marcado sesgo hacia asimetrías AT negativas vs. GC positivas en regiones codificantes proteicas observadas en genomas mitocondriales de moluscos (Rawlings et al., 2010). Si bien en nuestro caso el análisis se limitó a la región parcial de un único gen, los valores de asimetrías obtenidos marcan una tendencia similar a la informada tanto para genomas parciales y completos de otros caenogastropodos, heterobranquios, así como para el chitón Katharina tunicata (Boore \& Brown, 1994; Grande et al., 2008; Rawlings et al., 2010).

La mayor variabilidad nucleotídica del gen COI se concentró en la tercera posición de los codones $(89,28 \%)$, sin que se detectaran cambios en la segunda posición (Figura 30). Este patrón concuerda con la hipótesis de balanceo que explica los cambios en la tercera posición, los que en su mayoría representan sustituciones sinónimas codifican el mismo aminoácido-, mientras que los cambios en la segunda posición son siempre no sinónimos, pudiendo llevar a la pérdida de funcionalidad de las proteínas (Kimura, 1977; Simon et al., 1994). En este contexto, los resultados obtenidos son consistentes con las restricciones funcionales que se aplican a las posiciones de los codones en genes codificantes para proteínas (Moritz et al., 1987; Hughes, 2005; Forsdyke, 2012).

Por otra parte, la ausencia de sustituciones aminoacídicas en el material de estudio, acompañada por altos niveles de complejidad de composición local de las secuencias de $\mathrm{ADN}$, indica un alto nivel de conservación de la proteína COI de estos gasterópodos -en términos de evolución aminoacídica-, lo cual probablemente se deba a rígidos requerimientos estructurales y funcionales de la macromolécula en el ambiente celular (Simon et al., 1994; Forsdyke, 2012). Finalmente, y dado el carácter sinónimo de las mutaciones nucleotídicas identificadas en la tercera posición (las que se suponen invisibles y no alcanzadas por la selección natural), es probable que el destino de tales 
mutaciones en las poblaciones esté siendo gobernado por factores estocásticos.

\section{III.4.3 DIVERSIDAD, HISTORIA DEMOGRÁFICA Y ESTRUCTURA GENÉTICA: ¿REFLEJOS DE UN CUADRO INCOMPLETO?}

Los datos obtenidos para las formas del Alto Paraná a partir de siete de sus registros geográficos dentro de su estrecha área de distribución demostraron la existencia de escasa diversidad genética en el paisaje. Esto quedó demostrado por la presencia de sólo tres haplotipos en la muestra, dos de los cuales (H1 y H2) se reconocieron dentro de A. chloroticum, siendo el tercero (H3) exclusivo del nuevo morfotipo.

En términos de diversidad genética, las estimaciones efectuadas evidenciaron niveles sensiblemente bajos, tanto de diversidad haplotípica $(\mathrm{Hd}=0,198)$ como nucleotídica $(\pi=0,00003)$ dentro de A. chloroticum, así como la inexistencia de variación dentro del nuevo morfotipo. Por tratarse de un estudio pionero en el género Aylacostoma, por el momento no es posible realizar comparaciones con otras especies relacionadas. Sin embargo, valores bajos de diversidad genética (e incluso ausencia) se han informado para otros miembros de Caenogastroda dentro de las tres familias donde existe partenogénesis apomíctica como sistema reproductivo: Hydrobiidae Troschel, 1857 [e.g. Tryonia protea (Gould, 1855); Hershler et al., 1999], Thiaridae [e.g. Melanoides tuberculata; Stoddart, 1983; Samadi et al., 1999], y Viviparidae Gray, 1847 [e.g. Campeloma decisum (Say, 1817); Johnson, 1992].

Las estimaciones de diversidad haplotípica y nucleotídica pueden proveer una primera aproximación sobre la historia de las poblaciones. Así, patrones caracterizados por baja diversidad haplotípica $(<0,5)$ y nucleotídica $(<0,5 \%)$ pueden ser explicados a través de eventos evolutivos tales como la ocurrencia de un cuello de botella reciente o un efecto fundador por uno o unos pocos linajes de ADNmt (Grant \& Bowen, 1998). En este contexto, los resultados obtenidos para A. chloroticum parecen consistentes con un modelo de expansión del rango geográfico de la especie por uno de sus haplotipos. Si bien no se encontró evidencia a favor de este modelo en las pruebas de neutralidad evaluadas con base en la carencia de resultados estadísticamente significativos, sí se la obtuvo a partir de la distribución de discrepancias pareadas donde se sustentarían hipótesis de expansión poblacional tanto bajo el modelo de expansión súbita reciente, 
como bajo el modelo de expansión espacial. Concordantemente para A. chloroticum, se observó una distribución unimodal en la representación gráfica de las discrepancias pareadas, tal como lo indica la interpretación estadística del índice de Harpending (Figura 37), sosteniendo así la idea de una expansión poblacional. Por el contrario, al incluir al nuevo morfotipo como parte de A. chloroticum, la distribución de las distancias genéticas interindividuales fue bimodal reflejando grandes diferencias entre las secuencias de los grupos de individuos. La bimodalidad obtenida para este conjunto de datos constituyó un rechazo a una historia de expansión poblacional; sin embargo, el patrón observado más que sustentar la hipótesis alternativa de estabilidad demográfica (Rogers \& Harpending, 1992; Rogers et al., 1996), resulta consistente con la hipótesis de que A. chloroticum y el nuevo morfotipo representan linajes claramente diferenciados.

Por otra parte, el análisis de estructura y distribución espacial de la diversidad genética en el Alto Paraná entre los seis registros geográficos de A. chloroticum, evidenció uniformidad en los acervos genéticos de cinco de las poblaciones analizadas (con presencia exclusiva de H1). Esto implicó que la diversidad genética estimada, a través de cualquier estadístico, para estas poblaciones fuera siempre $=0$. La excepción estuvo representada por la población paraguaya de Río Beach, para la cual se detectó heterogeneidad en su constitución genética. En esta población, se registraron simultáneamente los haplotipos $\mathrm{H} 1$ y H2, lo que implicó consecuentemente que esta fuera la población de mayor diversidad genética $(\mathrm{Hd}=0,571 ; \pi=0,00087)$. Por otra parte, la presencia de un único haplotipo (H3) para el nuevo morfotipo en sus localidades de registro, determinó valores de diversidad $=0$.

Hasta aquí, los datos obtenidos evidencian una homogeneidad genética en el Alto Paraná que, para A. chloroticum, se debe probablemente a la expansión en el rango geográfico del haplotipo H1. Si bien no se tiene un conocimiento acabado de aspectos fundamentales de la biología, ecología y etología de la especie, esta expansión en el espacio del H1 podría ser el resultado de la acción de fuerzas intrínsecas tales como la modalidad reproductiva. De acuerdo con Wares \& Turner (2003), la partenogénesis apomíctica resulta crucial en la determinación no sólo de la distribución de las especies, sino también de la diversidad genética sobre el paisaje, conllevando a una homogeneidad genético-espacial a partir de muy pocos linajes clonales. En el caso del 
nuevo morfotipo, el conocimiento de la historia natural de la forma es más escasa aún que en $A$. chloroticum, por lo cual resulta arriesgado atribuir al sistema de reproducción la inexistencia de diversidad genética y homogeneidad espacial observada, aunque no debería desestimarse la partenogénesis como la explicación más probable.

En este escenario, es posible indagar también si el patrón observado no podría ser justificado de acuerdo a dos hipótesis usualmente invocadas para explicar el éxito de los linajes partenogenéticos. La primera de ellas se conoce como Genotipo de Propósito Generalista (General Purpose Genotype, GPG), por cuanto los clones son generalistas (además de exitosos colonizadores), debido a que poseen una amplia tolerancia ambiental que les permite sobrevivir en una variedad de hábitats (Lynch, 1984; Vrijenhoek, 1998). En contraste, para la segunda hipótesis denominada Variación de Nicho Congelado (Frozen Niche Variation, FNV), los clones son especialistas (Vrijenhoek, 1979, 1998, Vrijenhoek \& Parker, 2009). Ambos modelos ya han sido utilizados para explicar los patrones obtenidos en estudios que caracterizaron la diversidad genética de gasterópodos partenogenéticos. A modo de ejemplo, en un estudio realizado en poblaciones de Potamopyrgus antipodarum (Gray, 1843) dentro de un lago de Nueva Zelanda, se halló una elevada diversidad clonal y una marcada especificidad de hábitat de los clones hacia las mayores profundidades, por lo que se sugirió un ajuste de la especie al FNV (Fox et al., 1996). En contraste, en un análisis realizado en Melanoides tuberculata sobre 11 localidades de cuatro islas de la Polinesia Francesa, se encontraron sólo dos haplotipos en una diversidad de hábitats (e.g. cunetas, arroyos, muelles), sugiriéndose el ajuste de esta especie al GPG (Myers et al., 2000). De acuerdo con Vrijenhoek \& Parker (2009), ambas hipótesis no son mutuamente excluyentes dado que en un organismo asexual pueden coexistir características generalistas y especialistas (e.g. tolerancia fisiológica, preferencia microespacial).

En nuestro caso, si consideráramos a $A$. chloroticum en función de la distribución evidenciada en el paisaje (prevalencia del H1), la especie parecería ajustarse mejor a la hipótesis GPG. Sin embargo, la distribución espacial restricta de H2 en $A$. chloroticum y $\mathrm{H} 3$ en el nuevo morfotipo parece consistente con la existencia de una preferencia por un tipo particular de ambiente, ajustándose más al modelo FNV. Esta idea se refuerza a la luz de los resultados del primer capítulo, donde los estudios morfogeométricos incluyendo las dos especies extintas provenientes del Alto Paraná, 
sugieren una especificidad de hábitat para esas formas. No obstante, debe tenerse en cuenta que como consecuencia de la modificación constante del paisaje desde el llenado del embalse, y ante la falta de antecedentes publicados, resulta imposible tener precisiones de las características originales de los ambientes ocupados por las especies de Aylacostoma. Desde una perspectiva más global, si se considera que la ocurrencia de las formas del Alto Paraná se conoce sólo para un pequeño sector del extenso recorrido del río Paraná en la Argentina, el sentido común pareciera sugerir que las especies de Aylacostoma se ajustarían mejor al FNV, dado que las particularidades de esta región no se replican en otros tramos del Paraná (Arzamendia \& Giraudo, 2012). En síntesis, para evaluar si los haplotipos caracterizados en este estudio se ajustan al modelo FNV, son necesarios nuevos estudios que permitan valorar su amplitud ecológica y fisiológica.

En cuanto a la posible influencia de fuerzas extrínsecas en el modelado de la distribución espacial de la variabilidad genética en Aylacostoma, nuestro estudio permitió desestimar la posibilidad del canal principal del río Paraná como agente modelador. Sin embargo, a partir del análisis de la distribución geográfica de los haplotipos y con respaldo en los valores de diferenciación obtenidos en el AMOVA, es posible afirmar que la mayor diversidad genética del género Aylacostoma en el Alto Paraná se ajusta a un modelo de zonación longitudinal. Meichtry de Zaburlín et al. (2010) reconocen para el embalse Yacyretá cuatro zonas, denominadas: i- zona de entrada, fluvial o lótica; ii- zona de transición, intermedia o río embalse; iii-zona del embalse o lacustre, y iv- brazos laterales o subembalses. Para el material en estudio, se observó que la mayor diversidad genética se encuentra asociada a la zona de entrada, fluvial o lótica, la cual a su vez constituye el límite Este de la distribución histórica del género Aylacostoma en el Alto Paraná. Este hecho supone que la mayor diversidad genética observada en el área no es casual, dado que al corresponder a la zona del embalse más alejada de la presa, es la que más se asemejaría a las características o condiciones "originales" del río y, a diferencia de la zona del embalse, sólo habría sufrido indirectamente los cambios como consecuencia de los aumentos de cota (Peso, 2012). Diversos estudios sobre la variación espacio-temporal de las comunidades planctónicas y bentónicas del área de influencia de Yacyretá sostienen esta idea, y han demostrado que los atributos de las comunidades de la zona de entrada (e.g. riqueza específica, diversidad, densidad) se han mantenido más o menos estables desde antes del cierre y llenado del embalse (Meichtry de Zaburlín, 1999, 2012; Meichtry de 
Zaburlín et al., 2010; Peso \& Bechara, 1999; Peso, 2012).

Finalmente, es pertinente aclarar que los resultados obtenidos representan una visión parcial del cuadro que otrora representaba el paisaje de la diversidad existente de estos caracoles en la naturaleza, ya que los mismos fueron obtenidos a partir del escaso material disponible para su análisis. Visto que como consecuencia de la construcción y llenado del embalse Yacyretá se extinguieron dos de las especies de Aylacostoma que habitaban la región, es factible suponer que de haber existido mayor diversidad genética en $A$. chloroticum e incluso en el nuevo morfotipo (e.g. en el área hoy inundada por el embalse), la misma pudo simplemente ser barrida por la modificación del ambiente. Es por ello que a nuestro entender las estimaciones obtenidas en el presente trabajo y las que puedan obtenerse en estudios futuro constituirán siempre el reflejo de un cuadro incompleto.

\section{III.4.4 PATRONES FILOGEOGRÁFICOS Y LA HISTORIA DEL ALTO PARANÁ}

Las relaciones filogenéticas obtenidas a partir de los cuatro métodos de reconstrucción ensayados, resultaron bastante similares, recuperándose en todos los casos la monofília del grupo Aylacostoma con valores de soporte de nodo máximos. Dentro de Aylacostoma se reconocieron dos agrupamientos mayores o clados (en virtud del árbol de MP), uno conteniendo A. chloroticum y el otro al nuevo morfotipo. Estos clados resultaron recíprocamente monofiléticos en los árboles de NJ, MP e IB, dado que ninguno de los ejemplares reconocidos conquiliológicamente como $A$. chloroticum se incluyó en el grupo conteniendo los representantes del nuevo morfotipo, y viceversa. Sin embargo, las relaciones filogenéticas obtenidas en el árbol de ML, representaron la excepción. En este caso no se evidenció monofília recíproca, y si bien fue posible reconocer en cierta medida los grupos mencionados, en la topología de árbol obtenida se los muestra como parte de un gran grupo sin resolución aceptable. De esta manera, es probable que esta topología represente un óptimo local dentro del espacio de topologías de árboles, debido a la naturaleza heurística de la búsqueda del árbol que mejor represente las relaciones filogenéticas (Guindon et al., 2009), y tal vez a consecuencia de los múltiples individuos que exhibieron secuencias nucleotídicas idénticas.

Siguiendo con un análisis más detallado, dentro del clado de $A$. chloroticum se 
reconocieron dos subclados aunque con valores de soporte de nodo medio-bajo, lo cual probablemente sea también consecuencia directa de la inexistencia de variación genética entre los individuos dentro de los subgrupos. Estos subclados fueron designados como mayor, donde quedaron incluidos la totalidad de los ejemplares procedentes de Candelaria, Arroyo San Juan, Rápidos del Apipé, Laguna San José, Puerto Posadas y algunos individuos procedentes de Río Beach; y menor representado únicamente por individuos procedentes de Río Beach (Figura 39 y Figura 40). Los mismos están caracterizados por la presencia exclusiva de los $\mathrm{H} 1$ y $\mathrm{H} 2$ respectivamente, evidenciando una vez más, que $\mathrm{H} 1$ resultó el haplotipo más ampliamente distribuido dentro de $A$. chloroticum. En referencia a ello, es importante destacar que en el subclado mayor quedaron incluidas además dos poblaciones que representan los extremos opuestos de la distribución de la especie, i.e. Rápidos del Apipé (Oeste) y Arroyo San Juan (Este). Esta evidencia, conjuntamente con los resultados de la prueba de Mantel, permiten desestimar la hipótesis de aislamiento por distancia para el material de A. chloroticum examinado. En relación con el clado del nuevo morfotipo, este estuvo caracterizado por el H3, e incluyó todos los ejemplares de Ita Cuá y el único ejemplar de esta forma procedente de Río Beach.

Por otra parte, el entendimiento de las relaciones filogenéticas mencionadas puede refinarse parcialmente a partir de la red de haplotipos. Según VázquezDomínguez et al. (2009) a partir de una red pueden efectuarse las siguientes predicciones (P): 1) los haplotipos con mayor frecuencia tienen alta probabilidad de representar alelos ancestrales; 2) los haplotipos con múltiples conexiones muy probablemente son ancestrales; 3) dentro de la red, los haplotipos ancestrales están en el interior y los haplotipos nuevos tienen mayor probabilidad de ser terminales; 4) se espera que los haplotipos ancestrales tengan una amplia distribución geográfica, básicamente porque los individuos que poseen esos haplotipos han tenido mucho tiempo para dispersarse; y 5) se predice que los haplotipos con una conexión estén unidos a los haplotipos de la misma población, dado que han evolucionado recientemente y por lo tanto sin tiempo para dispersarse. Sobre la base de estas predicciones y a partir de la red obtenida es posible sugerir entonces para $A$. chloroticum que: a) H1 muy probablemente representa un haplotipo ancestral, dada su mayor frecuencia y amplia distribución geográfica (P1 y P4); b) H2 posiblemente constituya un haplotipo nuevo, dada su posición terminal en la red (P3), el cual se habría originado dentro de la población de 
Río Beach -sin que haya transcurrido aún el tiempo suficiente para que se disperse(P5). Por otra parte, el elevado número de pasos mutacionales que separan $\mathrm{H} 3$ de H1, con presencia exclusiva dentro del nuevo morfotipo, es consistente con la sugerencia de que esta forma representaría una nueva entidad.

En relación con esto último, y atendiendo las relaciones plasmadas en los árboles obtenidos para $A$. chloroticum y el nuevo morfotipo, es trascendente traer a colación que ambos constituyen linajes notoriamente divergentes en términos de distancia genética, con una divergencia estimada del orden del 4,5\%. La "notoriedad" se sustenta en que, comparativamente, la distancia entre los haplotipos característicos de A. chloroticum (H1-H2) no supera el 0,15\%. En otras palabras, la distancia entre el nuevo morfotipo y A. chloroticum es unas 30 veces mayor que la evidenciada entre los haplotipos de esta última. De acuerdo con Hebert et al. (2004), es posible emplear un umbral de divergencia para delimitar especies y la idea subyacente es que la divergencia intraespecie sea menor que la divergencia interespecie (Frézal \& Leblois, 2008). Esta propuesta fue sugerida basándose en evidencia empírica obtenida para grandes conjuntos de secuencias (principalmente de organismos sexuales), a partir de la universalización de las secuencias del gen COI para la identificación de especies (Birky et al., 2010). Según Hebert et al. (2004) las especies pueden reconocerse a partir de un valor umbral de divergencia de diez veces la variación intraespecífica media (10x rule), acompañado de monofília recíproca en árboles de distancia. En este sentido, dado que la divergencia obtenida entre $A$. chloroticum y el morfotipo claramente supera el umbral recomendado y que ambos evidencian monofília recíproca, podría otorgársele el estatus de nueva especie al nuevo morfotipo. Sin embargo, a pesar de que la utilización de umbrales de divergencia ha resultado eficiente en diversos grupos animales como arañas, aves, crustáceos, lepidópteros y peces, entre otros (e.g. Hebert et al., 2004; Ward et al., 2005; Hajibabaei et al., 2006), su uso ha sido totalmente desaconsejado (Frézal \& Leblois, 2008). Una de las principales críticas se fundamenta en el hecho de que la identificación de especies aplicando la regla 10X utiliza límites empíricos de diferencias de secuencias, los cuales carecen de fundamentos teóricos sólidos (Birky et al., 2010). Otras críticas incluyen que el enfoque es de naturaleza fenética y no cladística y que la delimitación en muchos casos no posee un fuerte soporte biológico, dado que la mayoría de las veces está sólo fundada en los datos moleculares sin ser validada por líneas independientes de evidencia (Meyer \& Paulay, 2005; Hickerson et al., 2006; Birky, 
2007; Heethoff et al., 2011).

En este escenario, resulta conveniente entonces explorar otras alternativas para el nuevo morfotipo. Recientemente, un nuevo concepto de especie denominado Genético Evolutivo o EGSC (del inglés Evolutionary Genetic Species Concept) ha sido propuesto y aplicado para delinear especies partenogenéticas de ácaros, rotíferos y ostrácodos (Birky \& Barraclough, 2009; Birky et al., 2010, 2011; Martens et al., 2012; Shearn et al., 2012). Este concepto está basado en la genética evolutiva y de poblaciones, así como en datos de secuencias de ADN, y ha sido desarrollado prestando especial consideración a la especiación de organismos asexuales (Barraclough et al., 2003; Birky et al., 2005, 2010; Birky \& Barraclough, 2009). Así, para asignar organismos asexuales al EGSP, Birky et al. (2005) idearon un criterio denominado originalmente regla $4 \mathrm{X}(4 \mathrm{X}$ rule) también conocido como método $\mathrm{K} / \theta$ (Schön et al., 2012). La regla $4 X$ es una medida cuantitativa basada en distancias genéticas. Brevemente, la misma supone la identificación, a partir de árboles filogenéticos, de grupos de secuencias recíprocamente monofiléticas. Tales grupos son considerados entonces especies putativas, donde se verifica posteriormente, si las diferencias de secuencias entre individuos en los diferentes clados son $\geq 4$ veces la diferencia promedio de las secuencias entre los clados (Birky \& Barraclough, 2009). De acuerdo con Birky et al. (2010), esta regla no debe ser confundida con la 10X de Hebert et al. (2004), ya que la regla 4X no representa un umbral fijo, sino la relación de dos parámetros mensurables los cuales pueden ser mayor o menor que 4, dependiendo de los valores observados de diversidad de secuencia y del tamaño de la muestra. Una descripción detallada de cómo aplicar la regla 4X se presenta en Birky et al. (2010) y Schön et al. (2012). Si bien la comprobación rigurosa de la regla $4 X$ escapa a los alcances de este trabajo, algunos cálculos preliminares realizados nos permiten inducir que el material procedente del Alto Paraná satisfacería los requisitos de la regla, dado que la distancia media entre $A$. chloroticum y el nuevo morfotipo sería mucho más elevada que 4 veces la diversidad media dentro de los clados. En función de ello, tanto el nuevo morfotipo como A. chloroticum podrían ajustarse al EGSP, aunque esta alternativa debe explorarse en mayor profundidad.

Por otro lado, la estimación de los tiempos de divergencia en el material proveniente del Alto Paraná a través de las pruebas efectuadas permitieron aceptar el 
uso de un reloj molecular. En la primera de ellas (i.e. prueba de razón de verosimilitud global), a partir de los cálculos efectuados no fue posible rechazar la hipótesis nula de que las secuencias evolucionan a tasas homogéneas entre todas las ramas de la filogenia. Esto expresado en términos de significación estadística permite afirmar que las tasas de sustitución no varían significativamente entre las ramas, por lo que el uso de un reloj molecular resulta apropiado para el conjunto de secuencias analizadas. En el mismo sentido, en la prueba de tasas relativas de Tajima con un valor $p<0,05$ se rechaza la hipótesis nula de tasas constantes entre los linajes. Para los valores de significación obtenidos en la comparación, tanto entre los linajes de $A$. chloroticum como entre esta especie y el nuevo morfotipo, en ninguno de los casos se pudo rechazar la hipótesis nula. Así, en el contexto del conjunto de datos analizados y de acuerdo a la prueba de Tajima, la aplicación de un reloj molecular resulta apropiada. En virtud de ello, y utilizando las tasas de divergencia propuestas por Wilke et al. (2009) fue posible calibrar entonces el reloj.

Si nuestras estimaciones de tiempo son correctas, es probable que la divergencia entre A. chloroticum y el nuevo morfotipo haya ocurrido hace unos 3,6 a 2 millones de años, ubicando así el origen de esta divergencia entre mediados del Plioceno e inicios del Pleistoceno. Si se considera la estimación de máxima para esta divergencia (i.e. 6,34 - 0,61 Ma), su origen no sería más antiguo que finales del Mioceno. De igual forma, la divergencia entre los haplotipos de A. chloroticum es probable haya ocurrido alrededor de unos 0,38 a 0,12 millones de años antes del presente, es decir a finales del Pleistoceno, no siendo más antigua que mediados de esta época de acuerdo con la estimación de máxima (i.e. 0,84 - 0,008 Ma). Vale aclarar, que bajo una óptica paleontológica, el origen de ambas divergencias puede ser entendido como reciente, más aún si se considera que en América del Sur se conocen fósiles de Aylacostoma a partir del Paleoceno (Parodiz, 1969; Camacho \& Del Río, 2008).

En relación con la divergencia entre A. chloroticum y el nuevo morfotipo, su origen entre mediados del Plioceno e inicios del Pleistoceno es consistente con la historia geomorfológica del río Paraná, y podría estar vinculada a la historia geológica de la denominada Formación Ituzaingó, unidad sedimentaria cuya datación ha sido llevada al Plioceno medio-superior (Herbst, 2000; Popolizio, 2006). Los sedimentos de esta Formación se reconocen desde unos kilómetros al Este de la localidad correntina de 
Ituzaingó, ya que desde allí hacia el oriente y hacia el Norte el Paraná corre encajonado sobre un lecho de basalto (Alto Paraná Encajonado sensu Matteucci et al., 2004). De acuerdo con Herbst (2000), donde desaparecen los basaltos en superficie, en la zona de los ahora inundados Saltos de Apipé, el antiguo río Paraná (Paleoparaná) se abría en numerosos brazos en un enorme abanico aluvial húmedo, ajustándose a un modelo de río anastomosado. Sus aguas habrían sido más o menos límpidas y su fondo arenoso, con bancos de arena aflorando durante el estiaje y totalmente sumergidos durante las crecidas (mayor detalle en Herbst, 2000).

En este escenario y teniendo en mente que entre las décadas de 1950 a 1990 se mencionaron cinco formas de Aylacostoma en la zona de Apipé (Quintana \& Mercado Laczkó, 1997), dos de las cuales nunca fueron descriptas formalmente, es factible hipotetizar entonces que la especiación del ancestro de A. chloroticum y el nuevo morfotipo pudo haber ocurrido a partir de la oportunidad de colonizar ambientes transicionales, como el modelo arriba descripto supone. A favor de esta hipótesis, Herbst (2000) describe diversas evidencias que dan cuenta de la existencia de una variedad de ambientes en el área, entre ellas dos especies fósiles de bivalvos registrados en una zona cercana a la presa de Yacyretá (Morton \& Sequeira, 1991). Adicionalmente, un análisis panbiogeográfico reciente de Arzamendia \& Giraudo (2012), destaca que la zona de convergencia entre el Alto Paraná Encajonado y el tramo inferior del Alto Paraná (Posadas-Encarnación, hasta confluencia con el Paraguay), es una zona de transición gradual entre dos provincias biogeográficas (i.e. Chaco y Bosque Atlántico), con elevada riqueza de especies y elementos taxonómicos de diversos orígenes. Así, este área constituye un biogeographic crossroad que refleja las interrelaciones espaciales y temporales de diferentes componentes bióticos y geológicos (Arzamendia \& Giraudo, 2012). En este contexto, y dado que a partir de los resultados obtenidos fue posible delimitar un rango temporal y una unidad estratigráfica particular, sería importante que la posible especiación de Aylacostoma en el pasado del Alto Paraná sea corroborada con estudios paleontológicos que incluyan esta nueva información.

Finalmente, en relación con la divergencia entre los haplotipos de $A$. chloroticum, su origen en el Pleistoceno supone un escenario con un río muy similar al existente antes del represamiento del río Paraná, caracterizado por amplios meandros 
encerrando varias islas, en una amplia planicie de inundación (Neiff, 1986; Álvarez et al., 1995; Neiff et al., 2000; Arzamendia \& Giraudo, 2012). En función de nuestra red de haplotipos, puede inferirse que la mutación que sustenta la divergencia muy probablemente pudo haberse originado en la zona de la actual región de Río Beach, aunque en vistas al vacío de información genética que representan gran parte de los ambientes actualmente inundados, no es posible descartar un origen en una zona distinta de la actual.

\section{III.4.5 DELIMITACIÓN DE ESUS: UNA CONTRIBUCIÓN PARA LA CONSERVACIÓN DE LAS FORMAS}

Uno de los objetivos primarios de la biología de la conservación es asegurar el mantenimiento de la biodiversidad, de la cual la diversidad genética es un componente fundamental (DeSalle \& Amato, 2004). Un programa de conservación eficiente debería incluir la identificación inequívoca de unidades de manejo que representen distintos linajes evolutivos, a cuyo efecto la información genética constituye un medio objetivo para determinar prioridades de conservación (King \& Burke, 1999; DeSalle \& Amato, 2004). En el presente estudio hemos localizado geográficamente tres linajes evolutivos en el Alto Paraná, dos dentro de A. chloroticum y uno representado por el nuevo morfotipo, los cuales ameritan ser reconocidos como ESUs. Si bien a la luz de la monofília recíproca $A$. chloroticum -como un todo- y el nuevo morfotipo califican en la definición más estricta del término, sugerimos que los dos haplotipos de $A$. chloroticum (H1 y H2) deberían ser considerados en sí mismos como dos ESUs. Esta proposición se sustenta en que, a nuestro entender, ambos haplotipos representan historias evolutivas independientes ya que se encuentran condicionadas a la partenogénesis apomíctica de la especie. En este sentido, es probable que estemos siendo testigos de un incipiente evento de especiación más allá de que, al presente, no existe diferenciación morfológica somática evidente entre los portadores de estos linajes, aunque no necesariamente deba haberla (e.g. especies crípticas).

En este contexto, entender la localización geográfica en el Alto Paraná de las tres ESUs propuestas es vital para identificar y priorizar áreas de protección, de manera tal que la representación genética de Aylacostoma en la naturaleza pueda ser maximizada. Nuestro análisis de distribución espacial de la diversidad genética claramente evidencia que la zona de entrada o lótica del embalse de Yacyretá reconocida por Meichtry de 
Zaburlín et al. (2010) constituye un área de gran interés en términos de conservación. En esta zona, y particularmente en Río Beach, es donde convergen las tres ESUs. Por ello, esta localidad no sólo representa un relicto genético que amerita especial consideración, sino que también constituye una fuente clave de diversidad genética para alimentar la conservación ex situ del grupo.

En este punto es importante enfatizar que durante el desarrollo de esta tesis se completó el llenado del embalse del río Paraná a su cota definitiva. Si bien comparativamente la zona de entrada del embalse resultó la menos impactada por el alcance de la nueva cota y el manejo operativo de la represa, este nuevo incremento resulta preocupante por cuanto la escasa variación genética determinada para el área pudo haberse perdido. Desde la óptica conservacionista, esta situación pone de manifiesto la necesidad imperiosa de ser diligentes para evitar una nueva pérdida que resultaría catastrófica para las poblaciones relictuales de Aylacostoma en el Alto Paraná y justifica cabalmente los esfuerzos para preservar la diversidad de estos endemismos relictuales, tal es el caso de $A$. chloroticum y el nuevo morfotipo, los cuales ameritan las máximas prioridades de conservación.

Finalmente, a partir de este trabajo y atendiendo a la vigencia del "Programa Aylacostoma", donde no sólo se desarrollan tareas de conservación ex situ, sino que también se intentan reintroducciones y translocaciones directas a campo, se sugiere que tales acciones deberían realizarse, de ser posible, en áreas de la reconocida zona de entrada del embalse, a los efectos de intentar preservar los procesos evolutivos y comprometer lo menos posible el futuro del potencial evolutivo de las formas de Aylacostoma existentes en la actualidad y descritas en el presente trabajo pionero. 


\section{CONCLUSIONES}

En el presente trabajo de Tesis se abordó un análisis filogeográfico aplicado a conservación de las especies endémicas y amenazadas del género Aylacostoma del río Paraná. El mismo permitió poner a prueba las hipótesis previamente planteadas y a partir de los resultados obtenidos, aportar información fundamental para el mejor entendimiento y conservación de sus poblaciones relictuales.

En primer lugar, el análisis mediante morfometría geométrica de las conchillas de las tres especies descriptas para el Alto Paraná en la década de 1950 permitió una discriminación exitosa de A. guaraniticum, A. stigmaticum y A. chloroticum a partir de la variación observada en la última vuelta, abertura y espira. Estas diferencias podrían estar relacionadas a un uso diferencial del hábitat o a diferentes grados de exposición a la corriente de agua; información que resulta relevante por cuanto A. guaraniticum y A. stigmaticum están extintas en la naturaleza -principalmente producto de la construcción y llenado del Embalse Yacyretá-, y no existen al presente partes blandas depositadas en las colecciones malacológicas que permitan otros abordajes. Así, se sugiere que las conchillas más globosas de las formas extintas habrían estado asociadas a los hábitats y sustratos con mayor velocidad de la corriente de agua, mientras que la conchilla más estilizada de $A$. chloroticum reflejaría la preferencia por hábitats más protegidos como aquellos que actualmente habita.

En segundo lugar, el examen y la primera descripción de los caracteres endosomáticos para A. chloroticum, así como para un nuevo morfotipo identificado en el Alto Paraná, permitieron profundizar el conocimiento anatómico del género que presenta muy pocos antecedentes de abordaje. Si bien en el material examinado las principales diferencias se concentraron a nivel de conchilla, a partir del análisis de los órganos del manto fue posible discriminar ambas formas por la presencia de vasos transversales entre la branquia y el seno ad-rectal, muy poco evidentes en $A$. chloroticum y conspicuos en el nuevo morfotipo. Asimismo, ambas formas del Alto Paraná, pudieron ser discriminadas de las caracterizadas anatómicamente para Brasil, a partir de sus rádulas y particularmente por la presencia de dos dentículos basales en cada vértice exterior del diente raquídeo, los cuales están ausentes en las especies brasileñas. Adicionalmente a las diferencias detectadas a nivel conquiliológico y 
endosomático, consideramos que sería oportuno a futuro complementar esta descripción con evidencias provenientes de otros abordajes metodológicos, y de ser posible con datos sobre la ecología e historia de vida de las entidades.

En tercer lugar, este estudio demostró la utilidad de los marcadores moleculares para la valoración de la estructura y diversidad genética, así como de las relaciones filogenéticas y patrones filogeográficos en las poblaciones de Aylacostoma procedentes del Alto Paraná, muchas de las cuales no se encuentran actualmente en su ambiente natural, aunque sí preservadas en el "Programa Aylacostoma" enfocado en su conservación ex situ. Es oportuno resaltar, que el presente trabajo representa la primera investigación genético-poblacional relacionada a cualquier especie Sudamericana de Aylacostoma. Por ello, para el material del Alto Paraná deseamos destacar algunos de los aspectos previamente discutidos:

a- A partir de descriptores típicos y adicionales caracterizados para las secuencias parciales del gen COI, el material analizado se ajusta a los patrones esperados para genes mitocondriales de gasterópodos en cuanto a la composición de nucleótidos, complejidad de composición local y sesgos en sus asimetrías composicionales.

b- En términos generales, la diversidad genética dentro de A. chloroticum resultó sensiblemente baja, y fue inexistente en el nuevo morfotipo. Se identificaron sólo tres haplotipos en la muestra, dos en la primera especie $(\mathrm{H} 1 \mathrm{y} \mathrm{H} 2$, siendo $\mathrm{H} 1$ probablemente el alelo ancestral), y uno en la restante forma (H3). En ambos casos, la reproducción por partenogénesis apomíctica constituiría la explicación más razonable para los niveles de diversidad observados.

c- A pesar de la uniformidad en los acervos génicos de la mayoría de las poblaciones de A. chloroticum, se individualizó la localidad paraguaya de Río Beach como la de mayor diversidad, donde coexisten los dos haplotipos de la especie conjuntamente con el haplotipo del nuevo morfotipo.

d- El análisis de la distribución espacial de la diversidad genética sugiere que $A$. chloroticum podría haber experimentado una expansión de su rango geográfico a partir de uno de sus dos haplotipos (i.e. H1). 
e- La variación genética de las formas en el Alto Paraná se concentró en la región del embalse Yacyretá que mejor representa las características o condiciones originales del río, previo al represamiento (i.e. zona de entrada). En este punto vale destacar que de haber existido mayor diversidad en otras áreas, la misma pudo ser eliminada por la modificación del ambiente.

f- Las dos formas del Alto Paraná se ajustarían al modelo Frozen Niche Variation, considerando que su ocurrencia sólo se conoce a partir de un pequeño sector del extenso recorrido del río Paraná, y con base en la distribución espacial de la diversidad genética, lo cual debería corroborarse con nuevos estudios de índole ecológica.

g- Mediante los abordajes filogenéticos se pudo establecer que A. chloroticum y el nuevo morfotipo están estructurados filogeográficamente en clados genéticos diferentes, evidenciando a su vez monofília recíproca. En este sentido, la divergencia entre las formas probablemente haya ocurrido entre mediados del Plioceno e inicios del Pleistoceno y podría estar vinculada con la historia geomorfológica del río Paraná y particularmente a la historia geológica de la Formación Ituzaingó; donde el ancestro común pudo haber especiado como consecuencia de una oportunidad de ambientes transicionales en la zona de convergencia entre el Alto Paraná Encajonado y el tramo inferior del Alto Paraná.

h- Dentro de A. chloroticum, la divergencia de sus dos haplotipos habría ocurrido en el Pleistoceno, lo cual supone un escenario similar al actual en términos del paisaje.

En lo que respecta a la conservación de las entidades, a partir de los análisis efectuados se sugiere que el nuevo morfotipo debería ser considerado una ESU, así como ambos linajes presentes en A. chloroticum, dado que representan historias evolutivas condicionadas a la partenogénesis apomíctica. En el mismo sentido, la zona geográfica de mayor interés para su conservación en el Alto Paraná está representada por la región de entrada del Embalse Yacyretá, y particularmente en torno a la localidad de Río Beach, ya que allí convergen las tres ESUs, que no sólo categorizan al sitio como un relicto en términos de diversidad, sino también como una fuente clave de diversidad genética para alimentar la conservación ex situ. Atendiendo a las reintroducciones a 
campo previstas en el marco del "Programa Aylacostoma", se sugiere que las mismas se realicen, siempre que sea posible, en la zona de entrada del embalse.

Finalmente, con base en las evidencias recopiladas durante esta tesis se sugiere que el nuevo morfotipo representa una nueva especie para la ciencia. 


\section{REFERENCIAS}

Adams, D.C., Rohlf, F.J., Slice, D.E. 2004. Geometric morphometrics: ten years of progress following the ,revolution “. Italian Journal of Zoology 71: 5-16.

Aguirre, M.L., Perez, S.I., Sirch, Y.N. 2006. Morphological variability of Brachidontes Swainson (Bivalvia, Mytilidae) in the marine Quaternary of Argentina (SW Atlantic). Palaeogeography, Palaeoclimatology, Palaeoecology 239: 100-125.

Aljanabi, S., Martínez, I. 1997. Universal and rapid salt-extraction of high quality genomic DNA for PCR-based techniques. Nucleic Acids Research 25: 4692-4693.

Altschul, S.F., Gish, W., Miller, W., Myers, E.W., Lipman, D.J. 1990. Basic local alignment search tool. Journal of Molecular Biology 215: 403-410.

Álvarez, B.B., Lions, M.L., Aguirre, R. Céspedez, J., Hernando, A. 1995. Herpetofauna del área de influencia del embalse de la represa Yacyretá (Argentina-Paraguay). Facena 11: 57-73.

Anderson, M. 2001. A new method for non parametric multivariate analysis of variance. Austral Ecology 26: 32-46.

Anderson, L., Roopnarine, P. 2005. Role of constraint and selection in the morphologic evolution of Caryocorbula (Mollusca: Corbulidae) from the Caribbean Neogene. Palaeontologia Electronica 8(2): 32A. 18 p.

Arbogast, B., Kenagy, G.J. 2001. Comparative phylogeography as an integrative approach to historical biogeography. Journal of Biogeography 28: 819-825.

Arbogast, B.S., Edwards, S.V., Wakeley, J., Beerli, P., Slwinski, J.B. 2002. Estimating divergence times from molecular data on phylogenetic and population genetic timescales. Annual Review of Ecology, Evolution and Systematics 33: 707-740.

Archie, J.W. 1989. A randomization test for phylogenetic information in systematic data. Systematic Zoology 38: 239-252. 
Arzamendia, V., Giraudo, A.R. 2012. A panbiogeographcal model to prioritize areas for conservation along large rivers. Diversity and Distributions 18: 168-179.

Avise, J.C. 2000. Phylogeography: the history and formation of species. Cambridge: Harvard University Press.

Avise, J.C. 2004. Molecular markers, natural history and evolution. Second Edition. Sunderland: Sinauer Associates. 684 p.

Avise, J.C. 2005. Phylogenetics units and currencies above and below the species level. En: Purvis, A., Gittleman, J.L., Brooks, T. (eds.) Phylogeny and conservation. pp. 76-100. Cambridge: Cambridge University Press.

Avise, J.C. 2009a. Phylogeography: retrospect and prospect. Journal of Biogeography 36: 3-15.

Avise, J.C. 2009b. Timetrees: beyond cladograms, phenograms, and phylograms. En: Hedges, S.B., Kumar, S. (eds.) The Timetree of life. pp. 19-25. USA: Oxford University Press.

Avise, J.C., Arnold, J., Ball, R.M., Bermingham, E., Lamb, T., Neigel, J.E. Reeb, C.A., Saunders, N.C. 1987. Intraspecific phylogeography: the mitochondrial DNA bridge between population genetics and systematics. Annual Reviews in Ecology and Systematics 18: 489-522.

Ballard, J.W.O., Whitlock, M.C. 2004. The incomplete natural history of mitochondria. Molecular Ecology 13: 729-744.

Bandelt, H.J., Forster, P., Röhl, A. 1999. Median-joining networks for inferring intraspecific phylogenies. Molecular Biology and Evolution 16: 37-48.

Barraclough, T.G., Birky, C.W. Jr, Burt, A. 2003. Diversification in sexual and asexual organisms. Evolution 57: 2166-2172. 
Bastir, M., Rosas, A., Kuroe, K. 2004. Petrosal orientation and mandibular ramus breadth: evidence for an integrated petroso-mandibular developmental unit. American Journal of Physical Anthropology 123: 340-350.

Battistuzzi, F.U., Filipski, A.J., Kumar, S. 2011. Molecular clock: testing. En: eLS. $\begin{array}{llll}\text { Chichester: John Wiley \& Sons Ltd. [doi: } & \end{array}$ 10.1002/9780470015902.a0001803.pub2]. 7 p.

Bell, K.C., Hafner, D.J., Leitner, P., Matocq, M.D. 2010. Phylogeography of the ground squirrel subgenus Xerospermophilus and assembly of the Mojave Desert biota. Journal of Biogeography 37: 363-378.

Bensasson, D., Zhang, D.X., Hartl, D.L., Hewitt, G.M. 2001. Mitochondrial pseudogenes: evolution's misplaced witnesses. Trends in Ecology and Evolution 16: $314-321$.

Birky, C.W. Jr. 2007. Workshop on barcoded DNA: application to rotifer phylogeny, evolution and systematic. Hydrobiologia 593: 175-183.

Birky, C.W. Jr, Barraclough, T.G. 2009. Asexual species. En: Schön, I., Martens, K., van Dijk, P. (eds.) Lost sex - The evolutionary biology of parthenogenesis. pp. 201216. New York: Springer Publications.

Birky, C.W., Wolf, C., Maughan, H., Herbertson, L., Henry, E. 2005. Speciation and selection without sex. Hydrobiologia 546: 29-45.

Birky, C.W. Jr, Adams, J., Gemmel, M., Perry, J. 2010. Using population genetic theory and DNA sequences for species detection and identification in asexual organisms. PLOS ONE 5: e10609.

Birky, C.W. Jr., Riccim, C., Melonem, G., Fontaneto, D. 2011. Integrating DNA and morphological taxonomy to describe diversity in poorly studied microscopic animals: new species of the genus Abrochtha Bryce, 1910 (Rotifera: Bdelloidea: Philodinavidae). Zoological Journal of the Linnean Society 161: 723-734. 
Bookstein, F. 1989. Principal warps: Thin-plate splines and the decomposition of deformations. IEEE Transactions on Pattern Analysis and Machine Intelligence 11: $567-588$.

Bookstein, F.L. 1991. Morphometric tools for landmark data: geometry and biology. New York: Cambridge University Press. 435 p.

Boore, J.L. 1999. Animal mitochondrial genomes. Nucleic Acids Research 27: 17671780.

Boore, J.L., Brown, W.M. 1994. Complete DNA-sequence of the mitochondrial genome of the black chiton, Katharina tunicata. Genetics: 138: 423-443.

Brunhoff, C., Galbreath, K.E., Fedorov, V.B., Cook, J.A., Jaarola, M. 2003. Holarctic phylogeography of the root vole (Microtus oeconomus): implications for late Quaternary biogeography of high latitudes. Molecular Ecology 12: 957-968.

Burch, J.B., Cruz-Reyes, A. 1987. Clave genérica para la identificación de gastrópodos de agua dulce en México. México, D.F.: Instituto de Biología, UNAM. 46 p.

Camacho, H.H, Del Río, C.J. 2008. Gastropoda. En: Camacho, H.H, Longobuco, M.L. (eds.) Los invertebrados fósiles. Tomo I. pp. 323-376. Buenos Aires: Fundación de Historia Natural Félix de Azara, Universidad Maimónides, Vazquez Mazzini Editores.

Carvajal-Rodríguez, A., Conde-Padín, P., Rolán-Alvarez, E. 2005. Decomposing shell form into size and shape by geometric morphometric methods in two sympatric ecotypes of Littorina saxatilis. Journal of Molluscan Studies 71: 313-318.

Carvajal-Rodríguez, A., Guerra-Varela, J., Fernández, B., Rolán, E., Rolán-Álvarez, E. 2006. An example of the application of geometric morphometric tools to the morphological diagnosis of two sibling species in Nassarius (Mollusca, Prosobranchia). Iberus 24: 81-88.

Cassens, I., Mardulyn, P., Milinkovitch, M.C. 2005. Evaluating intraspecific "network" construction methods using simulated sequence data: do existing algorithms 
outperform the global maximum parsimony approach? Systematic Biology 54: 363372.

Castellanos, Z.J.A. de 1981. La familia Thiaridae Morrison 1952 en la Argentina. En: Ringuelet, R.A. (ed.) Fauna de agua dulce de la República Argentina. pp. 7-18. Buenos Aires: Fundación para la Educación, la Ciencia y la Cultura.

Castellanos, Z.J.A. de \& Landoni, N.A. 1995. Mollusca Pelecypoda y Gastropoda. En: Lopretto, E.C., Tell, G. (eds.). Ecosistemas de aguas continentales. Metodologías para su estudio. Vol. 2. pp. 759-801. La Plata: Ediciones Sur.

Cavalcanti, M., Monteiro, L., Lopes, P. 1999. Landmark-based morphometric analysis in selected species of serranid fishes (Perciformes: Teleostei). Zoological Studies 38: 287-294.

Cazzaniga, N.J. 1992. Dr. María Isabel Hylton Scott (1889-1990). A brief biography and bibliography. Walkerana 6: 295-313. [Reproducción facsimilar en: López, H.L., Cazzaniga, N.J., Ponte Gómez, J. 2010. Ictiólogos de la Argentina: María Isabel Hylton Scott. ProBiota, Facultad de Ciencias Naturales y Museo, Universidad Nacional de La Plata, Argentina. Serie Técnica y Didáctica 14(19): 150].

Cazzaniga, N.J. 2011. El género de los géneros. Una guía para formar y coordinar nombres cientificos en zoología. Bahía Blanca: EdiUNS. 446 p.

Chen, W., Liu, S., Liu, Y., Hao, H., Zeng, B., Chen, S., Peng, H., Yue, B., Zhang, X. 2010. Phylogeography of the large white-bellied rat Niviventer excelsior suggests the influence of Pleistocene glaciations in the Hengduan Mountains. Zoological Science 27: 487-493.

Cione, A.L., Tonni, E.P., Bargo, S., Bond, M., Candela, A.M., Carlini, A.A., Deschamps, C.M., Dozo, M.T., Esteban, G., Goin, F.J., Montalvo, C.I., Nasif, N., Noriega, J.I., Ortiz Jaureguizar, E., Pascual, R., Prado, J.L., Reguero, M.A., Scillato-Yané, G.J., Soibelzon, L., Verzi, D.H., Vieytes, E.C., Vizcaíno, S.F., Vucetich, M.G. 2007. Mamíferos continentales del Mioceno tardío a la actualidad 
en la Argentina: cincuenta años de estudios. Ameghiniana, publicación especial 11: 257-278.

Conde-Padín, P., Grahame, J.W., Rolán-Alvarez, E. 2007. Detecting shape differences in species of the Littorina saxatilis complex by morphometric analysis. Journal of Molluscan Studies 73: 147-154.

Crandall, K.A., Bininda-Emonds, O.R.P., Mace, G.M., Wayne, R.K. 2000. Considering evolutionary processes in conservation biology. Trends in Ecology and Evolution 15: 290-295.

Crooks, G.E., Hon, G., Chandonia, J.M., Brenner, S.E. 2004. WebLogo: A sequence logo generator. Genome Research 14: 1188-1190.

DeSalle, R., Amato, G. 2004. The expansion of conservation genetics. Nature Reviews Genetics 5: 702-712.

DeWaard, J.R., Ivanova, N.V., Hajibabaei, M., Hebert, P.D.N. 2008. Asembling DNA barcodes. En: Martin, C.C. (ed.) Methods in Molecular Biology $N^{o} 410$ Environmental Genomics. pp. 275-293. Totowa: Humana Press.

Dickerson, R.E. 1971. The structure of cytochrome $\mathrm{c}$ and the rates of molecular evolution. Journal of Molecular Evolution 1: 26-45.

Domínguez-Domínguez, O., Vázquez-Domínguez, E. 2009. Filogeografía: aplicaciones en taxonomía y conservación. Animal Biodiversity and Conservation 32.1: 59-70.

Dommergues, E., Dommergues, J.L., Magniez, F., Neige, P., Verrecchia, E.P. 2003. Geometric measurement analysis versus Fourier series analysis for shape characterization using the gastropod shell (Trivia) as an example. Mathematical Geology 35: 887-894.

Douris, V., Cameron, R.A.D., Rodakis, G.C., Lecadinou, R. 1998. Mitochondrial phylogeography of the land snail Albinaria in Crete: long-term geological and short-term vicariante effects. Evolution 52: 116-125. 
Dryden, I.L., Mardia, K.V. 1998. Statistical shape analysis. Chichester: John Wiley \& Sons. 347 p.

Epperson, B.K. 2003. Geographical genetics. Princeton: Princeton University Press. $356 \mathrm{p}$.

Eslahchi, C., Habibi, M., Hassanzadeh, R., Mottaghi, E. 2010. MC-Net: a method for the construction of phylogenetic networks based on the Monte-Carlo method. BMC Evolutionary Biology 10: 254.

Excoffier, L., Lischer, H.E.L. 2010. Arlequin suite ver 3.5: a new series of programs to perform population genetics analyses under Linux and Windows. Molecular Ecology Resources 10: 564-567.

Excoffier, L., Smouse, P.E., Quattro, J.M. 1992. Analysis of molecular variance inferred from metric distances among DNA haplotypes: application to human mitochondrial DNA restriction data. Genetics 131: 479-491.

Facon, B., Pointier, J.P., Glaubrecht, M., Poux, C., Jarne, P., David, P. 2003. A molecular phylogeography approach to biological invasions of the New World by parthenogenetic Thiarid snails. Molecular Ecology 12: 3027-2039.

Felsenstein, J. 1981. Evolutionary trees from DNA sequences: a maximum likelihood approach. Journal of Molecular Evolution 17: 368-376.

Felsenstein, J. 1985. Confidence limits on phylogenies: an approach using the bootstrap. Evolution 39: 783-791.

Ferson, S., Rohlf, F., Koehn, R. 1985. Measuring shape variation of two-dimensional outlines. Systematic Zoology 34: 59-98.

Fitch, W.M. 1971. Toward defining the course of evolution: minimum change for a specific tree topology. Systematic Zoology 20: 406-416. 
Folmer, O., Black, M., Hoeh, W., Lutz, R., Vrijenhoek R. 1994. DNA primers for amplification of mitochondrial cytochrome c oxidase subunit I from diverse metazoan invertebrates. Molecular Marine Biology and Biotechnology 3: 294-299.

Forsdyke, D.R. 2012. Functional constraint and molecular evolution. En: eLS. $\begin{array}{llll}\text { Chichester: John Wiley \& Sons Ltd } & \end{array}$ 10.1002/9780470015902.a0001804.pub3]. 9p.

Foster, P.G., Jermiin, L.S., Hickey, D.A. 1997. Nucleotide composition bias affects amino acid content in proteins coded by animal mitochondria. Journal of Molecular Evolution 44: 282-288.

Fox, J.A., Dybdahl, M.F., Jokela, J., Lively, C.M. 1996. Genetic structure of coexisting sexual and clonal subpopulations in a freshwater snail (Potamopyrgus antipodarum). Evolution 50: 1541-1548.

Frankham, R. 2010a. Challenges and opportunities of genetic approaches to biological conservation. Biological Conservation 143: 1919-1927.

Frankham, R. 2010b. Where are we in conservation genetics and where do we need to go? Conservation Genetics 11: 661-663.

Frankham, R., Ballou, J.D., Briscoe, D.A. 2002. Introduction to conservation genetics. Cambridge: Cambridge University Press. 617p.

Freeland, J. 2005. Molecular Ecology. West Sussex: John Wiley \& Sons. 308 p.

Frézal, L., Leblois, R. 2008. Four years of DNA barcoding: current advances and prospects. Infection, Genetics and Evolution 8: 727-736.

Fu, Y.X. 1997. Statistical tests of neutrality of mutations against population growth, hitchhiking and background selection. Genetics 147: 915-925.

Ghiringhelli, P.D., Cerrudo, C. 2007. Bioinformática (o una introducción a la bioinformática). Cuadernillo utilizado en el dictado del Curso de Postgrado Bioinformática - Universidad Nacional de Quilmes. 
Gillespie, J.H. 1991. The causes of molecular evolution. New York: Oxford University Press. 336p.

Glaubrecht, M. 1996. Evolutionsökologie und Systematik am Beispiel von Süb- und Brackwasserschnecken (Mollusca: Caenogastropoda: Cerithioidea): OntogeneseStrategien, paläontologische Befunde und Historische Zoogeographie. Leiden: Backhuys Publishers. 525 p.

Glaubrecht, M. 1999. Systematics and the evolution of viviparity in tropical freshwater gastropods (Cerithioidea: Thiaridae sensu lato) - an overview. Courier Forschungsinstitut Senckenberg 215: 91-96.

Glaubrecht, M. 2006. Independent evolution of reproductive modes in viviparous freshwater Cerithioidea (Gastropoda, Sorbeoconcha) - a brief review. Basteria 69 (Supplement 3): 28-32.

Gómez, M.I., Strong, E.E., Glaubrecht, M. 2011. Redescription and anatomy of the viviparous freshwater gastropod Hemisinus lineolatus (W. Wood, 1828) from Jamaica (Cerithioidea, Thiaridae). Malacologia 53: 229-250.

Grande, C., Templado, J., Cervera, J.L., Zardoya, R. 2002. The complete mitochondrial genome of the nudibranch Roboastra europaea (Mollusca: Gastropoda) supports the monophyly of opisthobranchs. Molecular Biology and Evolution 19: 16721685.

Grande, C., Templado, J., Zardoya, R. 2008. Evolution of gastropod mitochondrial genome arrangements. BMC Evolutionary Biology 8: 61.

Grant, W.A.S., Bowen, B.W. 1998. Shallow population histories in deep evolutionary lineages of marine fishes: inshigts from sardines and anchovies and lesson for conservation. The Journal of Heredity: 89: 415-426.

Greenwood, K.S., Thorp, J.H. 2001. Aspects of ecology and conservation of sympatric, prosobranch snails in a large river. Hydrobiologia 455: 229-236. 
Groenenberg, D.S.J., Goud, J., Heij, A.D., Gittenberger, E. 2009. Molecular phylogeny of North Sea Sepiolinae (Cephalopoda: Sepiolidae) reveals an overlooked Sepiola species. Journal of Molluscan Studies 75: 361-369.

Guindon, S., Gascuel, O. 2003. A simple, fast, and accurate algorithm to estimate large phylogenies by maximum likelihood. Systematic Biology 52: 696-704.

Guindon, S., Delsuc, F., Dufayard, J.F., Gascuel, O. 2009. Estimating Maximum Likelihood phylogenies with PhyML. En: Posada, D. (ed.) Methods in Molecular Biology $N^{o} 537$ - Bioinformatics for DNA Sequence Analysis. pp. 113-137. New York: Humana Press.

Guo, S.W., Thompson, E.A. 1992. Performing the exact test of Hardy-Weinberg proportion for multiple alleles. Biometrics 48: 361-372.

Gutiérrez Gregoric, D.E., Núñez, V., Rumi, A., Roche, M.A. 2006. Freshwater gastropods from Del Plata Basin, Argentina. Checklist and new locality records. Comunicaciones de la Sociedad Malacológica del Uruguay 9: 51-60.

Gutiérrez Gregoric, D.E., Núñez, V., Ferrando, N.S., Rumi, A. 2007. First record of invasive snail Melanoides tuberculatus (Müller) (Gastropoda: Prosobranchia: Thiaridae) for the Iguazú River Basin, Argentina - Brazil. Comunicaciones de la Sociedad Malacológica del Uruguay 9: 109-112.

Hadfield, M.G., Holland, B.S., Olival, K. 2004. Contributions of ex situ propagation and molecular genetics to the conservation of hawaiian tree snails. En: Gordon, M., Bartol, S. (eds.) Experimental approaches to conservation biology. pp. 16-34. Berkeley \& Los Angeles: University of California Press.

Hajibabaei, M., Janzen, D.H., Burns, J.M., Hallwachs, W., Hebert, P.D.N. 2006. DNA barcodes distinguish species of tropical Lepidoptera. Proceedings of the National Academy of Sciences 103: 968-971.

Hall, T.A. 1999. BioEdit: a user-friendly biological sequence alignment editor and analysis program for Windows 95/98/NT. Nucleic Acids Symposium Series 41: 9598. 
Hammer, Ø., Harper, D., Ryan, P. 2001. PAST: Paleontological statistics software package for education and data analysis. Palaeontologia Electronica 4(1): 9 p.

Harpending, H.C. 1994. Signature of ancient population growth in a low-resolution mitochondrial DNA mismatch distribution. Human Biology 66: 591-600.

Hebert, P.D.N., Stoeckle, M.Y., Zemlak, T.S., Francis, C.M. 2004. Identification of birds through DNA barcodes. PLoS Biology 2: e312.

Heethoff, M., Laumann, M., Weigmann, G., Raspotnig, G. 2011. Integrative taxonomy: combining morphological, molecular and chemical data for species delineation in the parthenogenetic Trhypochthonius tectorum complex (Acari, Oribatida, Trhypochthoniidae). Frontiers in Zoology 8: 2.

Herbst, R. 2000. La Formación Ituzaingó (Plioceno). Estratigrafía y distribución. INSUGEO, Serie de Correlación Geológica 14: 181-190.

Hershler, R., Liu, H.P., Mulvey, M. 1999. Phylogenetic relationships within the aquatic snail genus Tryonia: implications for biogeography of the North American Southwest. Molecular Phylogenetics and Evolution 13: 377-391.

Hershler, R., Liu, H.P., Thompson, F.G. 2003. Phylogenetic relationships of North American nymphophiline gastropods based on mitochondrial DNA sequences. Zoologica Scripta 32: 357-366.

Hickerson, M.J., Meyer, C.P., Moritz, C. 2006. DNA barcoding will often fail to discover new animal species over broad parameter space. Systematic Biology 55: 729-739.

Hoeh, W.R., Blakley, C.H., Brown, W.M. 1991. Heteroplasmy suggests limited biparental inheritance of Mytilus mitochondrial DNA. Science 251: 1488-1490.

Holland, B.S., Hadfield, M.G. 2002. Islands within an island: phylogeography and conservation genetics of the endangered Hawaiian tree snail Achatinella mustelina. Molecular Ecology 11: 365-375. 
Holznagel, W. 1998. A nondestructive method for cleaning gastropod radulae from frozen, alcohol-fixed, or dried material. American Malacological Bulletin 14: 181183.

Huelsenbeck, J.P., Ronquist, F., Nielsen, R., Bollback, J.P. 2001. Bayesian inference of phylogeny and its impact on evolutionary biology. Science 294: 2310-2314.

Hughes, A.L. 2005. Selective and Structural Constraints. En: eLS. Chichester: John Wiley \& Sons Ltd. [doi: 10.1038/npg.els.0005124]. 3p.

Hurt, C.R. 2004. Genetic divergence, population structure and historical demography of rare springsnails (Pyrgulopsis) in the lower Colorado River basin. Molecular Ecology 13: 1173-1187.

Hylton Scott, M.I. 1953. El género Hemisinus (Melaniidae) en la costa fluvial argentina (Mol. Prosobr.). Physis 20: 438-443.

Hylton Scott, M.I. 1954. Dos nuevos melánidos del Alto Paraná (Mol. Prosobr.). Neotropica 1: 45-48.

Ihering, H. 1902. As Melanias do Brazil. Revista do Museu Paulista 5: 653-682.

Ihering, H. 1909. Les mélaniidés Américains. Journal de Conchyliologie 57: 289-316.

Innes, D.J., Bates, J.A. 1999. Morphological variation of Mytilus edulis and Mytilus trossulus in eastern Newfoundland. Marine Biology 133: 691-699.

Ivanova, N., Grainger, C. 2006. COI amplification. En: CCDB Protocols. Canadian Centre for DNA Barcoding (www.dnabarcoding.ca). $2 p$.

Johnson, S.G. 1992. Spontaneous and hybrid origins of parthenogenesis in Campeloma decisum (freshwater prosobranch snail). Heredity 68: 253-261.

Kimura, M. 1968. Evolutionary rate at the molecular level. Nature 217: 624-626.

Kimura, M. 1977. Preponderance of synonymous changes as evidence for the neutral theory of molecular evolution. Nature 267: 275-276. 
Kimura, M. 1983. The neutral theory of molecular evolution. Cambridge: Cambridge University Press. 367p.

King, T.L., Burke, T. 1999. Special issue on gene conservation: identification and management of genetic diversity. Molecular Ecology 8: S1-S3.

Köhler, F., Glaubrecht, M. 2001. Morphology, reproductive biology and molecular genetics of ovoviviparous freshwater gastropods (Cerithioidea, Pachychilidae) from the Philippines, with description of a new genus Jagora. Zoologica Scripta 32: $35-59$.

Kokshoorn, B., Gittenberger, E. 2012. Phylogeography of the land snail Abida secale (Draparnaud, 1801) (Chondrinidae). Journal of Molluscan Studies 78: 128-133.

Konopka, A.K. 2005. Sequence complexity and composition. En: eLS. Chichester: John Wiley \& Sons Ltd. [doi: 10.1038/npg.els.0005260]. 8p.

Konopka, A.K., Owens, J. 1990. Complexity charts can be used to map functional domains in DNA. Gene Analysis Techniques and Applications 7: 35-38.

Knowles, L.L. 2009. Statistical phylogeography. Annual Review of Ecology, Evolution, and Systematics 40: 593-612.

Knowles, L.L., Maddison, W.P. 2002. Statistical phylogeography. Molecular Ecology 11: 2623-2635.

Krapivka, S., Toro, J.E., Alcapán, A.C., Astorga, M., Presa, P., Pérez, M., Guiñez, R., 2007. Shell-shape variation along the latitudinal range of the Chilean blue mussel Mytilus chilensis (Hupe 1854). Aquaculture Research 38: 1770-1777.

Kroll, O., Hershler, R., Albrecht, C., Terrazas, E.M., Apaza, R., Fuentealba, C., Wolff, C., Wilke, T. 2012. The endemic gastropod fauna of Lake Titicaca: correlation between molecular evolution and hydrographic history. Ecology and Evolution 2: 1517-1530. 
Kumar, S. 2005. Molecular clocks: four decades of evolution. Nature Reviews Genetics 6: 654-662.

Ladle, R.J., Whittaker, R.J. 2011. Conservation biogeography. Chichester: John Wiley \& Sons. $301 \mathrm{p}$.

Lande, R. 1988. Genetics and demography in biological conservation. Science 241: 1455-1460.

Lanteri, A.A., Confalonieri, V.A. 2003. Filogeografía: objetivos, métodos y ejemplos. En: Llorente Bousquets, J., Morrone, J.J. (eds.). Una perpectiva latinoamericana de la biogeografía. pp. 185-193. México: Facultad de Ciencias, UNAM.

Lanteri, A.A., Loiácono, M.S., Margaría, C. 2002. Aportes de la biología molecular a la conservación de los insectos. En: Costa, C., Vanin, S.A., Lobo, J.M., Melic, A. (eds.) Proyecto de Red Iberoamericana de Biogeografía y Entomología Sistemática. PrIBES 2002. Vol. 2. pp. 207-220. Zaragoza: m3m-Monografías Tercer Milenio, Sociedad Entomologica Aragonesa (SEA).

Larkin, M.A., Blackshields, G., Brown, N.P., Chenna, R., McGettigan, P.A., McWilliam, H., Valentin, F., Wallace, I.M., Wilm, A., Lopez, R., Thompson, J.D., Gibson, T.J., Higgins, D.G. 2007. Clustal W and Clustal X version 2.0. Bioinformatics 23: 2947-2948.

Lele, S., Richtsmeier, J. 2001. An invariant approach to statistical analysis of shapes. Boca Raton: Chapman and Hall/CRC. 308 p.

Lévêque, C., Balian, E.V., Martens, K. 2005. An assessment of animal species diversity in continental waters. Hydrobiologia 542: 39-67.

Librado, P., Rozas, J. 2009. DnaSP v5: A software for comprehensive analysis of DNA polymorphism data. Bioinformatics 25: 1451-1452.

Liu, J.X., Tatarenkov, A., Beacham, T.D., Gorbachev, V., Wildes, S., Avise, J.C. 2011. Effects of Pleistocene climatic fluctuations on the phylogeographic and 
demographic histories of Pacific herring (Clupea pallasii). Molecular Ecology 20: 3879-3893.

Loaiza, J.R., Scott, M.E., Bermingham, E., Rovira, J., Conn, J.E. 2010. Evidence for Pleistocene population divergence and expansion of Anopheles albimanus in Southern Central America. American Journal of Tropical Medicine and Hygiene 82: $156-164$.

López, J.V., Yuhki, N., Masuda, R., Modi, W., O'Brian, S.J. 1994. Numt, a recent transfer and tandem amplification of mitochondrial DNA to the nuclear genome of the domestic cat. Journal of Molecular Evolution 39: 174-190.

Lydeard, C., Lindberg, D.R. 2003. Challenges and research opportunities in molluscan molecular phylogenetics. En: Lydeard, C., Lindberg, D.R. (eds.) Molecular systematics and phylogeography of mollusks. pp. 1-13. Washington: Smithsonian Books.

Lydeard, C., Cowie, R.H., Ponder, W.F., Bogan, A.E., Bouchet, P., Clark, S.A., Cummings, K.S., Frest, T.J., Gargominy, O., Herbert, D.G., Hershler, R., Perez, K.E., Roth, B., Seddon, M., Strong, E.E., Thompson, F.G. 2004. The global decline of nonmarine mollusks. BioScience 54: 321-330.

Lynch, M. 1984. Destabilizing hybridization, general-purpose genotypes and geographic parthenogenesis. The Quarterly Review of Biology 59: 257-290.

Makarenkov, V., Kevorkov, D., Legendre, P. 2006. Phylogenetic network construction approaches. En: Arora, D.K., Berka, R.M., Singh, G.B. (eds.) Applied mycology and biotechnology. Vol 6. pp. 61-97. Amsterdam: Elsevier.

Mansur, M. 2000a. Aylacostoma guaraniticum. En: IUCN 2011. IUCN Red List of Threatened Species. Version 2011.2. (www.iucnredlist.org). Consultado el 6 de junio de 2012.

Mansur, M. 2000b. Aylacostoma stigmaticum. En: IUCN 2011. IUCN Red List of Threatened Species. Version 2011.2. (www.iucnredlist.org). Consultado el 6 de junio de 2012. 
Mansur, M. 2000c. Aylacostoma chloroticum. En: IUCN 2011. IUCN Red List of Threatened Species. Version 2011.2. (www.iucnredlist.org). Consultado el 6 de junio de 2012.

Mantel, N. 1967. The detection of disease clustering and a generalized regression approach. Cancer Research 27: 209-220.

Marani, H.A. 2010. Morfometría geométrica: características generales y su aplicación en arqueología (www.soc.unicen.edu.ar/newsletter/n16/marani.html). Newsletter 16. Consultado el 25 de septiembre de 2012.

Mardulyn, P. 2012. Trees and/ or networks to display intraspecific DNA sequence variation? Molecular Ecology 21: 3385-3390.

Margoliash, E. 1963. Primary structure and evolution of cytochrome c. Proceedings of the National Academy of Sciences 50: 672-679.

Márquez, F., Robledo, J., Peñaloza, G.E., Van der Molen, S. 2010. Use of different geometric morphometrics tools for the discrimination of phenotypic stocks of the striped clam Ameghinomya antiqua (Veneridae) in north Patagonia, Argentina. Fisheries Research 101: 127-131.

Martens, K., Halse, S., Schön, I. 2012. Nine new species of Bennelongia De Deckker \& McKenzie, 1981 (Crustacea, Ostracoda) from Western Australia, with the description of a new subfamily. European Journal of Taxonomy 8: 1-56.

Martin, A.P. 2007. Molecular Clocks. En: eLS. Chichester: John Wiley \& Sons Ltd. [doi: 10.1002/9780470015902.a0001669.pub2]. 6 p.

Martín, S.M., César, I.I. 2004. Catálogo de los tipos de moluscos (Gastropoda, Bivalvia, Cephalopoda) del Museo de La Plata. La Plata: Fundación Museo de La Plata. $76 \mathrm{p}$.

Matteucci, S.D., Morello, J., Rodríguez, A.F., Mendoza, N.E. 2004. El Alto Paraná Encajonado argentino-paraguayo: mosicos de paisaje y conservación regional. Buenos Aires: Ediciones FADU-UNESCO. 160p. 
Meichtry de Zaburlín, N. 1999. La comunidad fitoplanctónica durante las primeras etapas del llenado del embalse de Yacyretá, Argentina. Revista de Ictiología 7: 1526.

Meichtry de Zaburlín, N. 2012. Estructura de la comunidad fitoplanctónica. Embalse Yacyretá (Argentina - Paraguay). Editorial Académica Española. 152p.

Meichtry de Zaburlín, N.R., Peso, J.G., Garrido, G., Vogler, R.E. 2010. Sucesión espacio-temporal del plancton y bentos en periodos posteriores al llenado del Embalse Yacyretá (Río Paraná, Argentina-Paraguay). Interciencia 35: 897-904.

Meyer, C.P., Paulay, G. 2005 DNA Barcoding: error rates based on comprehensive sampling. PLoS Biology 3: e422.

Michel, E. 2004. Vinundu, a new genus of gastropod (Cerithioidea: 'Thiaridae') with two species from Lake Tanganyika, East Africa, and its molecular phylogenetic relationships. Journal of Molluscan Studies 70: 1-19.

Milbury, C.A., Gaffney, P.M. 2005. Complete mitochondrial DNA sequence of the eastern oyster Crassostrea virginica. Marine Biotechnology 7: 697-712.

Milbury, C.A., Lee, J.C., Cannone, J.J., Gaffney, P.M., Gutell, R.R. 2010. Fragmentation of the large subunit ribosomal RNA gene in oyster mitochondrial genomes. BMC Genomics 11: 485.

Miller, M.P. 2005. Alleles in space (AIS): computer software for the joint analysis of interindividual spatial and genetic information. Journal of Heredity 96: 722-724.

Min, X.J., Hickey, D.A. 2007. DNA asymmetric strand bias affects the amino acid composition of mitochondrial proteins. DNA Research 14: 201-206.

Ministério da Saúde. Secretaria de Vigilância em Saúde. Departamento de Vigilância Epidemiológica. 2007. Vigilância e controle de moluscos de importância epidemiológica. Diretrizes técnicas: Programa de Vigilância e Controle da Esquistossomose (PCE) -2. ed-. Brasilia: Editora do Ministério da Saúde. 178p. 
Monteiro, L., Reis, S.F.D. 1999. Principios de morfometria geometrica. Riberão Preto: Holos Editora. 188 p.

Moritz, C. 1994. Defining „evolutionary significant units ${ }^{\text {ee }}$ for conservation. Trends in Ecology and Evolution 9: 373-375.

Moritz, C. 2002. Strategies to protect biological diversity and the evolutionary processes that sustain it. Systematic Biology 51: 238-254.

Moritz, C., Dowling, T.E., Brown, W.M. 1987. Evolution of animal mitochondrial DNA: relevance for population biology and systematics. Annual Review of Ecology and Systematics 18: 269-292.

Morrison, J.P.E. 1954. The relationship of old and new world melanians. Proceedings of the United States National Museum 103: 357-394.

Morton, L.S., Sequeira, P.A. 1991. Pelecípodos de agua dulce de la Formación Ituzaingó (Plioceno Tardío) de la presa de Yacyretá, Departamento Itapúa, Paraguay. Revista de la Asociación de Ciencias Naturales del Litoral 22: 25-34.

Myers, M.J., Meyer, C.P., Resh, V.H. 2000. Neritid and thiarid gastropods from French Polynesian streams: how reproduction (sexual, parthenogenetic) and dispersal (active, passive) affect population structure. Freshwater Biology 44: 535-545.

Nei, M. 1973. Analysis of gene diversity in subdivided populations (population structure/genetic variability/heterozygosity/gene differentiation). Proceedings of the National Academy of Sciences 70: 3321-3323.

Nei, M. 1977. F-statistics and analysis of gene diversity in subdivided populations. Annals of Human Genetics London 41: 225-233.

Nei, M. 1987. Molecular evolutionary genetics. New York: Columbia University Press. $512 \mathrm{p}$.

Nei, M., Kumar, S. 2000. Molecular evolution and phylogenetics. New York: Oxford University Press. 333p. 
Nei, M., Li, W.H. 1979. Mathematical model for studying genetic variation in terms of restriction endonucleases. Proceedings of the National Academy of Sciences 76: $5269-5273$.

Nei, M., Suzuki, Y., Nozawa, M. 2010. The neutral theory of molecular evolution in the genomic era. Annual Review of Genomics and Human Genetics 11: 265-289.

Neiff, J.J. 1986. Las grandes unidades de vegetación y ambiente insular del río Paraná en el tramo Candelaria - Itá Ibaté. Revista de la Asociación de Ciencias Naturales del Litoral 17: 7-30.

Neiff, J.J., Poi de Neiff, A.S.G., Patiño, C.A.E., Basterra de Chiozzi, I. 2000. Prediction of colonization by macrophytes in the Yaciretá Reservoir of the Paraná River. Revista Brasileira Biología 60: 615-626.

Nielsen, R. 2005. Molecular signatures of natural selection. Annual Review of Genetics 39: 197-218.

Nielsen, R., Beaumont, M.A. 2009. Statistical inferences in phylogeography. Molecular Ecology 18: 1034-1047.

Núñez, V., Gutiérrez Gregoric, D.E., Rumi, A. 2010. Freshwater gastropod provinces from Argentina. Malacologia 53: 47-60.

Ostrowski de Nuñez, M., Quintana, M.G. 2008. The life cycle of Stephanoprora aylacostoma n.sp. (Digenea: Echinostomatidae), parasite of the threatened snail Aylacostoma chloroticum (Prosobranchia, Thiaridae), in Argentina. Parasitology Research 102: 647-655.

Palmer, M., Pons, G., Linde, M. 2004. Discriminating between geographical groups of a Mediterranean commercial clam (Chamelea gallina (L.): Veneridae) by shape analysis. Fisheries Research 67: 93-98.

Palumbi, S.R. 1996. Nucleic Acids II: the polymerase chain reaction. En: Hillis D.M., Moritz, C., Mable, B.K. (eds.) Molecular systematics. pp. 205-247. Sunderland: Sinauer Associates. 
Parodiz, J.J. 1969. The Tertiary non-marine Mollusca of South America. Annals of Carnegie Museum 40: 1-242.

Passamonti, M., Scali, V. 2001. Gender-associated mitochondrial DNA heteroplasmy in the venerid clam Thapes philippinarum (Mollusca Bivalvia). Current Genetics 39: 117-124.

Peakall, R., Smouse, P.E. 2009a. GenAlEx Tutorials - Part 2: Genetic distance and analysis of molecular variance (AMOVA). Disponible en: www.anu.edu.au/BoZo/GenAlEx/new_version.php. Consultado el 10 de septiembre de 2012.

Peakall, R., Smouse, P.E. 2009b. GenAlEx Tutorials - Part 3: Spatial genetic analysis. Disponible en: www.anu.edu.au/BoZo/GenAlEx/new_version.php. Consultado el 10 de septiembre de 2012.

Peña, C. 2011. Métodos de inferencia filogenética. Revista Peruana de Biología 18: 265-267.

Perna, N.T., Kocher, T.D. 1995. Patterns of nucleotide composition at fourfold degenerate sites of animal mitochondrial genomes. Journal of Molecular Evolution 41: 353-358.

Peso, J.G. 2012. Distribución espacio temporal del zoobentos en el embalse de Yacyretá. Editorial Académica Española. 188p.

Peso, J.G., Bechara, J.A. 1999. Estructura del zoobentos del embalse de Yacyretá, Argentina en dos estaciones de muestreo antes y después del llenado a cota 76 m.s.n.m. Revista de Ictiología 7: 37-47.

Pilkington, M.M., Wilder, J.A., Mendez, F.L., Cox, M.P., Woerner, A., Angui, T., Kingan, S., Mobasher, Z., Batini, C., Destro-Bisol, G., Soodyall, H., Strassmann, B.I., Hammer, M.F. 2008. Contrasting signatures of population growth for mitochondrial DNA and Y chromosomes among human populations in Africa. Molecular Biology and Evolution 25: 517-525. 
Piñero, D., Barahona, A., Eguiarte, L., Rocha Olivares, A., Salas Lizana, R. 2008. La variabilidad genética de las especies: aspectos conceptuales y sus aplicaciones y perspectivas en México. En: Soberón, J., Halffter, G., Llorente Bousquets, J. (eds.) Capital Natural de México. Vol. I: Conocimiento actual de la biodiversidad. pp. 415-435. México: CONABIO.

Pool, J.E., Aquadro, C.F. 2006. History and structure of Sub-Saharan populations of Drosophila melanogaster. Genetics 174: 915-929.

Popolizio, E. 2006. El Paraná, un río y su historia geomorfológica. Revista Geográfica 140: 79-90.

Posada, D. 2008. jModelTest: phylogenetic model averaging Molecular Biology and Evolution 25: 1253-1256.

Posada, D., Crandall, K.A. 2001. Intraspecific gene genealogies: trees grafting into networks. Trends in Ecology and Evolution 16: 37-45.

Pullin, A.S. 2002. Conservation biology. Cambridge: Cambridge University Press. 345 p.

Quintana, M.G. 1982. Catálogo preliminar de la malacofauna del Paraguay. Revista del Museo Argentino de Ciencias Naturales Bernardino Rivadavia 11: 61-158.

Quintana, M.G., Mercado Laczkó, A.C. 1997. Caracoles de los rápidos en Yacyretá. Ciencia Hoy 7: 22-31.

Quintana, M.G., Peso, J.G., Pérez, D.C. 2001-2002. Alteración del régimen fluvial y reemplazo de especies de Thiaridae en el embalse de Yacyretá (ArgentinaParaguay). Journal of Medical and Applied Malacology 11: 107-112.

Rambaut, A., Drummond, A.J. 2009. Tracer v1.5. http://beast.bio.ed.ac.uk/Tracer.

Ramírez-Soriano, A., Ramos-Onsins, S.E., Rozas, J., Calafell, F., Navarro, A. 2008. Statistical power analysis of neutrality tests under demographic expansions, contractions and bottlenecks with recombination. Genetics 179: 555-567. 
Ramos-Onsins, S.E., Rozas, J. 2002. Statistical properties of new neutrality tests against population growth. Molecular Biology and Evolution 19: 2092-2100.

Rawlings, T.A., MacInnis, M.J., Bieler, R., Boore, J.L., Collins, T.M. 2010. Sessile snails, dynamic genomes: gene rearrangements within the mitochondrial genome of a family of caenogastropod molluscs. BMC Genomics 11: 440.

Rawson, P.D., Hilbish, T.J. 1995. Evolutionary relationships among the male and female mitochondrial DNA lineages in the Mytilus edulis species complex. Molecular Biology and Evolution 12: 893-901.

Reeve, L.A. 1860. Monograph of the genus Hemisinus. En: Conchiologia Iconica: or, Illustrations of the shells of molluscous animals. Vol. 12. London: Lovell Reeve.

Reid, D.G., Rumbak, E., Thomas, R.H. 1996. DNA, morphology and fossils: phylogeny and evolutionary rates of the gastropod genus Littorina. Philosophical Transactions of the Royal Society of London B 351: 877-895.

Richly, E., Leister, D. 2004. NUMTs in sequenced eukaryotic genomes. Molecular Biology and Evolution 21: 1081-1084.

Rogers, A.R., Harpending, H. 1992. Population growth makes waves in the distribution of pairwise genetic differences. Molecular Biology and Evolution 9: 552-569.

Rogers, A.R., Fraley, A.E., Bamshad, M.J., Watkins, W.S., Jorde, L.B. 1996. Mitochondrial mismatch analysis is insensitive to the mutational process. Molecular Biology and Evolution 13: 895-902.

Rohlf, F. 1993. Relative warp analysis and an example of its application to Mosquito. En: Marcus, L., Bello, E., García-Valdecasas, A. (eds.) Contributions to Morphometrics. pp. 131-159. Madrid: Museo Nacional de Ciencias Naturales.

Rohlf, F.J. 1999. Shape statistics: procrustes superimpositions and tangent spaces. Journal of Classification 16: 197-223.

Rohlf, F. 2008. TPSDIG: Version 2.12. New York State University at Stony Brook. 
Rohlf, F. 2009. TPSUTIL: Version 1.44. New York State University at Stony Brook.

Rohlf, F. 2010. TPSRELW: Version 1.49. New York State University at Stony Brook.

Rohlf, F. 2011. TPSREGR: Version 1.38. New York State University at Stony Brook.

Rohlf, F.J., Marcus, L.F. 1993. A revolution in morphometrics. Trends in Ecology and Evolution 8: 129-132.

Rohlf, F.J., Slice, D. 1990. Extensions of the Procrustes method for the optimal superimposition of landmarks. Systematic Zoology 39: 40-59.

Rohlf, F., Loy, A., Corti, M. 1996. Morphometric analysis of Old World Talpidae (Mammalia, Insectivora) using partial-warp scores. Systematic Biology 45: 344362.

Ronquist, F., Teslenko, M., van der Mark, P., Ayres, D.L., Darling, A., Höhna, S.,Larget, B., Liu, L., Suchard, M.A., Huelsenbeck, J.P. 2012. MrBayes 3.2: efficient bayesian phylogenetic inference and model choice across a large model space. Systematic Biology 61: 539-542.

Rozas, J. 2009. DNA sequence polymorphism analysis using DnaSP. En: Posada, D. ed.) Methods in Molecular Biology $N^{o} 537$ - Bioinformatics for DNA Sequence Analysis. pp. 337-350. New York: Humana Press.

Rubidge, E.M., Patton, J.L., Lim, M., Burton, A.C., Brashares, J.S., Moritz, C. 2012. Climate-induced range contraction drives genetic erosion in an alpine mammal. Nature Climate Change 2: 285-288.

Rufino, M.M., Gaspar, M.B., Pereira, A.M., Vasconcelos, P. 2006. Use of shape to distinguish Chamelea gallina and Chamelea striatula (Bivalvia : Veneridae): linear and geometric morphometric methods. Journal of Morphology 267: 1433-1440.

Rumi, A., Gutiérrez Gregoric, D.E., Núñez, V., Tassara, M.P., Martín, S.M., López Armengol, M.F., Roche, A. 2004. Biodiversidad de moluscos de agua dulce de la Región Mesopotámica, Argentina. Miscelánea, INSUGEO 12: 211-216. 
Rumi, A., Gutiérrez Gregoric, D.E., Núñez, V., César, I.I., Roche, M.A., Tassara, M.P., Martín, S.M., López Armengol, F. 2006. Freshwater Gastropoda from Argentina: species richness, distribution patterns, and an evaluation of endangered species. Malacologia 49: 189-208.

Rumi, A., Gutiérrez Gregoric, D.E., Núñez, V., Darrigran, G.A. 2008. Malacología Latinoamericana. Moluscos de agua dulce de Argentina. Revista de Biología Tropical 56: 77-111.

Rutschmann, F. 2006. Molecular dating of phylogenetic trees: a brief review of current methods that estimate divergence times. Diversity and Distributions 12: 35-48.

Ryder, O.A. 1986. Species conservation and systematic: the dilemma of subspecies. Trends in Ecology and Evolution 1: 9-10.

Saitou, N., Nei, M. 1987. The neighbor-joining method: a new method for reconstructing phylogenetic trees. Molecular Biology and Evolution 4: 406-425.

Samadi, S., Mavárez, J., Pointier, J.P., Delay, B., Jarne, P. 1999. Microsatellite and morphological analysis of population structure in the parthenogenetic freshwater snail Melanoides tuberculata: insights into the creation of clonal variability. Molecular Ecology 8: 1141-1153.

Sánchez, R., Serra, F., Tárraga, J., Medina, I., Carbonell, J., Pulido, L., De María, A., Capella-Gutiérrez, S., Huerta-Cepas, J., Gabaldón, T., Dopazo, J., Dopazo, H. 2011. Phylemon 2.0: a suite of web-tools for molecular evolution, phylogenetics, phylogenomics and hypotheses testing. Nucleic Acids Research 39: W470-W474.

Santos, S.R., Xiang, Y., Tagawa, A.W. 2011. Population structure and comparative phylogeography of Jack species (Caranx ignobilis and C. melampygus) in the High Hawaiian Islands. Journal of Heredity 102: 47-54.

Schmidt, D., Pool, J. 2002. The effect of population history on the distribution of the Tajima's D statistic (www.cam.cornell.edu/ deena/TajimasD.pdf). Consultado el 10 de septiembre de 2012 . 
Schneider, H. 2007. Métodos de análise filogenética: um guía prático. $3^{\text {ra }}$ ed. Riberão Preto: Holos Editora \& Sociedade Brasileira de Genética. 200p.

Schneider, T.D., Stephens, R.M. 1990. Sequence logos: a new way to display consensus sequences. Nucleic Acids Research 18: 6097-6100.

Schön, I., Pinto, R.L., Halse, S., Smith, A.J., Martens, K., Birky, C.W. Jr. 2012. Cryptic species in putative ancient asexual Darwinulids (Crustacea, Ostracoda). PLoS ONE 7: e39844.

Seddon, M.B. 2000. Molluscan biodiversity and the impact of large dams. Switzerland: IUCN. 42p.

Shearn, R., Koenders, A., Halse, S., Schön, I., Martens, K. 2012. A review of Bennelongia De Deckker \& McKenzie, 1981 (Crustacea, Ostracoda) species from eastern Australia with the description of three new species. European Journal of Taxonomy 25: 1-35.

Simison, W.B., Boore, J. 2008. Molluscan evolutionary genomics. En: Ponder, E.F., Lindberg, D.R. (eds.) Phylogeny and evolution of the Mollusca. pp. 447-461. Berkeley: University of California Press.

Simon, C., Pääbo, S., Kocher, T.D., Wilson, A.C. 1990. Evolution of mitochondrial ribosomal RNA in insects as shown by the polymerase chain reaction. En: Clegg, M., O'Brien, S (eds.) Molecular evolution. UCLA Symposium on Molecular and Cellular Biology, New Series. Vol 122. pp. 235-244. New York: Wiley-Liss.

Simon, C., Frati, F., Beckenbach, A., Crespi, B., Liu, H., Flook, P. 1994. Evolution, weighting, and phylogenetic utility of mitochondrial gene sequences and a compilation of conserved polymerase chain reaction primers. Annals of the Entomological Society of America 87: 651-701.

Simone, L.R.L. 2001. Phylogenetic analysis of Cerithioidea (Mollusca: Caenogastropoda) based on comparative morphology. Arquivos de Zoologia 36: $147-263$ 
Simone, L.R.L. 2006. Land and freshwater molluscs of Brazil. São Paulo: EGB, Fapesp. 390 .

Simone, L.R.L. 2011. Phylogeny of the Caenogastropoda (Mollusca), based on comparative morphology. Arquivos de Zoologia 42: 161-323.

Slatkin, M., Hudson, R.R. 1991. Pairwise comparisons of mitochondrial DNA sequences in stable and exponentially growing populations. Genetics 129: 555-562.

Song, H., Buhay, J.E., Whiting, M.F., Crandall, K.A. 2008. Many species in one: DNA barcoding overestimates the number of species when nuclear mitochondrial pseudogenes are coamplified. Proceedings of the National Academy of Sciences 105: 13486-13491.

Sorenson, M.D., Quinn, T.W. 1998. Numts: a challenge for avian systematics and population biology. The Auk 115: 214-221.

Stätdler, T., Frye, M., Neiman, M., Lively, M. 2005. Mitochondrial haplotypes and the New Zealand origin of clonal European Potamopyrgus, an invasive aquatic snail. Molecular Ecology 14: 2465-2473.

Stoddart, J.A. 1983. The accumulation of genetic variation in a parthenogenetic snail. Evolution 37: 546-554.

Stöver, B.C., Müller, K.F. 2010. TreeGraph 2: combining and visualizing evidence from different phylogenetic analyses. BMC Bioinformatics 11: 7.

Strauss, R.E. 2010. Discriminating groups of organisms. En: Elewa, A.M.T. (ed.) Morphometrics for nonmorphometricians, lecture notes in Earth Sciences 124. pp. 73-91. Heidelberg: Springer-Verlag.

Strong, E.E., Gargominy, O., Ponder, W.F., Bouchet, P. 2008. Global diversity of gastropods (Gastropoda; Mollusca) in freshwater. Hydrobiologia 595: 149-166. 
Strong, E.E., Colgan, D.J., Healy, J.M., Lydeard, C., Ponder W.F., Glaubrecht, M. 2011. Phylogeny of the gastropod superfamily Cerithioidea using morphology and molecules. Zoological Journal of the Linnean Society 162: 43-89.

Sunnucks, P., Hales, D.F. 1996. Numerous transposed sequences of mitochondrial cytochrome oxidase I-II in aphids of the genus Sitobion (Hemiptera: Aphididae). Molecular Biology and Evolution 13: 510-524.

Swofford, D.L. 2002. PAUP* Phylogenetic Analysis Using Parsimony (*and Other Methods). Version 4. Sunderland: Sinauer Associates.

Tablado, A., Mantinian, J. 2004. Catálogo de ejemplares tipo de la División Invertebrados del Museo Argentino de Ciencias Naturales. II. Mollusca. Revista del Museo Argentino de Ciencias Naturales, Nueva Serie 6: 363-384.

Tajima, F. 1989. Statistical method for testing the neutral mutation hypothesis by DNA polymorphism. Genetics 123: 585-595.

Tajima, F. 1993. Simple methods for testing molecular clock hypothesis. Genetics 135: 599-607.

Tamura, K., Nei, M., Kumar, S. 2004. Prospects for inferring very large phylogenies by using the neighbor-joining method. Proceedings of the National Academy of Sciences 101: 11030-11035.

Tamura, K., Peterson, D., Peterson, N., Stecher, G., Nei, M., Kumar, S. 2011. MEGA5: Molecular evolutionary genetics analysis using maximum likelihood, evolutionary distance, and maximum parsimony methods. Molecular Biology and Evolution 28: 2731-2739.

Teacher, A.G.F., Griffiths, D.J. 2011. HapStar: automated haplotype network layout and visualization. Molecular Ecology Resources 11: 151-153.

Templeton, A.R. 2009. Statistical hypothesis testing in intraspecific phylogeography: nested clade phylogeographical analysis vs. approximate Bayesian computation. Molecular Ecology 18: 319-331. 
Toro, I.M.V., Manriquez, S.G., Suazo, G.I. 2010. Morfometría geométrica y el estudio de las formas biológicas : de la morfología descriptiva a la morfología cuantitativa. International Journal of Morphology 28: 977-990.

Tzeng, T.D., Yeh, S.Y., Hui, C.F. 2004. Population genetic structure of the kuruma prawn (Penaeus japonicas) in East Asia inferred from mitochondrial DNA sequences. ICES Journal of Marine Science 61: 913-920.

Valladares, A., Manríquez, G., Suárez-Isla, B.A. 2010. Shell shape variation in populations of Mytilus chilensis (Hupe 1854) from southern Chile: a geometric morphometric approach. Marine Biology 157: 2731-2738.

Vázquez-Domínguez, E., Castañeda-Rico, S., Garrido-Garduño, T., Gutiérrez-García, T.A. 2009. Avances metodológicos para el estudio conjunto de la información genética, genealógica y geográfica en análisis evolutivos y de distribución. Revista Chilena de Historia Natural 82: 277-297.

Vega, R., Amori, G., Aloise, G., Cellini, S., Loy, A., Searle, J.B. 2010. Genetic and morphological variation in a Mediterranean glacial refugium: evidence from Italian pygmy shrews, Sorex minutus (Mammalia: Soricomorpha). Biological Journal of the Linnean Society 100: 774-787.

Vogler, R.E. 2012. Aylacostoma chloroticum Hylton Scott, 1954: antecedentes de la especie. Amici Molluscarum 20: 43-46.

Vogler, R.E., Vera, N.S., Hoffmann, Y.G., Peso, J.G. \& Argüelles, C.F. 2006. Extração de DNA a partir de embriões de Aylacostoma chloroticum (Caenogastropoda: Thiaridae). En: Resumos do $52^{\circ}$ Congresso Brasileiro de Genética. p. 86.

Vrijenhoek, R.C. 1979. Factors affecting clonal diversity and coexistence. American Zoologist 19: 787-797.

Vrijenhoek, R.C. 1998. Animal clones and diversity. Bioscience 48: 617-628.

Vrijenhoek, R.C., Parker, E.D. Jr. 2009. Geographical parthenogenesis, general purpose genotypes and frozen niche variation. En: Schön, I., Martens, K., van Dijk, P. 
(eds.) Lost sex - The evolutionary biology of parthenogenesis. pp. 99-131. New York: Springer Press.

Wang, H.F., Hou, W.R., Niu, D.K. 2008. Strand compositional asymmetries in vertebrate large genes. Molecular Biology Reports 35: 163-169.

Ward, R.D., Zemlak, T.S., Innes, B.H., Last, P.R., Hebert, P.D.N. 2005. DNA barcoding Australia's fish species. Philosophical Transactions of the Royal Society B 360: 1847-1857.

Wares, J.P., Turner, T.F. 2003. Phylogeography and diversification in aquatic mollusks. En: Lydeard, C., Lindberg, D.R. (eds.) Molecular systematics ans phylogeography of mollusks. pp. 229-269. Washington: Smithsonian Books.

Watterson, G.A. 1975. On the number of segregating sites in genetical models without recombination. Theoretical Population Biology 7: 256-276.

Weir, B.S., Cockerham, C.C. 1984. Estimating $F$-statistics for the analysis of population structure. Evolution 38: 1358-1370.

Wesselingh, F.P., Ramos, M.I.F. 2010. Amazonian aquatic invertebrate faunas (Mollusca, Ostracoda) and their development over the past 30 million years. En: Hoorn, C., Wesselingh, F.P. (eds.) Amazonia: landscape and species evolution. A look into the past. pp. 302-316. Oxford: Blackwell Publishing.

Wesselingh, F.P., Salo, S.A. 2006. A Miocene perspective on the evolution of the Amazonian biota. Scripta Geologica 133: 439-458.

Wilke, T., Schultheiß, R., Albrecht, C. 2009. As time goes by: a simple fool's guide to molecular clock approaches in invertebrates. American Malacological Bulletin 27: $25-45$.

Williams, S.T., Knowlton, N. 2001. Mitochondrial pseudogenes are pervasive and often insidious in the snapping shrimp genus Alpheus. Molecular Biology and Evolution 18: 1484-1493. 
Wilson, A.B., Glaubrecht, M., Meyer, A. 2004. Ancient lakes as evolutionary reservoirs: evidence from the thalassoid gastropods of Lake Tanganyika. Proceedings of the Royal Society of London B 271: 529-536.

Wolff, J.N., Shearman, D.C.A., Brooks, R.C., Ballard, J.W.O. 2012. Selective enrichment and sequencing of whole mitochondrial genomes in the presence of nuclear encoded mitochondrial pseudogenes (Numts). PLoS ONE 7: e37142.

Wright, S. 1951. The genetical structure of populations. Annals of Eugenics 15: 323354.

Xia, X., Lemey, P. 2009. Assessing substitution saturation with DAMBE. En: Lemey, P., Salemi, M., Vandamme, A.M. (eds.) The phylogenetic handbook: a practical approach to DNA and protein phylogeny. 2nd ed. pp. 615-630. Cambridge: Cambridge University Press.

Xia, X., Xie, Z. 2001. DAMBE: Data analysis in molecular biology and evolution. Journal of Heredity 92: 371-373.

Xia, X., Xie, Z., Salemi, M., Chen, L., Wang, Y. 2003. An index of substitution saturation and its application. Molecular Phylogenetics and Evolution 26: 1-7.

Yang, Z., Rannala, B. 2012. Molecular phylogenetics: principles and practice. Nature Reviews Genetics 13: 303-314.

Ye, J., Coulouris, G., Zaretskaya, I., Cutcutache, I., Rozen, S., Madden, T. 2012. Primer-BLAST: A tool to design target-specific primers for polymerase chain reaction. BMC Bioinformatics 13: 134.

Yuan, Y., Li, Q., Yu, H., Kong, L. 2012. The complete mitochondrial genomes of six heterodont bivalves (Tellinoidea and Solenoidea): variable gene arrangements and phylogenetic implications. PLoS ONE 7: e32353.

Zainudin, R., Nor, S.M., Ahmad, N., Md-Zain, B.M., Rahman, M.A. 2010. Genetic structure of Hylarana erythraea (Amphibia: Anura: Ranidae) from Malaysia. Zoological Studies 49: 688-702. 
Zelditch, M.L., Swiderski, D.L., Sheets, H.D., Fink, W.L. 2004. Geometric morphometric for biologists. New York: Elsevier Academic Press. 416p.

Zhang, D.X., Hewitt, G.M. 1996. Nuclear integrations: challenges for mitochondrial DNA markers. Trends in Ecology and Evolution 11: 247-251.

Zuckerkandl, E., Pauling, L. 1962. Molecular disease, evolution and genetic heterogeneity. En: Marsha, M., Pullman, B. (eds.) Horizons in biochemistry. pp. 189-225. New York: Academic Press.

Zuckerkandl, E., Pauling, L. 1965. Evolutionary divergence and convergence in proteins. En: Bryson, V., Vogel, H.J. (eds.) Evolving genes and proteins. pp. 97166. New York: Academic Press. 


\section{APÉNDICE I: SOLUCIONES DE LABORATORIO}

\section{LIMPIEZA DE RÁDULAS}

\section{Buffer NET}

$1 \mathrm{ml}$ Tris $\mathrm{pH} 8.0$

$2 \mathrm{ml} \mathrm{0,5} \mathrm{M}$ EDTA

$1 \mathrm{ml} 5 \mathrm{M} \mathrm{NaCl}$

$20 \mathrm{ml} \mathrm{10 \%} \mathrm{SDS}$

$76 \mathrm{ml}$ agua

\section{EXTRACCIÓN DE ADN GENÓMICO TOTAL}

\section{Buffer BHS}

$0,4 \mathrm{M} \mathrm{NaCl}$

$10 \mathrm{mM}$ Tris/HCl

2 mM EDTA

Buffer TEC/SDS

Tris/HCl $10 \mathrm{mM}$

EDTA pH $810 \mathrm{mM}$

$\mathrm{NaCl} 10 \mathrm{mM}$

SDS $10 \%$

\section{Buffer CTAB}

CTAB $2 \% \mathrm{p} / \mathrm{v}$

$\mathrm{NaCl} 1,4 \mathrm{M}$

EDTA $20 \mathrm{mM}$

TRIS/HCl 100mM

b-Mercaptoetanol 0,2\%

\section{ELECTROFORESIS EN GEL DE AGAROSA}

Buffer TBE 10X

Tris 108 gr

Ácido Bórico 55 gr

EDTA 9,3 gr

$\mathrm{H} 2 \mathrm{O}$ destilada hasta $1000 \mathrm{ml}$ 


\section{APÉNDICE II: CÓDIGO GENÉTICO}

Tabla XXXII. Código genético mitocondrial de invertebrados.

\begin{tabular}{|c|c|c|c|c|c|c|c|}
\hline CoDón & AMINOÁCIDO & CODóN & AMINOÁCIDO & CODón & AMINOÁCIDO & CODón & AMINOÁCIDO \\
\hline UUU & Phe $(F)$ & UCU & $\operatorname{Ser}(\mathrm{S})$ & UAU & $\operatorname{Tyr}(Y)$ & UGU & Cys (C) \\
\hline UUC & Phe $(F)$ & UCC & Ser (S) & UAC & $\operatorname{Tyr}(Y)$ & UGC & Cys (C) \\
\hline UUA & Leu (L) & UCA & Ser (S) & UAA & Stop $(*)$ & UGA & $\operatorname{Trp}(\mathrm{W})$ \\
\hline UUG & Leu (L) & UCG & Ser (S) & UAG & Stop $(*)$ & UGG & $\operatorname{Trp}(\mathrm{W})$ \\
\hline CUU & Leu (L) & $\mathbf{C C U}$ & Pro $(\mathrm{P})$ & CAU & His $(\mathrm{H})$ & CGU & $\operatorname{Arg}(\mathrm{R})$ \\
\hline CUC & Leu (L) & $\mathrm{CCC}$ & Pro $(\mathrm{P})$ & CAC & His $(\mathrm{H})$ & CGC & $\operatorname{Arg}(\mathrm{R})$ \\
\hline CUA & Leu (L) & CCA & Pro $(\mathrm{P})$ & CAA & $\mathrm{Gln}(\mathrm{Q})$ & CGA & $\operatorname{Arg}(\mathrm{R})$ \\
\hline CUG & Leu (L) & CCG & Pro $(\mathrm{P})$ & CAG & Gln $(\mathrm{Q})$ & CGG & $\operatorname{Arg}(\mathrm{R})$ \\
\hline AUU & Ile (I) & $\mathbf{A C U}$ & $\operatorname{Thr}(\mathrm{T})$ & $\mathbf{A A U}$ & $\operatorname{Asn}(\mathrm{N})$ & AGU & $\operatorname{Ser}(S)$ \\
\hline AUC & Ile (I) & ACC & Thr (T) & AAC & $\operatorname{Asn}(\mathrm{N})$ & AGC & Ser (S) \\
\hline AUA & $\operatorname{Met}(\mathrm{M})$ & ACA & $\operatorname{Thr}(\mathrm{T})$ & AAAA & Lys (K) & AGA & Ser (S) \\
\hline AUG & $\operatorname{Met}(\mathrm{M})$ & ACG & $\operatorname{Thr}(\mathrm{T})$ & AAG & Lys (K) & AGG & Ser (S) \\
\hline GUU & $\operatorname{Val}(\mathrm{V})$ & GCU & Ala (A) & GAU & Asp (D) & GGU & Gly (G) \\
\hline GUC & $\operatorname{Val}(\mathrm{V})$ & GCC & Ala (A) & GAC & Asp (D) & GGC & Gly (G) \\
\hline GUA & $\operatorname{Val}(\mathrm{V})$ & GCA & Ala (A) & GAA & Glu (E) & GGA & Gly (G) \\
\hline GUG & $\operatorname{Val}(\mathrm{V})$ & GCG & Ala (A) & GAG & Glu (E) & GGG & Gly (G) \\
\hline
\end{tabular}

Codificación de los aminoácidos: Ala (A): Alanina; Arg (R): Arginina; Asn (N): Asparagina; Asp (D): Ácido aspártico; Cys (C): Cisteína; Gln (Q): Glutamina; Glu (E): Ácido glutámico; Gly (G): Glicina; His (H): Histidina; Ile (I): Isoleucina; Leu (L): Leucina; Lys (K): Lisina; Met (M): Metionina; Phe (F): Fenilalanina; Pro (P): Prolina; Ser (S): Serina; Thr (T): Treonina; Trp (W): Triptófano; Tyr (Y): Tirosina; Val (V): Valina. 


\section{APÉNDICE III: SECUENCIAS OBTENIDAS EN ESTA TESIS}

\section{Secuencia COI Aylacostoma chloroticum. Haplotipo 1 (H1)}

GACTTTATATATTTTGTTTGGTATGTGATCCGGGTTAGTCGGGACAGCATTAAGCCTTTTGATTCGTGCTGAATTAGGACAAC CAGGTGCTCTACTCGGAGACGATCAATTATACAATGTAATTGTAACAGCTCATGCATTTGTAATAATTTTCTTTTTGGTTATG CCTATGATAATTGGGGGATTTGGAAACTGATTAGTCCCCTTAATATTAGGTGCTCCAGATATAGCTTTTCCACGATTAAATAA TATAAGTTTCTGACTTCTTCCGCCTGCTCTGTTACTACTTTTGTCTTCAGCTGCTGTTGAAAGAGGAGTCGGAACAGGTTGAA CAGTTTATCCACCCTTAGCAGGAAATCTAGCTCATGCTGGGGGATCTGTAGATCTTGCTATTTTTTCTCTACATCTAGCAGGT GTTTCATCTATTTTAGGAGCTGTAAATTTTATTACAACAATTATTAATATGCGATGACGGGGGATACAATTTGAACGACTTCC TTTATTTGTATGGTCTGTAAAAATTACAGCAATTCTTCTTCTTCTATCATTACCAGTCTTAGCTGGAGCTATTACTATACTTC TTACAGATCGGAACTTTAATACTACATTTTTTGACCCAGCAGGAGGAGGTGATCCGATTTTATACCAACATCTATTC

\section{Secuencia COI Aylacostoma chloroticum. Haplotipo 2 (H2)}

GACTTTATATATTTTGTTTGGTATGTGATCCGGGTTAGTCGGGACAGCATTAAGCCTTTTGATTCGTGCTGAATTAGGACAAC CAGGTGCTCTACTCGGAGACGATCAATTATACAATGTAATTGTAACAGCTCATGCATTTGTAATAATTTTCTTTTTGGTTATG CCTATGATAATTGGGGGATTTGGAAACTGATTAGTCCCCTTAATATTAGGTGCTCCAGATATAGCTTTTCCACGATTAAATAA TATAAGTTTCTGACTTCTTCCGCCTGCTCTGTTACTACTTTTGTCTTCAGCTGCTGTTGAAAGAGGAGTCGGAACAGGTtGAA CAGTTTATCCACCCTTAGCAGGAAATCTAGCTCATGCTGGGGGATCTGTAGATCTTGCTATTTTTTCTCTACATCTAGCAGGT GTTTCATCTATTTTAGGAGCTGTAAATTTTATTACAACAATTATTAATATACGATGACGGGGGATACAATTTGAACGACTTCC TTTATTTGTATGGTCTGTAAAAATTACAGCAATTCTTCTTCTTCTATCATTACCAGTCTTAGCTGGAGCTATTACTATACTTC TTACAGATCGGAACTTTAATACTACATTTTTTGACCCAGCAGGAGGAGGTGATCCGATTTTATACCAACATCTATTC

\section{Secuencia COI Aylacostoma (nuevo morfotipo). Haplotipo 3 (H3)}

AACTCTATATATTTtGTTTGGTATGTGATCTGGGTTAGTCGGGACAGCATTAAGCCTTTTGATTCGTGCTGAACTAGGACAAC CAGGTGCTCTACTCGGAGACGATCAATTATACAATGTAATTGTAACAGCTCATGCATTTGTAATAATTTTCTTTTTAGTTATA CCTATGATAATTGGAGGATTTGGAAACTGATTAGTGCCCTTAATGCTAGGCGCTCCGGATATAGCTTTTCCACGATTAAATAA TATAAGTTTCTGACTTCTTCCTCCTGCTCTATTACTACTTTTGTCTTCAGCTGCTGTTGAAAGAGGGGTTGGAACAGGTTGAA CAGTTTATCCCCCTTTAGCAGGAAACCTAGCTCATGCTGGGGGATCTGTAGATCTTGCTATTTTTTCTCTACATCTAGCAGGT GTTTCATCTATTTTAGGAGCTGTAAATTTTATTACAACAATTATTAATATGCGATGACGAGGAATGCAATTTGAACGACTTCC TTTATTTGTATGGTCTGTAAAAATTACAGCAATTCTCCTTCTTCTGTCATTGCCAGTCTTAGCTGGAGCTATTACTATACTTC TTACAGATCGGAACTTTAATACTACATTTTTTGACCCAGCAGGAGGAGGCGATCCAATCTTATACCAACATCTATtC

\section{Secuencia COI. Grupo externo: Doryssa sp.}

TACTCTTTATATTTTATTTGGAATATGATCTGGGTTAGTTGGAACTGCACTTAGCTTGCTAATTCGAGCTGAACTAGGTCAAC CAGGCGCTCTTTTAGGGGACGATCAGCTGTATAATGTTATTGTAACAGCACATGCATTTGTTATAATTTTTTTTCTAGTTATG CCGATAATAATTGGCGGATTTGGTAACTGACTTGTCCCTTTAATGCTGGGAGCTCCAGATATAGCTTTTCCTCGATTAAATAA TATAAGTTTTTGGTTATTACCGCCTGCTCTTTTGCTTTTGCTTTCATCAGCTGCTGTAGAAAGCGGGGTTGGGACAGGATGGA CTGTTTACCCTCCTCTGGCTGGAAATCTGGCCCACGCAGGAGGGTCTGTAGATCTAGCTATTTTTTCGCTACATTTAGCTGGT GTTTCTTCTATCTTGGGGGCTGTAAATTTTATTACAACTATTATTAACATACGATGACGAGGGATGCAATTTGAACGACTTCC TTTATTTGTTTGATCTGTAAAAATTACAGCCATCCTTCTACTTCTTTCTCTTCCAGTTTTAGCTGGAGCAATTACTATACTTT TAACTGATCGAAATTTTAATACAGCTTTTTTTGACCCGGCTGGAGGGGGGGATCCTATTTTATATCAGCATTTATTT 


\section{Secuencia COI. Grupo externo: Pachychilus laevissimus}

CACTCTCTATATTCTTTTCGGGATATGATCTGGCCTAGTTGGAACTGCACTTAGTTTATTAATTCGAGCTGAACTAGGCCAGC CTGGCGCTCTGCTGGGCGATGATCAACTATATAATGTTATTGTGACAGCACATGCATTTGTTATAATTTTTTTCTTAGTCATA CCAATAATAATTGGTGGGTTTGGAAATTGACTTGTTCCCTTGATACTTGGGGCTCCTGACATAGCTTTTCCACGATTAAATAA TATAAGTTTTTGGTTGCTTCCTCCCGCTCTTTTACTTTTACTTTCTTCAGCTGCTGTAGAAGGCGGAGTCGGAACAGGATGAA CTGTTTATCCTCCATTAGCTGGAAATTTGGCCCATGCAGGAGGGTCTGTAGATCTTGCTATCTTTTCGTTACACCTAGCTGGT GTTTCTTCTATTTTAGGGGCTGTAAATTTTATTACAACTATTATTAACATGCGGTGGCGAGGCATGCAGTTTGAACGACTCCC TTTATTTGTCTGATCTGTGAAGATCACAGCCATTCTTTTGCTTCTTTCTCTTCCGGTCTTAGCTGGAGCAATTACTATGCTTT TAACTGATCGAAATTTTAATACGGCTTTTTTTGATCCTGCTGGGGGAGGAGATCCTATCTTGTATCAACATTTATT

\section{Secuencia COI. Grupo externo: Pachychilus nigratus}

AACATTATATATTTTATTTGGAATATGGTCTGGGCTAGTTGGAACTGCTTTAAGACTACTGATTCGAGCTGAGCTTGGGCAAC CTGGTGCTCTTTTAGGGGATGATCAGCTATACAATGTTATTGTAACGGCTCATGCTTTTGTAATAATTTTCTTTTTAGTTATA CCTATAATAATTGGCGGATTTGGTAACTGGCTAGTTCCGTTAATATTAGGGGCTCCAGATATAGCTTTTCCTCGATTAAACAA CATAAGCTTCTGATTATTACCTCCTGCTTTACTGCTTTTACTTTCTTCAGCTGCAGTTGAAAGTGGGGTTGGAACAGGCTGGA CTGTGTATCCGCCATTAGCTGGTAATCTTGCTCATGCTGGGGGATCAGTAGACCTGGCTATTTTTTCTTTACACCTAGCTGGT GTTTCTTCTATCTTAGGAGCTGTTAATTTTATTACAACTATTATCAATATACGATGACGGGGGATACAGTTTGAACGATTACC TTTATTTGTCTGATCTGTCAAGATTACAGCAATTCTTTTATTACTATCACTTCCTGTATTGGCTGGAGCAATTACAATGCTTt TAACGGACCGGAACTTTAATACAGCATTTTTTGACCCTGCTGGGGGAGGGGATCCAATTCTTTACCAGCATTTATtT 